\title{
CONTRIBUICCÃO AO ESTUDO DA DISPONIBILIDADE DE ENXOFRE EM SOLOS BRASILEIROS
}

\author{
HUBERTO JOSÉ KLIEMANN
}

Orientador: Dr. EURÍPEDES MALAVOLTA

\begin{abstract}
Tese apresentada à Escola Superior de Agricultura "Luiz de Queiroz", da Universidade de São Paulo, para obtenção do título de Doutor em Agronomia: Área de Concentração: Solos $\theta$ Nutrição de Plantas.
\end{abstract}

PIRACICABA

Estado de São Paulo - Brasil

Março - 1987 
.ii.

Aos meus pais,

ERVINO ZENO E HILDA

\section{AGRADEÇO}

A Nice Helena, minha esposa

e aos nossos filhos

Marco Antônio

Teresa Cristina e

Paulo Humberto 
.iii.

\section{AGRADECIMENTOS}

Ao Dr. Eurípedes Malavolta, Professor da Escola Superior de Agricultura "Luiz de Queiroz" (ESALQ) e pesquisador do Centro de Energia Nuclear na Agricultura (CENA) pela orientação, pelos ensinamentos e pela amizade.

A Universidade Federal de Goiás (UFG), pela oportunidade re realização do curso de Doutoramento.

A Escola Superior de Agricultura "Luiz de Queiroz" (ESALQ) e Centro de Energia Nuclear na Agricultura (CENA) pela oportunidade de realização do Curso de Pós-Graduação e desta pesquisa.

Ao Convênio FEAQ/FINEP pelo suporte financeiro desta pes-. quisa.

Ao Convênio FEALQ/ALLIED CORPORATION pelo suporte financei ro desta pesquisa.

A Fundação de Amparo à Pesquisa do Estado de São Paulo (FAPESP) pelo suporte financeiro desta pesquisa. 
Ao Conselho Nacional de Desenvolvimento Científico e Tecno lógico (CNPą) pela concessão de bolsa de estudos de Dou toramento.

Aos Professores Manoel Passos de Castro e Lázaro José Chaves que me substituiram nas minhas funções durante o pe riodo de afastamento da UFG.

Ao Centro Nacional de Pesquisa de Arroz, Feijão (CNPAFEMBRAPA), na pessoa do Dr. Francisco P. Zimmermann pelo suporte estatístico e processamento de parte dos dados desta pesquisa.

Ao Dr. Sebastião A. de Oliveira, Professor da UNB-DF, pela cessão de "Software" para processamento dos dados desta pesquisa e, sobretudo, pelos ensinamentos, pelo coleguismo e pela amizade.

Ao Dr. Takashi Muraoka, pesquisador do Centro de Energia Nuclear na Agricultura (CENA-USP) pelas sugestões na condução de parte da pesquisa referente ao uso do enxofre radioativo $(35 \mathrm{~S})$ e pelo uso do laboratório da Seção de Fertilidade do Solo. 
Ao, Dr: Virgílio F. Nascimento Fo, pesquisador do Centro de Energia Nuclear, na Agricultura (CENA-USP) pelas sugestões e uso do Laboratôrio de Radioquímica.

As Senhoritas Maria Lígia Malavolta e Cleusa Pereira Cabral pelo auxílio no Laboratório da Seção de Nutrição de Plantas do CENA-USP e pela amizade.

Aos mestres do Curso de Pôs-Graduação em Solos e Nutrição de Plantas pela formação e amizade. 


\section{INDICE}

Păgina

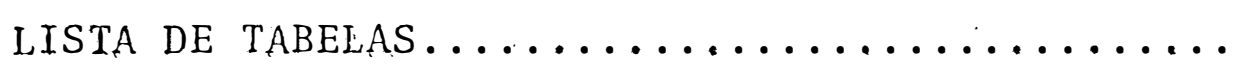

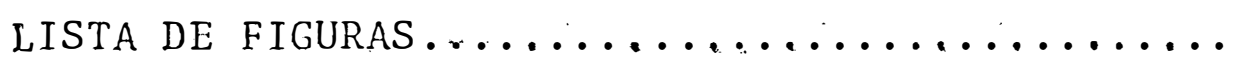

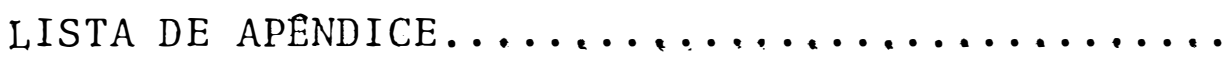

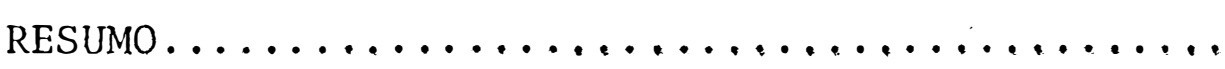

SUMMARY

1. INTRODUÇAO $\ldots \ldots \ldots \ldots \ldots \ldots \ldots \ldots \ldots \ldots \ldots \ldots \ldots \ldots \ldots$

2. REVIST̃o de literatURa.................. 3

2.1. Formas de enxofre nas rochas e nos solos 4

2.1.1. Enxofre total nas rochas....... 4

2.1.2. Enxofre total nos solos e relações $\mathrm{C} / \mathrm{N} / \mathrm{S} \ldots \ldots \ldots \ldots \ldots \ldots \ldots \ldots$

2.1.3. Enxofre orgânico nos solos...... 7

2.1.4. Formas de $S$ inorgânico nos solos. 10

2.2. Transformações do enxofre nos solos.... 12

2.2.1. Mineralização do enxof re ...... 12

2.2.2. Imobilização do $\mathrm{S}_{-} \mathrm{SO}_{4}^{=}$inorgânico. 14

2.2.3. Oxidação do enxofre no solo..... 15

2.2.4. Redução do enxofre no solo...... 17

2.2.5. Condições ambientais e manejo dos solos que afetam a mineralização do enxofre nos solos.......... 18

2.2.6. Migração do enxofre-sulfato no perfil do solo............... 
. vii.

página

2.3. Avaliação da disponibilidade de enxofre

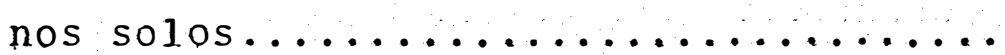

2.3.1. Deficiências e respostas ao enxo

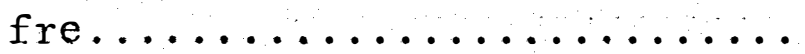

2.3.2. Avaliação da disponibilidade de

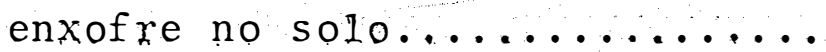

2.3.3. Avaliação do potencial de minera lização de nitrogênio e enxofre dos solos por modelos matemâti $\cos \ldots \ldots \ldots \ldots \ldots \ldots \ldots \ldots$

2.4. Análise de tecido para avaliaça do es tado nutricional de enxofre em plantas.

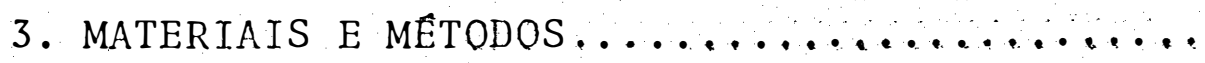

3.1. Solos - caracterização física e química

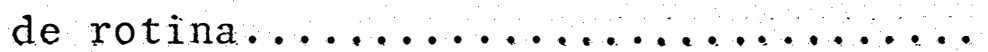

3.2. Determinação do teor de $S$ total nas a-

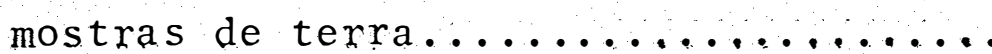

3.2.1. Digestão das amostras da teṛra..

3.2.2. Determinação analítica do $\mathrm{S}$ to-

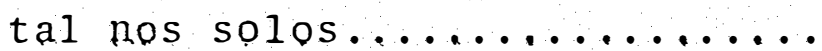

3.3. Determinação do $\mathrm{S}-\mathrm{SO}_{4}=$ disponível nos so

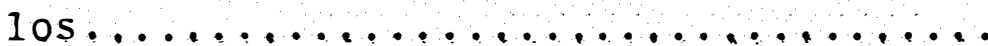

$3,3.1$. Aceta to de amônio $0,5 \mathrm{~N}$ em ácido acético $0,25 \mathrm{~N} \ldots \ldots \ldots \ldots \ldots \ldots$

$3.3 .2 \cdot \mathrm{Ca}\left(\mathrm{H}_{2} \mathrm{PO}_{4}\right)_{2} \cdot \mathrm{H}_{2} \mathrm{O}-500 \mathrm{ppm} \mathrm{P} \mathrm{em}$ ácido acético $2,0 N \ldots \ldots \ldots \ldots \ldots$. 
.viii.

Página

3.3.3. Cloreto de cálcio a $0,15 \% \ldots \ldots \ldots 61$

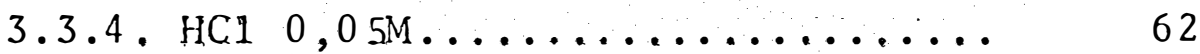

3.4. Experimento de casa-de-vegetação...... 62

3.4.1. Quantidade de terra usada por va

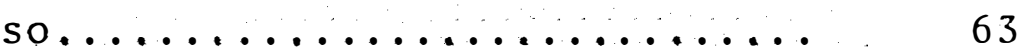

3.4.2. Calagem e gesso................... 63

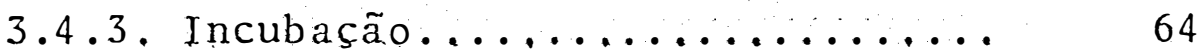

3.4.4. Adubação e cultivo das terras... 64

3.4.5. Plantio e colheita da plantâ-tes

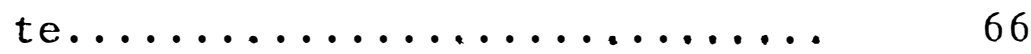

3.4.6. Anấlises de plantas.......... 66

3.4.7. Coleta de amostras de terra após

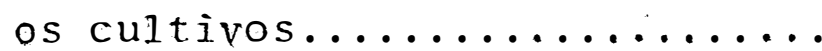

3.5. Experimento de laboratório: mineralização aerỏbia de enxofre $\left(S_{-} \mathrm{SO}_{4}^{\bar{N}}\right)$ e nitrogênio $\left(\mathrm{N}-\mathrm{NH}_{4}^{+}+\mathrm{NO}_{3}^{-}\right)$, por têcnicas de in

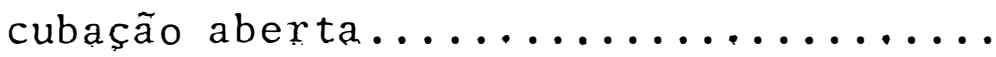

3.5.1. Solos e têcnicas anarieiticas usa-

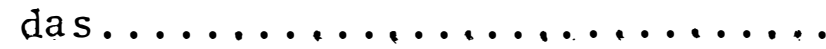

3.5.2. Colunas de incubação e lixivia -

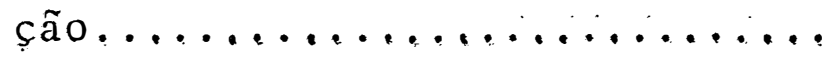

3.5.3. Adubação das amostras de terra e Iixiviação do enxofre e nitrogênio minera $1 \ldots \ldots \ldots \ldots \ldots \ldots$ 
. ix .

pâgina

3.5 .4 . Minera 1 ização aeróbia de $\mathrm{S}-\mathrm{SO}_{4}^{=}$ em amostras de terras marcadas com enxofre radioativo $\left({ }^{35} S\right) \ldots$

3.6. Delineamento experimental e avaliação

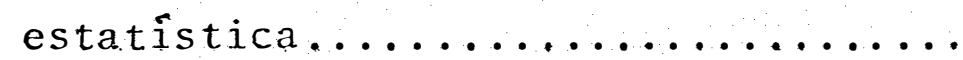

3.6.1. Experimento de casa-de-vegeta-

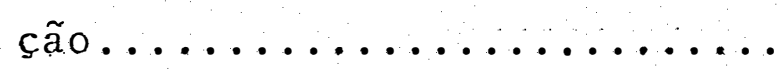

3.6.2. Experimento de laboratório...

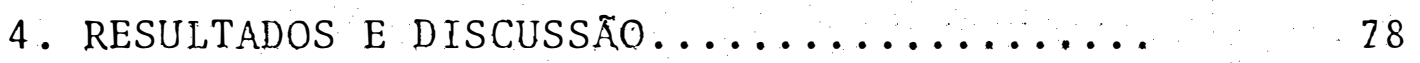

4.1. Resultados de anâlise de terra...... 78

4.1.1. Teores de carbono, nitrogênio e enxofre totais em amostras de terras não tratadas......

4.1.2. Teores de carbono, $\mathrm{pH}, \mathrm{P}, \mathrm{Ca}$, $\mathrm{Mg}$, e $\mathrm{H}+\mathrm{Al}$ nas amostras subme tidas a incubação e a dois cul tivos com milho na ausência e presença de calagem........

4.1.3. Evolução dos teores de enxofre $\left(\mathrm{S}_{-} \mathrm{SO}_{4}^{=}\right)$disponivel em fun ção da incubação, dos cultivos sem e com calagem.......

4.1.4. Problemas de extração e deter minação analítica de $\mathrm{S}-\mathrm{SO}_{4}=\mathrm{dos}$ 
solos relacionados com o desempe-

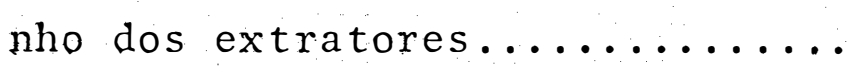

4.2. Mineralização de nitrogênio e enxofre por incubação aberta, na ausência e presen

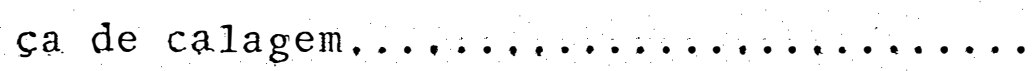

4.3. Mineralização aeróbica de $\mathrm{S}-\mathrm{SO}_{4}^{=}$: efeitos de incubação aberta, na ausência e presença de calagem sobre a atividade especifica de ${ }^{35}{ } \ldots \ldots \ldots \ldots \ldots \ldots \ldots \ldots$

4.4. Efeitos da calagem, gesso e cultivos na produção de matêria seca e absorção de enxofre...................

4.5. Curvas de resposta ao gesso na ausên cia e presença de calagem, em dois culti vos sucessivos dos solos.............

4.5.1. Doses de gesso versus produção de matéria seca da parte aérea do mı

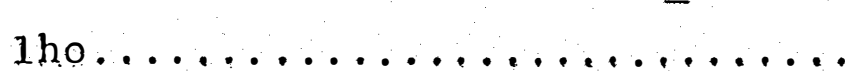

4.5.2. Doses de gesso versus absorção de enxofre pela parte aérea do milho

4.6. Teores de enxofre total na parte aêrea e

$\sim$ razoes N/S e P/S versus produção de maté ria seca e absorção de enxofre pelo mi1ho. 
4.6.1. Evolução dos teores de nitrogênio, fôsforo e enxofre em função da calagem, do gesso e dos cultivos.

4.6.2. Enxofre total e razões N/S e $P / S$

na parte aérea do milho versus pro dução de matéria seca e absorção

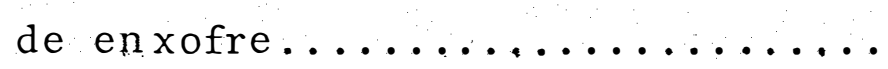

4.7. Relações de carbono, enxofre total, razão C/S e potenciais de minexalização de enxo fre dos solos entre si e com a absorção

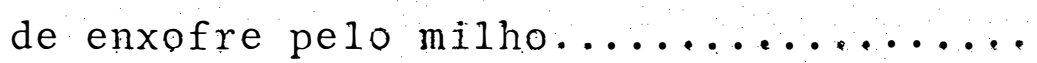

4.7.1. Relação da absorção de enxofre pe10 milho versus teores de carbono nos solos submetidos a dọis cultivos na ausência e presença de cala

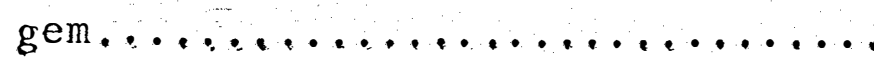

4.7.2. Relação entre potenciais de minerạ lização de enxofre dos solos e absorção relativa de enxofre pelo mi

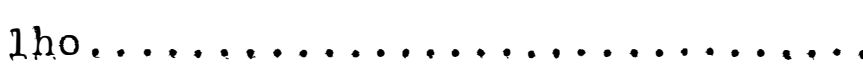

4.8. Correlação e calibração de anẫiises de en xofre-sulfato disponîvel nos solos e determinação dos nîveis críticos.......... 
.xii.

Página

4.8.1. Correlação do $\mathrm{S}-\mathrm{SO}_{4}^{=}$disponî́e 1 nos solos versus absorção de

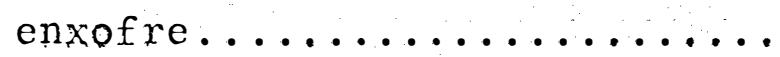

4.8.2. Calibração de mêtodos de anâli ses de enxofre-sulfato dispon vel e níveis críticos nos so$10 s \ldots \ldots \ldots \ldots \ldots \ldots \ldots \ldots \ldots \ldots \ldots \ldots \ldots \ldots \ldots$

4.8.3. Absorção relativa de enxofre pelo milho versus $\mathrm{S}-\mathrm{SO}_{4}=$ estima do por extratores químicos...

4.9. Relações conjuntas de anâlises de solos e de plantas com a produção de ma téria seca e absorção de enxofre pelo milho.

4.9.1. Relações das anâlíses de solos e de plantas nos solos com teo res de carbono maiores do que $1,2 \%$ com a produção de matéria seca e absorção de enxofre pe-

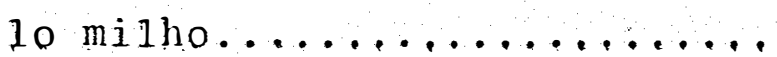

4.9.2. Relações das anâlises de solos e de plantas nos solos com teo res de carbono maiores do que $1,2 \%$ com a produção de matéria seca e absorção de enxofre... 
.xiii.

Página

4.10. Considerą̧ões finais............. 177

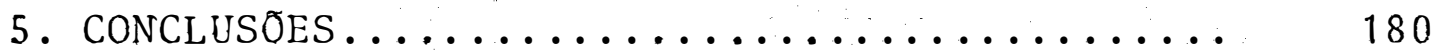

6. REFERENCIAS BIBLIOGRĀFICAS .............. 184

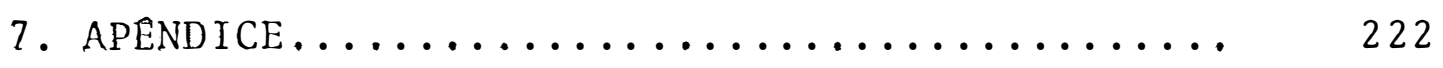


.xiv.

\section{LISTA DE TABELAAS}

TABELA

Pågina

3.1. Caracteristicas gerais das amostras de terra utilizadas nos experimentos (mé-

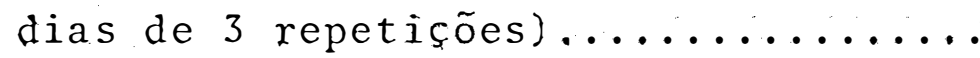

4.1. Teores de enxofre total dos solos obti dos por digestão nitroperclórica e de-

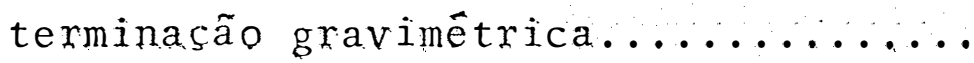

4.2. Resultados de anâalises de amostras de terra coletadas do nivel de 40 ppm $S$

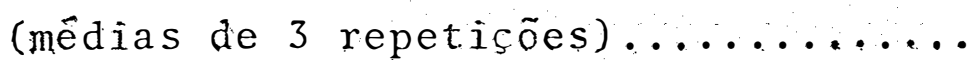

4.2. Resultados de anâlises de amostras de terra coletadas do nîvel de 40 pmm S

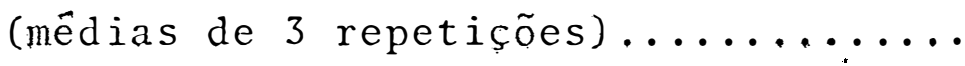

4.3. Parâmetros das curvas de calibração de $\mathrm{S}-\mathrm{SO}_{4}=$ para os extratores $\mathrm{NH}_{4} \mathrm{OAC} 0,5 \mathrm{~N}_{2}$ em ácido acético $0,25 \mathrm{~N}, \mathrm{Ca}\left(\mathrm{H}_{2} \mathrm{PO}_{4}\right)_{2} \cdot \mathrm{H}_{2} \mathrm{O}$ 500 ppm $\mathrm{P}$ em ácido acético $2,0 \mathrm{~N}, \mathrm{CaCl}_{2}$ $0,15 \%$ e HC1 $0,05 \mathrm{M} \ldots \ldots \ldots \ldots \ldots \ldots \ldots$ 
4.4. Matriz de coeficientes de correlação 1 inear simples entre absorção de enxofre versus extratores de $\mathrm{S}_{-} \mathrm{SO}_{4}=$ disponivel nos solos, entre produção de matëria seca ver sus extratores e entre os próprios extra

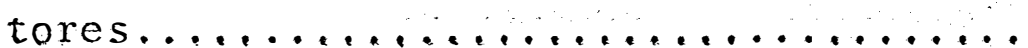

4.5. Parâmetros das equações hiperbổicas e tempos necessârios (semanas) para esti mar as metades do enxofre $\left(1 / 2 \mathrm{~S}_{0}\right)$ e do nitrogênio $\left(1 / 2 \mathrm{~N}_{0}\right)$ potencialmente minera lizâveis por incubação aberta na ausência e presença de calagem............

4.6. Quałro de anảiise de variância coṇjunta da produção de matêria seca da parte aérea do milho e absorção de enxofre.

4.7. Quadro de mêdias de produção de matêria seca da parte aérea do mịho e absorção de enxofre, comparando-se os efeitos de solos, cultivos, calagem e gessagem.... 
x x i.

TABELA

Pâgina

4.8. Curvas de resposta da produção de matéria seca (g/vaso) versus doses de gesso $(0,20$ e 40 ppm S), na ausência e presença de calagem e em dois cultivos dos solos, de forma individual e conjun

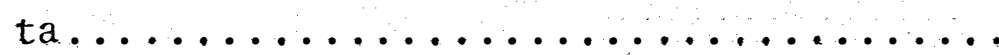

4.9. Curvas de respostas de absorção de enxo fre (mg S/vaso) versus doses de cgesso $(0,20$ e $40 \mathrm{ppm}$ S), na ausência e presença de calagem e em doìs cultivos dos solos, de forma individual e conjun

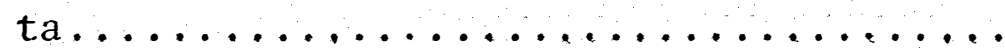

4.10. Teores de nitrogênio, fósforo e enxofre na parte aêrea do milho nos dois cultivos (médias de 3 repetições) .........

4.11. Coeficientes de determinação $\left(R^{2}\right.$ e $\left.r^{2}\right)$ da produção de matêria seca da parte aêrea do milho e absorção de enxofre versus porcentagem de enxofre total e razões N/S e P/S, em dois cultivos de miTho 
.xvii.

TABELA

Pâgina

4.12. Matriz de correlação linear simples de pa xâmetros de solos entre si e entre $a$ ab-

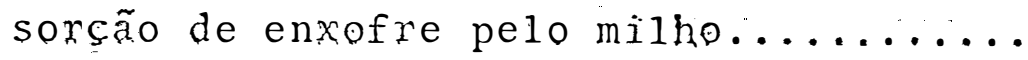

4.13. Equações de regressão descritivas dạ relą ção entre a absorpção de enxofre pelo enxọ fre versus $\mathrm{S}_{-} \mathrm{SO}_{4}^{=}$extraîvel por três extra tores e respectivos níveis crîticos que estimam $90 \%$ da absorção relativa mâxima $(n=72) \ldots \ldots \ldots \ldots \ldots \ldots \ldots \ldots \ldots$

4.14. Coeficientes de regressão linear múltipla das relações de anâlises de solos e de plantas com a produção de matéria seca de mitho (g/vaso) e absorção de enxofre (mg/ vaso), obtidos por regressão "stepwise". 170 
.xviii.

\section{LISTA DE FIGURAS}

FIGURA

Pâgina

4.1.1. Evolução dos teores de enxofre disponível $\left(\mathrm{S}_{-} \mathrm{SO}_{4}^{\bar{*}}\right)$, extraîdo por $\mathrm{Ca}\left(\mathrm{H}_{2} \mathrm{PO}_{4}\right)_{2}$. $\mathrm{H}_{2} \mathrm{O}-500$ ppm P em ácido acētico 2,0N em função dạ ausência e presença de calagem e doses, de gesso, de 0,20 e 40 ppm de $S$, em amostras colhidas após incubação
(A), após o primeiro cultivo (B) e após
o segundo cultivo (C) ..............

4:1.2. Evolução dos teores de enxofre disponível $\left(\mathrm{S}-\mathrm{SO}_{4}^{=}\right)$, extraído por $\mathrm{NH}_{4} \mathrm{HOAc} 0,5 \mathrm{~N}$ em ácido acético $0,25 \mathrm{~N}$, em função da ausência e presença de calagem e das doses de ges sso de 0,20 e $40 \mathrm{ppm}$ de $\mathrm{S}$, em amostras colhidas após a adubação (A), apôs - primeiro cultivo (B) e apôs o seguñ

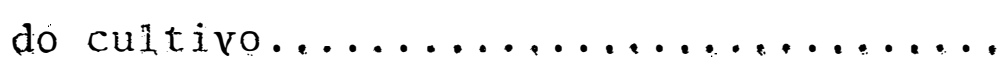

4.1.3. Evolução dos teores de enxofre disponível $\left(\mathrm{S}_{-} \mathrm{SO}_{4}\right)$, extraído por $\mathrm{CaCl}_{2} 0,15 \%$, em função da ausêncìa e presença de calagem e das doses de gesso de 0,20 
. xix.

FIGURA

e $40 \mathrm{ppm}$ de $\mathrm{S}$, em amostras colhidas apôs a incubação (A), apôs o primeiro cultivo (B) e após o segundo cultivo (C)..

4.2. Efeitos da incubação aberta e da cala gem nas quantidades acumuladas de enxofre $\left(\mathrm{S}-\mathrm{SO}_{4}^{=}\right)$e nitrogênio $\left(\mathrm{N}-\mathrm{NH}_{4}^{+}+\mathrm{NO}_{3}^{-}\right) \mathrm{mi}$ neralizadas em função do tempo........

4.3. Efeitos de incubação aberta e da calagem na atividade especifica ${ }^{35}$ S (cpm $x$ $1000 / \mu \mathrm{g} \mathrm{S}-\mathrm{SO}_{4}=$ ) nos 1 ixiviados em KCl

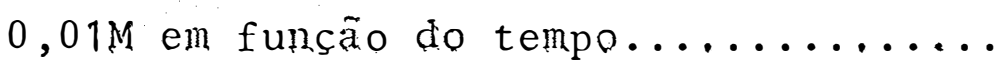

4.4. Produção de matéria seca de milho ver-sus teores de enxofre total nas plantas, com agrupamento dos solos pelos teores de carbono e pelos cultivos...........

4.5. Absorção de enxofre pelo milho versus teores de enxofre total, com agrupamento dos solos pelos teores de carbono e

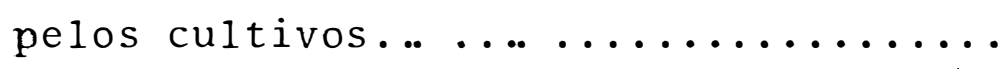


$. x \times$.

FIGURA

Página

4.6. Absorção de enxofre pelo milho versus razões N/S das plantas, com agrupamen to dos solos pelos teores de carbono

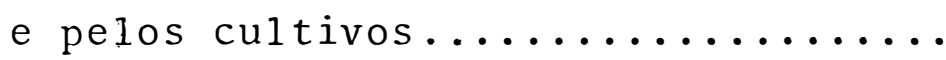

4.7. Absorção de enxofre pelo milho versus razões $\mathrm{P} / \mathrm{S}$ nas plantas, com agrupamen to dos solos pelos teores de carbono

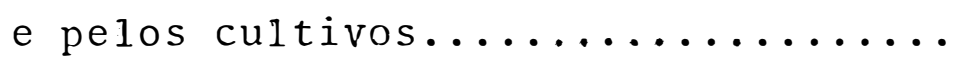

4.8. Absorção de enxofre (mg/vaso) pelo $\mathrm{mi}$ tho versus percentagem de carbono nos solos submetidos a dois cultivos na ausência e presença de calagem e no

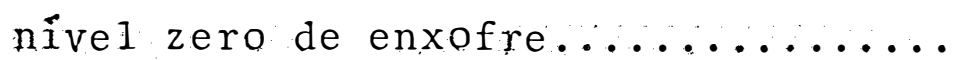

4.9. Potenciais de mineralização $\left(S_{0}\right)$, estimados pela equação hiperbólica (STANFORD \& SMITH, 1972) versus absor ção relativa de enxofre $\left(\mathrm{S}^{-} / \mathrm{S}_{20} \times 100\right)$, na ausência e presença de calagem.... 
.$x x i$

FIGURA

Página

4.10. Absorção de enxofre peio milho versus $\mathrm{S}-\mathrm{SO}_{4}=$ disponível via extrator $\mathrm{CaCl}_{2}$ $0,15 \%$ referentes aos dois cultivos dos

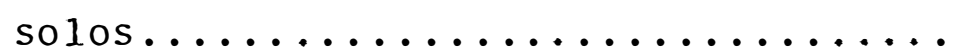

4.11. Absorção de enxofre pelo milho versus $\mathrm{S}-\mathrm{SO}_{4}=$ disponivel via extrator $\mathrm{NH}_{4}-\mathrm{OAC}$ $0,5 \mathrm{~N}$ em ácido acêtico $0,25 \mathrm{~N}$ referen tes a os dois cultivos dos solos.....

4.12. Absorção de enxofre pelo milho versus $\mathrm{S}-\mathrm{SO}_{4}=$, disponivel via extrator $\mathrm{Ca}\left(\mathrm{H}_{2} \mathrm{PO}_{4}\right)_{2}-500 \mathrm{ppm} \mathrm{P}$ em äcido acét $\underline{\mathrm{i}}$ co $2,0 N$, referentes aos dois cultivos

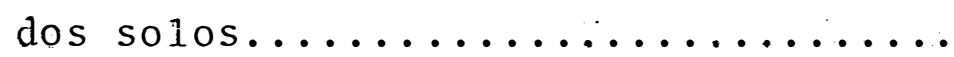

4.13. Produção relativa de matéria seca de milho versus $\mathrm{S}-\mathrm{SO}_{4}=$ disponivel extraído por $\mathrm{CaCl}_{2} 0,15 \%$ nos dois cultivos

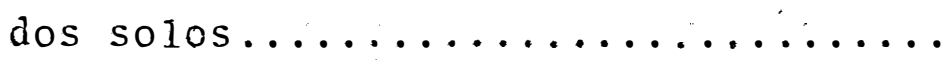

4.14. Produção relativa de matéria seca de milho versus $\mathrm{S}_{-} \mathrm{SO}_{4}^{\overline{4}}$, disponível extraí do por $\mathrm{NH}_{4} \mathrm{OAc} 0,5 \mathrm{~N}$ em ácido acético $0,25 \mathrm{~N}$ nos dois cultivos dos solos... 
.xxii.

FIGURA

Pāgina

4.15. Produção relativa de matéria seca de milho versus $\mathrm{S}_{-} \mathrm{SO}_{4}^{=}$disponivel extrai do por $\mathrm{Ca}\left(\mathrm{H}_{2} \mathrm{PO}_{4}\right)_{2} \cdot \mathrm{H}_{2} \mathrm{O}-500 \mathrm{ppm} \quad \mathrm{P}$ em âcido acético $2,0 \mathrm{~N}$ nos solos nos

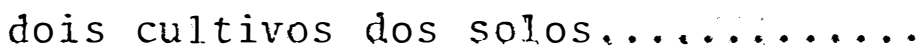


.$x x i i i$

\section{LISTA DE APENDICE}

TABELA

Pâgina

1 Resultados das anâlises de rotina de terra amostradas, apōs a incubação (A), após o primeiro cultivo (B) e após o segundo cultivo (C) (médias de 3 repetições)....

Produção de matêria seca da parte aérea do milho (g/vaso), em fun ção da calagem e gessagem, com dois cultivos sucessivos........

Teores totais de nitrogênio, fôsforo e enxofre na parte aérea do milho, em função da calagem e da gessagem em dois cultivos sucessi $\operatorname{vos} \ldots \ldots \ldots \ldots \ldots \ldots \ldots$

4 Reșultados das determinações de S-SO $=$ disponivel nas amostras de terra apōs a incubação, após o primeiro cultivo e após o segundo

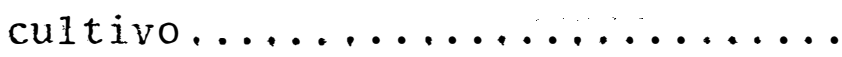


.$x x i v$.

TABELA

5.1. Efeitos da incubação aberta e da ca lagem na mineralização do enxofre dos solos ( $\left.\mathrm{S}-\mathrm{SO}_{4}^{=}\right)$em condições de microcolunas, submetidas à lixivia-

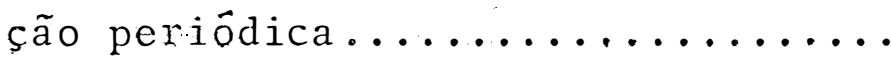

5.2. Efeitos da incubação aberta e da ca lagem na mineralização do nitrogê nio dos solos $\left(\mathrm{NH}_{4}^{+}+\mathrm{NO}_{3}^{-}\right)$em condições de microcolunas, submetidas à Iixiviação periódica............

6.1. Valores de cpm /0,1 m (corrigidos para o tempo "zero" nos Iixiviados em KCI $0,01 \mathrm{M}$ sob condições de incubação aberta, na ausência e presen-

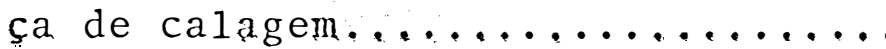

6.2. Valores de atividade específica de ${ }^{35} \mathrm{~S}$ nos lixiviados em KCI $0,01 \mathrm{M}$ sob condições de incubação aberta, na ausência e presença de calạgem.... 
.$\times \times V \cdot$

\title{
CONTRIBUICÃO AO ESTUDO DA DISPONIBILIDADE DE ENXOFRE EM SOLOS BRASTLEIROS
}

\author{
Autor: HUBERTO JOSE KLIEMANN
}

Orientador: Prof. Dr. EURIPEDES MALAVOLTA

RESUMO

Conduziu-se um experimento com amostras superficiais de 12 solos, provenientes dos Estados de São Pau 1o, Minas Gerais e Goiảs (Brasil), com teores de carbono va riando de 0,50 a $3,03 \%$, de enxofre total de 0,0104 a $0,031 \%^{\circ}$ e de argila de 8 a $60 \%$. Fez-se a avaliação de $\mathrm{S}_{-} \mathrm{SO}_{4}^{=}$disponível através de 4 extratores químicos, Ca( $\left(\mathrm{H}_{2} \mathrm{PO}_{4}\right)_{2} \cdot \mathrm{H}_{2} \mathrm{O}$ 500 ppm $\mathrm{P}$ em ácido acêtico $2,0 \mathrm{~N}, \mathrm{NH}_{4} \mathrm{OAc} 0,5 \mathrm{~N}$ em ácido acétj co $0,25 \mathrm{~N}, \mathrm{CaCl}_{2} 0,15 \%$ e HCl $0,05 \mathrm{M}$.

Realizou-se um ensaio biológico em casa-de-vegetação, com dois cultivos sucessivos. Usou-se um de Iineamento fatorial completo, em biocos casualizados por solo, com os tratamentos: 12 solos, 3 doses de gesso: $(0$, 20 e 40 ppm de S), ausência e presença de calagem, 2 culti vos e 3 repetições e o milho (Zea mays J..) como planta-tes te.

Inicialmente incubaram-se os solos na ausên 
cia e presença de calagem e o enxofre nas doses indicadas; em sacos piâsticos semi-abertos para evitar ambiente anaerôbico. Apôs 15 dias de incubação retiraram-se porções de terra para anâlises posteriores e transferiram-se $5 \mathrm{~kg}$ para vasos de cerâmica e acrescentaram os demais nutrientes. O primeiro cultivo, dos solos foi de 42 dias e o segundo de 48 dias. Após o primeiro retiraram-se novamente porções de terra para análises posteriores e removeram - se as raizes para o segundo cultivo com $4,5 \mathrm{~kg}$ de terra por vaso. Apôs o segundo cultivo, colheram-se novas porçōes de terra para anạilises posteriores.

Em laboratório conduziram-se dois experjmen tos de incubação aberta em colunas com $50 \mathrm{~g}$ de terra, na ausência e presença de calagem. Estabilizou-se a umidade das amostras de terra atravês de sucção a $60 \mathrm{~cm}$ de $\mathrm{Hg}$. Nos dois experimentos submeteram-se, de duas em duas semanas, as colunas à lixiviação com solução de $\mathrm{KCl} 0,01 \mathrm{M}$, retornan do-as à tensão de umidade inicial. No primeiro experimento utilizaram-se os lixiviados para a determinação de $\mathrm{NH}_{4}^{+}+$ $\mathrm{NO}_{3}^{-}$e $\mathrm{S}_{-} \mathrm{SO}_{4}^{=}$. No segundo experimento acrescentou-se enxofre radioativo $\left({ }^{35} \mathrm{~S}\right.$, livre de carregador, na forma de $\left.\mathrm{H}_{2}{ }^{35} \mathrm{SO}_{4}\right)$, com atividade inicial de $0,62134 \mu \mathrm{Ci} \cdot \mathrm{g}^{-1}$ de terra no tempo "zero" (antes da primeira lixiviação).

Para a avaliação da disponibilidade do enxo fre nos solos consideraram-se as variáveis independentes carbono, enxofre total, potenciais de mineralização de enxofre $\left(S_{0}\right)$ e $S-S_{4}^{=}$extraível dos solos, enxofre total e ra- 
.xxvii.

zões N/S e P/S das plantas e as vaniâvejs dependentes produção cle matêria seca e absorção de enxofre (absolutas e relativas). Na avaliação individual das variâveis independentes utilizaram-se têcnicas estatísticas usuais e na ava 1iação conjunta a regressão linear múltîpla. Determinaram-se os potenciais de mineralização de nitrogênio e enxofre com auxílio de algoritmo computacional iterativo.

Os resultados experimentais permitam as seguintes conclusões:

Os solos arenosos e de baixos teores de car bono possuem pequenos potenciais de mineralização de nitro gênio e enxofre nativos, sendo afetados de forma não signi ficativa pela calagem. Os solos argilosos e com mais altos teores de carbono tem potenciais de mineralização de nitro gênio e enxofre mais elevados, com efeitos signüficativos da calagem.

A meia-vida (tempo necessário para minerali zar a metade do nitrogênio e do enxofre potencialmente mineralizầiseis), foi modificada pela calagem, não se verificando proporcionalidade na mineralização do nitrogênio e do enxofre.

A mineralização do nitrogênio e do enxofre e o decaimento da atividade especifica de ${ }^{35} S$ estabilizaram-se por volta da oitava semana de incubação aberta, tanto na ausência quanto na presença de calagem.

Os teores de carbono e os potenciais demineralização do enxofre dos solos são estreitamente correla 
.xxviii.

cionados com a absorção de enxofre pelo milho, nạ presença de calagem. Não houve correlação significativa entre os potenciais de mineralização de enxofre no primeiro cultivo e os teores de carbono nos solos no segundo cultivo versus absorção de enxofre na ausência de calagem, mostrando que a acidez jmpede a mineralização e a dessorção do enxofre nativo dos solos. O enxofre total dos solos em nenhum caso apresentou correlação com a absorção de enxofre dos solos.

Dentre os extratores estudados, o Ca $\left(\mathrm{H}_{2} \mathrm{PO}_{4}\right)_{2}$ - $\mathrm{H}_{2} \mathrm{O}-500 \mathrm{ppm} \mathrm{P}$ em ácido acético $2,0 \mathrm{~N}$ demonstrou o melhor desempenho tanto em termos oneracionais ảe laborató rio, quando na correlação com a produção de matéria seca e

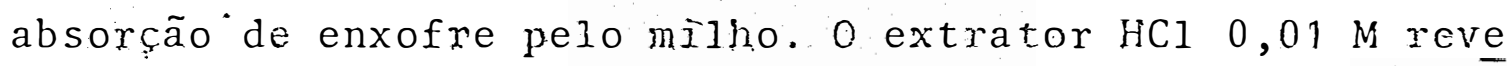
lou-se totalmente inadequado por não se terem obtido extra tos jümpidos para a determinaça turbidimétrica do $\mathrm{S}-\mathrm{SO}_{4}=$

Os extratores $\mathrm{NH}_{4} \mathrm{OAc} 0,5 \mathrm{~N}$ em ảcido acético $0,25 \mathrm{~N}$ e $\mathrm{O} \mathrm{CaCl}_{2} 0,15 \%$ correlacionaram-se significativamente com a absorção de enxofre, mas apresentam o inconvenien te da necessidade de determinação imediata do $\mathrm{S}_{-} \mathrm{SO}_{4}=$ dos ex tratos ou de seu armazenamento em refrigerador para evitar desenvolvimento de fungos.

Os niveis críticos de $\mathrm{S}-\mathrm{SO}_{4}=$ nos solos para a obtenção de $90 \%$ da produção máxima relativa de matéria seca foram: (a) $\mathrm{Ca}\left(\mathrm{H}_{2} \mathrm{PO}_{4}\right)_{2} \cdot \mathrm{H}_{2} \mathrm{O}-500$ ppm P em ácido acético 2,0N: $11 \mathrm{ppm}$; (b) $\mathrm{NH}_{4} \mathrm{OAc} 0,5 \mathrm{~N}$ em äcido acético $0,25 \mathrm{~N}$

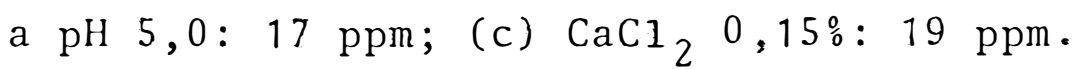


Os niveis criticos de enxofre total na parte aérea do milho versus produção de matéria seca e absorção de enxofre foram de $0,14 \%$ e $0,20 \%$, respectjvamente, no primeiro cultivo dos solos arenosos; no segundo cultivo determinou-se o nivel crítico de $0,14 \%$ para ambos os casos. No primeiro cultivo dos solos argilosos (com teores de car bono superiores a $1,2 \stackrel{\circ}{\circ})$, os coefic:entes de regressão não significativos, não permitiram, assim, estabelecer os níveis críticos; no segundo cultivo; os nívejs de enxofre to taI nas plantas foram đie $0,20 \%$ para a produção de matéria e de $0,30 \%$ para a absorção de enxofre.

A razão N/S da parte aèrea do milho que caracteriza a deficiência de enxofre está por volta de 10 a 12/1, relacionada com a absorção de enxofre. A correlação foi altainente significativa no primeiro e no segundo culti vos.

A razão $P / S$ na parte aérea do milho não apresentou correlação significativa com a absorção de enxofre no primeiro cultivo. Na anăise conjunta dos dois cultivos è no segundo isoladamente as correlações com a absorção de enxofre foram significativas. Por causa da maior dispersão dos pontos não se node estabelecer precisamente a razão $\mathrm{P} / \mathrm{S}$ que caracteriza a deficiência de enxofre nas plantas. Tentativamente, propõe-se a räzão P/S $1 / 1$ como va lor critico.

$\mathrm{Na}$ àvaliação conjunta de análises de solos e de plantas versus produção de matéria seca por regressão 
linear múltipla, contribuíram, significativamente os seguintes parâmetros:

a) solos arenosos (teores de carbono menores que $7,2 \%$ ) - en xofre total. e razão $\mathrm{N} / \mathrm{S}$ das plantas e $\mathrm{S}-\mathrm{SO}_{4}^{\circ}$ extraível dos solos;

b) solos argilosos (teores de carbono maiores que $1,2 \%$ ) enxofre total e razão $N / S$ das plantas, $\mathrm{pH}, \mathrm{Ca}, \mathrm{Mg}, \mathrm{H}+\mathrm{AI}$ e carbono dos solos;

e versus absorção de enxofre:

a) solos arenosos - enxofre total e razão N/S das plantas, $\mathrm{S}_{-} \mathrm{SO}_{4}^{=}$extrajvel e pH dos solos;

b) solos argilosos - enxofre total e razões N/S e P/S das plantas, $\mathrm{S}_{-} \mathrm{SO}_{4}=$ extraivel, $\mathrm{pH}, \mathrm{H}+\mathrm{AI}$ e carbono dos solos.

Dentre os parâmetros estudados, a razão N/S revelou-se como o mais preciso para diagnosticar a deficiência nutricional de enxofre para as plantas. 
$. x \times x i$

\title{
CONTRIBUTION TO THE STUDY OF THE SULPHUR AVAILABILITY IN BRAZILIAN SOILS
}

\author{
Author: HUBERTO JOSÉ KLIEMANN \\ Adviser: EURIPEDES MALAVOLTA
}

\section{SUPMARY}

In the experiments dealt with in this contribution surface samples $(0-20 \mathrm{~cm})$ of 12 soils from the States of São Paulo, Miñas Gerais and Goiás (Brazil) were used. Carbon (C) content varied from 0.50 to 3.03\%, and total sulphur (S) was in the range of 0,0104 to $0.0319 \%$. The clay content varied from 8 to $60 \%$.

The availability of $S$ was measured by determining the $\mathrm{SO}_{4}^{-\mathrm{S}}$ content as extracted by the following solutions: $\mathrm{Ca}\left(\mathrm{H}_{2} \mathrm{PO}_{4}\right)_{2} \cdot \mathrm{H}_{2} \mathrm{O}-500 \mathrm{ppm}$ in $2.0 \mathrm{~N}$ acetic acid, $0.5 \mathrm{~N}$ ammonium acetate in $0.25 \mathrm{~N}$ acetic acid $0.15 \% \mathrm{CaCl}_{2}$ and $0.05 \mathrm{M} \mathrm{HC} 1$.

Corn (Zea mays L.) was grown in the greenhouse in two successive crops in the presence initially of three rates of $S$ applied as gypsum; name $1 y 0,20$ and 40 
.xxxii.

ppm, both in the presence and absence of lime. The experimental design was a complete factorial with 3 replicates.

The twelve soils were previously incubated with gypsum and lime (or no Ijme). After 15 days samples were withdrawn for analysis. Five $\mathrm{kg}$ portions of soị were placed in earthenware pots wherein a basal treatment of macro and micronutrients was given throughout. The first cropping period was 42 days and the second one lasted 48 days. Before starting the second growing period samples were taken for analysis and the root system of the corn plants was removed. After the second cropping new samples were taken for analysis.

Two open incubation experiments werc carried out in the laboratory using columns containing $50 \mathrm{~g}$ of soil. The moisture content of the soil was previously stabilized by suction at $60 \mathrm{~cm} \mathrm{Hg}$. In both trials the soil columns were leached every other week with $0.01 \mathrm{M} \mathrm{KCl}$; after the treatment moisture tension was returned to the original one. In the first experiment the leachate was used for the determination of $\mathrm{NH}_{4}^{+}+\mathrm{NO}_{3}^{-}$and $\mathrm{SO}_{4}^{-\mathrm{S}}$. In the second incubation trial carrier free $\mathrm{H}_{2} \mathrm{~S}^{35} \mathrm{O}_{4}\left(0.62 \mu \mathrm{Ci} . \mathrm{g}^{-1}\right.$ soil $)$ was applied at zero time.

The availability of $S$ in soils under study was assessed by using the following variables: total $C$ and $\mathrm{S}$; mineralization potential; extractable $\mathrm{SO}_{4}-\mathrm{S}, \mathrm{N} / \mathrm{S}$ and P/S ratio in the plant material, dry matter yield and 
absolute and relative sulphur uptake. Analysis both of variance and regression were used. The mineralization potentials of $N$ and $S$ were estimated by using hyperbolic equations.

The experimental results allowed for the following conclusions to be drawn.

Sandy soils low in $C$ possess smal1

mineralization potentials of $N$ and $S$ being unaffected by liming. The reverse is true in the case of clayey soils with higher C content.

The half 1 ife of the mineralization both of $N$ and $S$ was modifjed by liming; there was not, however, a proportionality factor between the mineraization rates of the two components.

The mineralization of native $\mathrm{N}$ and $\mathrm{S}$, as well as the decay of the specific activity of the added ${ }^{35} \mathrm{~S}$ tended to level off in the $8 \mathrm{th}$ week of incubation, no effect of liming being evident.

S uptake by the corn plant in the presence of lime is strongly correlated with C content of the soils, and with the mineralization potential of the soil sulphur. There was no significant correlation between $S$ mineralization potential in the first cropping and the c content in the second one against sulphur uptake in the absence of 1 iming. Total soil $S$ in no case showed significant correlation with sulphur taken up by the plants. 
.$x x x i v$

Among the extracting solutions calcium

phosphate in HAc provided the best performance both in operational terms, and with respect to correlations with dry matter yield and S uptake. Dilute HCl proved to be thoroughy inadequate due to the impossibility of giving clear uncolored extracts suitable for the turbidimetric determination of $\mathrm{SO}_{4}-\mathrm{S}$ thereof.

Both $\mathrm{NH}_{4} \mathrm{OAc}$ and dilute calcium chloride gave good correlation wịth S absorption; they have, however, the inconvenience of the need for determining the $\mathrm{SO}_{4}^{-S}$ in the extracts shortly after their obtention or after being kept under refrigeration to avoid fungal growth.

The critical levels (concentration required for $90 \%$ of the relative yield) were, in $\mathrm{ppm}$ of $\mathrm{SO}_{4}-\mathrm{S}$ :

(a) $\mathrm{Ca}\left(\mathrm{H}_{2} \mathrm{PO}_{4}\right)_{2} \cdot \mathrm{H}_{2} \mathrm{O}(500$ ppm $\mathrm{P})$ in $2.0 \mathrm{~N}$ acetic acid - 11 ; (b) $\mathrm{NH}_{4} \mathrm{OAC}$ $0.5 \mathrm{~N}$ in 0.25 acetic acid -17 ; (c) $\mathrm{CaCl}_{2} 0.15 \%-19$.

In sandy soils the critical level for total $S$ in the tops of the corn plants were $0.14 \%$, and $0.20 \%$, respectively for dry matter yield and $S$ uptake, in the case of the first cropping. For the second cropping it was $0.14 \%$ S. In the case of the first cropning in clayey soils $(\mathrm{C}>1.2 \%)$, the correlation coefficients were not significant; in the second cropping, however, the levels were found to be $0.20 \%$ for dry matter yield, and $0.30 \%$ for $s$ uptake.

Highly significant correlations were determined, both in the first and in the second cropping 
when the N/S ratio in the tops was plotted against S uptake: sulphur deficiency is associated with a ratio of $10-12 / 1$.

In the first cropping the $\mathrm{P} / \mathrm{S}$ ratio in the tops did not show significant correlation with $S$ uptake. When data from the two croppings were analysed jointly, as we11 as in the case of the second one, significant correlation between $\mathrm{P} / \mathrm{S}$ and $\mathrm{S}$ absorption were found. Tentatively it is suggested that the $1 / 1$ ratio is used as a critical value.

In the joint evaluation of soil and plant analyses against dry matter yield, through multiple linear regression, a significant contribution was given by the following parameters:

(a) sandy soils $(C<1.2 \%)$ - total $C$ and $N / S$ in the plant and $\mathrm{soil}_{\mathrm{SO}_{4}^{-\mathrm{S}}}$

(b) clayey soils $(\mathrm{C}>1.2 \%)$ - total $S$ and $N / S$ ratio in the plants, $\mathrm{pH}, \mathrm{Ca}, \mathrm{Mg}, \mathrm{H}+\mathrm{Al}$ and $\mathrm{C}$ in the soil;

when $S$ uptake is the dependent variable the following was found:

(a) sandy soils - total $S$ and $N / S$ ratio in the plant, soil $\mathrm{SO}_{4}-\mathrm{S}$ and $\mathrm{pH}$;

(b) clayey soils - total $\mathrm{S}, \mathrm{N} / \mathrm{S}$ and $\mathrm{P} / \mathrm{S}$ ratios in the $\mathrm{plant}$; $\mathrm{SO}_{4}-\mathrm{S}, \mathrm{pH}, \mathrm{H}+\mathrm{Al}$, and $\mathrm{C}$ in the soil. 
$. x \times x v i$.

Among al1 parameters the $N / S$ ratio proved to be the most reliable for the evaluation of the nutritional status of the plants with respect to sulphur. 


\section{INTRODUCก̃o}

A essencialidade do enxofre é reconhecida desde os primeiros dias da nutrição mineral de plantas. No entanto, não tem causado maiores preocupações, porque se usaram formulações com baixas concentrações de $N, P$ e $K$ e relativamente altas de enxofre, como ânion acompanhante, .em forna de sulfato. Com o advento dos concentrados de $\mathrm{N}$ e P. sem enxofre, da correção dos solos e do aumento gera] de produtividade agropecuária, a exaustão do enxofremativo dos solos, vem se manifestando em praticamente todas as partes do mundo, incluindo o Brasiz.

Embora, não sejam muito recentes as cons.. tataçöes de deficiência de enxofre nos solos agrícolas, o assunto não tem despertado maior interesse entre os pesquisadores. Os trabalhos relacjonados à predição das necessidades de enxofre na literatura mundial e brasileira são bastante escassos. As pesquişas referentes a mêtodos de ex tração de enxofre disponível nos solos tem mostrado avanços pouco significativos devido a dificuldades analíticas e o caráter biodinânico do enxofre-sulfato nos solos. No Brasil, as pesquisas sobre disponibilidade do enxofre nati vo nos solos e respostas à adubação sulfatada tiveram certo impulso com estudos de lixiviação de $\mathrm{S}-\mathrm{SO}_{4}=$ e bases acom panhantes e desenvolvimento em profundidade do sistema ra- 
dicular de culturas econômicas em șolos sob vegetação de cerrado, visando o aumento da resistência à seca.

Pox outro lado com a opção da indústria mundial de fertilizantes pela produção de nitrogenados (uréia) e fosfatados (superfosfato triplo e amônio-fosfatos), é imperativo que se avalie o potencial de fornecimento de enxofre dos solos, determinando-se a real necessidade de se complementar a adubação com alguma fonte de enxofre.

Desenvolveu-me este trabalho para cestar extratores quimjcos de enxofre disponivel, a resposta adubação sulfatada, estimar o potencial de mineralização do nitrogênio e do enxofre orgânico, na ausência e presença de calagem em solos dos Estados de São Paulo, Minas Gerais e Goiâs. Estes parâmetros são correlacionados com o nível de enxofre na planta teste (milho), com as razões $N / S$ e P/S, com a produção de matêxia seca e absorção de en xofre em condições de casa de vegetação. As informações ob tidas servirão de subsídjos para a obtenção do nível criti co de enxofre disponivel nos solos em condições de campo. 


\section{REVISẼO DE LITERATURA}

0 recente interesse pelo estudo do enxofre nos solos parte de dois enfoques básicos: o ambiental e o agrïcola.

A grande expansão industrial que se constat́a em várias partes do mundo provoca sêrias perturbações à ecologia, com a emissão de gases sulfurosos, chuvas äcidas e consequente degradação do meio ambiente. De acordo com BETTANY \& STEWART (1983), em regiões com severa poluição industrial, os teores de enxofre total nos solos podem ser superiores a $50.000 \mathrm{ppm}$

A agricultura tạmbêm vem mostrando significativa expansão atravês do aumento da produtividade e da ocupação de novas terras, em geral de baixa fertilidade. Em ambos os casos a utilização de maiores quantidades de fertilizantes se tornou imperativa. Inicialmente, pensou-se que seria mais interessante autilização de concentrados de $N, P$ e K, devido ao barateamento do transporte por unidade de nutriente. Logo se verificou o equívoco, com a depleção do enxofre nativo dos solos de baixa fertilidade, como atestam COLEMANN (1966) e MALAVOLTA (1980).

Nas novas fronteiras agrícolas brasileiras, a deficiência de enxofre nos solos de baixa fertilida 
de (cerrados e florestas tropicais e equatoriais) começa a manifestar-se a partir do segundo ou terceiro ano de cul tivo e uso de fertilizantes $N, P$ e $K$ sem enxofre. Experimentos conduzidos no Instituto de Pesquisas IRI (Matão, SP) demonstraram que a adubação nitrogenada, sem enxofre induziu a deficiência de enxofre em pastagens (McCLUNG \& QUINN, 1959). Mais tarde em solos de várzeas do Baixo Amazonas, WANG et alii $(1976 \mathrm{a}, \mathrm{b})$ observaram que nos primeiros culti vos $N$ e $P$ são mais importantes, porém, com 3 safras suces.sivas de arroz inundado e emprego de formulações $N$ P K sem enxofre os rendimentos sofreram decrêscimos da ordem de 40 a $60 \%$. De um modo gerâ a inđução da deficiencia de enxofre è mais notâvel em solos arenosos (COLEMAN, 1966).

\subsection{Fompas de ENXOFRE NAS ROCHAS E NOS SOL}

\subsubsection{ENXOFRE TOTAL NAS ROCHAS}

0 enxofre ocorre em muitas formas nas rochas, por causa desua valência que varia de -2 a +6 , tendo-se os sulfitos e os sulfatos nos dois extremos. A crosta terrestre possui teores variâveis de 0,01 a $0,1 \%$ de enxo fre total. Os silicatos geralmente apresentam menos de $0,01 \%$, as rochas âcidas acima de $0,01 \%$, as rochas bâsicas acima de $0,1 \%$. As rochas sedimentares, peia sua densidade 
de origem, apresentou ao redor de $0,02 \%$ nos arenitos; $0,13 \%$ nos calcärios; e 0,22 nos argilitos, folhelhos e ardösias (RICKE, 1960).

A forma mais comum de enxofre nas rochas são os sulfetos de metais (ferro, chumbo, manganês, níquel, cobre, etc), contidos nas rochas plutônicas. $A$ medida que estas rochas são intemperizadas, ocorre a oxidação dos sulfetos para sulfatos. Em regiões âridas são precipitados com sais solúveis ou insolưveis ou então, novamente, reduzidas a sulfitos e sulfetos sob condições redutoras. En regiöes chuvosas, grande narte do enxofre é mineralizacio a sulfato e perdido (Iixiviado) pelạs águas de drenagem, com destino final nos sedimentos maxinhos.

\subsubsection{ENXOFRE TOTAL NOS SOLOS E RELACÕES $\mathrm{c} / \mathrm{N} / \mathrm{S}$}

Os valores de enxofre total nos solos variam de 22 a $35.000 \mathrm{ppm}$. Em condições naturais, os valores mais altos são encontrados em regiões plantanosas, em solos com caráter tiomôrfico. Em regiões industrializadas com severa poluição industrial, os teores de enxofre total nos solos podem ser superiores a 50.000 ppm (BETTANY \& STEWART, 1983). Em regiões temperadas, os teores de S total declinam com o grau de intemperismo dos solos, com cerca de 540 ppm para os mollisols e 210 ppm para os alfisols (BLAJR, 
1979). Em regiões tropicajs é muito grande a variação. Na Nigêria BROMFIELD (1972) achou teores muito baixos de 38 a $52 \mathrm{ppm}$; nas Indias Ocidentais HAQUE \& HMSLEY (1973) encontraram teores variando de 110 a $510 \mathrm{ppm}$ de $S$ total. No Estado de São Paulo (Brasil), segundo MALAVOLTA (1950), os teores de $S$ total nos solos varian de 70 a 960 partes por milhão por $100 \mathrm{~g}$ de solo, enquanto que em solos de cerrado (São Paulo e Goiảs) os teores de $S$ total variam de 36 a 247 ppm para os solos virgens e de 24 a $60 \mathrm{ppm}$ de enxofre orgânico para os solos cultivados (McCLUNG et alii, 1959).

Os teores de enxofre total dos solos, à semelhança do nitrogênio, tem pouco valor interpretatjvo para o ciclo do enxofxe e fertijidade do solo. Porém, as relações $C / N$ e N/S dão uma idéia geral sobre os processos de formação do hümus dos solos de deterninada região. As relações C/S e N/S nos solos erain tidas como tipicamente ao redor de $100 / 1$ e 10/1. Porém, confrontando-se dados de várias partes do mundo, observaram-se variações significativas, em função do material de origem, processos de forma ção de solo é efeitos do clima. BETTANY \& STEWART (1983), em revisão de literatura, constataram que a relação C/S varia de 60 - 270 e a relação N/S de 4 a 20. Dados de Mohr (1948), citado por MALAVOLTA (19.50), mosiram que nos solos do Rio Grande do Sul a relação C/S varia de 10 a $\$ 50$ com valor médio de 30. Segundo WILLIAMS \& STEINBERGS (1959) e HARWARD et MOKR, W. O enxofre nas p]antas e no solo. 1948. [datilografado]. 
alii (1962), quanto maior a acidez dos solos (como os podzols e solos de florestas), mais larga tende a ser a razão $\mathrm{C} / \mathrm{S}$.

0 efeito do cultivo dos solos, de forma bastante generalizada faz aumentar as relações C/S e N/S (BETTANY \& STEWART, 1983).

2.1.3. ENXOFRE ORGÂNICO NOS SOLOS

O enxofre orgânico na maioria dos solos é superior a $90 \%$, o que é indicado pelas estreitas relações entre C orgânico, $N$ total e S total (BEIDERBECK, 1978; METSON, 1979). No subsolo podem predominar as formas inorgânicas (ESMINGER, 1954).

O fracionamento de entidades químicas específicas é problemätico do ponto de vista analítico. os procedimentos químico-analíticos disponiveis diferenciam o enxofre ligado a oxigênio ( $-0-\mathrm{SO}_{3}^{-}$e $\mathrm{C}-\mathrm{N}-\mathrm{O}-\mathrm{SO}_{3}^{-}$) e enxofre ligado diretamente a carbono (C-S). O enxofre ligado a oxigênio é considerado a fração reduzível, compreendendo ê teres e ésteres de sulfatos (fenóis, polissacarideos, coli nå , metionina e lipidios). E facilmente hidrolisado a $\mathrm{S}_{-} \mathrm{SO}_{4}=$ inôrganico, por isso considerada a fração mais lábil (TABATABAY \& BREMNER, 1972). O enxofre ligado diretamente a carbono (C-S) è determinado pela redução a sulfito com Raney-níquel. Porém, devido à baixa repetibilidade do 
método (interferência de ferro e manganês e produção de artefatos de húmus), nos trabalhos mais recentes a fração C-S é estimada pela subtração do S reduzível em HI do S to ta 1 dos solos (De LONG \& LOWE, 1962; TABATABAI \& BREMNER, 1972 ; BETTANY et alii, 1973). A fração C-S inclui, principalmente, aminoácidos, proteínas e compostos heterocíclicos. A 1 igação C-S não è rompida pela mistura redutora contendo HI . Da mesma forma os sulfetos (sulfitos) orgânicos, mercaptanas, etc. não são incluídos na fração de S-reduzível em HI. O enxofre C-S contribui com 5 a $70 \%$ do total (BETTANY et a1ii, 1973; NEPTUNE et a1ii, 1975; MC LAREN et a ij, 1985) .

A fração do S-reduzível é mais elevada em solos mais fërteis (tipo chernozem), decrescendo progressi vamente para os solos cinzentos de florestas, em condições de clima temperado. Representa entre 33 a $78 \%$ do $S$ total (BETTANY et a1ii, 1973; BETTANY \& STEWART, 1983). O inverso ocorre com a fração C-S.

Em solos brasileiros a fração do S-orgâni co varia de 77 a $95 \%$ e a fração de S-reduzivel em HI varia de 36 a $70 \%$ (NEPTUNE et a1ii, 1975).

Existe ainda uma fração variável e não identificada do S-orgânico, que consiste em grande parte, se não totalmente, de S ligado a carbono (BETTANY et alii, 1975; MAYNARD et alii, 1985).

A fração orgânica do solo compreende uma mistura complexa e heterogênea de organismos vivos e de 
plantas e animais parcialmente decompostos e resíduos microbianos em íntima associação com as partículas minerais do solo. Assim, não é surpreendente que a determinação de frações orgânicas (C-O-S e C-S) dos solos sobre o tturnover" do $S$ nos solos. Tentativas tem sido feitas para: a) isolamento identificação e determinação de compostos individuais, pertencen a grupos quínicos definidos; b) extra ção química e separação físico-quîmica, tais como âcidos hứmicos, fûlvico e humina; c) separações fî́sicas dos solos, em vários tamạnhos de frações organo-minerais; d) desenvolvimento de têcnicas biolögicas, auxiliadas com isótopos radioativos e estáveis, com o objetivo de isolar e identificar as frações que são significativas em termos ciclagem de nutrientes (BETTANY \& STEWART, 1983).

A fração orgânica mais promissora, em termos de indices de disponibilidade de $\mathrm{S}_{-} \mathrm{SO}_{4}=$ para as plantas, parece ser a de S-reduzível em HI. MAYNARD et.alii (1985) verificaram que a maior parte do ${ }^{35} \mathrm{~S}$ incorporado na matéria orgânica foi encontrada na fração de S-reduzível em HI. Quando as concentrações de sulfato da solução do solo foram diminuîdas via absorção pelas plantas ou adição de celulose aos solos, houve redução no ${ }^{35} \mathrm{~S}$ incorporado na fração de S-reduzível em HI. Resultados semelhantes foram obtidos por TSUJI \& GOH (1979), em que a absorção de $S$ por Lolium perene (L.) mostrou alta correlação com o decrêscimo de $S$ reduzível em HI nos solos, durante o cultivo. 


\subsubsection{FORMAS DE S INORGÂNICO NOS SOLOS}

Nas rochas e minerais primários existem técnicas para se diferenciar sulfetos e sulfatos (RICKE, 1960), porên em solos essa distinção impraticável (METSON, 1979) .

As formas mais comuns de S-inorgânico são o S-sulfito, o S-sulfato (ocluído, precipitado, adsorvido e o sulfato solúvel em água). O S elementaré raramente encontrado nos solos, a naõ ser que tenha sido recentemente adicionado como tal. O S elementar pode ter existência efê mera, como formas intermediârias nas transformações microbiológicas. BARROW (1968), descreveu um procedimento para a extração do $\mathrm{S}$ elementar com clorofôrmio e redução a $\mathrm{H}_{2} \mathrm{~S}$. o S-sulfito é constituinte comum em solos alagados. O mono-sulfito de ferro II é o produto final da redução microbiológica do $\mathrm{S}_{-} \mathrm{SO}_{4}^{=}$a $\mathrm{H}_{2} \mathrm{~S}$, na presença de maté ria orgânica. Sob alagamento constante e bom suprimento da matéria orgânica, pode ser convertida à forma mais está vel de $\mathrm{FeS}_{2}$. Subsequentemente, com a drenagem, a pirita $\left(\mathrm{FeS}_{2}\right.$ ) é oxidada a $\mathrm{H}_{2} \mathrm{SO}_{4}$, seguida pela precipitação a jaro sita-sulfato básico de ferro e potâssio-KFe ${ }_{3}\left(\mathrm{SO}_{4}\right)_{2}$ (METSON, 1979).

O S-sulfato ocluído (ou co-precipitado) ocorre em alguns solos calcários, como sulfato de cálcio insolúvel, co-precipitado com os depósitos de carbonato de câlcio. Esta forma de S-sulfato é virtualmente indisponí- 
vel às plantas (WILLIAMS \& STEINBERGS, 1964).

O S-sulfato precipitado, inclui, alëm de outros, sulfato de bário e estrôncio, sulfatos básicos de r ferro e alumínio, como a jarosita, basaluminita e alunita (ADAMS \& RAWIJFIH, 1977).

Diversos estudos, citados por METSON (1979), mostram que a adsorção química( $\mathrm{HPO}_{4}^{=}, \mathrm{H}_{2} \mathrm{PO}_{4}^{-}, \mathrm{SO}_{4}^{=}$e $\mathrm{Mo}_{6} \mathrm{O}_{4}^{=}$, etc.) é essencialmente a expressão das espécies químicas nas superfícies dos óxidos hidratados de Fe e Al (como os "coatings" dos minerais de argila) nos cantos dos minerais tipo-camada. Existem dois tipos de adsorção: específ ca e não especifica. Estudo valioso sob o assunto foi feito por HINGSTON et alii (1972).

O S-sulfato solūvel em água apresenta variações extremas em função do clima. Os solos de regiões áridas e os afetados pela água do mar podem conter apreciá veis quantidades de sulfatos solúveis em âgua, juntamente com outros sais. Nos solos de regiões úmidas encontram-se apenas algumas ppm, por causa das seguintes reações: adsorção pelos colóides do solo, lixiviação para os horizontes inferiores do solo, utilização pelas plantas e microor ganismos e nos solos âcidos sulfatados pode ser precipitado como produtos insolûveis, como a jarosita (METSON, 1979). 


\subsection{TRansformacóes do Enyogre nOS SOlOS}

A transformação do enxofre no solo $\vec{e}$ realizado por processos essencialmente microbiológicos, em bora também sejam possíveis alguns processos, estritamen te químicos como a oxidação do $\mathrm{H}_{2} \mathrm{~S}$. Existem quatro processos distintos: mineralização, imobilização, oxidação e redução.

\subsubsection{MINERALIZAÇÃO DO ENXOFRE}

Os mecanismos envolvidos na mineralização do enxofre orgânico são aintra largamente desconhecidos. Inicialmente pensava-se, uma vez que o enxofre e o nitrogênio estão intimamente associados na matéria orgânica, desses dois elementos apresentariam padrões similares de mine ralização. Todavia, experimentos de diversas partes do mun do mostram considerầvel controvêrsia nessa ârea. Em alguns casos, a incubação de solos em laboratório mostrou que a mineralização de enxofre, concomitantemente com a de nitro gênio, ocorre em razões maiores do que a da matêria orgânica (WILLIAMS, 1967 ; HAOQUE \& WALMSLEY, 1972; KOWALENKO \& LOWE, 1975), enquanto que em outros estudos razões mais estreitas foram observadas (TABATABAI \& AL-KHAFAJI, 1980; BETTANY \& STEWART, 1983). Contradição maior ê mostrada em 
trabalho de SAGGAR et alii (1981), em que ocorreu minerali zação de nitrogênio com concomitante imobilização de enxofre.

Possiveis explicações para esse comportamento do enxofre no solo estão nos processos de mineraliza ção envolvidos. Mc GILL \& COLE (1981) sugeriram que, se qualquer elemento estâ associado com a matéria orgânica do solo, para a qual existem mecanismos específicos de degradação, ele pode mineralizar-se independentemente dos outros elementos. Foi demonstrada também a existência de enzimas, a sulfo-hidrolase e aril-sulfatase em solos (TABATABAI \& BREMNER, 1970a, b; BETTANY \& STEWART, 1983). Ess as enzimas são altamente específicas e liberam $\mathrm{S}_{-} \mathrm{SO}_{4}=$ inorgâni. co de ésteres sulfatados orgânicos. Esse tipo de mineralização è chamado de "mineralização bioquímica" e resulta de uma solicitação específica por $\mathrm{S}$. Por outro lado, a "mine ralização biológica", tanto do $N$ quanto do S ligado a carbono, ocorre como resultado da utilização do C como fonte de energia e não especificamente em resposta à necessidade por $N$ ou S. A mineralização Iîquida do enxofre, então, è consequência dos dois mecanismos (BETTANY \& STEWART, 1983).

Outra explicação possível para os resulta dos, aparentemente contraditôrios, está nos métodos de incu bação em laboratório, usados para determinar os indices de mineralização do S-orgânico. Dados de SAGGAR et alii (1981) obtidos pelo sistema de incubação fechada mostram $\underline{i}$ mobilização líquida de eṇofre e mineralização líquida de 
N. A incubação dos mesmos solos em um sistema aberto, no qual o $\mathrm{N}$ e o $\mathrm{S}$ mineralizados foram lixiviados periodicamen te com solução diluĩda de KCl, mostrou mineralização líqui da de ambos os elementos. Sugere-se que existe um mecanismo retro-alimentador para a mineralização de $S$ na incubação fechada, talvez pela desativação de enzimas, como as sulfatases envolvidas na mineralização bioquímica (MAYNARD et alii, 1983; BETTANY \& STEWART, 1983).

\subsubsection{IMOBILIZACÃO DO S-SO $\frac{\overline{4}}{4}$ INORGÂIICO}

A imobijização do $\mathrm{S}_{-} \mathrm{SO}_{4}=$ inorgânico nos so los ocorre, principalmente, em condições de acidez e razão C/S muito elevadas (WILLIAMS, 1967; BETTANY \& STEWART, $1983)$.

Os mecanismos de decomposição de compostos vegetais, animais e microbianos e sua subsequente incorporação na matéria orgânica do solo são largamente desconhecidos. As pesquisas nessa área estão num nîvel ele mentar, limitando-se ao estudo do destino de compostos mar cados durante a incubação. Em estudo de SCHARPENSEEL \& KRAUSE (1963) verificou-se que uma quantidade de S foi incorporada no ácido húmico do solo, quando o sulfato e enxo fre de aminoâcidos foram diretamente adicionados aos solos. Todavia, quando plantas de azevém foram cultivados com ${ }^{35} 5_{-S O}=$ marcado e os resíduos incorporados ao solo, apreciá 
veis quantidades do enxofre marcado foram encontrados nos ácidos húmicos do solo. Outro estudo mostrou que após 168 dias de incubação cerca de $50 \%$ do sulfato marcado estava incorporado na fração orgậnica do solo. A adição de substrato de C (glicose) aumentou a quantidade incorporada para $82 \%$. O traçador radioativo foi encontrado tanto na fração de S-reduzível em HI quanto na de S ligado a carbono, tendo aquele mostrado a maior atividade específica. O estu do mostrou, após, que a fração de ácido fúlvico continha cen ca de $75 \%$ do S imobilizado, dos quais $90 \%$ se encontram na forma reduzível em HI (FRENEY et alii, 1971).

Em estudo de incubação a ́́curto prazo 64 dias) mais recente, SAGGAR et alii (1981) confirmaram que o sulfato inorgânico quando imobilizado encontra-se na fra ção de ácido fúlvico. Levanta-se a hipótese de que essa fração é um componente altamente ativo dos solos, represen tada por materiais húmicos de baixo peso molecular, metabö litos celulares, e produtos de decomposição relativamente simples, de origem vegetal, animal e microbiológica (BETTA NY \& STEWART, 1983).

\subsection{3, OXIDAÇ̃̃O DO ENXOFRE NO SOLO}

o processo de oxidação é de considerável importância, uma vez que a.fonte primäria de enxofre nos solos são os minerais e muitos fertilizantes de $S$ são ba- 
seadas em formas reduzidas.

0 enxofre elementax, sulfitos e tio-sulfa to podem ser oxidados vagarosamente por processos puranente químicos, porêm a oxidação microbiolôgica por um grupo diverso de bactérias autotróficas, heterotróficas e fotossintêticas, fungos e actinomicetos é muito râpida sob condições favoráveis (BETTANY \& STEWART, 1983).

0 grupo mais estudado de microrganismos o xidantes de $S$ pertence à família Thiobacteriaceae. Esses microrganismos parecem ser ubíquos, operam sob uma grande variação de temperatura e pH e são capazes de altas taxas de oxidação "in vitro". Todavia, o número desses organismos nos solos parece ser baixo, exceto quando enxofre elementar tiver sido adicionado recentemente via poluição ou adubação (MOSER \& OLSON, 1953).

As reações de oxidação de compostos redu zidos de $S$ em solos inundados, pântanos e zonas de lagos e sedimentos em condições redutoras são realizados por bactêrias fotossintêticas, como Chromatium (bactêrias Spûrpureas) e Chlorobium (bactêrias S-verdes). A energia provém da luz solar e os elétrons derivados da oxidação do $\mathrm{S}$ são usados para reduzir $\mathrm{O}_{\mathrm{CO}_{3}}$. A grande variedade de fatores microbiológicos e ambientais que influenciam a ox dação do $S$ introduz considerâvel variabilidade nos indices ("ritmos") de oxidação entre solos. Em um estudo com 273 solos da Austrâlia, VITOLINS \& SWABY (1969) constata - 
ram que em 19\% não ocorria oxidação apreciável do $S$ elemen tar adicionado, enquanto que $39 \%$ mostraram indices de oxidação muito rápidos. Em diversos trabalhos, citados por BETTANY \& STEWART (1983), com solos do norte do EE.UU. e do norte do Canadâ observa-se grande variabilidade nos índi.. ces de oxidação. A aplicação do S elementar para corrigir deficiências de $S$ nas culturas deve ser encarada com cuida do. Por estudos recentes ficou claro que dois fatores afetam significativamente as taxas de oxidação do $S$ clementar: a granuiometria (mais corretamente, superficie de ârea) e o lapso de tempo que o fertilizante está em contato com o solo. Podem-se esperar taxas de oxidação maiores com o aumento da superfície de ârea e tempo de residência '(BET TANY \& STEWART, 1983; JANZEN et alii, 1982). Em solos de cerrado MC CLUNG \& QUINN (1959) verificaram recuperaçöes, mais demoradas da grama batatais (Paspalum notatum L.) com o uso de enxôfre elementar enquanto que com $\mathrm{CaSO}_{4}$ e $\mathrm{Na}_{2} \mathrm{SO}_{4}$ houve imediato desaparecimento da clorose.

\section{2 .4 . REDUÇÃO DO ENXOFRE NO SOLO}

A redução desassimilatória ou "respiratória" do sulfato ê efetuada exclusivamente por certas bac térias que usam o sulfato como aceitador terminal de elêtrôns para seus processos respiratôrios. Os microorganis- 
mos predominantes envolvidos nessa reação são anaeróbios, pertencendo a dois grupos de bactérias, Desulphomaculatum e Desulfonibrio. A redução do sulfato a sulfito somente ocorre' na ausência de ar. Assim,o processo não é comum em solos agrícolas bem arejados. Todavia', em solos sujeitos a inundações periódicas ou encharcamentos, podem existir con dições para a produção de grandes quantidades de $\mathrm{H}_{2} \mathrm{~S}$, especialmente na presença de resíduos de plantas prontamente decomponiveis (BETTANY \& STEWART, 9983 ). O $\mathrm{H}_{2} \mathrm{~S}$ reage com Fe, formando a pirita $\left(\mathrm{FeS}_{2}\right)$, sendo o composto de $S$ reduzi do mais importante em áreas costeiras. São comuns nestas á reas teores de 4 a 5\% de enxofre total (BLOOMFIELD, 1969), A drenagem desses solos sulfurosos (carāter tio-mórfico) provoca a oxidação do $\mathrm{H}_{2} \mathrm{~S}$ a $\mathrm{H}_{2} \mathrm{SO}_{4}$, com abaixamento do pH a menos de 2,5. São impróprios para agricultura.

2.2.5. CONDICÕES AMBIENTAIS E MANEJO DOS SOLOS QUE AFETAM A MINERALIZZCÃ̃O DO ENXOFRE NOS SOLOS

As condiçōes ambientais que mais influenciam no crescimento micróbiológico e na produção e ativida de de enzimas são a umidade, a temperatura, o pH e a dispo nibilidade de substrato. Todavia, outros fatores, como a presença de plantas (SPENCER \& FRENEY, 1960; TSUJI \& GOH, 1970) e a secagem e o aquecimento aceleram a liberação do sulfato orgânico e inorgânico da matêria orgânica do solo (WILLIANis, 
1967 ; SWIFT, 1985).

$$
\begin{aligned}
& \text { 2.2.5.1. Efeitos da temperatura, umidade e } \\
& \text { secamento na mineralização do enxo } \\
& \text { fre no solo }
\end{aligned}
$$

O efeito da umidade na mineralização do S orgânico é conclusivamente ilustrado pelo trabalho de WILLIAMS (1967). O indice de produção de S-suifato verificado é pequeno a baixos teores de umidade, atinge o máximo a cerca de $40 \%$ de umidade e decresce rápidamente quando o solo se torna saturado. E possível que o enxofre ainda possa ser mineralizado nessas condições, porêm não'a sulfa to (SWIFT, 1985).

0 efeito da temneratura nos indices de mi neralização de enxofre è mostrado no artigo de SWIFT (1985). TABATABAI \& AL-KHAFAJI (1980) constataram aumentos significativos na mineralização de $\mathrm{N}$ e $\mathrm{S}$, em função da tem peratura. A $20^{\circ} \mathrm{C}$, os valores mêdios de $\mathrm{N}$ orgânico minerali zado chegaram a $3,8 \%$, enquanto que a $35^{\circ} \mathrm{C}$, o percentual e levou-se para 16,6\%. Os valores médios de enxofre orgânico mineralizado a $20^{\circ} \mathrm{C}$ e $35^{\circ} \mathrm{C}$ atingiram $7,8^{\circ}$ e $22,8 \%$, respectivamente.

O secamento de amostras de solos podem al. terar significativamente os valores de $S$ mineralizado BIE 
DERBECK, 1978) relata o efeito "BIRCH", que vem a ser um "pulso" de mineralização de $S$ atribuído ao secamento de amostras. Relatando diversos trabalhos, o autor acha este efeito uma super-simplificação, uma vez que o "pulso" pode ser observado, mesmo quando os solos são conservados ümidos e, inversamente, o reumidecimento nem sempre produz o esperado "pulso" (WILLIAMS, 1967). Uma complicação adicional é que os níveis de sulfato são aumentados pelo simples secamento dos solos, indicando que está ocorrendo um processo não biológico. A produção de sulfato ê devido, provavelmente, à lise do tecido microbiano e/ou às desdobramento de ésteres de sulfato muito lábeis (KOWALENKO \& LOWE, 1975).

2.2.5.2. Efeitos da reação do solo (cala: gem) na mineralização e disponibilidade do enxofre no solo

E prática comum fazer a calagem algumas semanas antes do plantio, o tempo suficiente para que o calcário possa reagir com o solo. Isso pode alterar significativamente a capacidade de reação do enxofre sulfato do solo (CHAO et alii, 1962; WILLIAMS, 1967; COUTO et alij, 1979 ; MARTINI \& MUTTERS, 1984 ).

A maioria dos estudos sobre adsorção de 
sulfato tem mostrado que a adsorção e a retenção aumentam com o decrêscimo do pH da solução de equilíbrio, dentro da faixa de pH de 6,5 a 4,0. Em faixas de $\mathrm{pH}$ acima de 6 a 7 a quantidade de $\mathrm{S}_{-} \mathrm{SO}_{4}=$ adsorvido ê geralmente pequena (HARWARD \& REISENHAÜER, 1966; SINGH, 1984a, b) .

A calagem pode ser traduzida como sendo um efeito direto do $\mathrm{pH}$ ou como efeito do deslocamento do S-SO $=\mathrm{SO}_{4}$ pelos grupos $\mathrm{OH}^{-}$dos sittios de adsorção nos óxidos de Fe e Al (HINGSTON et alii, 1972) ou ainda como efeito da solubilização de compostos fosfatados em pH mais elevado para competir pelos sítios de troca (METSON, 1979).

0 decréscimo na retenção de $\mathrm{S}-\mathrm{SO}_{4}=$, apōs a calagem, aumentam a disponibilidade e absorção de $S$ pelas plantas (WILJIAMS \& STEINBERGS, 1964; MARTINI \& MUTTERS, 1984). O efeito imediato da calagem sobre a absorção de $S$ pode ser atribuída tanto à dessorção dos sítios de troca aniônica (PROBERT, 1976) e ao aumento na mineralização do S-orgânico (ESMINGER, T954; WILLIAMS, 1967). 
2,2,6. MigRACÃO DO ENXOFRE-SULFATO NO PERFiL DO So. LO

2.2.6.1. Interação sulfato-fosfato

Outro aspecto da dessorção e disponibiliża ção de $S$ para as plantas é a interação sulfato-fosfatos. FIELDES \& SCHOFIELD (1960) propuseram a ordem da afinidade pelos sitios de adsorção para os oxiânions: sulfato < molibdênio < fosfato < vanadato, combase na sua contribui ção de valência para os âtomos de oxigênio coordenados ao alumínio tetraédrico. Isso implica na adsorção e retenção preferencial do fosfato, quando os ânions suifato e fosfato estão simultaneamente presentes em un sistema de solução do solo. Dados de campo sustentam essa conciusão, pois com a adição simultânea de sulfato e fosfato (superfosfato simples, p. ex.), este tende a ser retido na camada superficial, enquanto que o sulfato ê lixiviado perfil abaixo (ESMINGER, 1954; TABATABAI \& BREMNER, 1972; RITCHEY et alii, 1980). Esta distribuição pode resultar no deslocamen to do sulfato pelo fosfato dos sitios de adsorção da camada superficial do solo para os horizontes inferiores onde os fosfatos e a matêria orgânica não estão presentes. Também pode ser atribuida a um maior conteúdo de material coloidal no subsolo e, portanto, mais sítios de adsorção aniônica. Provavelmente, ambos os fatores contribuem (MET- 
SON, 1979). A ação de ânions orgânicos na migração do sulfato ê sugerida pelo trabalho de BROMFIELD (1972), que num experimento de 19 anos mostramigração perfil abaixo de $\mathrm{S}_{-} \mathrm{SO}_{4}^{=}$(inorgânico) em quantidades superiores ao do $\mathrm{S}$ orgânico em parcelas que receberam, alêm de sulfato de amônio e superfosfato simples, adubação orgânica com esterco. Segundo SINGH (1984a, b), o sulfato desorvido por $\mathrm{Ca}\left(\mathrm{H}_{2} \mathrm{PO}_{4}\right)_{2}$ foi afetado o mínimo pela natureza do complexo adsortivo, $\mathrm{pH}$ e quantidade adsorvida, indicando que o fosfato ê capaz de dessorver o $\mathrm{SO}_{4}=$ adsorvido tanto devido às cargas permanentes quanto às dependentes de $\mathrm{pH}$.

Experimentos de laboratório, estufa e de campo demonstram o movimento descendente do sulfato no per fil do solo, com a adição de $\mathrm{SO}_{4}^{-} \mathrm{e} \mathrm{H}_{2} \mathrm{PO}_{4}^{-}$METSON \& BLAKEMORE (1978), em experimento de laboratório, com solos da Nova Zelândia, constataram que solos combaixo nivel de sulfato adsorvido, tem baixa capacidade de reter o sulfato, que foi posteriormente diminuîdo ou eliminado com a aplịcação de fosfato. Pox outro lado, BORNEMISZA \& LLANOS (1967) observaram que solos altamente retentivos, tem retido substanciais quantidades de sulfato, mesmo na presença de fosfato. Em solos arenosos (não retentivos de sulfato) da Dinamarca JENSEN (1963) mostrou que é impossivel construir níveis de reserva de $S$ através de superfosfato e conclui que o $S$ deve ser aplicado da mesma forma que o $N$.

A migração do $\mathrm{S}_{-} \mathrm{SO}_{4}^{=}$tem importantes impli cações na utilização dos solos com vegetação de cerrado (LE 
distróficol, principalmente, quando o subsolo tem caräter álico. RITCHEY et alii (1981) estudaram culturas de milho em áreas adjacentes durante um ano em que ocorreu um veranico muito severo. Na ärea adubada com superfosfato simples ( $559 \mathrm{~kg} \mathrm{P} / \mathrm{ha}$ ) alguns anos antes, as plantas não murcharam, pois houve desenvolvimento de raízes até a profundidade de $120 \mathrm{~cm}$; na ârea que recebeu mais recentemente SFT ( $148 \mathrm{~kg}$ P/ha), as plantas murcharam e as raizes desenvolveram-se apenas até a nrofundidade de $45 \mathrm{~cm}$.

\subsubsection{Efeito da calagem na migração} $\mathrm{S}_{-\mathrm{SO}_{4}}=$ para o subsolo

A calagem provoca a dessurção do $\mathrm{S}_{-} \mathrm{SO}_{4}=\mathrm{na}-$ tico e a mineralização do S-orgânico, podendo acelerar a lixiviação do $\mathrm{S}_{-} \mathrm{SO}_{4}=$ mineralizado atravês do perfil (ESMINGER, 1954). Em condições de estufa MARTINI \& MUTTERS (1984) verificaram que a calagem acima das doses recomendadas teve efeito depressivo sobre o crescimento, concetração e ab sorção de S por milho e soja; Em condições de campo, culti vando soja, não foi registrado efeito depressivo da calagem acima das doses recomendadas, por causa da lixiviação do $\mathrm{S}-\mathrm{SO}_{4}^{=}$do horizonte A para o B. No horizonte A o $\mathrm{S}_{-} \mathrm{SO}_{4}^{=}$ aumentou significativamente durante as duas primeiras sema nas, devido à adubação e a partir dấ decresceu por causa da absorção pelas plantas e lixiviação para o horizonte $B$. 
Embora não tenha havido diferenças significativas nos teores de enxofre do solo por efeito da calagem, observa-se a tendência de ela promover a lixiviação do $S_{-} \mathrm{SO}_{4}=$ dessorvi do para o horizonte $B$.

Em trabalho de estufa KORENTAJER et alii (1983) estudaram os efeitos da calagem e da lixiviação dos solos sobre a capacidade de fornecimento de $\mathrm{S}_{-} \mathrm{SO}_{4}=$. Nos solos lixiviados, a gessagem mostrou resposta significativa, principalmente no segundo cultivo dos solos. A calagem sem lixiviação aumentou a liberação do enxofre do solo, resultando em maior absorção pelas puantas. Ao conträrio, a calagem seguida de lixiviação diminuiu a produção de matéria seca, por causa da exaustão do enxofre nativo do solo, o que explica a significativa resposta à gessagem.

2.2.6.3. Efeitos dos ânions acompanhantes ṇa Iix̣iviação de bases e sua distribuição no pèrfil do solo

Pelo que consta, os trabalhos mais antigos relatando o efeito dos ânions acompanhantes na lixivia ção de bases no perfil do solo foram executados por PEARSON et alii (1962), por ABRUNA et alii (1964). em solo argiloso de Port Rico e VILLAMIZAR \& LOTERO (1967) em solo Andept (cinza vulcânica) da Colômbia. Nos dois primeiros casos os autores estudaram o efeito de doses de sulfato de 
amônio, verificando o decréscimo do pH e da percentagem de saturação de bases na camada superficial $(0-15 \mathrm{~cm})$, mantendo-se praticamente constantes na camada sub-superficial $(15-30 \mathrm{~cm})$. No experimento conduzido na Colômbia foi estudado o efeito de doses e fontes de nitrogênio nas produções de capim Pangola. Após 5 anos (25 cortes) notou-se a diminuição progressiva do $\mathrm{pH}$ na camada de $0-20 \mathrm{~cm}$, em fun-ção das doses de sulfato de amônio, enquanto que para o salitre e a uréia o pH não apresentou alterações significativas.

Em muitos solos tropicais, a camada subsu perficial possui carâter âlico, o que constitui impedimento químico severo para o desenvolvimento radicular em profundidade. A neutralização do Al trocâvel no subsolo atravês de calcârios requer incorporação profunda, mas esse procedimento tem um custo energëtico muịto elevado. Por ou tro lado, como os materiais calcârios são pouco solûveis e o ânion $\mathrm{CO}_{3}^{=}$é pouco estâvel, o $\mathrm{Ca}^{++}$não consegue migrar para o subsolo, A lixiviação somente ocorre quando há pareamento de íns (eletroneutralidade), isto é, um ânion (estável) deve mover-se justamente com o cátion e a velocidade do processo depende da mobilidade e estabilidade do ânion acompanhante. Para estudar este efeito RITCHEY et alii (1980) construiram colunas de solos em tubos de PVC, onde foram adicionados $\mathrm{CaCO}_{3}$ (carbonato), $\mathrm{CaSO}_{4}$ (sulfato) e $\mathrm{CaCl}_{2}$ (cloreto) e submetidos à lixiviação. No tratamento com $\mathrm{CaCO}_{3}$, o $\mathrm{Ca}^{++}$alcançou a profundidade de apenas 15 a 
$25 \mathrm{~cm}$. A maior profundidade foi atingida pelo cloreto de câlcio (cerca de $150 \mathrm{~cm}$ ), enquanto que o sulfato chegou aos $60 \mathrm{~cm}$. O menor indice de lixiviação do sulfato em relação ao cloreto é devido à adsorção específica, aos ôxidos de Fe e Al,à menor solubilidade do $\mathrm{CaSO}_{4} \cdot 2 \mathrm{H}_{2} \mathrm{O}$ e ao cloreto não sofrer adsorção especifica. O trabalho conduzido por RITCHEy et alii (1980) confirma os resultados de REEVE \& SUMNER (1972), que neutralizaram o $\mathrm{Al}^{+++}$trocável do subso 10 com o gesso em oxissolos sul-africanos.

$$
\text { Os mecanismos de ação e mobilidade do }
$$
$\mathrm{CaSO}_{4} \cdot 2 \mathrm{H}_{2} \mathrm{O}$ em relação ao $\mathrm{CaCO}_{3}$ são elucidados pelo trabalho de PAVAN et alii (1984), em condições de colunas de solos, concluindo que $40 \%$ do Ca total está presente como $\mathrm{CaSO}_{4}^{0}$, portanto, potencialmente lixiviável e como $\mathrm{CaSO}_{4} \cdot 2 \mathrm{H}_{2} \mathrm{O}$, que reage com as diversas espécies de Al solüveis. Em anālise computadorizada das soluções drenadas as espécies de $\mathrm{Al}^{3+}, \mathrm{AlOH}^{2+}, \mathrm{Al}(\mathrm{OH})_{2}^{+}$e $\mathrm{Al}(\mathrm{OH})_{3}^{\mathrm{O}}$ representam $50,25,12$ e $11 \%$, respectivamente do $A 1_{T}$ (tota 1 ) drena do. A aplicação do gesso resultou em altas concentrações de $\mathrm{Ca}, \mathrm{Mg}, \mathrm{SO}_{4}$ e pequenas de Al nos lixiviados das colunas, redução do Al trocável no perfil e cerca de $44 \%$ do Al trocável foi convertida a uma forma não solûvei em KCI ou água. O tratamento $\operatorname{com} \mathrm{CaSO}_{4} \cdot 2 \mathrm{H}_{2} \mathrm{O}$ resultou na distribuição bastante uniforme do Ca no perfil, enquanto o $\mathrm{CaCO}_{3}$ ificou retido nos $10 \mathrm{~cm}$ superficiais.

Apesar de os efeitos benéficos do gesso na distribuição do Ca no perfil e neutralização do Al tro- 
cáveI, deve-se ter em conta que tambêm sao lixiviadas as outras bases, como $\mathrm{Mg}$ e $\mathrm{K}$. A anlicação de $\mathrm{CaSC}_{4} \cdot 2 \mathrm{H}_{2} \mathrm{O}$ reduziu: drasticamente o teor de marnésio na camada superficial em relação às testemunhas (QUAGGIO et alii, $1982)$; EMBRAPA, 1982). A.êm do Ca e do Mg, a gessagem também induz à lixiviação de $K$ atravês do perfill do solo, o que foi constatado por QUAGGIO et alii (1982) em ensaio com amendoim.

Em condições de coluna e de campo verificou-se que a aplicação isolada de gesso promoveu lixiviação mais intensa de potâssio do que a observada com a prática conjunta da calagem e da gessagem (EMBRAPA, 1982). Pa ra compensar a lixiviação de $\mathrm{Mg}$ e $\mathrm{K}$, recomenda-se que a gessagem seja acompanhada de calagem com calcảrio dolomíti co e adubações equilibradas de $K$.

\subsection{Avaliagão da isponibilidade de EnXofre hos Solos}

\subsubsection{DEFICIENCIAS E RESPOSTAS AO ENXOFRE}

Segundo COI.EMAN (1966) existe maior probạ bilidade de deficiência de enxorre em solos arenosos, a nivel mundial. Por isso, a textura pode ser usada como um critêrio auxiliar para estimar o enxofre disponivel nos so Ios. Além da textura, outros fatores são determinantes das 
respostas, como a acidez do solo, relação C/S, teores efetivamente baixos $S$ total e histórico de cultivo.

2.3.1.1. Acidez do solo, rélașão $\mathrm{C} / \mathrm{S}$ e cala gem

A corresão da acidez do solo implica na dessorção do $\mathrm{S} \mathrm{SO}_{4}=$ dos sítios de adsorção (HINGSTON et alii, 1972; SINGH, 1984 a, b) e mineralização do S-orgânico (WILLIAMS, 1967; METSON, 1979). Assim, o enxorre disponibilizado pela calagem implica na falta de resposta e até o efeito depressivo da gessagem. Colozza et alii constataram em solos PVA (Laras) e PVA (fase terraço) que apôs a calagem, o enxofre, apIicado como gesso, causou efeito depressivo no crescimento e na fixação de $\mathrm{N}_{2}$ atmosférico na soja perene. A aplicação isolada de gesso também causou efeito depressivo, o que mostra a deficiência de câlcio e não de enxofre. Este comportamento também foi observadopor outros pesquisadores. MONTEIRO et alii (1982).. cultivando soja perene em solo PVA (var. LARAS) e CASAGRANDE et alii (1982) cultivando leguminosas e gramineas tropicais em latossolo roxo $\left(L_{3}\right)$, não obtiveram resposta à gessagem com calagem prêvia. Por outro lado, a interaçã gessagem-cajagem vem sendo observada com maior frequência. Em cultura de milho Malavolta (s.d.), citado por VitTI \& MALAVOLTA (1985) obteve resposta conjunta ao calcário e ao gesso, 
usados na proporção de 7:3 em dois solos de São Paulo. Em solos de cerrado de Minas Gerais MALAVOLTA (1984) observou interação positiva entre calagem e gessagem na produção de cafeeiro (soma das duas primeiras safras). Em experimento com Leucaena leucocephala, Cv. Cunningham, em solo LE de cerrado, a interação da calagem e đa gessagem na produção de matêria seca foi igualmente posjtiva (EMBRAPA/CPAC', 1981). A relação C/S muito larga ocorre frequen... temente associada à acidez, em solos turfosos, de regiões frias, de altitude e de florestas. Com relaçäo C/S superior a 120 NASCIMENTO \& MORELLI (1980a, b) obtiveram respostas à aplicação de enxofre. Este fato explica-se pela imobilização do enxofre na matêria orgânica, que è liberada pela correção da acidez (ESMINGER, 1954; WILLIAMS, 1967). $\hat{E}$ importante salientar os dados obtidos por FREIRE et alii (1972) em solos de Minas Gerais. Nos solos J.E com 3,5\% de matéria orgânica e TE com 4,4\% não lograram resposta do milho à aplicação de enxofre, ao passo que em solos hidromóxficos com 5,7\% e 19\% de matêria orgânica, a resposta foi muito significativa com a dose de $20 \mathrm{~kg} \mathrm{~S} / \mathrm{ha}$. Em outro experimento de FREIRE et alii (1974) com solo turfoso com $23,8 \%$ de matéria orgânica, a resposta ao enxofre foi muito significativa. 
2.3.1.2. Histórico de cultivo e exaustão do enxofre dos solos

Nos solos arenosos e areias quartzosas, com teores de matêria orgânica e enxofre total efetivamente baixos a probabilidade de resposta ao enxöfre $\vec{e}$ muito alta. Na Nigéria, em solos arenosos de savana e florestas OSINAME \& KANG (1975) diagnosticaram defjuciências severas de enxofre. Em areais quartzosas de cerrado CASAGRANDE \& SOUZA (1982) e CASAGRANDE et alii (1982) obtiveram respos tas imediatas de leguminosas e gramíneas tropicais, ao passo que em latossolo roxo o enxofre nativo foi suficiente. Outros experimentos comprovam que a mineralização do enxofre orgânico pode fornecer parte do enxofre absorvido pelas plantas, particularmente quando o teor de matéria orgâa nica é mais elevado. Porèm, o cultivo continuado pode le-var à exaustão do enxofre nativo, como comprovam dados de MC CLUNG et alii (1959). Nos solos virgens o conteûdo de $\mathrm{S}$ orgânico varia de 72 a $494 \mathrm{~kg} / \mathrm{ha}$, ao passo que nos locais cultivados durante 20 a 30 anos baixa para 48 a 120 kg S/ha. O cultivo dos solos, por outro lado, aumenta as relações C/S e C/N/S, o que demonstra mineralização mais intensa do enxofre do que do carbono e do nitrogênio (BETTANY \& STEWART, 1983).

O fornecimento de enxofre atravês de superfosfato simples, sujfato de amônio e defensivos agríco- 
las pode ser suficiente ciurante muitos cultivosaMIYASAKA et alii (1966) encontraram resposta em apenas um dos sete 10 cais estudados, que anteriormente haviam recebido aplicações de fertilizantes, que aumentaram a reserva de enxofre desses solos.

A exaustão do enxofre nativo dos solos po de ser acelerada pela queima de restos culturais, como é o caso do algodoeiro, o que justifica a resposta encontra-. da por MC CLUNG et alii (1961) e MIKKELSEN et alii (1963). De um modo geral, os xendimentos mâximos foṛam obtidos com $20-40 \mathrm{~kg} / \mathrm{ha}$ aplicados em solos deficientes.

A indução da deficiência de $S$ nos solos tambêm ocorre pelo uso de fertilizantes isentos de enxofre MC CLUNG \& QUJNN (1959), encontraram pronta resposta da gra mas Batatais à anlicação de enxofre em campo cerrado de Matão (SP), previamente adubado durante 18 meses com 450 $\mathrm{kg}$ de $\mathrm{N}$, na forma de nitrocálcio. Por outro lado, a recupe ração das pastagens foi mais lenta com a aplicação de $S$ elementar, enquanto que com $\mathrm{CaSO}_{4}$ e $\mathrm{Na}_{2} \mathrm{SO}_{4}$ houve imediato desaparecimento da clorose.

Em solos de várzeas do Baixo Amazonas WANG et alii (1976a, b) observaram que no início da utilização dos solos o $N$ e o $P$ são mais importantes, porém, com 3 cultivos sucessivos de arroz inundado, usando formulações NPK sem enxofre, as produções foram reduzidas para 1 a $3 \mathrm{t} / \mathrm{ha}$. Com a aplicação de 24 a $27 \mathrm{~kg} \mathrm{~S} / \mathrm{ha}$, as produ- 
ções voltaram aos niveis originais de $5 \mathrm{a} 7 \mathrm{t} / \mathrm{ha}$. Com dois ou três cultivos com N-P-K isentos de enxofre, elevam-se as razões N/S, implicando na imobilização do enxofre.

Apesar de as quantidades de $S$ consumidas pela maioria das culturas ser prôximas das de $\mathrm{P}_{2} \mathrm{O}_{5}$, as deses do primeiro que se devem usar na aảubação são mais bai xas. Ocorre que o $S-S \bar{\phi}$ é fixado em pequenas quantidades aos colóides do solo, e permanece disponivel às plantas ao invés do $\mathrm{H}_{2} \mathrm{PO}_{4}^{-}$e do $\mathrm{HPO}_{4}^{=}$são fixados pelos óxidoshi dratados de $\mathrm{Fe}$ e AI. A adsorção de $\mathrm{S}-\mathrm{SO}_{4}^{=}$é maior em solos altamente intemperizados, mas a ađição de fosfato provoca. a dessorção, pelo deslocamento dos ions S-SQ $\bar{q}$ das superfícies carregadas (BARRON, 1969). A adsorção de sulfato ê dependente da concentração e do pH (KAMPRATH et alịi,1956). Iso significa que a aplicação fe fertilizantes fosfatados e corretivos (calcários), a umentan o pH do solo, podem diminuir a retenção de sulfato. Assim, o sulfato aplicado ao solo deve apresentar maior percentagen de recuperação. BEATON et alii (1968-69) mostraram que em três anos sucessivos a alfafa, em condições đe campo,absorveu $50 \%$ do S aplicado como gesso (15\%, $17 \%$ e $18 \%$ ). De forma similar SHEARD (1980), cultivando Bromus inermis (L.) e alfafa [Hedicago sativa (L.)] em condições de campo recuperou de $9,4 \%$ a $27,4 \%$ em três colheitas no primeiro ano, com a recuperação decrescendo com o aumento dos niveis de $\mathrm{S}$ e $\mathrm{N}$ aplicados. Na primeira colheita do segundo ano 2,5 a $15 \%$ 
do $S$ nas pastagens, anlicado no ano anterior, foi recunerado. o autor considera que hâ coincidência do movimento descendente do $S$ no perfil do solo, explicando-se, desse modo, o pequeno efeito residual do gesso. Isso é confirmado por MARTINI \& MUTTERS (1984) cultivando soja em condições de campo, onde as anâlises de solo acusaram significá tiva migração de $\mathrm{S}_{-} \mathrm{SO}_{4}=$ do horizonte A para o horizonte B. Em solos arenosos ou sem poder de retenção de $\mathrm{S}_{-} \mathrm{SO}_{4}=$, adubações fosfatadas pesadas podem induzir à exaustão do enxofre nativo, como sugerem trabalhos de JENSEN (1963) na Dinamarca e WATSON (1969) na Austräiia. Dados de CATANI et alii (1971) mostram que solos brasilei ros parecem ter baixa capacidade de adsorção de sulfatos. Essas informações complementam as de MC CLUNG \& QUINN, (1959), que induziram a deficiência de enxofre, com adubações fosfatadas sem enxofre em solos de cerrados, cultivan do a grama batatais [Paspalum notatum (L.)] e as de RITCHEY et alii (1981) e QUAGGIO et alii (1982) referentes ao movimento descendente do ânion $\mathrm{S}_{-} \mathrm{SO}_{4}^{=}$e cátions acompanhantes ( $\mathrm{Ca}, \mathrm{Mg}$ e $K$ ) no perfil do solo.

A razão apropriada de N/S na adubação sugerida por BEATON et alii (1974) é de 5/1. Para a colza JANZEN \& BETTANY (1984) sugexem a relação $7 / 1$. Para as leguminosas essa relação N/S não parece ser apropriada, porque as necessidades de $N$, em parte, são satisfeitas pela fixação biológica. Neste caso sugere-se a relação $\mathrm{P} / \mathrm{S}$. 
Para o estudo das razões adequadas de nutrientes na adubação HOMẼS (1955, 1963 e 1966) introduziu, o método das "variantes sistenáticas". PREVOT \& OLAGNIER, (1964) comparando experimentos fatoriais com as "variantes sistemáticas" afirmam que a grande objeção a esse método é a de indjcar .... apenas a razão entre eles. Para evi tar este inconveniente RICHARD (1959) introsuziu uma modificação no mêtodo, ao utiłizar diferentes somas constantes, às quais deu o nome de "cortes" (coupes). No estudo da re lação P/S tem-se verificado um equilíbrio dinâmico (HoMẽs, 1966 ; COOPER, 1968; BARRON, 1969). Para o caso do fósforo e do enxofre tem-.se sugerido a razão P/S de 7-10/1 (MALAVOLTA, 1981). Em solos de Minas Gerais ALVAREz et aiji, (1976) encontraxam relações $\mathrm{P} / \mathrm{S}$ mais amplas, cultivando aveia pelo método de Neubauer. As relações $\mathrm{P} / \mathrm{S}$ encontradas foram de 14,5/1 no Latossolo Roxo e 12,2/1 no Latossolo Vermelho Amarelo. Esta relação tão ampla parece exp̧licar- se pela pronta disponibilidade das formas mais lábeis de enxöfre e deslocamento do $\mathrm{S}_{-} \mathrm{SO}_{4}^{=}$pelo fosfato do complexo de adsorção e o curto período de cultivo. Segundo SIMONSYLVESTRE (1960) supõemse que não existe "alimentação de luxo" para o enxofre jsto é, as plantas absorvem-no apenas nas quantidades suficientes ao seu desenvolvimento. No entanto, nos solos estudados por ALVAREz et alii (1976) ob servou-se consumo de luxo do enxofre pela aveia, com altas doses de fósforo, na presença e ausência de calagem. Os au 
tores atribuem o fato ao curto período de cultivo.

2.3.2. AVALIAÇÃO DA DISPONIBILIDADE DE ENXOFRE NO SOLO

Os métodos de predição da disponibilidade de nutrientes, foram desenvolvidos com base na idéia de que um extrator quimico extrairia teores proporcionais aos absorvidos pelas plantas. Para o caso expecífico do enxofre os estudes tem sido dirigidos para a extração e determinas̃a analitica do $\mathrm{S}_{-} \mathrm{SO}_{4}^{\bar{*}}$, uma vez que o $\mathrm{S}$ total ou qua 1 quer outra forma orgânica ou mineral do elemento não tem dado boas estimativas de disnonibilidade para as plantas (ESMINGER \& FRENEY, 1966).

0 enxofre removido do solo por extratores químicos, segunḍo REISENAUER et alii (1973), reüne-se em três grupos: a) sulfato prontamente solûvel, que poḍe ser extraîdo com âgua ou soluções de $\mathrm{LiCl}_{2} \mathrm{e} \mathrm{CaCl}_{2}$, cujos ânions não são capazes de deslocar o $\mathrm{S}_{-} \mathrm{SO}_{4}$ adsorvido; b) sulfato solúvel e parte do adsorvido, que nodem ser extraídos com soluções bâsicas como $\mathrm{KH}_{2} \mathrm{PO}_{4}$ e $\mathrm{Ca}\left(\mathrm{H}_{2} \mathrm{PO}_{4}\right)_{2}$ e a solução neutra de $\mathrm{NH}_{4} \mathrm{OAC} \mathrm{N} ;{ }^{\circ}$ c) sulfato solúvel mais adsorvido mais fração doS-orgânico tem sido extraîdos com $\mathrm{NaHCO}_{3}$ e as soluções de fosfatos em ácido acético. 
2.3.2.1. Problemas relacionados com a repe tibilidade dos resultados analiti$\cos$

Os maiores problemas encontrados em estudos com enxofre são os associados com as têcnicas analíticas e preparação de amostras. Erros nessas fases levam a grande variações nos resudtados. Para minimizâ-las precauções devem ser tomadas na amostragem, preparação de amostras, extração e determinações analîticas. BLAIR aconselha que a amostra composta de una área deve ser fei ta com 20 sub-amostras, tomadas em zig-zag. A profundidade de amostragem para um nutriente móvel como o enxofre deve ser maior, pois ele se acumula no perfil. Este problema foi experimentado por COOPER (1968) em solos de Nova Zelân dia. Em solos tropicais em que os sulfatos tem sido lixiviados perfil adentro, esses ainda são acessiveis às plan tas. Quaisquer experimentos visando a avaliação de anälise de solo para enxofre devem incluir a distribuição vertical do $S$, no mínimo no começo do experimento. Dor causa da natureza dinâmica do S nos solos, a época do ano para a coleta de amostras deve ser feita tão longe quanto possîvel de adubações prévias e táo perto do plantio quanto for pratică vel.

A natureza läbil dos ésteres sulfatados dos solos implica no manuseio cuidadoso das amostras, an- 
tes da extração química. FRENEY et alii (1962) julgam que grande parte dos insucessos em obter correlações entre o S-sulfato extraível e resposta node ser atribuída ao método de secagem da amostra. WILIIAMS \& STEINBERGS (1964) acharam aumentos variảveis no $S$ extraível entre solos e extratos quando os solos foram secados ao ar a 17 a $19^{\circ} \mathrm{C}$. E $\underline{s}$ tes aumentos variaram de 0 a 12,1 ppm de $S$ extraivel em $\mathrm{KH}_{2} \mathrm{PO}_{4}$. PEVERILL et alii (1974), estudaram o problema e ve rificaram que a adição de carvão ativado à solução extrato ra de fosfato de câlcio reduz a variação resultante da secagem e do armazenamento a nîvel significante.

Por causa da grande diversidade de solos, os extratores não se comportam de maneira similar, isto é, não são suficientemente seletivos para extrair o $S$ efe-tivamente disponîvel para as plantas. As soluções contendo fosfato são as mais comumente usadas, por que o fosfato efetivamente desloca o S-sulfato do complexo de adsorção. Dentre os extratores fosfatados, o fosfato de cálcio teve a maior aceitação, porque o Ca divalente, não provoca a dispersão da argi ia e da matêria orgânica, como pode ocorrer quando se usa o potâssio ou o sódio. por outro lado, a vantagem competitiva do fosfato sobre o sulfato está implícita nos métodos comumente usados. Sais e âcidos diluídos de ânions fracamente (não especificamentee) adsorvidos, como o $\mathrm{Cl}^{-}$e o $\mathrm{NO}_{3}^{-}$, extraem essencialmente o $\mathrm{S}_{-} \mathrm{SO}_{4}^{-}$solüvel em àgua (WILLIAMS \& STEINBERGS, 1972; TABATABAI \& BREMNER, 
1973). O fosfato, ou outros ânions especificamente adsorvi dos (hidroxilas, fluoretos), são usados para deslocar o $\mathrm{S}-\mathrm{SO}_{4}=$ do complexo de adsorção. Todavia, a forte afinidade de alguns solos pelo fosfato rapidamente remove o fosfato da solução durante a extração, diminuindo assim a concentração e a eficiência (BARROW, 1967). Em tais casos recomenda-se o uso da relação solo: extrator mais larga (MET SON , 1979) .

Os extratores à base de $\mathrm{Ca}\left(\mathrm{H}_{2} \mathrm{PO}_{4}\right)_{2}$ foram estudados por FONTES (1979), em solos de Minas Gerais. O extrator $\mathrm{Ca}\left(\mathrm{H}_{2} \mathrm{PO}_{4}\right)_{2}-500 \mathrm{~mm} \mathrm{Pem}$ ácido acëtico 2, 0N mostrou o melhor desempenho, comparando-o com o extrator de MORGAN e o $\mathrm{Ca}\left(\mathrm{H}_{2} \mathrm{HO}_{4}\right)_{2}-\mathrm{H}_{2} \mathrm{O} \cdot \mathrm{O}$ autor obteve alta correlação entre a norcentaøem de recuneração de $\mathrm{S}-\mathrm{SO}_{4}^{=}$anós o nrimeiro cultivo extraido $\mathrm{Ca}\left(\mathrm{H}_{2} \mathrm{PO}_{4}\right)_{2}-500$ ppm $\mathrm{P}$ em ácido acético $2,0 \mathrm{~N}$ com a produção relaiva $(r=0,943$ a $0,993 * * *)$.

A solução de $\mathrm{NH}_{4} \mathrm{OAc} \mathrm{N}$ foi utilizado por MC CLUNG et alij (1959) em latossolos, fase cerrado de São Paulo e Goiás, por FREIRE et alii (1974) em solos de Minas Gerais e NASCIMENTO \& MORELLI (1980b) em solos do Rio Gran de do Sul.

0 extrator $\mathrm{CaCl}_{2} 0,15^{\circ}$ foi usado com rela tivo sucesso. WILLIAMS \& STEINBERGS (1959), usancio a relação solo: solução $1: 5$, obtiveram estreita correlação entre o S-sulfato extraído por $\mathrm{CaCl}_{2} 0,15$ e absorção de $\mathrm{S}$ por aveia em solos da Austrâlia. KOWALENKO \& IOWE (1975) cons i. deraram a solução de $\mathrm{CaCl}_{2} 0,15 \%$ o extrator que apresentou 
estreita correlação entre o $\mathrm{S}-\mathrm{SO}_{4}=$ extraído e a evolução de $\mathrm{CO}_{2}$ e "enxofre mineralizado. O cloreto de cálcio $(0,15 \%)$ foi usado por diversos pesquisadores, para extrair o $\mathrm{S}_{-} \mathrm{SO}_{4}=$, em diversas relações solo:solução (BARROW, 1961; TABATABAI \& BREMNER, 1972), o que dificulta a comparação de resultados. Segundo ESMINGER \& FRJENY (1966) e KOWALENKO \& LOWE (1975), o cloreto de cálcio extrai muito pouca matêria orgânica e não ë eficiente na recuperação de $\mathrm{S}-\mathrm{SO}_{4}=$ adsorvido.

ISLAM \& PONNAMPERUMA (1982), propuseram a solução diluîda de $\mathrm{HCl} 0,05 \mathrm{M}$ como extrator de $\mathrm{S}_{-} \mathrm{SO}_{4}=$ em con diçōes de solo inundado. Embora o extrator não se corrèiacione bem com os componentes de produção de arroz ( $\begin{aligned} & 0 \\ & 0\end{aligned}$ N/S na parte aẻrea, palha e grão) os autores consideram -no merecedor de mais estudos, devido a sua simplicidade e poder extrair simultaneamente boro, cobre e zinco.

Por outro lado, ISLAM \& PONNAMPERUMA (1982), consideram digno de nota de que as anālises de solo seco mostrem correlação satisfatória com a produção do arroz cultivado em solos inundados. Uma explicação para o fato é que a rizosfera do arroz ê oxidada, o que the confere ca räter, química e biologicamente, aeröbico.

O fato de que grande parte do enxofre do solo está presente em formas orgânicas e uma fração des se enxofre orgânico é facilmente solüvel em âgua, alguns pesquisadores aventaram a possibilidade de uma parte adi- 
cional da fração orgânica ser liberada por hidrólise suave. Em solos da Austrália WillinMS \& STEINBERGS (1959) estudaram o enxofre extraído por água fria, ägua quente e por aquecimento a seco de amostras secas ao ar e concluiram que o calor é o principal responsävel pela liberação adicional de enxofre. A correlação obtida entre o enxofre solubilizado pelo calor e o enxofre absorrido por aveia em vasos foi altamente significativa $(r=0,90)$.

A solução alcalina de bicarbonato de sôdio a pH 8,5 comumente usada como extrator de "fósforo dis ponive1", foi experimentada por BARSDLEY \& KJLMER (1963) para avaliar o enx ofre disponível. O extrator é problemâti co para a determinação turbidimêtrica do $\mathrm{S}_{\mathrm{S}} \mathrm{SO}_{4}$, por causa da dispersão da matêria orgânica pelo sốdio.

As relações entre o $S$ total ou $S$ orgânico e resposta de plantas tem sido consideradas pobres ou inexistentes em solos de regiões temperadas. Todavia, num estudo feito em solos tropicais da Nigéria por ENWEZOR (1976), o S liberado pela incubação (S-orgânico) é extreitamente relacionado com a resposta das plantas. Em 45 solos usados, o autor notou que aqueles mineralizando menos de 6 ppm de $S$ (extraído com acetato de sódio) responderam ao en xofre em experimento de vasos com milho cultivado durante 45 dias.

A extração de nitrogênio e enxofre minera lizado durante a incubação foi feita com diversos extrato- 
res, destacando-se o CaCl, $0,15 \%$ e $\mathrm{KCI} 0,01 \mathrm{M}$. O extrator $\mathrm{CaCl}_{2} 0,15 \%$ foi considerado o melhor dentre outros testados por WILLIAMS \& STEINBERGS (1959) e KOWALENKO \& LOWE. (1975). Em virtude de intensidade de liberação de $\mathrm{N}$ e $\mathrm{S}$ ser afetada pelo pH TABATABAI \& AL-KHAFAJI (1980) optaram por uma solução neutra de $\mathrm{KCl} 0,01 \mathrm{M}$, em vez de $\mathrm{CaC}_{2} 0,01 \mathrm{M}$ $(\mathrm{pH}=6,0)$, recomendada por STANFORD \& SMITH (1972). Outra razão para o uso da solução de KCl foi para evitar a adição de $\mathrm{Ca}^{++}$, que pode precipitar o sulfato liberado.

Os métodos de determinações analíticas do S-total e S-SO $=$ disponivel nos solos, constantes na literatura, valem-se da turbidimetria ou do método redutor com HI de JOHNSON \& NISHITA (1952). Esse método é muito pre ciso, mas seus inconvenientes são a lentidão e o custo dos reagentes químicos utilizados. Por isso, muitos pesqui sadores tem optado pelo método turbimétrico. Todavia, nas determinações turbidimétricas é essencial que se tenham extratos bem limpos (BARDSLY \& LANCASTER, 1965). O problema mais sério é a instabilidade da suspensão de sulfato de bârio, que pode ser contornado com o uso de estabilizadores como a goma aräbica, o ålcool polivinílico (BLAIR, 1979) e o TWEEN -80 utilizado por QUINN \& WOODS (1976) para anâlises de plantas. Em ex tenso trabalho de revisão de literatura BEATON et alii (1968) listaram cerca de 107 métodos de extração e detemninação analítica de $S$ e 66 combinações de incineração e métodos analíti- 
cos para material de plantas e solos, o que torna bastante dificil a interpretação agronômica.

2.3.2.2. Correlação, calibração e interpretação de métodos de análises de enxofre no solo

A maioria dos mêtodos publicados sobre en xofre disponível nos solos, de alguma forma, são correlacionados com a resposta das plantas. As correlacõos, gera 1 mente, são melhores a partir de dados de experimentos em vasos do que de dados de campo, porque é alta a densidade de enraizamento e ểnima a influência de outros fatores (outros nutrientes, clima, etc.) sobre o crescimento das plantas. Os estudos são geralmente de valor limitado, por serem, em geral estudos de esgotamento a curto prazo, em vez de medirem a capacidade de suprimento de enxofre duran te o ciclo completo da cultura (BLAIR, 1979).

Enbora os estudos de correlação em estufa sejam uma forma eficiente de discriminar solos responsivos dos não responsivos a determinado elemento deficiente, os experimentos de calibração a campo são indispensáveis. Os dois métodos gerais de câlibração são: 1) relação entre a porcentagem de produção máxima (produção sem o elemento/ produção com o elemento) x 100 e análise de solo e 2) sele 
ção de um valor acima do qual pouca ou nenhuma resposta $\vec{e}$ provâvel.

Devido aos diversos extratores pesquisados, a Jiteratura mostra "valores críticos" os mais variados possiveis (ESMTNGER \& FRENEY, 1966; REISENHAVER, 1975; BEATON et alii, (1974), o que torna bastante difícil a sua capacidade preditora, quando se analisam os dados de forma conjunta. Em solos do Estado de São paulo MC CLUNG et alii (1959) encontraram o valor crítico de $6-7 \mathrm{ppm}$ de $\mathrm{S}_{-} \mathrm{SO}_{4}^{*}$, para o extrator $\mathrm{NH}_{4} \mathrm{OAc} 0,5 \mathrm{~N}$, em solos de cerrado, usando o milheto como planta teste. Para solos da Nigéria, KANG \& OSINAME (1976) acharam o valor critico de $4 \mathrm{ppm}$ de $\mathrm{S}_{-} \mathrm{SO}_{4}^{=}$ para o extrator $\mathrm{NH}_{4} \mathrm{OAC} 0,5 \mathrm{~N}$, usando milho como planta-tes te. Em solos de arroz inundado, ISLAM \& PONNAPERUMA (1982) encontraram o nível crítico de $30 \mathrm{ppm} \mathrm{S}-\mathrm{SO}_{4}^{=}$pelo extrator $\mathrm{NH}_{4} \mathrm{OAC}$ para o arroz.

Para o extrator $\mathrm{Ca}\left(\mathrm{H}_{2} \mathrm{PO}_{4}\right)_{2}-500$ ppin $\mathrm{P}$ em HOAC 2 ,ON HOEFT et alii (1973), em solos de WISCONSIN (USA), obtiveram o nível crítico de $10 \mathrm{ppm} \mathrm{S}_{-} \mathrm{SO}_{4}^{=}$para a alfafa..Pa ra o arroz inundado nas Filininas ISLAM \& PONNAMPERUMA. (1982) obtiveram o nivel crîtico de 9 ppm de $\mathrm{S}_{-} \mathrm{SO}_{4}{ }^{\circ}$. Em solos de Minas Gerais (Brasil) FONTES (1979) obteve niveis críticos de 1,2 a $12 \mathrm{ppm} \mathrm{S}-\mathrm{SO}_{4}=$ com o extrator $\mathrm{Ca}\left(\mathrm{H}_{2} \mathrm{PO}_{4}\right) 2_{2}-500 \mathrm{ppm}$ P em HOAC 2 , (IN usando o sorgo come planta-teste, em solos de gênese variada. Na Austrälia, PROBERT \& JONES (1977), a través de média ponderada de perfil, loopraram distinguir entre 1o cais responsivos e não responsivos a enxofre sob pasta- 
gens de leguminosas tropicais.

O enxofre-sulfato prontamente solúvel é estimado por cloretos de cálcio, lítio e magnésio. Para pastagens (gramíneas e leguminosas) no Canadá BEATON \& Fox (1971) determinaram o nível critico de $6 \mathrm{ppm} \mathrm{S-50=} \mathrm{ex-}$ traîdo pelo $\mathrm{CaCl}_{2} 0,01 \mathrm{M}$. Na Nova Zelândia usando o extrator $\mathrm{CaCl}_{2} 0, \mathrm{~T}_{5 \%}$ COOPER (1968) determinou o nível crítico de $6 \mathrm{ppm}$. Em arroz inundado ISIAM \& PONNAMPERUMA determinaram o nivel de 9 ppm de $\mathrm{S}_{-} \mathrm{SO}_{4}^{=}$como para o extrator $\mathrm{CaCl}_{2} 0,15 \%$ em arroz inundado; enquanto que para o extrator LiCl $0,1 \mathrm{M}$ o nîvel crítico determinado foi de $25 \mathrm{ppm}$ de $\mathrm{S}-\mathrm{SO}_{4}=$

0 âcido clorícrico tambëm foi empregado como extrator de enxofre disponivel. Em pastagens na "Austrália, ANDREW (1975) aponta um nível crítico de 200 ppm de $\mathrm{S}_{-} \mathrm{SO}_{4}=$. ISLAM \& PONNAMPERUMA (1982), para o arroz inunda do, determinaram o nivel critico de $5 \mathrm{ppm}$ de $\mathrm{S} \cdot \mathrm{SO}_{4}=$

A variabilidade entre os resultados obtidos entre os diversos estudos de nível crítico de enxofre disponível, enfatiza a necessidade de se limitar a interpretação de resultados experimentais a äreas restritas de solos semelhantes e mesmos extratores e procedimentos anali ticos de $\mathrm{S}_{-} \mathrm{SO}_{4}^{=}$. Assim, a extrapolação de resultados de experimentos de calibração somente serâ vâlida em condições similares (BLAIR, 1979).

Outro fator complicador na interpretação 
conjunta de resultados de experimentos com enxöfré é profundidade de amostragem. Em solos de pastagens SAUNDERS \& COOPER (1975) não conseguiram demonstrar qualquer vantagem em amostragens de $0-15 \mathrm{~cm}$ de profundidade comparadas com as de $0-7 \mathrm{~cm}$. Todavia esses resultados não são necessâa riamente aplicáveis para situações onde as acumulações de sulfato no subsolo são utilizadas por plantas de enraizamento profundo. BARDSLEY \& KILMER (1963) acharam as melhores correlações entre os dados đe produção relativa e anâlise de solos com uso da profundidade de amostragem de 0-30 cm. Num caso extremo BLAKEMORE et aIii (1969) vericicaram que a alfafa de terras altas extrai $\mathrm{S}_{-} \mathrm{SO}_{4}=$ (solúvelem âgua) de profundidades superiores a $100 \mathrm{~cm}$, em solos com os horizontes superficiais extremamente deficientes em enxofre.

2.3.3. AVALIACẼ̃O DO POTENCIAL DE MINERALIZAÇ̃̃O DE NITROGENIO E ENXOFRE DOS SOLOS POR MODELOS MATEMÁTICOS

A maioria dos estudos referentes à minera lização de $\mathrm{N}$ e $\mathrm{S}$ tem envolvido períodos curtos de incubação, projetados para serem métodos rápidos de predição de $N$ e $S$ para as plantas. Por causa da estreịta relação en tre a conversão microbiana de $\mathrm{N}$ e $\mathrm{S}$, supunha-se que os 
Indices relativos de mineralização dos dois elementos seriam similares, isto é, $N$ e $S$ mineralizariam aproximadamen te na mesma razão (WHITE, 1959). Esta suposição, todavia, não consegue explicar resultados de diversos estudos, nos quais a razão N/S de mineralização foi major que a da matéria orgânica (WILLIAMS, 1967; TABATABAI \& BREMNER, 1972; HAQUE \& WALMSLEY, 1972). Outros estudos mostraram razões N/S de mineralização menores do que as da matêria orgânica (NELSON, 1964). Poucos estudos, no entanto, mostram razões N/S de mineralização iguais à da matéria orgânica (NELSON, 1964 ; KOWALENKO \& LOWE, 1975).

Poucos trabalhos de mineralização de $\mathrm{N}$ e $S$ foram conduzidos por períodos prolongados de incubação. Stanford e colaboradores (STANFORD \& SMITH, 1972; STANFORD et alii, 1977) desenvolveram um procedimento para estudar os potenciais de mineralização de $\mathrm{N}$ dos solos, por processo de incubação aberta e lixiviação em intervalos prê-determinados com soluções diluídas de $\mathrm{CaCl}_{2}$ e $\mathrm{KCl}$.

Diversos modelos matemáticos podem ser usados para descrever os dados obtidos quando a acumulação de $\mathrm{N}$-mineralizado $\left(\mathrm{NH}_{4}^{+}+\mathrm{NO}_{3}^{-}\right)$è analisada em função do tem po de incubação. As relações curvilineares, em geral tem mostrado o melhor grau de ajustamento (STANFORD \& SMITH, 1972; MOLINA et alii, 1980). Estas relações são comumente descritas pelas equações hiperbólica e exponencial de primeira ordem. A equação hiperbólica aplicada à mineralização de $N$ é: 


$$
N=N_{O}^{H} \cdot t /\left(b N_{O}^{H}+t\right)
$$

onde: $\mathrm{N}$ é o $\mathrm{N}$ mineralizado cumulativamente $\left(\mu \mathrm{g}, \mathrm{g}^{-1}\right.$ so-.. 10), $N_{0}$ é definido como o "pool" de $N$ potencialmente mineralizâvel, $t$ é o tempo e b è uma constante [sema nas ( $\mu \mathrm{g} N \cdot \mathrm{g}^{-1}$ solo $\left.)^{-1}\right]$. Muitos pesquisadores usaram uma transformação linear da equação acima (STAN FORD \& SMITH, 1972; CAMPBELL et alii, 1981).

A equação exponencial de primeira ordem que descreve a mineralização líquida de N é:

$$
N=N_{O}^{F}[1-\exp (-K t)]
$$

onde: $N$ é o $N$ mineralizado líquido acumulado até o tempo $t$, $K$ - é a constante de indice invariante ( semanas $^{-1}$ ) e $\mathrm{N}_{\mathrm{O}}^{\mathrm{F}}$ é definido como "pool" de $\mathrm{N}$ potencialmente mine ralizâvel no tempo $t=0$. Os valores de $N_{O}^{k}$ e $K$ esti mados pelo método dos mínimos quadrados não lineares (MARY \& REMY, 1972; SMITH et alii, 1980) são mais precisos e menos ambíguos do que os obtidos usando as duplas recíprocas da equação hiperbólica, nara obter um valor inicial de No (STANFORD \& SMITH, 1972).

A constante b da equação hiperbólica pode ser escrita sob a forma:

$$
\mathrm{b}=\mathrm{Tc} / \mathrm{N}_{\mathrm{O}}^{\mathrm{H}} \text {, }
$$

onde: Tc é o tempo necessārio (semanas) para mineralizar $1 / 2 \mathrm{~N}_{\mathrm{O}}^{\mathrm{H}}$, obtenđo-se: 


$$
N=N_{O}^{H} \cdot t /(T C+t) .
$$

Devido à pequena capacidade de predição do rendimento das culturas e adsorção de $\mathrm{N}$ das equações de primeira ordem e hiperbólica (SMITH et alii, 1980; STANFORD ot alii, 1977), MOLINA et alii (1980) sugeriram que a mine ralização de $\mathrm{N}$ pode ser vista como a decomposição de dois ou mais compostos com indices variâveis de decaimento. Daî propuseram que a mineralização deveria ser modelada como sendo a soma de dois ou mais exponenciais para alguns solos, conforme a equação proposta por MOLINA et alii (1980), $N_{+}=N_{0} S\left(1-e^{h t}\right)+N_{0}(1-S)\left(1-e^{-k t}\right)+\xi$,

onde: $N_{+}$é a concentração de substrato no tempo $t, N_{0}$, o substrato mineralizável ou notencialmente, no tempo $0, S$ e $(1-S)$ representam as frações de $N$ orgânico, de râpida e lenta decomposição respectivamente, $K$ e $h$ as respectivas constantes e $\xi 0^{\prime}$ termo de erro com média zero e uma variância fixa $\sigma^{2}$.

O modelo de MOLINA et alii (1980) ajustou-se bem aos de LINDEMAN \& \&\& CARDENAS (1984), aplicando esgoto digerido anaerobicamente irradiado com raios gama. Os métodos que usam uma exponen cial são inadequados para estimar $N_{n}$, quando uma fonte orgânica, como o esgoto, é adicionada. Os indices de mineralização de solos tratados com esgoto mudam dramaticamente nas primeiras semanas de incubação e após permanecem ainda mais altos do que nos solos não tratados. O método de MOLI 
NA et a1ii (1980) assume que as duas formas de $N$, que se decompõe a Indices diferentes deram o melhor ajustamento aos dados experimentais (JUMA et alii, 1984).

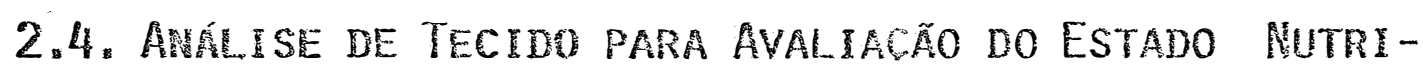 cIOnAl de Enxofre eM Plantas}

As anālises de tecido para avaliação do estado nutricional tem validade somente quando especificados os métodos de incineração e digestão ümida e mêtodos de determinação a nalitica. Este fato torna-se imediatamente evidente, quando se consulta a literatura referente a análises de enxofre, com implicações muito sérias para se estabelecer o nivel critico do teor de enxofre na planta. KANG \& OSINAivE (1976), com o uso o método de fusão de carbonato de sôdio e HCl encontraram o nível crítico de $0,14 \%$ de $S$ total na folha bandeira de arroz, relacionando-o com a produção de arroz. Para o milho doce DAIGGER \& FOX (1971) sugeriram o nivel crítico de $0,24 \%$, com o uso da digestão nîtrico. perclórica. SANSUM \& ROBINSON (1974) concluíram que a recu peração do S na planta depende do método de digestão na incineração a seco o teor de $S$ total foi de $0,15^{\circ}$; para a digestão $\mathrm{HNO}_{3} / \mathrm{HClO}_{4}$ de $0,207^{\circ}$; para a digestão $\mathrm{HNO}_{3} / \mathrm{HClO}_{4}$ e mais uma hora de digestão anós o clareamento de $0.335 \%$. 
Assim, os nîveis criticos de $S$ total devem ser estabelecidos em função das exigências culturạis e das técnicas de laboratório, isto ể, digestão e determinações analíticas. Dos métodos disponíveis para oxidar o enxofre orgânico a sulfato, a incineração ûmida, usando a mistura nitrico-perclórica majs dicromato e metavanadato e ma hora de digestão após a mựança de coloração parece o mais accitâvel (SANSUM \& ROBINSON, 1974). Um segundo método digno de investigação é o mêtodo da mistura de nitrato de magnésio com ảcido percuórico, proposto por QUINN \& WOODS (1976). Ambos os métodos requerem um mínimo de equipamentos e, com pessoal treinado, são rápidos e reproduzíveis (BLAIR, 1979).

A incineração a seco parece determinar apenas o $-\mathrm{SO}_{4}=$, pois as formas reduzidas de $\mathrm{S}$ são volatilizadas durante o processo. O $\mathrm{S}_{-} \mathrm{SO}_{4}^{=}$por incineração a seco representa, possivelmente, quantidades similares às de Sreduzível em HI, que se julga estar principalmente na forma de éster-sulfato (MAYNARD et alii, 1983).

Para as gramíneas, de um modo geral, o nível crítico de $S$-total estâ a redor de $0,15 \%$. Para o sorgo FONTES (1979) e para o capim colonião MALAVOLTA et a1ii (1984a) observaram, respectivamente, os niveis críticos de 0,16 e $0,15 \%$, usando a digestão nítrico-perclörica. Para culturas exigentes como a colza está ao redor de 0,6 a 0,7\% (MALAVOLTA et a iii, 1984 b; JANZEN \& BETTANY, 1984). 
LOT'T et a]ii (1960) concluiram que o $\mathrm{S}_{-} \mathrm{SO}_{4}=$ é mais sensivel que o S-total como indice de deficiência de S para o cafeeiro. EREITAS et alii (1972) concluiram que cerca de $200 \mathrm{ppm}$ de $\mathrm{S}_{-} \mathrm{SO}_{4}$ em folhas de cafeeiro indicam um nịvel nutricional de $S$ adequado. Todavia, ANDERSON \& SPENCER (1950) jâ a. Iertaram para o fato de que este critērio por si sô não ê satisfatório, pois o $\mathrm{S}_{-} \mathrm{SO}_{4}^{=}$ pode acumular-se nas plantas sob condições de deficiência de Mo, mesmo quando o enxofre estâ deficiente no solo. Por outro 1ado, BLAIR (1979) considera o teor de $\mathrm{S}_{-} \mathrm{SO}_{4}^{=}$em fothas de cafeeiro colhidas em vầrias estações do ano por FREITAS et alii (1972) um critêrio pouco sensivel como dia gnose foliar, por causa da dispersão dos dados. Estas variações também foram vistas por diversos trabalhos feitos na Austrâlia, citados por CLARKE \& LEWIS (1974). Estas diferenças se tornam mais evidentes nor força de variações estacionais tanto em leguminosas quanto em gramíneas forra geiras.

Diversos indicadores do estado nutricional de $S$ nas plantas tem sido investigados, além de percentagem de S-total, como a percentagem de S-reduzível em HI, as razões N/S e S-reduzîvel em HI/S-total. Como hạ grandes variações estacionais nos teores de S-total e S-reduzí vel em HI nas culturas perenes, pastagens e anuais, diversos autores tem empregado a razão S-reduzível em HI/S - total como indicativos do estado nutricional de enxofre (RAS SMUSSEN et alii, 1977; MAYNARD et alii, 1983b). 
As variacões nas concentrações de enxofre total entre plantas de trigo deficientes e não deficientes foi muitaz vezes"menor do que as varias.ões de ano nara ano, das concentrações de enxofre total em plantas amostra das no mesmo desenvolvimento. Assim, a razão S-reduzívelem HI/S total foi considerado o indice do estado nutricional de enxofre em plantas mais consistente e satisfatório para experimentos (RASSMUSSEN et alii, 1977; SPENCER \& FRENEY, 1980 ; MAYNARD et alii, 1983b). Por outro lado, a razão S-reduzível em HI/S total foi o único indice não afetado significativamente pelos teores de outros nutrientes nas plantas, particularmente o N (GOH \& KEE, 1978; FRENEY et alii, 1978; MAYNARD et alii, 1983b). Entretanto, o nível da razão S-reduzível em HI/S total varia entre espécies. FRENEY et alii (1978), encontraram indices variando de 0,26 a 0,30 para o trigo, enquanto que na colza [Brassica campestris (L.)], MAYNARD et alii (1983b) encontraram indices de 0,48 a 0,56 .

As variações entre a concentração de $S-$ to tal entre trigo deficiente e não deficiente foi muitas vezes menor do que a variação de ano para ano de concentra ção de $S$ total de plantas amostradas no mesmo estágio de crescimento. Assim, a razão S-reduzível em HI/S total foi considerado o indice de planta mais consistente e satisfatório em estudos de campo. Por outro lado, a razão.S-reduzível em HI/S total foi o ünico indice não afetado 
significativamente pelos niveis de outros nutrientes, particularmente o N (GOH \& KEE, 1978; FRENEY et alii, 1978). 0 nível crítico da razão S-reduzível em $H /$ S total varia entre espëcies diferentes. FRENEY et alii (1978) encontraram indices variando de 0,26 a 0,30 para o trigo, enquanto que para a colza [Brassica campestris (L.)] MAYNARD $\because$ et alii (1983b) encontraxam indices de 0,48 a 0,56 .

Muitos pesquisadores tem sugerido que a razão N/S possa ser usada como meio de diagnóstico. DIJ-. KSHOORN \& VAN WIJK (1976) fizeram uma revisão compreensiva, com citações referentes à razão $\mathrm{N} / \mathrm{S}$ no conteûdo de proteîna de folhas de plantas em crescimento. Adubações nitrogenadas na ausência de enxofre induzem ao efeito de dilujsão de $S$ no tecido vegetal. A razão $N / S$ encontrada variou de cerca de 14:1 para leguminosas atê $17: T$ para gramíneas. No entanto, para uma cultura exigente como a colza Brassica napus L.) JANZEN \& BETTANY (1984) encontraram a relação $\mathrm{N} / \mathrm{S}=7$ como a mais adequada. MALAVOLTA et alii (1984 b) encontraram relações semelhantes, caracterizando a deficiência de $S$ na colza, com a relação N/S > na lâmina foliar; o teor foi considerado adequado com relação N/S > 6. MALAVOLTA et alii (1984a) estabelecerama deficiência de $S$ para o capim colonião (Panicum maximum Jacq.) com relação $N / S>20$.

O exesso de nitrogênio em relação ao enxọ fre disponível afeta severamente a produção de sementes de colza, como atestam os trabalhos de MAYNARD et alii (1984b) 
e JANZEN \& BETTANY (1984). Este efeito é atribuído ao acumulo de níveis töxicos de metabólitos de N. Por outro lado aplicações excessivas de $\mathrm{S}$ em relação à disponibilida de de $S$, produziram acumulo de $S$ nos tecidos da planta. As folhas e, até certo ponto, os pecíolos, foram os locais de acúmu... 10 excessivo do nutriente. No entanto, nas sementes da col $z$ a as concentrações de $S$ mantiveram-se relativamente constantes (JANZEN \& BETTANY, 1984).

A relação P/S no tecido foliar também foi sugerida como indicador do estado nutricional do enxofre na planta. Segundo MALAVOLTA et alii (1984a) a relação $P / S>2$ caracteriza a deficiência de enxotre no capim colonião. Em outro experimento, MALAVOLTA et alij (1984 b), considerando apenas a lâmina foliar da colza, julgaram como adequada a relação $P / S=1$ nos tratamentos com enxofre. 


\section{MITERIAIS E MÉTOROS}

\subsection{Solos - Caracterizacho física e química de Rotina}

As caracteristicas físicas e químicas dos solos estão reunidas na tabela 3:1. A classificação dos solos, apesar de as amostras de terra não terem sido coleta das em perfis modais, foi feita pelo Sistema Brasileiro de Classificação de Solos (EMBRAPA, 1981). As anālises físicas (granulometria, densidade global e capacidade de embebição) foram feitas por metodologia de rotina (EMBRAPA, 1979).

As anâlises axínicas de rotina de terra $\left(\mathrm{pH}, \mathrm{P} \mathrm{K}^{+}, \mathrm{Ca}^{++}, \mathrm{Mg}^{++}, \mathrm{Al}^{++r} \mathrm{e} \mathrm{H}^{+}\right)$foram determinadas pela metodologia empregada na ESALQ/USP (CATANI E JACINTHO, 1974).

$Q$ carbono no solo foi determinado, pela têcnica de WALKLEY-BLACK (ALLISON, 1965) e o nitrogênio total do solo segundo BREMNER (1965). 


\subsection{DETERMMACẼO DO TEOR DE S TOTAL NAS AMOSTRAS DE TERRA}

Para a determinaça do teor de $S$ total nas amostras de terra obedeceram-se aos seguintes procedimen tos:

3.2.1. DIGESTÃO DAS AMOSTRAS DA TERRA

As amostras de terras foram digeridas $u-$ tilizando-se, basicamente, a metdologia de CHAPMAN \& PRATT (1960). Nas amostras de terra, com alta percentagem de argila, como o LEd de Catalão (GO) e LVd do Rio Páranaíba (MG) dobraram-se as quantidades de ácido perciórico e nitrico para se obter a completa digestão do material. 


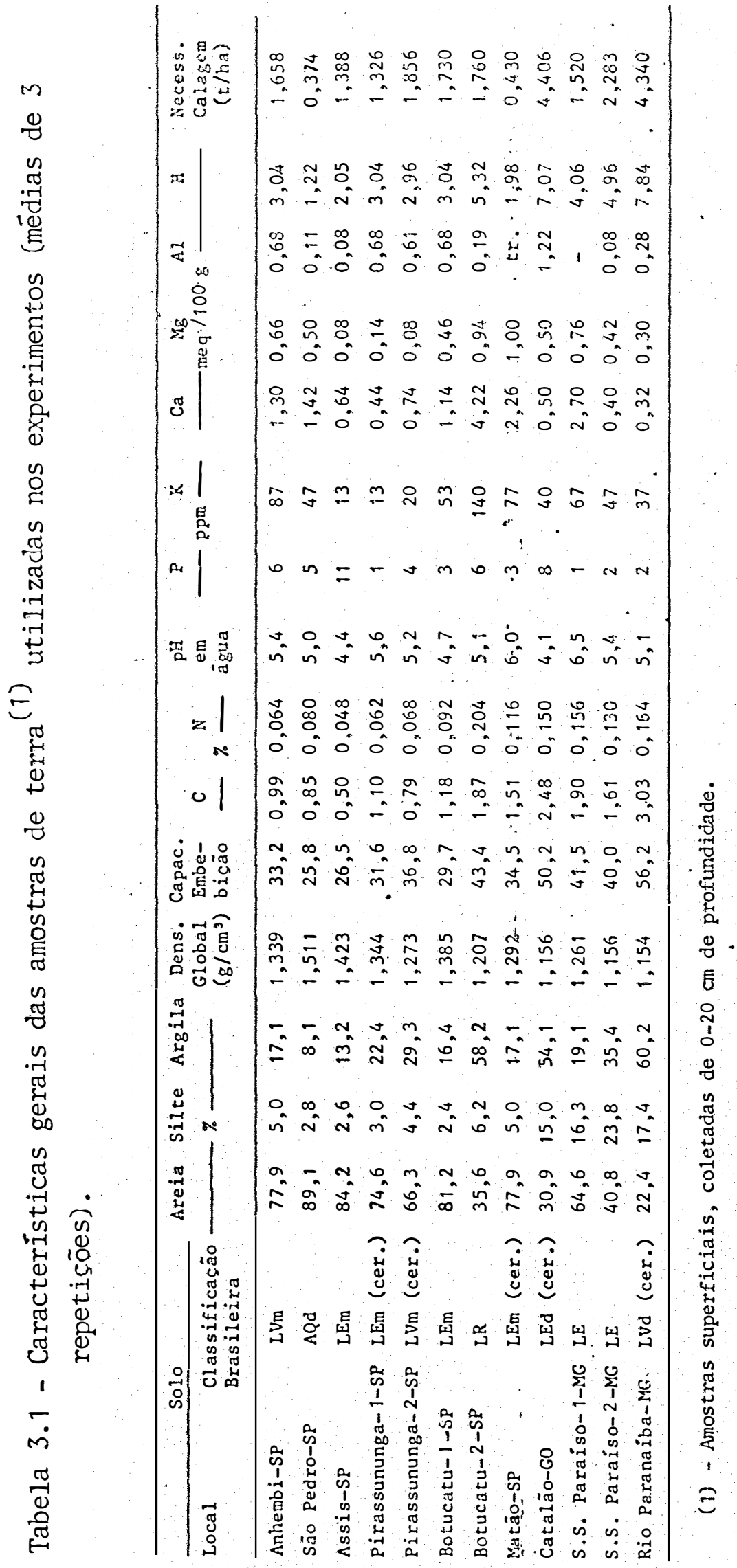


.59 .

3.2.2. DETERMINACÃO ANALITICA DO S TOTAL NOS SOLOS

A determinação analítica do $S$ total foi feita pelo procedimento de MALAVOLTA (1950), com ligeiras modificações. Apōs a digestão completa do material, filtra ram-se os digeridos em papel quantitativo, com água desionizada, até recolher $100 \mathrm{ml}$. A seguir, tomaram-se alïquotas de $50 \mathrm{ml}$, que foram aquecidas até a ebulição, precipitando-se então os sulfatos com $10 \mathrm{ml}$ de $\mathrm{BaCl}_{2}$ a $10 \%$. Ferveram-se as alíquotas por 5 minutos, deixando-as, após, em repouso por uma noite. No dia seguinte filtraram-se as alíquotas em papel quantitativo (Tipo S \& S, faixa azul), com cerca de $250 \mathrm{ml}$ de água desionizada, atê o filtradonão acusar mais presença de cloretos. 0 papel de filtro com o precipitado foi secado lentamente em estufa e, a seguir, incine rado, elevando-se gradativamente a temperatura, a $550^{\circ} \mathrm{C}$ por 3 horas. Apôs esfriar, pesaram-se os precipitados. Fizeram-se braricos.

\subsection{Determinacão do S-SO $\overline{\overline{4}}$ Disponível nos Solos}

O enxofre disponível para as vlantas, foi estimado via extratores ọuímicos: a) acetado de amônio $0,5 \mathrm{Nem}$ ácido acético $0.25 \mathrm{~N}$ (BARDSLEY \& IANCASTER, 1965); b) fosfato de câ1cio, 500 ppm de $\mathrm{P}$ em ácido acético $2,0 \mathrm{~N}$ (HOEFT et alii, 1973); c) cloreto de cálcio a 0,15\% (WILLIAMS \& STEINBERGS, 
1959); d) äcido cloridrico 0,05 M (ISLAM \& PONNAPERUMA, 1982) .

3.3.1. ACETATO DE AMÔNIO 0,5 N EM ÁCIDO ACÉTICO $0,25 \mathrm{~N}$

$\mathrm{Na}$ técnica de BARDSLEY \& LANCASTER (1965) foram feitas as seguintes modificações:

3.3.1.1. Sólução extratora-foi usada a modificação de VITTI \& SUZUKI (1978)

3.3.1.2. Filtração do extrato - em vez do papel quantitativo utilizou-se o papel qualitativo de filtração rápida (tipo FRAMA). No entanto, constatou-se a ne cessidade de eliminação do enxofre-sulfato, de acordo com a seguinte têcnica: lava-se o papel por 2 vezes com HC1 $0,1 \mathrm{~N}$ e a seguir com o pröprio extrator. Deixa-se o pa pel no funil e utiliza-se no dia seguinte. Apôs a agitação da amostra, a terra, com o extrato são passados para o funil e o extrato, é refiltrado por 2 a 3 vezes, no mesmo funil, até se mostrar completamente Iímpido. 
.61

3.3.1.3. Determinação analítica do $\mathrm{S}_{-} \mathrm{SO}_{4}=$ extraído-segundo a modificação de VITTI \& SUZUKI (1978).

3.3.2. FOSFATO DE CÁLCIO - Ca $\left(\mathrm{H}_{2} \mathrm{PO}_{4}\right)_{2} \cdot \mathrm{H}_{2} \mathrm{O}-500 \mathrm{ppm}$ P em äcìdo acético 2,0N

3.3.2.1. Solução extratora e extração - seguiu-se a metodologia de HOEFT et alii (1973)

3.3.2.2. Filtração do extrato - idem secção 3.3 .1 .2 .

3.3.2.3. Determinação analîtica de $\mathrm{S}-\mathrm{SO}_{4}^{=}-$idem secção $3.3 \cdot 1 \cdot 3$.

3.3.3. CLORETO DE CÁlCIO A 0,15\%

3.3.3.1. Solução extratora e extração - seguiu-se a metodologia de WILLIAMS \& STEINBERGS (1959).

3.3.3.2. Filtração do extrato - idem secção $3.3 \cdot 1 \cdot 2$. 
3.3.3.3. Determinação analïtica de $\mathrm{S}-\mathrm{SO}_{4}=\ldots$ idem secção $3.3 \cdot 1.3$.

$3.3 .4 .11 \mathrm{Cl} 0,05 \mathrm{M}$

3.3.4.1. Solução extratora e extração - seguiu-se a metodologia de ISLAM \& PONNAMPERUMA (1982);

3.3.4.2. Filtração do extrato - idem secção $3.3 .1 .2 . ;$

3.3.4.3. Determinação analítica - idem secç̃̃o $3.3 \cdot 1 \cdot 3$.

\subsection{EXPerimento de CASA de Vegetação}

As amostras de terra foram passadas em pe neira de $6 \mathrm{~mm}$ e secadas na casa-de-vegetação, para uso pos terior. 
3.4.1. QUANTIDADE DE TERRA USADA POR VASO

$$
\text { Os solos usados constam na Tabela }
$$

3,1. Das amostras de terra provenientes de Anhembi (Piracicaba), São Pedro, Pirassununga, Botucatu e Matão (SP), Cạ talão (GO) e São Sebastião do Paraíso (MG), utilizaram-se $5,2 \mathrm{~kg}$ de terra seca por vaso. Das amostras provenientes de Assis (SP) e Rio Paranaíba (MG) utilizaram-se, respectiva mente, 3,5 e $2,6 \mathrm{~kg}$ de terra seca por vaso.

\subsubsection{CALAGEM E ADUBACÃO SULFATADA}

A calagem foi quantificada pela metodologia de QUAGGIO (1983), considerando-se 70\% da saturação de bases, a densidade global dos solos (Tabela 3.1.), uma camada de $20 \mathrm{~cm}$ de solo a ser corrigida e a acidez fisioló gica da uréia, essa usada, como fonte de N. Ácrescentaram-se mais $0,3445 \mathrm{~g}$ por quilo de terra a lém das quantidades constantes na Tabela 3.1. Essa quantidade adicional de corretivo foi calculada em função do equivalente de $\mathrm{CaCO}_{3}$ da uréia $/ 100 \mathrm{~g})$, do PRNT do corretivo MINERCAL (130\%) e da aplicação de 240 ppm de $N$ no primeiro cultivo.

A adubação sulfatada foi feita com gesso purificado da ULTRAFERTIL, nas doses de 0,20 e 40 ppm de $S$. 
.64

3.4.3. INCUBAC.̃AO

As doses de enxofre (coino gesso agrícola), na presença e ausência de calagem, foram adicionadas às terras, incubando-as com umidade equivalente a $80 \%$ de sua capacidade de embebição, em sacos plâsticos semi-abertos para permitir a aeração das amostas. A seguir, as terras foram colocadas na casa de vegetação pelo período de 20 dias. Semanalmente, revolveram-se as amostras de terra nos sacos plásticos, para previnir ambiente anaeróbico. Fin do o período de incubação, coletaram-se $200 \mathrm{~g}$ de terra (ba se seca ao ar), que secadas e peneiradas (em $2 \mathrm{~mm}$ ), foram acondicionadas em sacos plâsticos para posteriores anâlises.

\subsubsection{ADUBACẼO E CULTIVO DAS TERRAS}

Efetuaram-se dois cultivos das amostras de terra, sendo o primeiro de 42 dias e o segundo de 48 dias. Usou-se o milho como planta-teste. 
.65.

\subsubsection{Adubação no primeiro cultivo}

Antes do primeiro cultivo, apjicaräm-se, em forma de solução os seguintes nutrientes: potâssio: 150 ppm de $\mathrm{K}$ na forma de $\mathrm{Kl}_{2} \mathrm{PO}_{4}$; fósforo: $200 \mathrm{ppm}$ de $\mathrm{P}-118 \mathrm{ppm}$ como de $\mathrm{KH}_{2} \mathrm{PO}_{4}$ e $82 \mathrm{ppm}$ como $\mathrm{NH}_{4} \mathrm{H}_{2} \mathrm{PO}_{4}$; nitrogênio: 60 ppm de $\mathrm{N}-37 \mathrm{ppm}$ comio de $\mathrm{NH}_{4} \mathrm{H}_{2} \mathrm{PO}_{4}$ e $23 \mathrm{ppm}$ como de $\mathrm{Mg}\left(\mathrm{NO}_{3}\right)_{2} \cdot 6 \mathrm{H}_{2} \mathrm{O}$; magnésio: $40 \mathrm{ppm}$ de $\mathrm{Mg}$ como $\mathrm{Mg}\left(\mathrm{NO}_{3}\right)_{2} \cdot 6 \mathrm{H}_{2} \mathrm{O}$; câl cio: nos tratamentos sem-calagen aplicam-se 200 ppm de Ca como $\mathrm{CaCl}_{2} \cdot 2 \mathrm{H}_{2} \mathrm{O}$; molibdênio: $0,1 \mathrm{ppm}$ como $\left(\mathrm{NH}_{4}\right)_{6} \cdot \mathrm{MO}_{7} \mathrm{O}_{24}$. $4 \mathrm{H}_{2} \mathrm{O}$; boro: $0,5 \mathrm{ppm} \mathrm{B}$ como $\mathrm{H}_{3} \mathrm{BO}_{3}$; cobre: $1,5 \mathrm{ppm}$ como $\mathrm{CuCl}_{2} \cdot 2 \mathrm{H}_{2} \mathrm{O} ;$ zinco: $5 \mathrm{ppm}:$ como $\mathrm{ZnCl}_{2} \cdot$

Aos 21 dias após a semeadura aplicaram-se 90 ppm de $\mathrm{N}$ como urëia comercial; aos 35 dias aplicaram-se mais $90 \mathrm{ppm}$ de $\mathrm{N}$ e $70 \mathrm{ppm}$ de $\mathrm{K}$ como $\mathrm{KCl}$.

\subsubsection{Adubação no segundo cultivo}

Na adubação de base do segundo cultivo, $\underline{a}$ plicaram-se $2 / 3$ das quantidades de todos os nutrientes aplicados antes do primeiro cultivo, inluindo o cálcio, nos tratamentos sem calagem.

Aos 21,35 e 42 dias apôs a semeadura aplicaram-se, em cada cobertura, 60 ppm de $\mathrm{N}$ como urêia comercial e $70 \mathrm{ppm}$ de $\mathrm{K}$ como KCl. 


\subsubsection{Plantio e COl.heita dA PLANTA-TESTE}

Como planta-teste usou-se o milho (cv. piranão VD 2), con 3 plantas por vaso nos solos de Rio paranaíba (LVd) e Assis (LEm) e 5 plantas por vaso nos demais solos. Colheu-se a parte aérea do milho aos 42 dias após a semeadura no primeiro cultivo e aos 48 dias, no segundo cultivo. 0 material foi secado na estufa de circulação forçada a $75^{\circ} \mathrm{C}$, a té acusar peso constante. A moagem do tecido vegetal foi feita usando-se peneira de 20 mesh. o peso da matéria seca dos solos de Rio Paranajba e Assis foi corrigido para $5 \mathrm{~kg}$ de terra seca ao ar por vaso.

\subsubsection{ANÁLISES DE PLANTAS}

As digestões sulfürica $(N-\operatorname{tota} 1)$ e nítrico-perclórica e as determinações analíticas de $N$ e P foram feitas pelos procedimentos descritos por SARRUCE \& HAAG (1974). A de terminação analítica do S-total no extrato nítrico-perclôrico foi feita segundo VITTI \& RODELLA (1982). 
3.4.7. COLETA DE AMOSTRAS DE TERRA AP'S OS CULTIVOS

Apôs o primeiro cultivo, a terra foi des. torroada, peneirada em $6 \mathrm{~mm}$, e removidas as raizes. Tomaram-se $200 \mathrm{~g}$ para análises posteriores.

Para o segundo cultivo utilizaram-se 2,1 kg de terra seca ao ar nor vaso no Solo Rio Paranaíba (LVd); $3,0 \mathrm{~kg}$ no Solo de Assis (LEm) e 4,5 kg nos dema is solos. Terminado o segundo cultivo, repitiu-se o procedimento usado após o primeiro cultivo.

3.5. EXPERIMENTO DE LABORATÓRIO: Mineralização aeróbia de enxofre (S- $\left.\mathrm{SO}_{4}^{-}\right)$e nitrogênio $\left(\mathrm{N}_{-} \mathrm{NH}_{4}^{+}+\mathrm{NO}_{3}^{-}\right)$, por técnica de incubação aberta.

\subsubsection{SOLOS E TECNICAS ANALITICAS USADAS}

Para o experimento de incubação aberta en laboratório utilizaram amostras de terra dos solos de São Pedro (AQd), Assis (LEm), Pirassununga-1 (LEm), Matão (LEm, cer rado), Catalão (LEd,cerrado), São Sebastião do Paraíso-2 (LRd) e Rio Paranaíba, (LVd), conforme tabela 3.1. Para a incu bação aberta utilizaram-se amostras de terra previamente 
incubadas pela técnica descrita na seç̧ão 2.4.3.

Os procedimentos de incubação aberta e Iixiviação das amostras de terra foram descritas por STANFORD \& SMITH (1972) \& TABATABAI \& AL-KHAFAJI (1980). A determinação analítica do $\mathrm{S}_{-} \mathrm{SO}_{4}=$ mineralizado e lixiviado foi feita pelos procedimentos de BARDSLEY \& IANCASTER (1965), com modificação de VITTI \& SUzUKI (1978). o nitrogênio mineralizado $\left(\mathrm{N}^{-\mathrm{NH}_{4}^{+}}+\mathrm{NO}_{3}^{-}\right)$foi determinado segundo BREMNER (1965).

\subsubsection{COLUNAS DE INCUBACÃO E LIXIVIACÃO}

Como colunas de lixiviação utilizaram - se bisnagas para "CATCHUP", em posição vertical invertida, for rando-se ä base do "bico" com lã de vidro (fibra média), uma tela plástica e novamente com uma camada de lã de vidro. Em seguida parafusou-se o "bico" ao frasco, cortando-se o fundo deste para introduzir as amostras de terra.

\subsubsection{ADUBAÇ̃̃ DAS AMOSTRAS DE TERRA E LIXIVIACÃO DO ENXOFRE E NITROGENIO MINERAL}

Antes da introdução das amostras de terra nas colunas de lixiviação, adicionaram-se $150 \mathrm{ppm}$ de P, 200 
ppm de K, 40 ppm de $\mathrm{Mg}, 200 \mathrm{ppm}$ de Ca (nos tratamentos sem calagem), 0,1 ppm de Mo, 0,5 ppm de B, 1,5 ppm de $\mathrm{Cu}$ e 5 ppm de $\mathrm{Zn}$, empregando-se as mesmas substâncias da secção 2.4.4. Utilizaram-se $50 \mathrm{~g}$ de terra seca ao ar,peneirada em $1 \mathrm{~mm}$, misturando-a com $50 \mathrm{~g}$ de silica, com diâmetro de .2$3 \mathrm{~mm}$. Apōs a introdução da mistura terrae sîlica, cobriumse a mistura com lã de vidro. A seguir procedeu-se a primeira lixiviação com $100 \mathrm{ml}$ de $K C 10,01 \mathrm{M}$, a partir da qual se es tabeleceu o "tempo zero" de incubação. As lixiviações sub sequentes foram feitas com intervalos de duas senanas, atê a décima semana, com uma lixiviação adicional na dêcima quarta semana.Apôs a lixiviação e sucção dos tubos, para deixar os solos incubando com tensão de umidade $60 \mathrm{~cm}$ de Hg,fez-se a filtração dos lixiviados com papel de filtro qualitativo, usando-se a mesma técnica descrita em 2.3.1. Tímaram-se alíquotas das lixiados para determinar o $\mathrm{S}-\mathrm{SO}_{4}$ e $\mathrm{N}-\left(\mathrm{NH}_{4}^{+}+\mathrm{NO}_{3}^{-}\right)$mineralizados.

\subsubsection{MINERALIZAČ̃̃ AERÓBICA DE S-SO $=\frac{\overline{4}}{4}$ EM AMOS- TRAS DE TERRAS MARCADAS COM ENXOFRE RADIOA- TIVO (35S)}

Paralelamente ao experimento de incubação aeróbia para estimar o $\mathrm{S}_{-} \mathrm{SO}_{4}^{=}$e $\mathrm{N}-\left(\mathrm{NH}_{4}^{+}+\mathrm{NO}_{3}^{-}\right)$mineralizados instalou-se outra bateria de colunas de lixiviação, com 
todos os tratamentos idênticos aos usados na seção 2.5.1. mais enxofre radioativo como traçador $\left({ }^{35} S\right.$, livre de carregador na forma de $\mathrm{H}_{2}{ }^{35} \mathrm{SO}_{4}$ ) com atjuidade inicial de $0,62134 \mu \mathrm{Ci} \cdot \mathrm{g}^{-1}$ de terra no tempo "zero", isto é, por ocasião da primeira lixiviação.

Para a perfeita homogeneizaşão do ${ }^{35} \mathrm{~S}$ com as amostras de terra, passaramase estas em peneira de $1 \mathrm{~mm}$, misturando o traçador ( $1 \mathrm{ml}$ de $\mathrm{H}_{2}{ }^{35} \mathrm{SO}_{4}$, diluído para atividade de $31,067 \mu \mathrm{Ci} / \mathrm{m} 1$ ) com $5 \mathrm{~g}$ de terra, em porções suces sivas até completar $50 \mathrm{~g}$ por coluna.

A lixiviação seguiu a técnica usada na secção 3.5.3., a té a décima semana de incubação.

Para a detecção de ${ }^{35} \mathrm{~S}$ nos extratos com KCl 0,01 M em solução aquosa utilizaram-se os procedimen tos de NASCIMENTO \& LOBÃO (1977) para o preparo da solução cintiladora, uso de padrão interno, etc. Para superar o problema de cristalização (1) da emulsão do TRITON $X-100$ (fornecido pela Central de Drogas do CNPq) adotou-se o pro cedimento de PATTERSON \& GREEN (1965), usando-se para $1 \mathrm{ml}$ do extrato em KCl $0,01 \mathrm{M} 3 \mathrm{ml}$ de etanol p.a. e $10 \mathrm{ml}$ de solução cintiladora.

Os valores finais da atividade de ${ }^{35} \mathrm{~S}$ em todos os lixiviados foram corrigidos para o tempo "zero" de incubação.

Entende-se por cristalização a formação de solução leitosa, quando há contato da emulsão de TRITON X-100 com soluções aquosas. 


\subsection{DELINEAMENTO EXPERIMENTAL E AVALIAÇÃO ESTATISTICA}

\subsubsection{EXPERIMENTO DE CASA-DE-VEGETACÃO}

Utilizou-se um fatorial completo $2 \times 3$, com ausência e presença de calagem, conforme recomendações cons tantes na tabela 3.1.:3 doses de gesso (0, 20 e 40 ppm de S), 12 unidades de solo (tabela 1) e 3 repetições por tratamento. Agruparam-se os vasos por solo, com os tratamentos inteiramente casualizados dentro de cada solo. Semanal mente fez-se a rotação aleatôria dos vasos para cada solo.

\subsubsection{Anâlise da variância}

A anâlise da variância fez-se individualmen te para solo, por cultivo e de forma conjunta com todos os solos pelo SAS (1982). Na análise conjunta da produção de matéria seca (parte aérea do milho) e absorção de enxofre pela planta-teste procedeu-se ao ajuste do número de graus de 1 iberdade do resíduo segundo COCHRAN (1952), para então se fazerem as comparações de mêdias.

3.6.1.2. Anālise de corrélação e regressão

Inicialmente, em carāter geral e exploratôrio fez-se a matriz de correlação entre os dados de anälises dos solos e os de plantas para se selecionar as corre- 
lações de maior interesse, conforme discriminadas na discussão dos resultados. As análises de correlação e regressão seguiram a metodologia usual (SAS, 1982), de forma separada para dados de solos e dados de plantas e de forma conjunta para dados de solos e plantas, por regressão múltipla ("stepwise"), agrupando-se os solos pelo teor de car bono, isto $\vec{e}$, menores e maiores do que $1,2 \%$.

3.6.1.2.1. Anâlise de correlação entre dados de solos

Correlacionaram-se os teores de C e S total, C/S e $S_{0}$ (potencial de mineralização) dos solos. A evolução do teor de $\mathrm{S}_{-} \mathrm{SO}_{4}=$ disponivel nos solos com função da calagem, incubação e cultivos é apresentada apenas na forma grâfíca.

3.6.1.2.2. Anâlises de correlação e regressão entre dados de plantas

As anâlises de correlação e regressão para plantas efetuaram-se agrupando-se os solos pelos seus teores de carbono, isto é, menores e maiores do que $1,2 \%$ e por cultivo:

a) regressões entre os teores de $S$ total na planta e produ. ção de matéria seca e absorção de enxofre;

b) regressões entre as razões N/S e P/S e produção de matê 
ria seca e absoṛção de enxofre.

Para o $S$ total nas plantas usou-se a regres são polinomial de segundo grau e para as razões $N / S$ e $P / S$ usou-se o modelo exponencial. $\quad\left(y=a \cdot e^{b x}\right)$, tomando-se como variável dependente a produção de matéria seca ou a absorção de enxofre pela planta-teste.

3.6.1.2.2. Anâlises de regressão entre dados de plantas e solos do experi mento de casa-de-vegetação

As anâlises de regressão entre dados de solos e plantas foram feitas de forma isolada por cultivo e de forma conjunta, com os solos agrupados pelos teores de carbono.

3.6.1.3.2. Correlaçãos regressão entre os teores de carbono e $S$ total nos solos, relação $\mathrm{C} / \mathrm{S}$.

As anâlises de correlação e regressão entre os teores de carbono nos solos a longo dos cultivos e absorção de enxofre pelo milho foi feita pelo modelo linear. Para o $S$ total e a relação CLS são apresentados os coeficientes de correlação. 
3.6.1.3.3. Anâlises de correlação e regres. são entre dados de análises de terras e plantas para fins de ca 1ibração

As anâlises de correlação e regressão para predizer a disponibilidade de enxofre e a calibração de análises químicas de $\mathrm{S}_{-} \mathrm{SO}_{4}=$ referem-se aos extratores arrola dos nas secções 3.3.1., 3.3.2., 3.3.3. e 3.3.4. os dados de $\mathrm{S}_{-} \mathrm{SO}_{4}^{=}$(para cada extrator) são relacionados com a produ ção absoluta e relativa de matêria seca e a absorção absoluta e relativa de enxofre pelo milho, usando-se os seguin tes modelos:

a) Polinomial de 2 grau;

b) $y=a+b x+c \cdot 1 / x$.

Para a calibração das anâlises químicas de $\mathrm{S}_{-} \mathrm{SO}_{4}^{=}$disponivel e determinação dos nî̀veis críticos de $\mathrm{S}_{-} \mathrm{SO}_{4}=$ nos solos pelos extratores das seç̧ões 3.3.1., 3.3.2. 3.3.3. e 3.3.4. transformaram-se os valores absolutos de produção de matéria seca e absorção de enxofre pela parte aérea do milho para valores relativos a partir de curvas de resposta à adubação com enxofre. Quando as equações mos traram máximos de produção de matéria seca e absorção de enxofre pelo milho $(y)$, dentro da faixa dos niveis de enxo fre estudados $(0,20$ e $40 \mathrm{ppm}$ de $\mathrm{S})$, esses valores foram tomados como denominadores das relações 


$$
\text { Produção relativa }=\frac{\text { Produção observada }}{\text { Produção máxima estimada }} \times 100
$$

e Absorção relativa $=\frac{\text { Absorção observada }}{\text { Absorção mâxima estimada }} \times 100$.

A produção de matêria seca e a absorção de enxofre máximas foram estimadas isoladamente para cada solo e para cada cul tivo, na ausência e presença de calagem. Quando as equações de regressão acusaram máximos fora da faixa das doses de enxofre estudado, tomou-se como denominador para a relação o valor máximo de produção de matêria seca para ca da solo e cada cultivo, senaradamente. Empregou-se o mesmo procedimento para estimax a absorção relativa de enxofre pelo milho.

\subsubsection{EXPERIMENTO DE LABORATÓRIO}

3.6.2.1. Mineralização aeróbia de enxofre e nitrogênio

Utilizaram-se amostras de terra previamente incubadas do experimento de casa-de-vegetação, isto é, ausência e presença de calagem com 3 repetições por tratamento.

A avaliação estatística dos dados experimen tais (N e S mineralizados), foi feita considerando-se os valores acumulados, a partir da 2 a lixiviação. Para esti- 
mar os potenciais de mineralização $\left(N_{0}\right.$ e $\left.S_{0}\right)$, usou-se a equação hiperbölica (ST ANFORD \& SM ITH,1972; JUM Aet alii, $1984)$.

$$
y=\frac{y_{0} \cdot t}{b \cdot y_{0}+t}
$$

onde:

$y=N$ ou $S$ cumulativamente minexalizado a partir do tempo "zero" de incubação ( $\mu \mathrm{g} N$ ou $\mathrm{S} \cdot \mathrm{g}^{-1}$ solo);

$y_{0}=N$ ou $S$ potencialmente mineralizível $\left(N_{, O}\right.$ e $\left.S_{. O}\right)$;

$t=$ tempo (semanas);

$\mathrm{b}=$ constante (semanas. $\mu \mathrm{g} N$ ou S$\cdot \mathrm{g}^{-1}$ solo) $)^{-1}$;

$\mathrm{Tc}=$ tempo necessâxio para mineralizar a metade do $\mathrm{N}_{\mathrm{O}}$ ou $S_{0}$ potencialmente mineralizivel.

A constante b pode ser escrita sob a forma:

$$
\mathrm{b}=\mathrm{Tc} / \mathrm{N}_{\mathrm{O}} \text { ou } \mathrm{b}=\mathrm{Tc} / \mathrm{S}_{\mathrm{O}}
$$

Então, $y=\frac{y_{0} \cdot t}{T c+t}$

Para o cấlculo dạ equação hiperbólica utili zou-se o algoritmo computacional iterativo idealizado por BORATTO (1984). 
3.6.2.2. Avaliação dos dados de mineralização aeróbia de enxofre dos solos via diluição isotôpica do ${ }^{35_{S}}$

Fez-se apenas a anâlise grâfica dos dados de atividade especifica do ${ }^{35}$ S dos lixiviados obtidos ao longo do período de incubação.

3.6.2.3. Anâlise de regressão entre os valo res estimados do potencial de mine ralização de enxofxe $\left(S_{0}\right)$ versus $a b$ sorção de enxofre pelo miliho

A relação entre os valores estimados de potenciais de mineralização de enxofre $\left(S_{0}\right)$ dos solos versus absorção (absoluta e relativa) de enxofre pelo milho foi feita por regressão linear simples. 


\title{
4. RESULTADOS E DISCUSSÃO
}

\author{
4.1. Resultados de análise de terRa
}

4.1.1. TEORES DE CARBONO; NITROGENIO E ENXOFRE TOTAIS EM AMOSTRAS DE TERRAS NÃO TRATADAS

Os resultados de anälises de terra para car bono e nitrogênio estão listadas como mêdias de três repetições na tabela 4.1. As determinações analíticas apresentaram ótima repetibilidade. O mesmo não ocorre com as determinações do enxofre total dos solos apresentando desvios consideráveis, como se observa na tabela 4.1. O método de digestão nitroperclórica, de CHAPMAN \& PRATT (1961) apresenta sérios problemas para a determinação do $S$ total nos solos, por causa das perdas por volatilização, provenientes das frações inorgânicas e orgânicas de enxofre reduzido. Melhores resultados têm siḍo obtidos com a adaptação de HESSE (1972) para anâlises de solos. Nesse mêtodo a amostra é refluída com âcido nítrico e os fumos conduzidos atravês de um segundo condensador para dentro de água bromada. Com adição posterior de água oxigenada o destilado é retornado ao frasco de digestão, evaporado atê secagem total e então determinado o sulfato no resíduo. Nas análises da tabela 4.1. o coeficiente de variação mostrou u 
Tabela 4.1 - Teores de enxofre total dos solos obtidos por digestão nitroperclórica e determinação gravimétrica.

\begin{tabular}{|c|c|c|c|c|c|c|}
\hline \multirow{3}{*}{ Solo (1.ocal) } & \multicolumn{6}{|c|}{ Teores de enxofre total $\left(\begin{array}{l}0 \\
0\end{array}\right)$} \\
\hline & \multicolumn{3}{|c|}{ Repetições } & \multirow{2}{*}{ Média } & \multirow{2}{*}{$\begin{array}{l}\text { Desvio } \\
\text { padrão }\end{array}$} & \multirow{2}{*}{$\begin{array}{c}C . V . \\
\left(\begin{array}{c}0 \\
0\end{array}\right)\end{array}$} \\
\hline & 1 & 2 & 3 & & & \\
\hline Anhembi & 0,00948 & 0,01154 & 0,01300 & 0,01134 & 0,00177 & 15,6 \\
\hline São Pedro & 0,01387 & 0,01566 & 0,01277 & 0,01410 & 0,00146 & 10,3 \\
\hline Assis & 0,00948 & 0,01154 & 0,01030 & 0,01044 & 0,00104 & 10,0 \\
\hline Piraçununga -1 & 0,01113 & 0,01168 & 0,01030 & 0,01136 & 0,00029 & 2,5 \\
\hline Piraç.ununga-2 & 0,02267 & 0,02363 & 0,02060 & 0,02230 & 0,00155 & 6,9 \\
\hline Botucatu-? & 0,01882 & 0,01841 & 0,02088 & 0,01937 & 0,00320 & 16,5 \\
\hline Botucatu-2 & 0,02995 & 0,02940 & 0,03283 & 0,03073 & 0,00184 & 6,0 \\
\hline Matão & 0,02596 & 0,02344 & 0,02376 & 0,02439 & 0,00137 & 5,6 \\
\hline Catalão & 0,02376 & 0,02624 & 0,02789 & 0,02596 & 0,00208 & 8,0 \\
\hline S.S.Paraíso-1 & 0,00659 & 0,00865 & 0,00824 & 0,00782 & 0,00109 & 13,9 \\
\hline S.S.Paraíso-2 & 0,01497 & 0,01154 & 0,01456 & 0,01369 & 0,00187 & 13,6 \\
\hline Rio Paranaíba & 0,02919 & 0,03480 & 0,03189 & 0,03193 & 0,00285 & 8,9 \\
\hline
\end{tabular}

ma amplitude de 2,5 a $16,5 \%$. Dentre os métodos citados por HESSE (1972), a fusão com peróxido de sódio e nitrato de magnésio, este preparado com magnésio "Specpure", foi usada por BUTTERS \& CHENERY (1959), que obtiveram resultados reproduzizeis de $S$ total nos solos, com coeficiente de variação de $3,1 \%$. 
4.1.2. TEORES DE CARBONO, $\mathrm{pH}, \mathrm{P}, \mathrm{Ca}, \mathrm{Mg} \mathrm{EH}+\mathrm{Al}$ NAS AMOSTRAS SUBMETIDAS À INCUBACÃO E A DOIS CULTIVOS COM MILHO NA AUSENCIA E PRESENÇA DE CALAGEM

Os solos utilizados no experimento variam significativamente em suas características gerais, tais co mo, os teores de argila $(8,1$ a $60,2 \%)$, carbono $(0,50$ a $3,03 \%)$, pH e saturação de bases. Isso tem como consequência necessidades de calagem, variando de 0,374 a 4.400 t/ ha, excluindo-se a quantidade adicional que foi usada para neutralizar a acidez fisiológica da uréia usada na adubação de cobertura.

Na tabela 4.2. observarse a evolução do pH, dos teores de carbono, P, K, Ca, Mg e H+Al, em função da incubação, de dois cultivos dos solos, na ausência e pre-sença de calagem.

O decréscimo dos teores de carbono já se tor nam evidentes após a incubação, sem mesmo terem sido culti vados. Nos solos de textura média a arenosa, a calagem pra ticamente não teve influência na oxidação da matéria orgânica. Nos solos de textura mais argilosa no entanto, a calagem aumentou a mineralização da matéria orgânica. BRAR \& GIDDENS (1968) consideram que a acidez e, principalmente o alumínio trocâvel inibem a mineralização da matêria orgâni ca. Este fato jâ foi observado por BOHNEN (1970) e KLIEMANN (1973) em solos do Rio Grande do Sul, em que a calagem aumentou significativamente a absorção de nitrogênio 


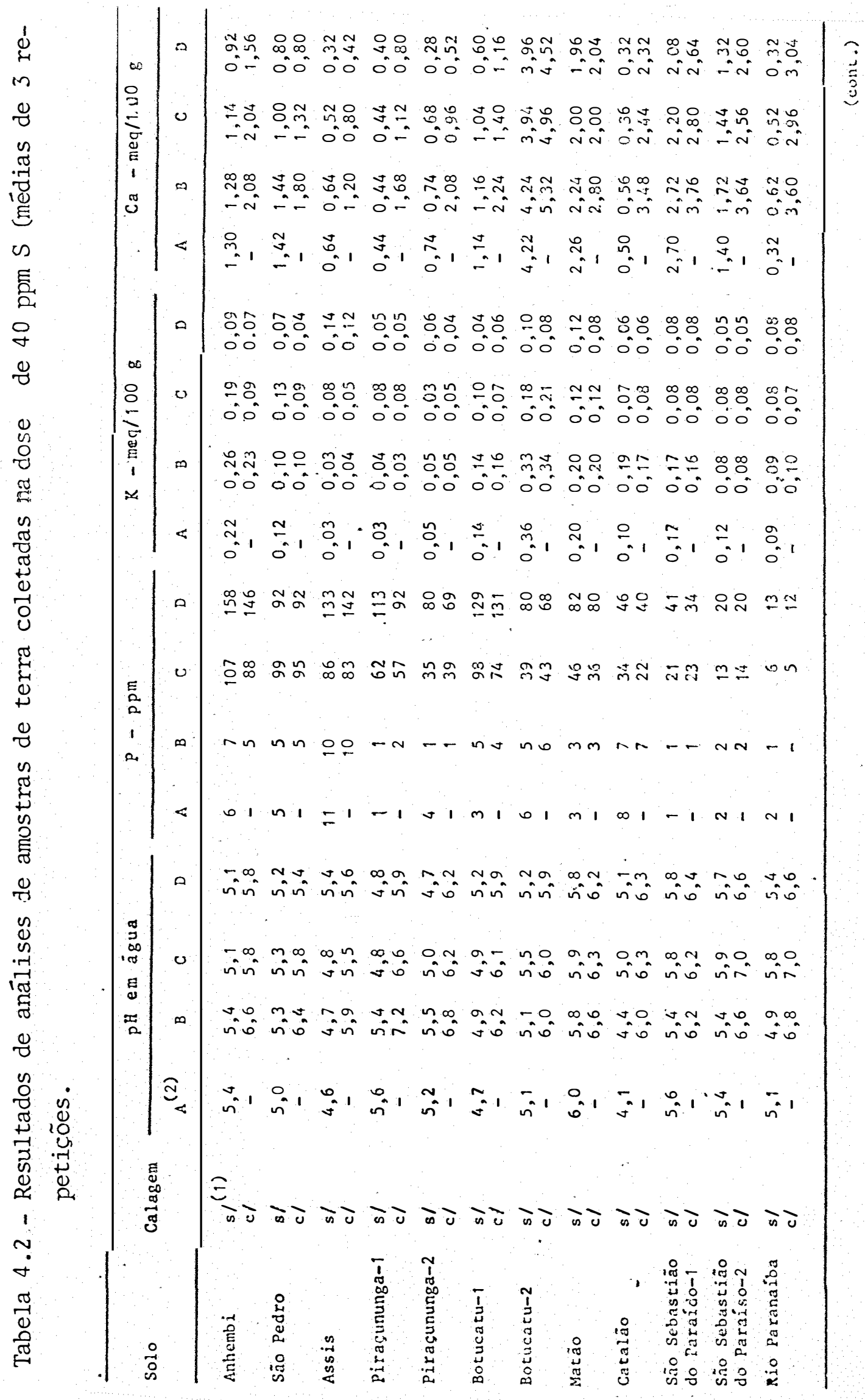




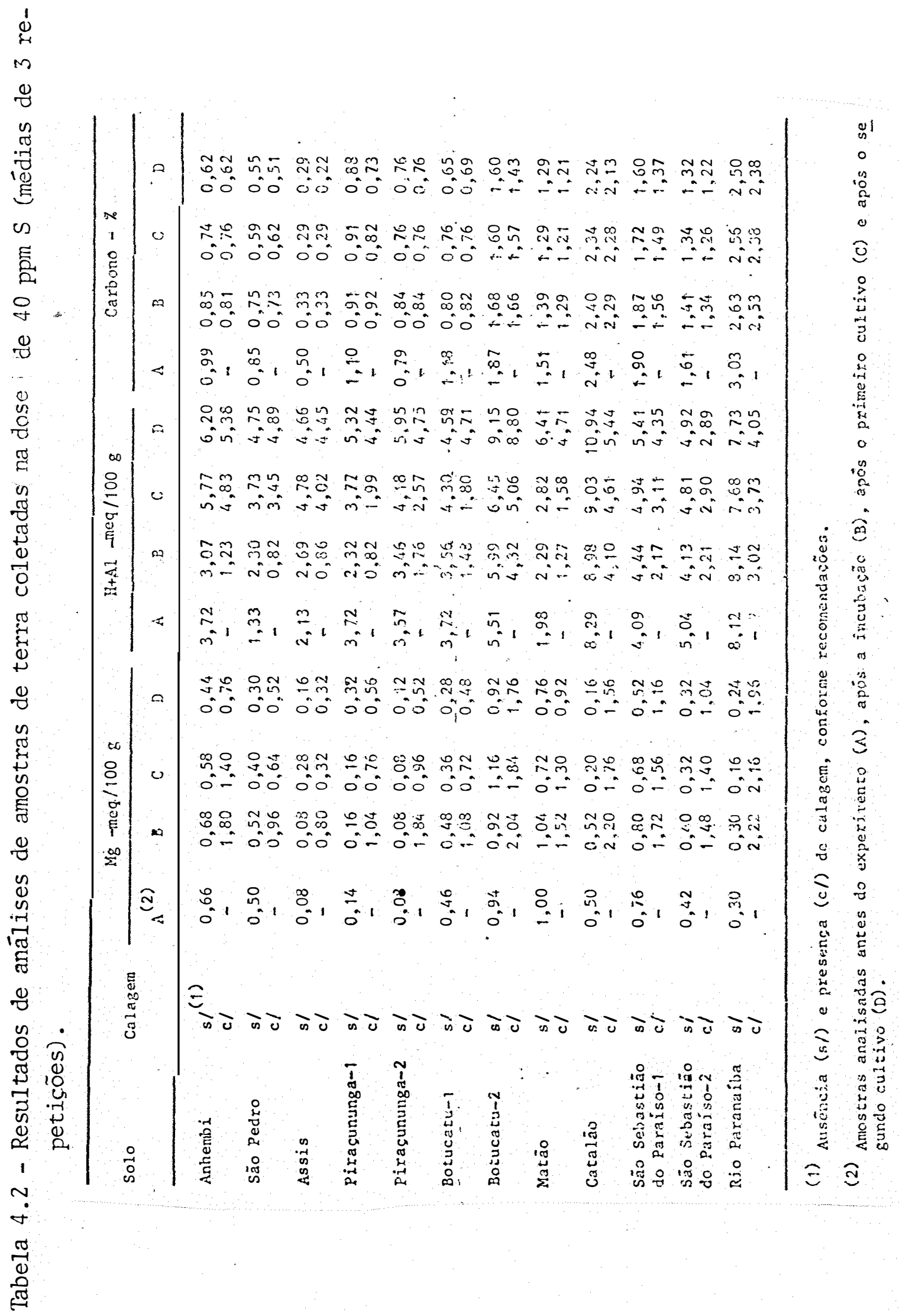


nativo. Na secção 4.2. ver-se-â que a calagem modifica substancialmente os potenciais de mineralização de nitrogênio e enxofre em solos com maiores teores de carbono.

Os teores de fôsforo disponível aumentaram em função das quantidades adicionadas: $200 \mathrm{ppm}$ de $\mathrm{P}$ adiconadasantes do primeiro cultivo e $2 / 3$ da mesma quantidade no segundo. observa-se que nos solos mais arenosos elevou-se o fósforo disponível a nîveis extremamente altos, não ocorrendo o mesmo com os solos mais argilosos, principalmente, os solos provenientes de Catalão (GO), São Sebastião do Paraí so-2 (MG) e Rio Paranaîba (MG), da região dos cerrados. Se gundo ALMEJDA NETO \& BRASIL SOBRo (1977), os solos de cerrado possuem alta capacidade de fixação de fôsforo, o que diminui a potência de extração dos extratores de fósforo. Para os solos arenosos, no entanto, altas adubações fosfatadas tem implicações sẹrias na disponibilidade, lixivia ção e adsorção do enxofre. O fosfato, sendo um forte deslo cador de ânions, segundo METSON \& BLAKEMORE (1978) e JENSEN (1963) provoca a lixiviação do sulfato, tornando-se im possivel, à semelhança do $N$, construir níveis de reserva do elemento em solos arenosos, em condições de campo.

A reação do solo ( $\mathrm{pH}$ e teores de $\mathrm{H}$ e A1) e bases trocáveis ( $\mathrm{K}, \mathrm{Ca}$ e $\mathrm{Mg}$ ) são profundamente alteradas por efeito dos cultivos e da calagem, Na tabela 4.2, obser va-se que a calagem aumenta os niveis de Ca e Mg e diminui os níveis de $\mathrm{H}$ e Al. Porém, com os cultivos dos solos 
ocorre um esgotamento progressivo de cảlcio e magnésio e o aumento do $\mathrm{H}$ e Al. Nas amostras de terra analisadas após o segundo cultivo, no entanto, a difexença entre os níveis de $\mathrm{Ca}, \mathrm{Mg}$, H e $\mathrm{Al}$ è ainda significativo, comparando-se os tratamentos com e sem calagem. Na secção 4.9. ver-se-â, na anâlise de variância conjunta e de regressão múltipla a contribuição dos teores de $\mathrm{Ca}$, Mg e H+Al nos solos, como parâmetros estimadores da produção de matéria seca e absorção de enxofre pelo milho.

0 esgotamento do potâssio por efeito dos cultivos generalizou-se em todos os solos, mesmo com as quantidades (acumuladas) de 530 ppmde $K$ adicionadas nos dois cultivos. Segundo SILVA \& RITCHE (1982) os cultivos sucessivos, a exportação e a lixiviação tendem a esgotar rapidamente, em condições de alta produtividade, as reservas do potássio dos solos de cerrados. Em solos da Africa Oriental com altas precipitações e altas adubações nitroge nadas quatro ou cinco cultivos sucessivos levam ao esgotamento das reservas de potássio (ANDERSON, 1973). Nas condi ções desse experimento os baixos nîveis de potássio verifi cados após dois cultivos exaustivos, justificam-se pela a 1 ta adubação nitrogenada e pela completa remoçăo do sistema radicular e da parte aêrea das amostras de solos. 
4.1.3. EVOLUCÃO DOS TEORES DE ENXOFRE (S-SO $\left.\mathrm{SO}_{4}^{\circ}\right)$ DISPONIVEL EM FUNÇÃO DA INCUBAÇÃO, DOS CULTIVOS, NA AUSENCIA DE CALAGEM

A evolução dos teores de enxofre $\left(\mathrm{S}-\mathrm{SO}_{4}^{=}\right)$ disponivel pelos diversos extratores estão listados na tabela 4 do apêndice. Para a melhor visualização do quadro, os dados de análises de terra para enxofre disponivel foram plotados contra as épocas de amostragem, istoé, apôs a incubação, após o primeiro cultivo e após o segundo cultivo, como se observa pelas figuras 4.1.4.1.2. e 4.1.3.

De um modo geral, a presença da calagem dis ponibilizou quantidades ligeiramente maiores de $\mathrm{S}_{-} \mathrm{SO}_{4}^{=}$em relação à ausência. A calagem dos solos ácidos, com propriedades de retenção de sulfatos, tem capacidade para des sorver certa quantidade de sulfato retido. O efeito da calagem pode ser encarado como sendo um efeito direto do $\mathrm{pH}$ ou como o deslocamento do $\mathrm{SO}_{4}=$ por grupos $\mathrm{OH}^{-}$(HARWARD \& REISENAVER, 1966; AYLMORE \& KARIM, 1968). No presente trabalho verificaram-se razoâveis diferenças entre as quantidades de $\mathrm{S}_{-} \mathrm{SO}_{4}^{=}$extraídos por $\mathrm{CaCl}_{2} 0,15 \%, \mathrm{NH}_{4} \mathrm{OAC} 0,5 \mathrm{~N}$ e $\mathrm{Ca}\left(\mathrm{H}_{2} \mathrm{PO}_{4}\right)_{2}-500$ ppm $\mathrm{P}$ em ácido acétice 2 , ON. Na figura 4.1.3. nota-se que a calagem altera significativamente as quantidades extraidas de $\mathrm{S}_{-} \mathrm{SO}_{4}=$ pelo $\mathrm{CaCl}_{2} 0,15 \%$, principalmente nos solos de cerrados, mais argilosos, como Catalão, São Sebastião do Paraîso-2 e Rio Paranaî́ba. 0 extrator $\mathrm{CaCl}_{2}$ $0,15 \%$ é considerado, segundo ESMINGER \& ERENEY (1966) e 

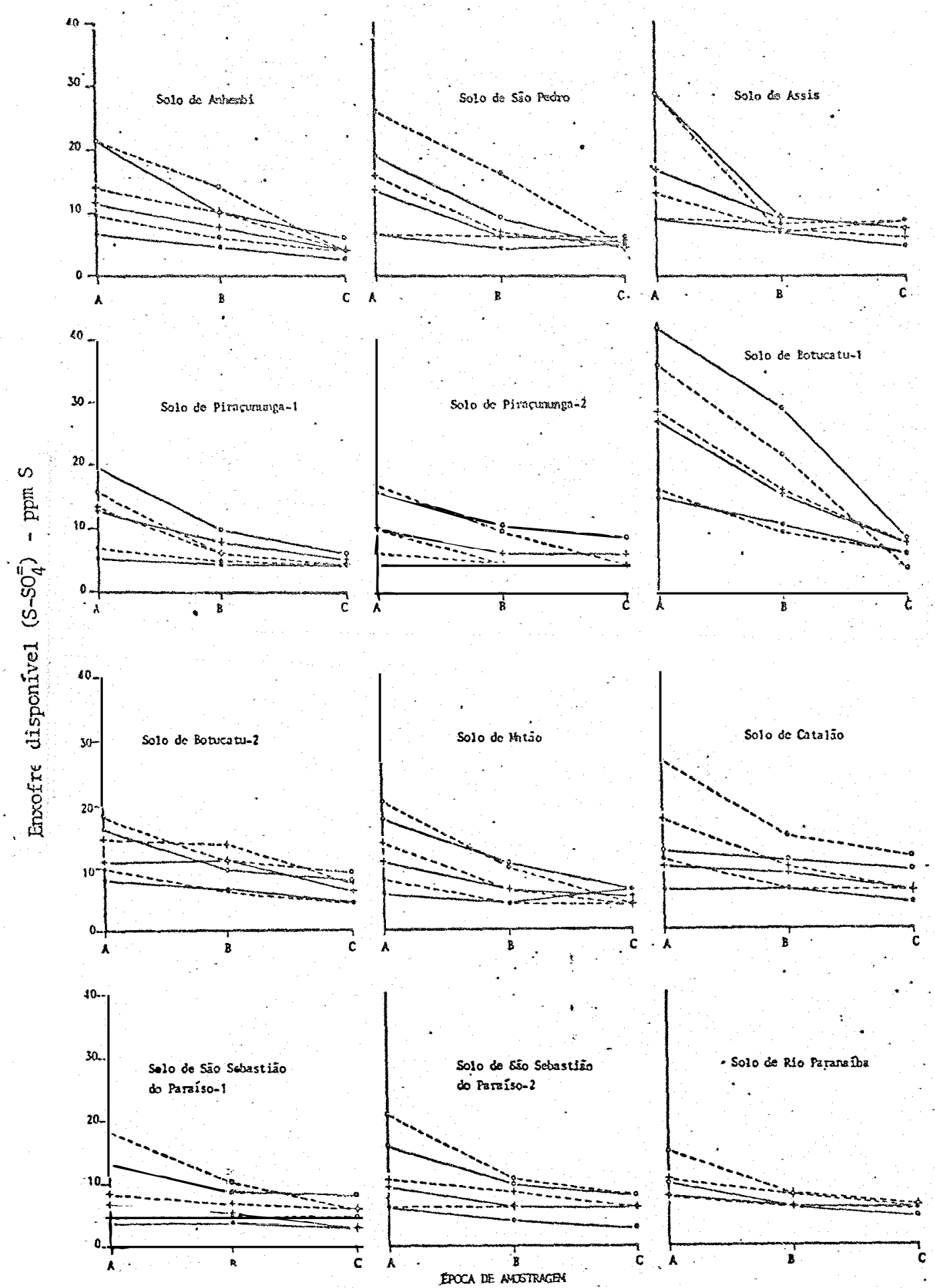

Figura 4.1.1. - Evolução dos teores de enxofre disponível $\left(\mathrm{S}_{-} \mathrm{SO}_{4}=\right.$ ), extraîdo por $\mathrm{Ca}\left(\mathrm{H}_{2} \mathrm{PO}_{4}\right)_{2} \cdot \mathrm{H}_{2} \mathrm{O}-500$ ppin $\mathrm{P}$ em ácido acêtico $2,0 \mathrm{~N}$ em função da ausência (-) e presença (--) de ca lagem e doses de gesso de o(0), 20(+) e $40(0)$ ppm de S, em amostras colhidas após incubação (A), apōs o primeiro cultivo (B) e após o segundo cultivo (C). 

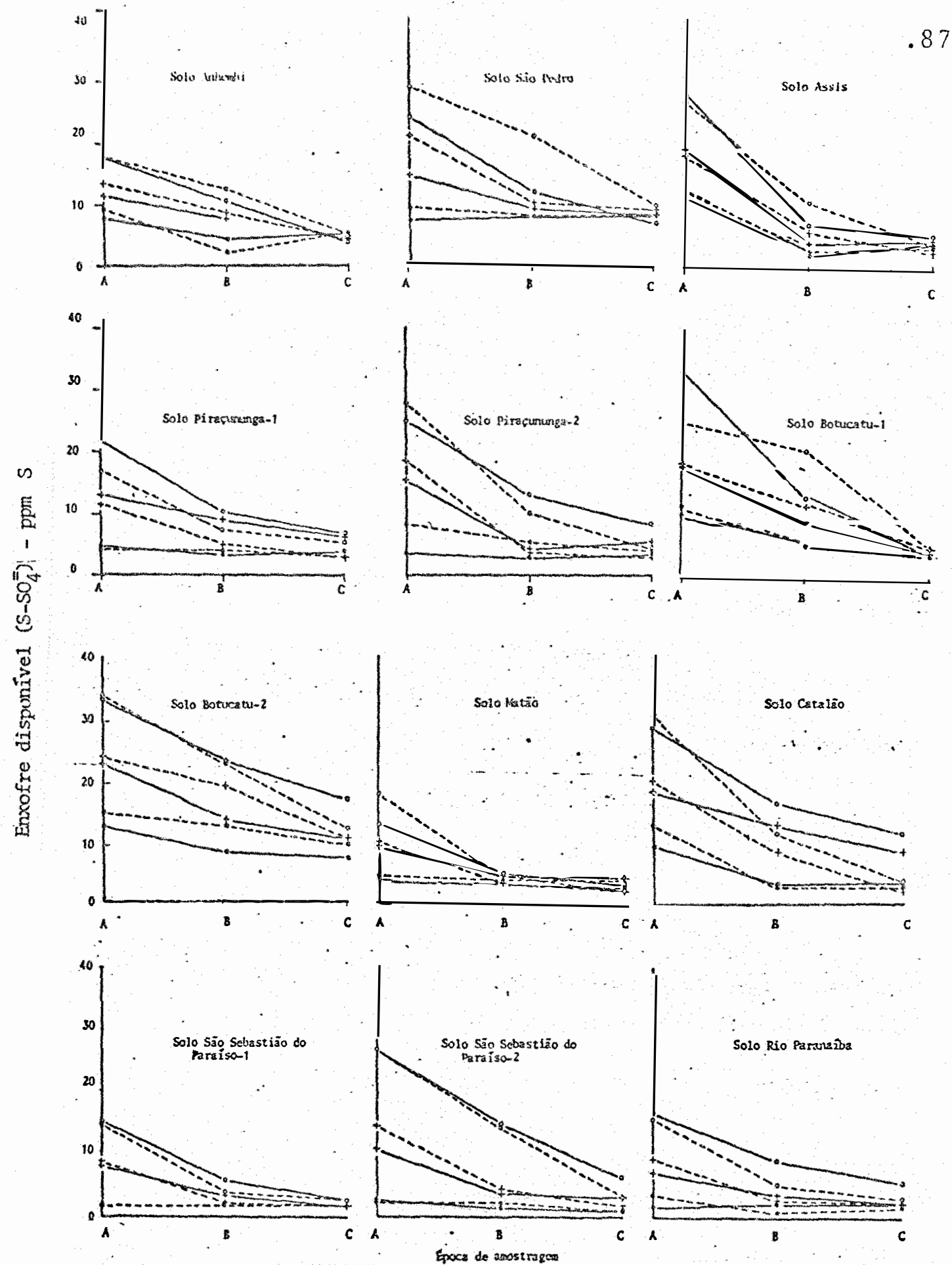

Figura 4.1.2. - Evolução dos teores de enxofre disponível (S-S $\left.{ }_{4}\right)$, extraído por $\mathrm{NH}_{4} \mathrm{HOAc} 0,5 \mathrm{~N}$ em ácido acético $0,25 \mathrm{~N}$, em função da ausência (-) e presença (---) de calegem e das doses de gesso de 0 (o), 20 (t) e 40 (o) ppm de $S$, em amostras colhidas após a adubação (A), após o primeiro cultivo (B) e apōs o segundo cultivo (C). 

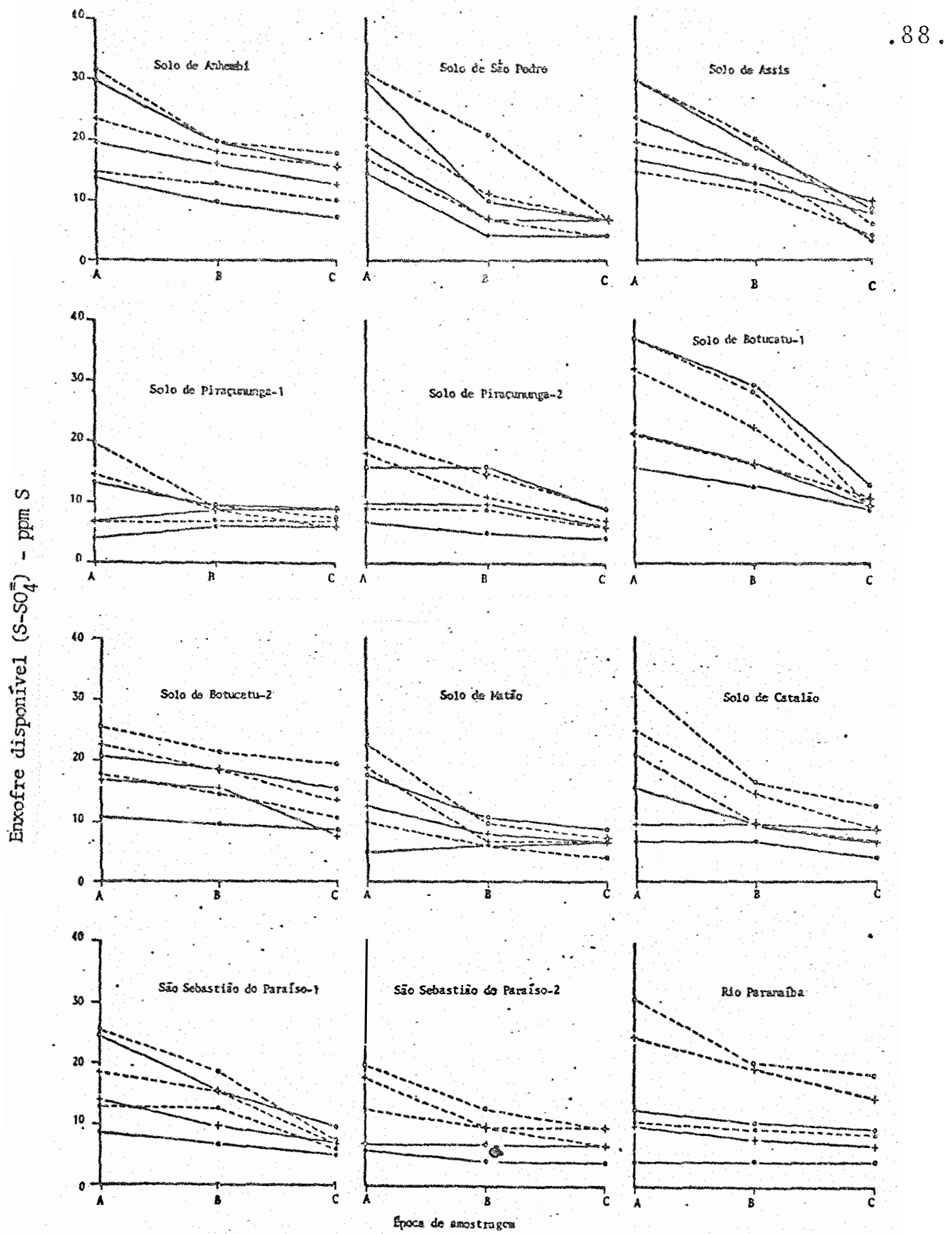

Figura 4.1.3 - Evolução dos teores de enxof re disponível ( $\left.\mathrm{S}_{-} \mathrm{SO}_{4}\right)$, extraîdo por $\mathrm{CaCl}_{2} 0,15^{\circ}$, em funcâa da ausência $(-)$ e presença (-.m) de calagem e das doses de gesso de 0 ( ) , $20(+)$ e 40 (o) ppm de $S$, em amostras colhidas após a incubação (A), apôs o primeiro cultivo (B) e após o segundo cultivo (C). 
REISENAUER et alii (1973), de baixo poder de extração, não conseguindo deslocar o $\mathrm{S}_{-} \mathrm{SO}_{4}$ adsorvido. Por isso, o decrés cimo na retenção de sulfato pelos solos via calagem deve ser responsabilizada pela maior extração de enxofre disponível (PROBERT, 1976). Porooutro lado, WILLIAMS \& STEIN.. BERGS (1964) atribuíram a maior absorção de enxofre pelas plantas à mineralização do S-orgânico.

As diferentes capacidades de dessorção de $\mathrm{S}-S O_{4}=$ dos solos por diversos extratores baseia-se na teoria de adsorção de ânions, desenvolvidas por HINGSTON et alii (1972). Na adsorção não específica os ânions balanceadores das cargas positivas das superfícies dos óxidos de ferro e alumínio são vistos como ocorrendo apenas na ca mada externa de Helmoltz Esses ânions, como $\mathrm{NO}_{3}^{-}$e $\mathrm{Cl}^{-}$ são adsorvidos e dessorvidos numa proporção simples de sua concentração. Os ânions especificamente adsorvidos, como $\mathrm{H}_{2} \mathrm{PO}_{4}^{-}, \mathrm{HPO}_{4}^{=}, \mathrm{F}^{-}$, e $\mathrm{MOO}_{6}^{=}$, por causadda sua forte afinidade com as superfícies dos óxidos, são adsorvidos, independentemente da sua concentração. Como a reação de adsorção ê não reversíve1, os íons especificamente adsorvidos não são trocáveis, a sua liberação da superfície sólida è governada por princípios de produtos de solubilidade e as concentrações de equilíbrio em solução são muito baixas (KINJO \& PRATT, 1971; MEKARU \& UEHARA, 1972). RAIJ (1986) considera que em muitos casos, o $\mathrm{SO}_{4}=$ é um ion indiferente (não a sorvido especificamente). No presente trabalho, com a maior extração de $\mathrm{S}-\mathrm{SO}_{4}=$ por $\mathrm{CaCl}_{2} 0,15 \%$, na presença de ca 


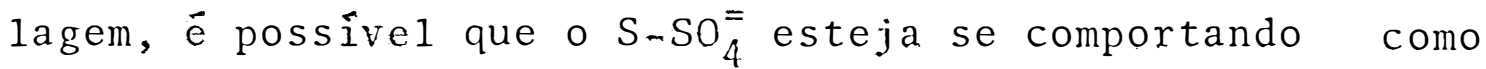
um ion indiferente por causa da sua liberação das superfícies dos ôxidos de ferro e a Iumínio.

Para a remoção de sulfatos solüveis mais os adsorvidos de solos fortemente retentivos, ânions como o fosfato, o fluoreto e hidroxilas sâo requeridos. Aí se tor na implicita a vantagem do fosfato sobre o sulfato, nos mé todos comumente utilizados para extrair sulfatos adsorvidos (BARROW, 1967; BROMFIELD, 1972). Pela figura 4.1.1. verifica-se que nos solos mais argilosos como Catalão e São Sebastião do Paraíso-2, a calagem teve significativa influência na extração de $\mathrm{S}-\mathrm{SO}_{4}^{=}$pelo extrator $\mathrm{Ca}_{2}\left(\mathrm{H}_{2} \mathrm{PO}_{4}\right)_{2}-500$ ppm P. No entanto, a extração de $\mathrm{S}_{-} \mathrm{SO}_{4}^{=}$no solo Rio Parana ba, é sensivelmente diminuída, apesar de ainda maior na presença de calagem. METSON (1979) considera que a forte a finidade de alguns solos por fosfatos, removem rapidamente - fosfato da solução durante a extração do sulfato, reduzindo a concentração e eficiência do extrator. Em tais casos recomenda-se o uso de uma relação extrator:solo mais larga, por exemplo, 20:T, como é proposto por SEARLE (1979).

Entre os extratores que extraem o sulfato solúvel e o adsorvido existem as soluções neutras de fosfa tos e as soluções de acetato de amônio. No presente trabaTho o extrator $\mathrm{NH}_{4} \mathrm{OAC} 0,5 \mathrm{~N}$ pH 5,0 extraiu quantidades iguais de $\mathrm{S}_{-} \mathrm{SO}_{4}$, não ocorrendo diferenças significativas em função da calagem. Um aspecto digno de nota é a constatação de ESMINGER (1954) de que o pH do extrator acetato de 
amônio teve pouco efeito na remoção do enxofre numa faixa de 4,8 a 7,0 .

Os teores de $\mathrm{S}-\mathrm{SO}_{4}=$ disponível estimados pelos três extratores são sensivelmente maiores em todos os solos estudados, na presença de calagem apôs a incubação. A exportação do enxofre ề evidente em todos os solos: em al guns casos, os teores de $\mathrm{S}_{-} \mathrm{SO}_{4}=$ disponível após o segundo cultivo são mais baixos nos tratamentos com calagem do que na sua ausência. Ver-șe-ão, na secção 4.4 . as interações entre calagem, gesso e cultivos na produção de matéria seca e adsorção de enxofre, fustificando o esgo tamento do enxofre, mesmo no nivel mais elevado de adubação (40 ppm S). Considerando-se o extrator $\mathrm{CaCl}_{2} 0,15 \%$, os teores de $\mathrm{S}-\mathrm{SO}_{4}=$ disponível mostraram ainda diferenças signïficativas, quando comparados os tratamentos sem e com ca lagem. Dados de KAMPRATH et alii (1956) e MARTINI \& MUTTERS (1984) mostram que com a calagem, tanto em condições de es tufa como de campo, hâ redução substancial de sulfatos nos solos através dos cultivos e da calagem.

\subsection{4, PROBLEMAS DE EXTRACÃO E DETERMINACÃA ANALI- TICA DE S-SO $=$ DOS SOLOS RELACIONADOS COM O DESEMPENHO DOS EXTRATORES}

Conforme relatado na secção $2.3 .$, o $\mathrm{S}-\mathrm{SO}_{4}=$ extraido foi determinado por turbidimetria. De acordo com BARDSLEY \& LANCASTER (1965) é essencial que os extratos es 
tejam absolutamente límpidos, sem o que está seriamente comprometida a linearidade da curva de calibração. Assim, para obter extratos que preencham essa condição, procedeu- se a sua filtração, conforme detalhado secção 3.3. Por cau sa do elevado custo do papel de filtro quantitativo, de filtragem lenta, fizeram-se, simultaneamente, as curvas de calibração para os quatro extratores estudados, com papel filtro quantitativo de filtragem lenta e com papel qualita tivo de filtragem râpida. Os parâmetros das curvas de cali bração de $\mathrm{S}_{-} \mathrm{SO}_{4}^{=}$para os extratores em estudo estão listados na tabela 4.3. Verifica-se que a têcnica empregada para a lavagem dos sulfatos do papel filtro qualitativo é adequada, pois os intexceptos e os coeficientes angulares das equações de regressões para cåa extṛator em particular, não diferem significativvamente entre si. Assim, o papel filtro qualitativo pode substituir o quantitativo, com menores custos e sem prejuízo para a exatidão dos resulta dos analiticos de enxofre-sulfato disponivel nos solos.

Independentemente do papel de filtro utilizado, a limpidez dos extratos (observação visual) apresentam sensiveis diferenças entre extratores.

Os extratores $\mathrm{NH}_{4} \mathrm{OAC} 0,5 \mathrm{~N}$ pH 5,0 e $\mathrm{Ca}\left(\mathrm{H}_{2} \mathrm{PO}_{4}\right)_{2}$ 500 nnm de ácido acético en HCAc 2,0N não apresentaram extratos límpidos sem adição do carvão ativado, ontando-se, entã், pelo seu uso sistemâtico em todas as extrações. WILLIAMS \& STEINBERGS (1964) concluíram que a secagem e o armazenamento aumentam de 0 a $12,1 \mathrm{ppm}$ de $\mathrm{S}-\mathrm{SO}_{4}^{=}$extraíve1 em $\mathrm{KH}_{2} \mathrm{PO}_{4}$. PEVERILL et 
Tabela 4.3 - Parâmetros das curvas de calibração de $\mathrm{S}_{-} \mathrm{SO}_{4}^{=}$para os extratores $\mathrm{NH}_{4} \mathrm{OAC} 0,5 \mathrm{~N}$ em HOAC $0,25 \mathrm{~N}, \mathrm{Ca}\left(\mathrm{H}_{2} \mathrm{PO}_{4}\right)_{2} \cdot \mathrm{H}_{2} \mathrm{O} 500$ ppm $\mathrm{P}$ em $\mathrm{HOAC} 2,0 \mathrm{~N}$ e $\mathrm{CaCl}_{2} 0,15^{\circ}$ e $\mathrm{HCl} 0,05 \mathrm{M}^{2}$.

\begin{tabular}{|c|c|c|c|c|c|c|}
\hline \multirow{3}{*}{ Extrator } & \multicolumn{6}{|c|}{ Papel de filtro } \\
\hline & \multicolumn{3}{|c|}{ Qualitativo } & \multicolumn{3}{|c|}{$\therefore$ quantitativo } \\
\hline & $a$ & $b$ & $r$ & $\mathrm{a}$ & $b$ & $\mathrm{r}$ \\
\hline $\mathrm{NH}_{4} \mathrm{OAC} \quad 0,5 \mathrm{~N}$ & 0,0071 & 0,0008040 & 0,9991 & 0,00705 & 0,0008 & 0,9983 \\
\hline $\begin{array}{l}\mathrm{Ca}\left(\mathrm{H}_{2} \mathrm{PO}_{4}\right)_{2}^{-} \\
500 \mathrm{ppm} \mathrm{P}\end{array}$ & 0,0086 & 0,0005758 & 0,9954 & 0,00839 & 0,0006057 & 0,9941 \\
\hline $\mathrm{CaCl}_{2} 0,15^{\circ}$ & 0,0062 & 0,000797 & 0,9990 & 0,00604 & 0,000798 & 0,9993 \\
\hline $\mathrm{HCl} 0,05 \mathrm{~s}:$ & 0,0094 & 0,000791 & 0,9983 & 0,00816 & 0,000793 & 0,9989 \\
\hline
\end{tabular}

${ }^{2}$ Os parâmetros das curvas de calibração foram calculadas a partir da média de três repetições por ponto da curva.

alii (1974) conseguiram reduzir a niveis insignificantes essas variações com o emprego do carvão ativado. Todavia, durante o decurso desse experimento, testaram-se diversas marcas de carvão ativado. A avaliação (qualitativa) do teor de $\mathrm{S}_{-} \mathrm{SO}_{4}^{=}$mostrou que seria aconselhâvel a lavagem do material com $\mathrm{HCl}$ diluído atê que o teste de $\mathrm{S}_{-} \mathrm{SO}_{4}^{\overline{7}}$ se mostrasse negativo.

Com o uso do extrator $\mathrm{CaCl}_{2} 0,15 \%$ não se fez necessário o emprego do carvão ativado para obtenção de ex tratos límpidos, após 2 a 3 filtragens sucessivas dos extratos. O extrator $\mathrm{HCl} 0,05 \mathrm{M}$ mostrou comportamento bem di- 
verso: os extratos obtidos, com ou sem cạrão ativado não se apresentaram límpidos para determinações turbidimétricas de $S-S_{4}=$. Os extratos se apresentaram mais turvos nos latossolos de textura arenosa a média, como Assis, Piraçunun ga-2, Botucatu-1 e Matão. As baixas correlações obtidas entre produção de matéria seca (e absorção de enxofre) do mi lho versus $\mathrm{S}-\mathrm{SO}_{4}=$ extraído por $\mathrm{HCl} 0,05 \mathrm{M}$ (tabela 4.4), justificam-se pelos problemas apresentados na extração, émbora, as correlações entre o $\mathrm{S}_{-} \mathrm{SO}_{4}^{=}$extraível por $\mathrm{HCl} 0,05 \mathrm{M}$ ver sus absorção de $S$ (e produção de matéria seca) pelo milho sejam estatisticamente significativas, por solo e por culti vo isolados. forma conjunta, se constatou associação apenas nos solos com teor de carbono inferior $1,2 \% \quad(r=0,376)$ e a ausência total de associação nos solos com carbono superior a $1,2 \%(r=-0,033)$.

\subsection{Mineral izacĩo de nItRogeño E ENXOFRE POR INCUBA- CÃO ABERTA, NA AUSENCIA E PRESENÇA DE CALAGEM}

Os primeiros estudos sobre mineralização de $N$ e $S$ foram projetados para serem usados como métodos râpi dos de predição da disponibilidade de $N$ e $S$ para as plantas. Devido a sua íntima relação nos processos biológicos, assumia-se que os índices relativos de mineralização de $\mathrm{N}$ e $S$ seriam semelhantes, isto $\vec{e}$, seriam mineralizados na mes ma razão em que ocorrem na matéria orgânica (WHITE, 1959). 
Tabela 4.4 - Matriz de coeficientes de correlaşão lincar simples entre absorção de cnxofre versus cxtratores de $\mathrm{S}_{-} \mathrm{SO}_{4}^{=}$disponível nos solos, entre producão de matéria seca versus extratores e entre os pröprios extratores.

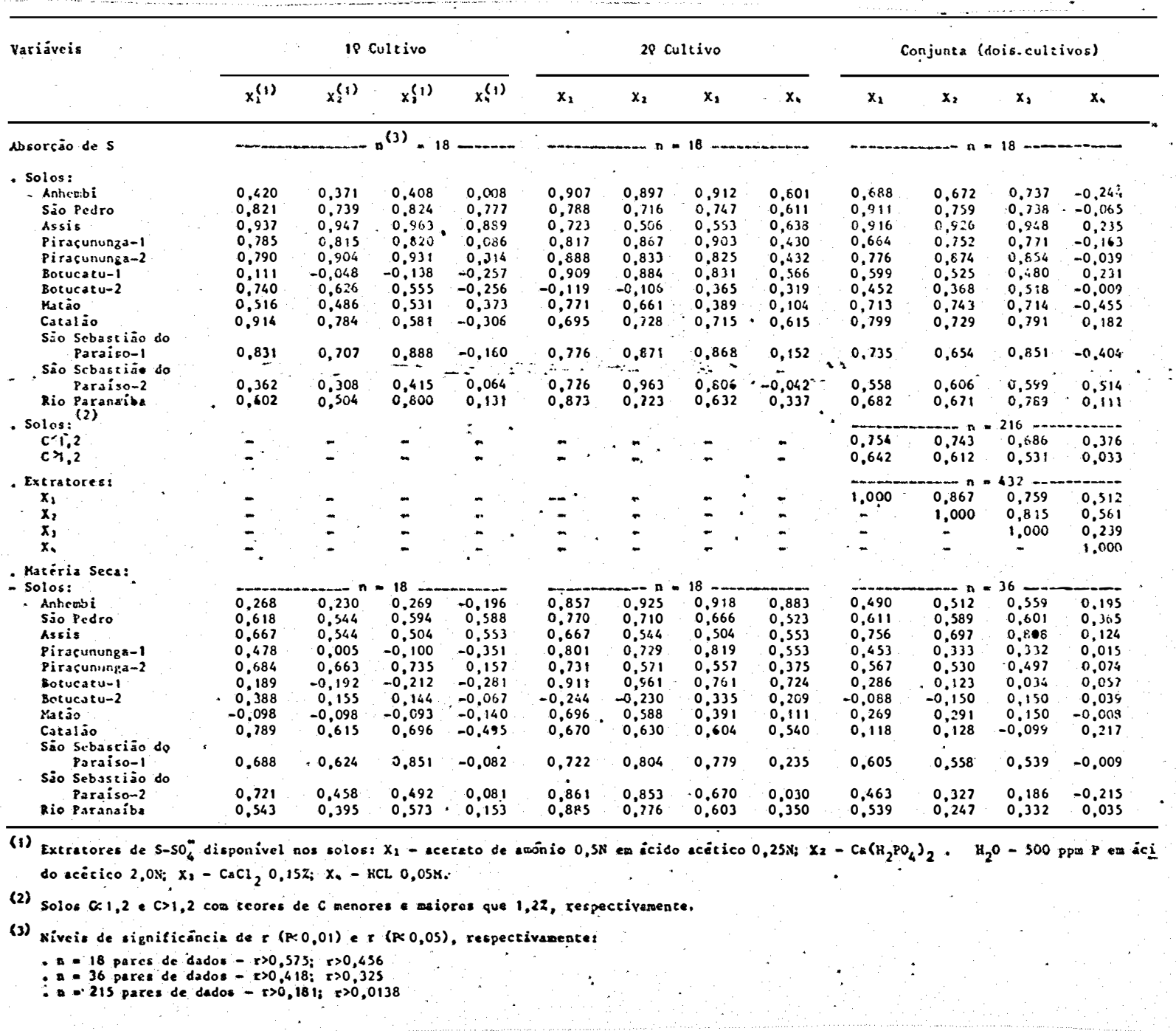


Nas figuras 4.2. (a-g) e na tabela 4.5. encontra-se a evolução dos teores de $\mathrm{N}$ e S mineralizados (cu mulativamente) e os paxâmetros das equações hiperbölicas (STANFORD \& SMITH, 1972) e os tempos necessārios (meia vida) para estimar as metades do enxofre $\left(1 / 2 S_{0}\right)$ e nitrogênio $\left(1 / 2 N_{0}\right)$ potencialmente mineralizáveis nos solos São Pedro, Assis, Piraçununga-1, Matão, Catalão, São Sebastião do Paraíso-2 e Rio Paranaíba. Verifica-se que a mineraliza ção de $\mathrm{N}$ e $\mathrm{S}$ se processa em razões bastante diferentes; princi palmente quando se analisa o efeito da calagem. Nos solos de baixos teores de carbono e de textura arenosa a média (São Pedro, Assis e Matão) a calagem praticamente não alte rou o tempo necessârio para mineralizar a metade de $\mathrm{N}$ e $\mathrm{S}$ potencialmente mineralizáveis. Nos solos mais argilosos (Catalão, São Sebastião do Paraíso-2 e Rio Paranaíba) os potenciais de mineralização são substancialmente modificados pela calagem. Isto indica que esses solos tem um estoque de $N$ e $S$ capaz de ser fornecido às plantas, desde que ;sejam removidas as condições de acidéz, que impedem a sua pronta mineralização. Os potenciąis, calculados para $\mathrm{N}$ e $S$ mostram que os dois elementos não se mineralizam na mesma razão dos seus teores originalmente existentes nos solos (veja tabelas 3.1. e 4.5.). MAYNARD et alii (1983) igualmente observaram que a mineralização de $\mathrm{N}$ e $\mathrm{S}$ em proporções diversas: as razões $\mathrm{N}_{-} \mathrm{NO}_{3}^{-} / \mathrm{S}_{-} \mathrm{SO}_{4}=$ mineralizados por incubação aberta e fechada foram diferentes daquelas razões do $N$ orgânico / S orgânico da matéria orgânica dos so- 

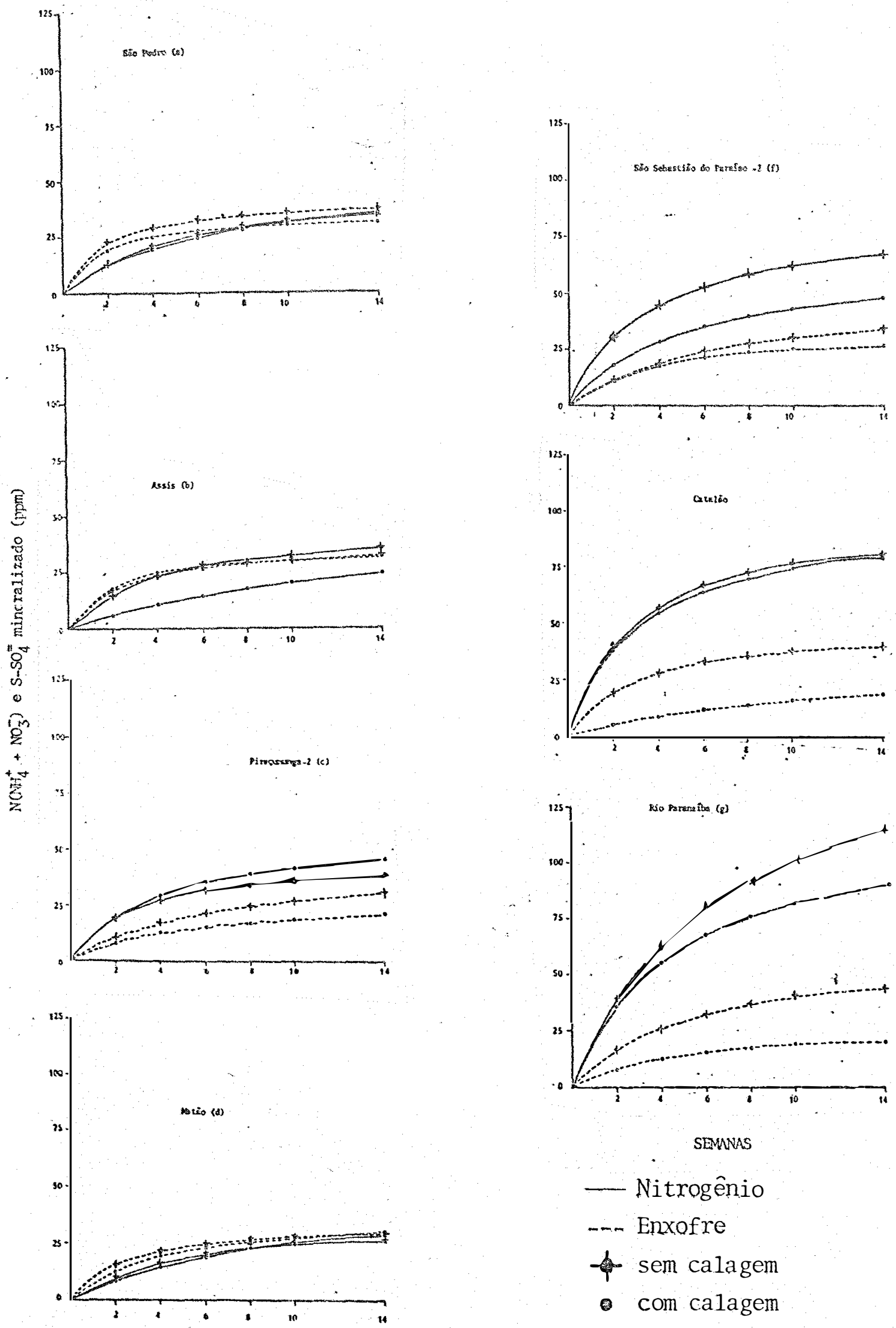

- Nitrogênio

.... Enxofre

- sem calagem

- com calagem

Figura 4.2 - Efeitos da incubação aberta e da calagem nạ quantidades acumuladas de enxofre $\left(\mathrm{S}_{-} \mathrm{SO}_{4}^{-}\right)$e nitrogênio $\left(\mathrm{N}_{-} \mathrm{NH}_{4}^{+}+\mathrm{NO}_{3}^{-}\right)$ mineralizados em função do tempo. 
los.

Existem vārios modelos matemáticos que podem ser usadas para estimar o $N$ e o $S$ cumulativamente mine ralizados em função do tempo (TABATABAI \& AL-KHAFAJI, 1980 ; STANFORD \& SMITH, 1972; MOLINA et alii, 1980; JUMA et alii, 1984). O potencial de mineralizaşão $\left(N_{0}\right)$ estimado pelos mo delos hiperbólico e exponencial de primeira ordem são considerados estimadores pobres para o rendimento de culturas e absorção de N. JUMA et alii (1984) verificaram que ambos os modelos estimam corretamente o $\mathrm{N}$ mineralizado durante 14 semanas de incubação, porém o $\mathrm{N}$ potencialmente mi. neralizável e a meia-vida do $N$ mineralizâvel são dependentes do modelo usado. LINDEMANN \& CARDENAS (1984) obtiveram valores muito variảveis para $k$, nos diferentes solos estudados para o modelo exponencial simples. MOLINA et: alii (1980) sugeriram que a mineralização de $\mathrm{N}$ deve ser vista como a decomposição de dois ou mais compostos com variáveis índices de mineralização, valendo-se de modelos estimadores de $\mathrm{N}$ mineralizável como sendo a soma de dois ou mais exponenciais para alguns solos. Com o modelo de duplo exponencial, o ajustamento obtido por LINDEMANN \& CARDENAS (1984) aos dados de observação foi mais preciso.

Nas condições desse experimento, o modelo hiperbólico ajustou-se estreitamente aos dados de minerali zação de $\mathrm{N}$ e $\mathrm{S}$, como se observa pelos coeficientes de determinação da tabela 4.5. No entanto, chama a atenção o fa to de como os potenciais de $N$ e $S$ são afetados diferente- 


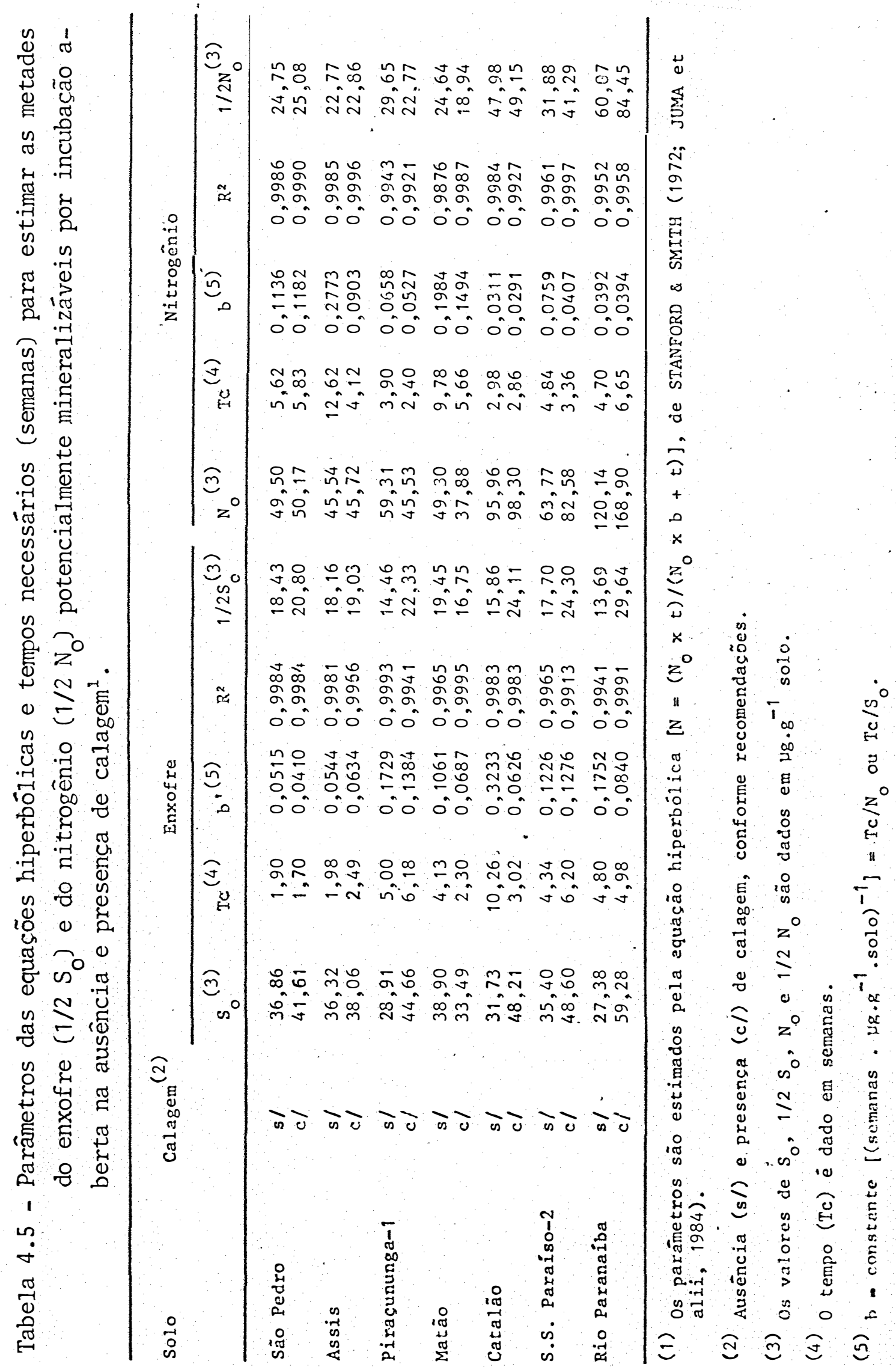


mente pela calagem nos solos mais argilosos de Catalão, São Sebastião do Paraíso-2 e Rio Paranaíba, sugerindo que uma fração de $\mathrm{N}$ e $\mathrm{S}$ é mineralizada por ação microbiológica e $\underline{u}$ ma parte adicional de $S \hat{e}$ disponibilizada por dessorção de $\mathrm{S}-\mathrm{SO}_{4}^{=}$, ambos incentivados pelo aumento do pH dos solos, como atestam os trabalhos de HARWARD \& REISENAUER (1966), WILLIAMS \& STEINBERGS (1967), BARROW (1970) e PROBERT (1976).

Nos solos de textura arenosa como Assis e São Pedro a calagem praticamente não exerceu influência so bre a mineralização de $\mathrm{N}$ e $\mathrm{S}$, indicando estoques reduzidos de $S$ e $N$ totais, com tendência ao rápido esgotamento, como mostra a reduzida meia-vida do enxofre mineralizävel (tabe 1a .5.). Nos solos de Matão e Catalão a calagem diminuiu a meia-vida do enxofre, mas intensificou a mineralização. Não havendo reposição, sob condições de cultivo exaustivo, ocorrerá o esgotamento do enxofre nativo dos solos. No so10 de Rio Paranaíba, com 60,2\% de argila e 3,03\% de carbono a calagem aumentou a mineralização líquida de $\mathrm{N}$ e $\mathrm{S}$, po rém a meia-vida de $S$ (potencialmente mineralizável) não se modificou significativamente, como ocorreu com a meia-vida do nitrögênio, indicando que parte do $N$ mineralizado porém de "pools" diferentes daqueles do enxofre. E interessante observar que no solo de Catalạo que o potencial de mineralização $\left(N_{0}\right)$ e a meia-vida do nitrogênio não foram alteradas pela calagem, ao contrário do que se observou para o enxofre. Esse fato sugere que cerca de $50 \%$ do enxofre disponibilizado é originārio de compostos outros que os sul- 
fo-nitrogenados (NEPTUNE et alii, 1975).

Comportamento diverso foi observado nos solos de Piraçununga-1 e São Sebastião do Paraíso-2. A calagem, alēm de intensificar a mineralização de enxofre, também prolongou a sua meia-vida. Nos dois solos verificou-se o contrário para a meia-vida do nitrogênio, todavia, não se encontrou explicação plausível para o menor potencial de mineralização de $\mathrm{N}\left(\mathrm{N}_{\mathrm{O}}\right)$ estimado na presença de calagem.

MCCILL \& COLE (1982) propuseram um modelo conceitual para explicar a dinâmica do enxofre orgânico nos solos, em que os mecanismos que estabilizam o C, N, P e S orgânicos, não são necessariamente comuns a todos os quatro elementos. Os autores propuseram que o $\mathrm{C}$ e o $\mathrm{N}$ são esta bilizados conjuntamente e mineralizados por mineralização biológica, enquanto que o Dorgânico e êsteres de $S$ são es tabilizados independentemente da fração orgânica principal e mineralizados por mineralização bioquímica. A mineralização biológica ê definida como a liberação de formas inor gânicas de $N$ e $S$ de materiais orgânicos durante a oxidação pelos microrganismos do solo para fornecer energia. A mineralização bioquímica resulta na liberação de fosfato e sulfato inorgânicos a partir de formas orgânicas através de catálise enzimātica exterior à membrana celular. Como tal, ela é fortemente controlado pelo suprimento e pela necessidade do elemento liberado (BETTANY \& STEWART, 1983).

Nos solos tropicais, altamente intemperizados parte significativa de enxofre, na forma de sulfato 
encontra-se adsorvido ao complexo coloidal, sendo sua dessorção fortemente dependente de $\mathrm{pH}$ e da presença de fosfatos (BARROW, 1970 ; HINGSTON et alii, 1972; PROBERT \& JONES, 1977). Os parâmetros da equação hiperbólica na tabela 4.5. deste experimento sugerem que nos solos latossolos argilosos de Catalão, São Sebastião do Paraíso-2 e Rio Paranaíba uma fração significativa de $S$ disponibilizado é prove-. niente do $\mathrm{S}_{-} \mathrm{SO}_{4}=$ dessorvido pelo aumento do $\mathrm{pH}$, além da fra ção orgânica mineralizada. Entretanto, para se conhecer a provável origem do $S$ formado disponîvel para as plantas $\vec{e}$ mister que se determinem as frações mais lábeis, como o $S$ redizíve1 em HI (GREGG \& GOH, 1978; TSUJI \& GOH, 1979) e a fração que- é dessorvida pela calagem (WILLIAMS, 1967; MARTINI \& MUTTERS, 1984 ; PROBERT, 1976).

\subsection{Mineralização aeróbica de S- $\mathrm{SO}_{4}=$ : efeitos de INCUBA CÃO ABERTA, NA AUSENCIA E PRESENÇA DE CALAGEM SO- BRE A ATIVIDADE ESPECIFICA DE ${ }^{35} \mathrm{~S}$}

Na figura 4.3. podemos observar os efeitos da incubação aberta, na ausência e presença de calagem, so bre a atividade especifica de ${ }^{35} \mathrm{~S}$ nos lixiviados com KCl $0,01 \mathrm{M}$, em função do tempo. A atividade inicial de ${ }^{35} \mathrm{~S}$ nas amostras incubadas foi de $0,62134 \mu \mathrm{Ci} \cdot \mathrm{g}^{-2}$ solo, por ocasião da primeira lixiviação. Na tabela 6 do apêndice, temos os dados de contagens por minuto (cpm $\times 1000 / \mathrm{ml}$ de $1 \mathrm{i}-$ 

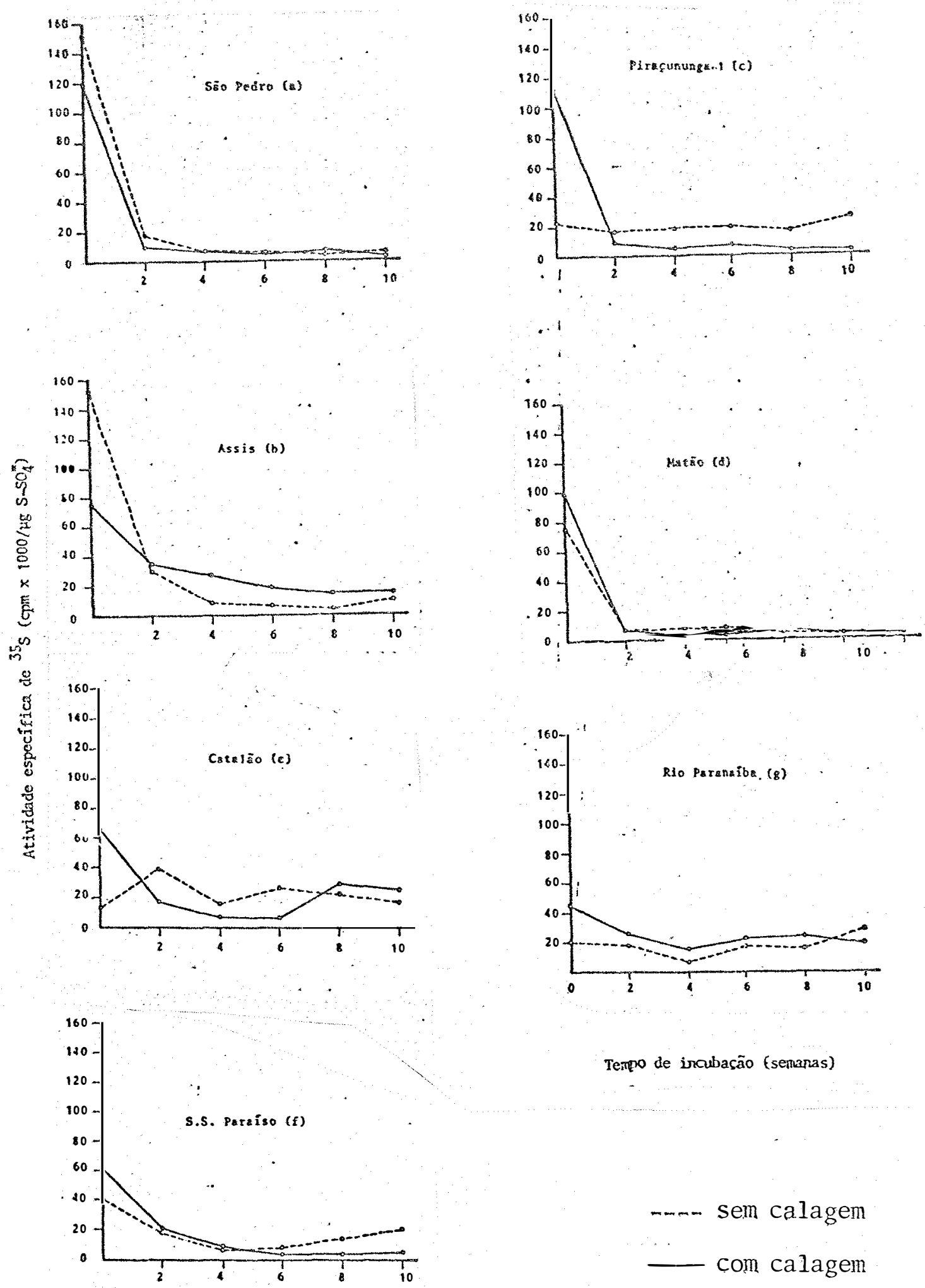

Terpo de ircubasão (semanas)

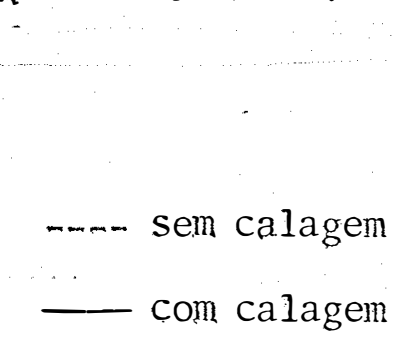

Figura 4.3 - Efeitos de incubạão aberta e da calagem na atividade especifica de ${ }^{35_{S}}$ (cpm $\times 1000 / \mu \mathrm{g} \mathrm{S}_{-} \mathrm{SO}_{4}=$ ) nos lixiviados em KCl $0,01 \mathrm{M}$ em função do tempo. 
xiviado) e atividade específica de ${ }^{35} \mathrm{~S}$ ( $\mathrm{cpm} \times 1000 / \mu \mathrm{g} \mathrm{S}-\mathrm{SO}_{4}^{=}$) e na figura 4.3. a evolução da atividade específica de ${ }^{35} \mathrm{~S}$ em função do tempo de incubação. Vếrse, de imediato, a fla grante diferença na atixidade especifica do ${ }^{35} \mathrm{~S}$ no $\cdots$, tempo "zero" de incubação entre os solos estudados. Enquanto que nos solos arenosos, como o de São Pedro e Assis se revelou mais elevada, nos solos latossolos argilosos de Cata 1ão, São Sebastião do Paraíso-2 e de Rio Paranaíba a ativi dade específica é significativamente mais baixa. Por outro lado, verifica-se, tambêm, que a calagem influi na ativida de especifica do $\mathrm{S}-\mathrm{SO}_{4}=$. Segundo BARROW \& SHAW (1977), COUTO et alii (1979) e SINGH (1984a,b) os teores de argila, ó xidos de ferro e alumínio, matéria orgânica, pH dos solos, extratores usados, temperatura e tempo de reação determinam a maior ou menor adsorção de $\mathrm{S}-\mathrm{SO}_{4}=$. Apesar de se neces sitarem de estudos mais específicos sobre adsorção de $\mathrm{S}_{-} \mathrm{SO}_{4}=$, os resultados deste experimento sugerem que a dessorção é inversamente proporcional aos teores de argila, matêria or gânica, pH e, principalmente, óxidos de ferro e alumínio.os dados de atividade específica de ${ }^{35}$ S mostram que a diluição isotópica apresenta, a partir da segunda lixiviação, diferenças maiores nos solos argilosos, sob efeito da cala gem. No solo de Catalão, os dados de atividade específica verificados da sexta para a dëcima semana de incubação, mos tram que a calagem acelera o processo de esgotamento do $S$ nativo. Isso é confirmado, observando-se a meia-vida do enxofre (tempo necessārio para mineralizar a metade do 
enxofre potencialmente mineralizâvel) que ficou reduzida a cerca de $30 \%$, isto $\vec{e}$, de 10,26 semanas na ausência de cala gem para 3,02 semanas na presença de calagem (veja tabeia 4.5.). No solo de Piraçununga-1, verifica-se um fato diverso: a calagem aumenta o potencial de mineralização de enxo fre, mas também prolonga a meia-vida. A atividade específi ca de ${ }^{35} \mathrm{~S}$, na ausência de calagem praticamente se torna es tacionária da segunda para oitava semana de incubação, a partir do qual então torna a aumentar, indicando o esgotamento do enxofre mineralizầvel, como se observa pelas figú ras $4.2 \cdot(a-g)$ e $4.3 .(a-g)$. No solo de São Sebastião do Paraíso-2 a ausência e presença de calagem fez a atividade específica decair atê a sexta semana de incubação: a partir daí, a presença da calagem faz a atividade específica de ${ }^{35}$ S estabilizar, enquanto que a sua ausência fá-la subir. Comparando-se as figuras 4.2 . (f) e 4.3 . (f) e tabela 4.5., nota-se que aumentaram o potencial de mineralização e a meia-vida do enxofre em função da calagem, explicando-se, assim, o aumento da atividade específica nos lixiviados a partir da sexta semana de incubação. No solo de Rio Paranaíba verificou-se queda na atividade de ${ }^{35} \mathrm{~S}$ a té a quar ta semana de incubação. A partir da quarta semana, na ausência de calagem, o aumento na atividade específica se torna nítida: a mineralização é praticamente inexpressiva, como se pode visualizar pelas figuras 4.2. (a-g) e 4.3. (a-g) . Nesse solo, embora a meia-vida do enxofre não tenha mostra do alteração significativa pela calagem, houve aumento su- 
perior a $100 \%$ no potencial de mineralização do enxofre - $\mathrm{S}_{\mathrm{O}}$ com a sua presença (veja tabela 4.5.).

Nos solos arenosos de'São Pedro e Matão, em bora se tenham observado diferenças na atividade especifica do ${ }^{35}$ S no tempo "zero" de incubação na ausência e presença de calagem, a partir da segunda semana de incubação tal diferença não mais se observou [figura 4.3. (c) e (d)]. A pequena diferença nas atividades especificas de ${ }^{35}$, por influência da calagem, verificada nesses dois solos justifica a diferença não significativa dos respectivos potenciais de mineralização de enxofre - $S_{0}$ (veja tabela 4.5.). Todavia, não se encontrou explicação plausível para a maior atividade especifica inicial de ${ }^{35} \mathrm{~S}$ no solo de Assis (figura 4.3. b), que foi maior na ausência de calagem, apesar de os potenciais de mineralização de enxofre serem praticamente iguais sem e com calagem.

De um modo geral, a diluição isotópica de ${ }^{35} \mathrm{~S}$ e a mineralização de enxofre dos solos observadas nesse experimento se estabilizam por volta da oitava semana de incubaşão, tanto na ausência como na presença de calagem, o que concorda com os valores encontrados por $\mathrm{GOH} \&$ TSUJI (1979) e MAYNARD et alii (1983b).

\subsection{EfEITOS DA CALAGEM, ENXOFRE E CULTIVOS NA PRODU- ÇÃO DE MATÉRIA SECA E ABSORCÃO DE ENXOFRE}

Na tabela 4.6. tem-se o quadro de análise 


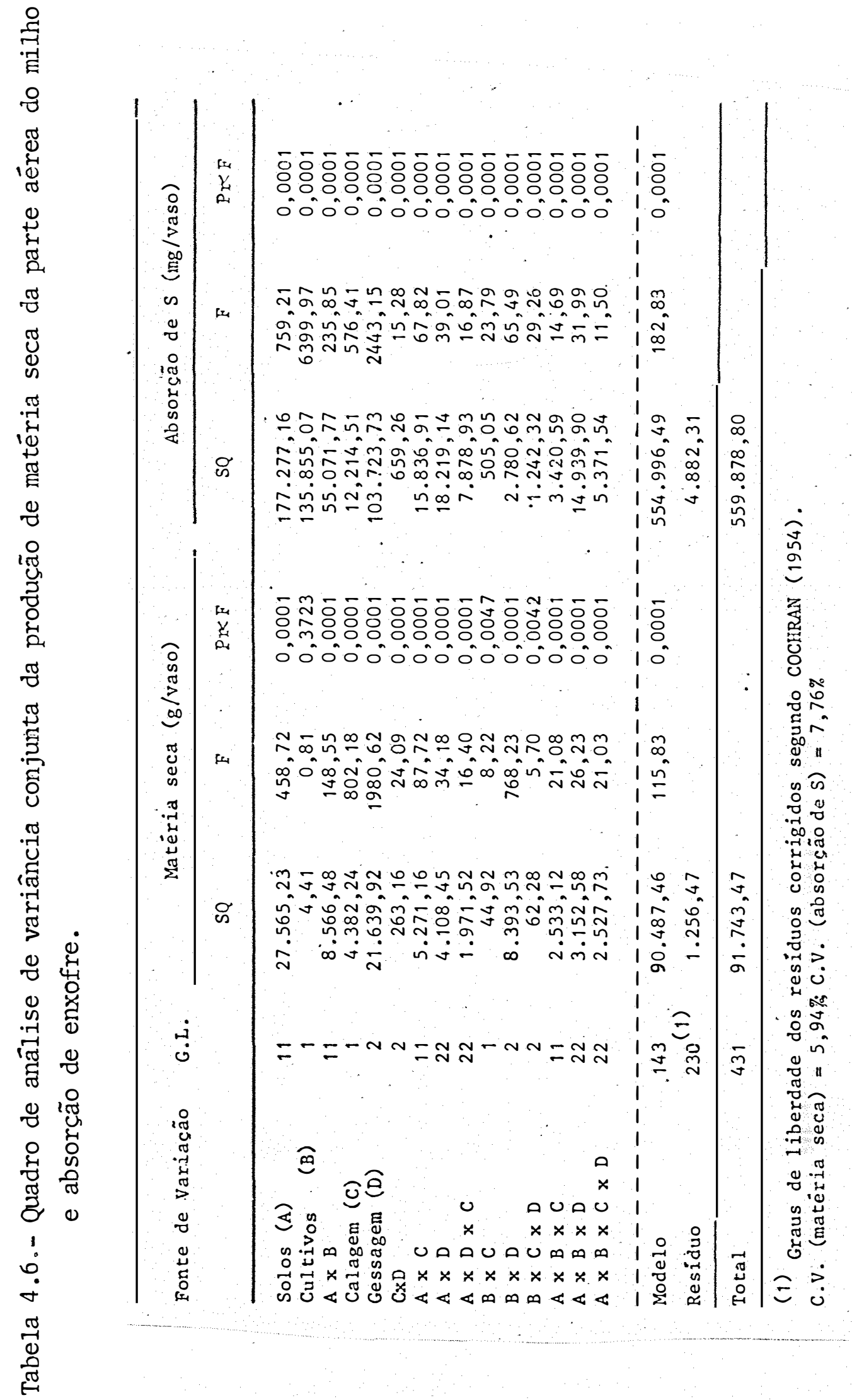


da variância da produção de matêria seca e absorção de enxofre pelo milho. A alta significância de $F$ deve-se aos di ferentes potenciais de produção dos solos (tabela 4.7.), ao fornecimento abundante de ägua e nutrientes e à alta tempe ratura na casa-de-vegetação durante os cultivos. Todas as interações observadas entre solos, cultivos, calagem e ges sagem demonstram a desigual capacidade de suprimento do en xofre pelos solos. Por outro lado chama a atenção a nãosignificância de $F$ da produção de matéria seca e a alta significância de F da absorção de enxofre pelo milho em função dos dois cultivos. Nas condições do experimento, as altas quantias de N, P, K e micronutrientes aplicados antes dos cultivos e de $\mathrm{N}$ e $\mathrm{K}$ em cobertura forçaram o luxuriante crescimento do milho, levando ao esgotamento do enxofre nativo e aplicado aos solos. Na tabela 4.7. verifica-se que, embora, as diferenças significativas nas produções médias de matéria seca analisando cada solo individualmente, tenham sido ora maiores no primeiro cultivo, ora no segundo, as diferenças na absorção de enxofre foram sistematicamente menores no segundo cultivo em todos os so los. Depreende-se daí que ocorreu esgotamento do enxofre nativo e aplicado aos solos. BETTANY et alii (1974) verifi caram que a absorção de enxofre pela alfafa, em função da adubação sulfatada, mostrou diferenças significativas em solos muito deficientes a partir do primeiro corte; nos so los com maior poder de suprimento de enxofre, as diferenças nas produçōes de matêria seca e absorção de enxofre 
somente se tornaram significativas a partir do terceiro cor te. FREITAS \& JORGE (1982) obtiveram respostas significati vas de produção de matêria seca de [Cynodon dactiylon (L.) Pers.] à aplicação de enxofre a partir do terceiro ano, apesar de o solo estudado (LVd, Matão, SP) ter baixo teor de matêria orgânica.

$\mathrm{Na}$ anâlise conjunta dos dois cultivos, por solo, notam-se, pela produção de matêria seca e absorção de enxofre, grandes diferenças na capacidade de suprimento de enxofre. Essa evidência ê complementada se considerados os efeitos da calagem e da gessagem nos dois cultivos. A diferença não significativa da produção de matéria seca den tro de cultivos, porém significativa dentro de calagem, mos tra que o enxofre nativo é insuficiente para o rendimento máximo do milho. Por outro lado, a diferença altamente sig nificativa na absorção de enxofre, dentro de calagem e den tro de cultivos demonstra que há disponibilização de enxo fre nativo, via correção da acidez, o que é confirmado pe10 aumento dos potenciais de mineralização de enxofre de alguns solos pela calagem, como consta na tabela 4.5. MARTINI \& MUTTERS (1984), verificaram que a calagem, nos níveis normalmente recomendados nara solos costeiros da Caro lina do Sul (USA), aumenta a produção de matéria seca e ab sorção de enxofre pelo milho. Todavia, dobrando-se as doses recomendadas, a calagem deprimiu o crescimento e a absorção de enxofre, por causa da maior quantidade de $\mathrm{S}_{-} \mathrm{SO}_{4}=$ Iixiviados dos solos para os pratos de drenagem. 
O esgotamento progressivo do enxofre nativo aplicado aos solos é evidenciado pela interação da gessa gem $x$ cultivos e pela interação trinla da calagem. gesso (veja tabela 4.6. e tabela 4.7.). A produção de matêria seca de milho em vasos, em função das doses de gessagem não se constituiu, nas condições desse experimento, em bom indicador de exportação do enxofre dos solos, por causa do efeito diluigor das altas quantias de $\mathrm{N}$ e $\mathrm{K}$ aplicados. JANZEN \& BETTANY (1984) atribuem às altas doses de $\mathrm{N}$ e ao insuficiente suprimento de $\mathrm{S}$ a acumulação de metabólitos tóxicos de $\mathrm{N}$ e a depressão da produção de sementes de colza (Brassica napus). Nas condições desse experimento, a absorção de enxofre pelo milho è coerente com a evolução dos teores de $\mathrm{S}_{-} \mathrm{SO}_{4}=$ disponível nos solos (figuras 3.1 .1$. a 3.1.3.): todo o $S$ aplicado foi prontamente exportado pelo milho, uma vez que o $\mathrm{S}_{-} \mathrm{SO}_{4}^{=}$estimado pelos extratores mostrou-se praticamente igual em todas doses de gesso apôs o segundo cultivo.

As quantidades de enxofre absorvido pelo mi Tho de cada solo, individualmente, mostram diferentes potenciais de suprimento de enxofre às plantas. Comparando- se os dados das tabelas 3.1., 4.5. e 4.7. é possível estabe lecer relações entre absorção de enxofre e teores de carbo no, enxofre total e potenciais de mineralização de enxofre. Na tabela 4.7. constata-se que o solo de Catalão foi o que forneceu a maion quantidade de enxofre (sem isolar o efeito da calagem), seguido dos solos São Sebastião do 


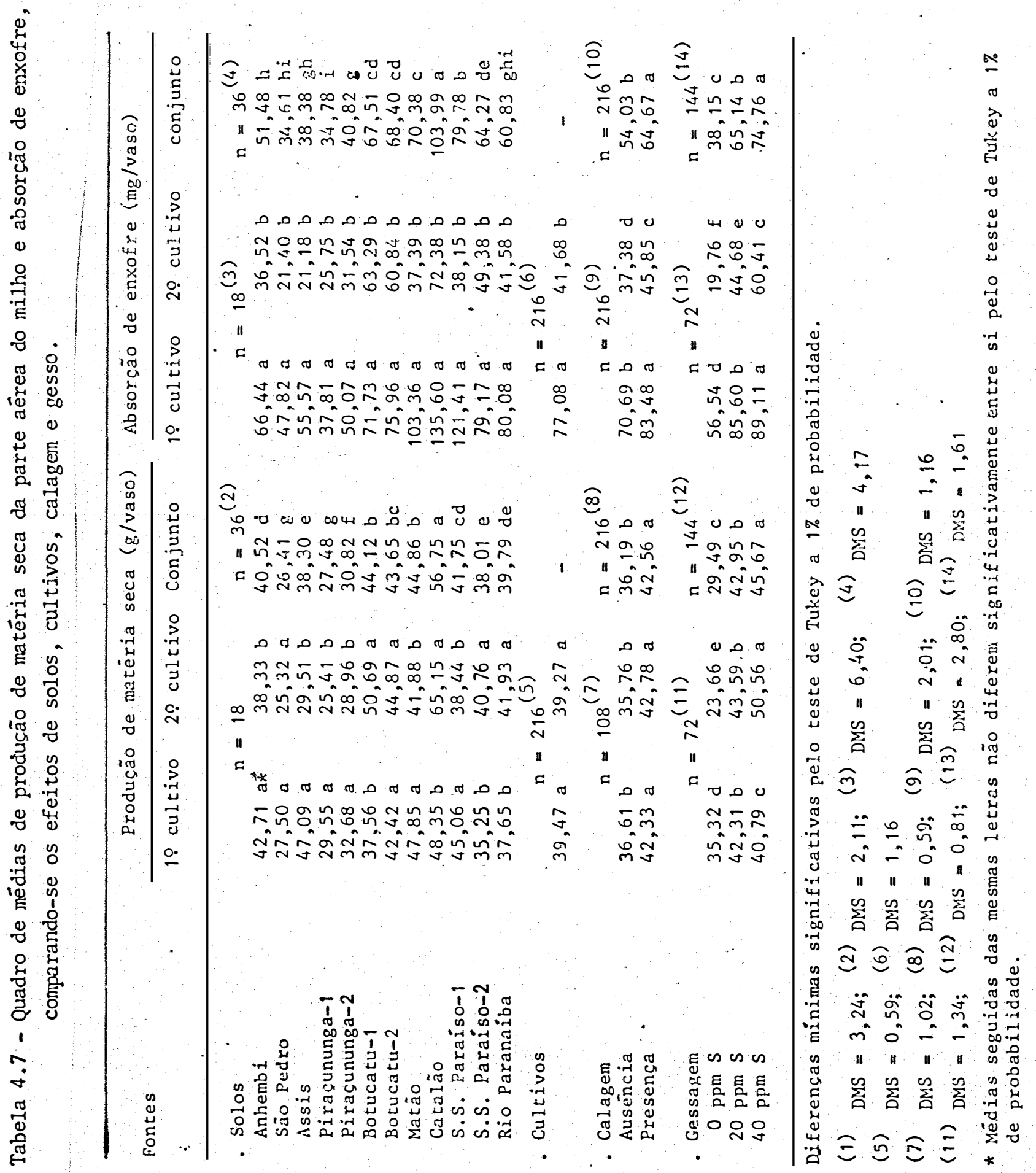


Paraíso-1, Matão, Botucatu-r, Botucatu-2, São Sebastião do Paraíso-2 e Rio Paranaíba. Os solos restantes (mais arenosos e com menores teores de carbonol absorveram as quantidades menores de enxofre. No entanto; é essencial que se levem em conta os efeitos da calagem e dos cultivos para valiar o potencial de fornecimento de enxofre, como será mostrado nas seções 4.5 . e 4.7. , em que serão estudadas as curvas de resposta ao gesso e as relações entre a absorção de enxofre versus teores de carbono, enxofre total e potenciais de mineralização.

\subsection{CuRvas de RESPOSta AO gesso na ausencia e PRESEN CA DE CALAGEM; EM DOIS CULTIVOS SUCESSIVOS DOS SO- LOS}

4.5.1. DOSES DE GESSO VERSUS PRODUCÃ̃O DE MATÉRIA SECA DA PARTE ÁÉREA DO MILHO

Na tabela 4.8. estão 1 istadas as equações de regressão das curvas de resposta da produção de matéria seca da parte aérea do milho (g/vaso) versus doses de gesso $(0,20$ e $40 \mathrm{ppm}$ de S $)$. De imediato, constata-se que os interceptos das equações de regressão na presença de calagem são mais elevados do que na ausência de:calagem, tanto, no primeiro quanto no segundo cultivo. Nos solos mais arenosos e com menores teores de carbono (no 1 a 6 da ta- 
Tabela 4.8 - Curvas de resposta da produção de matéria seca (g/vaso) versus doses de gesso. $(0,20$ e 40 ppm S), na auséncia e presença de calagem e em dois cultivos dos solos, de forma individual e conjunta.

\begin{tabular}{|c|c|c|c|c|c|c|c|c|}
\hline Solos & Calagew & $\begin{array}{c}\text { Cultivo } \\
\text { (ne) }\end{array}$ & Equacäo de regressäo & $\begin{array}{l}\text { nP de } \\
\text { peres }\end{array}$ & $\mathrm{R}^{\mathbf{2}}$ & $p<a$ & $x_{\operatorname{mix} .}{ }^{(2)}$ & $y_{\text {sisx. }}{ }^{(2)}$ \\
\hline 1-Anhembi & $\begin{array}{l}: 1(1) \\
: 1 \\
c 1 \\
c 1\end{array}$ & $\begin{array}{l}1 \\
2 \\
1 \\
2\end{array}$ & 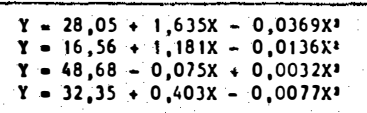 & $\begin{array}{l}9 \\
9 \\
9 \\
3\end{array}$ & $\begin{array}{l}0,9532 \\
0,9740 \\
0.3289 \\
0.9625\end{array}$ & $\begin{array}{l}0,01 \\
0,01 \\
n g \\
0,01\end{array}$ & $\begin{array}{l}22,15 \\
43,42 \\
26,30\end{array}$ & $\begin{array}{l}46.15 \\
42,20 \\
37,58\end{array}$ \\
\hline 2-Sío Pedro & $\begin{array}{l}: 1 \\
81 \\
c 1 \\
c 1\end{array}$ & $\begin{array}{l}1 \\
2 \\
1 \\
2\end{array}$ & $\begin{array}{l}Y=25,25=4,865 x+0,0857 X^{1} \\
Y=16,50+0,068 x-0,0074 X^{2} \\
Y=30,23=0,140 x+0,0054 X^{2} \\
Y=23,81+0,030 x+0,0041 X^{2}\end{array}$ & $\begin{array}{l}9 \\
9 \\
9 \\
9\end{array}$ & $\begin{array}{l}0,2356 \\
0,9485 \\
0,6996 \\
0,7770\end{array}$ & $\begin{array}{l}\text { ne } \\
0.01 \\
0.05 \\
0.05\end{array}$ & $\because 5$ & 16.65 \\
\hline 3-Aseis & $\begin{array}{l}\because 1 \\
\because 1 \\
c 1\end{array}$ & $\begin{array}{l}1 \\
2 \\
1 \\
2\end{array}$ & 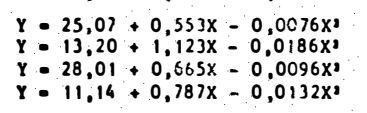 & $\begin{array}{l}9 \\
9 \\
9 \\
9\end{array}$ & $\begin{array}{l}0,0593 \\
0.9678 \\
0,9392 \\
0,9318\end{array}$ & $\begin{array}{l}0,01 \\
0,01 \\
0,01 \\
0,01\end{array}$ & $\begin{array}{l}.36,29 \\
30,19 \\
34,63 \\
29,82\end{array}$ & $\begin{array}{l}35,10 \\
30,15 \\
39,52 \\
22,87\end{array}$ \\
\hline 4-Piracununga-1 & $\begin{array}{l}81 \\
81 \\
c 1 \\
c 1\end{array}$ & $\begin{array}{l}1 \\
2 \\
1 \\
2\end{array}$ & $\begin{array}{l}Y=23,44+0,183 X-0,0032 X^{2} \\
Y=9,90+1,670 x=0,0266 X^{2} \\
Y=34,58+0,0056 x-0,0008 X^{2} \\
Y=8,61+1,856 x-0,0322 X^{2}\end{array}$ & $\begin{array}{l}9 \\
9 \\
9 \\
9\end{array}$ & $\begin{array}{l}0.4873 \\
0.9776 \\
0.0835 \\
0.9274\end{array}$ & $\begin{array}{l}n s \\
0,01 \\
n 8 \\
0,01\end{array}$ & $\begin{array}{r}28,77 \\
31,40 \\
3,27 \\
29,00\end{array}$ & $\begin{array}{l}26.06 \\
35,72 \\
34.55 \\
35,52\end{array}$ \\
\hline S-Piracununga-2 & $\begin{array}{l}\because 1 \\
\because 1 \\
c 1\end{array}$ & $\begin{array}{l}1 \\
2 \\
1 \\
2\end{array}$ & $\begin{array}{l}Y=24,01+0,813 x=0,0139 x^{2} \\
Y=10,10+1,509 x=0.02222 x \\
Y=24,67+1,375 x=0,0267 x \\
Y=11,08+2,179 x-0,0333 x^{2}\end{array}$ & $\begin{array}{l}9 \\
9 \\
9 \\
9\end{array}$ & $\begin{array}{l}0,9446 \\
0,9902 \\
0,9186 \\
0,9958\end{array}$ & $\begin{array}{l}0,01 \\
0.01 \\
0,01 \\
0.01\end{array}$ & $\begin{array}{r}29,20 \\
-\quad 34,00 \\
25,75 \\
32,72\end{array}$ & $\begin{array}{l}35,90 \\
35,78 \\
42,38 \\
46,76\end{array}$ \\
\hline 6-Botucatu-1 & $\begin{array}{l}\because 1 \\
\text { cl } \\
c 1\end{array}$ & $\begin{array}{l}1 \\
2 \\
1 \\
2\end{array}$ & $\begin{array}{l}y=33,97-0,164 x+0,0043 x^{2} \\
y=33,90=0,208 x+0,0201 x^{2} \\
y=43,37=0,012 x=0,0030 x \\
y=38,58 \div 1,0117 x=0,0202 x^{2}\end{array}$ & $\begin{array}{l}9 \\
9 \\
9 \\
9\end{array}$ & $\begin{array}{l}0,5567 \\
0.9843 \\
0,7334, \\
0.9940\end{array}$ & $\begin{array}{l}n 8 \\
0.01 \\
0,03 \\
0,01\end{array}$ & $\begin{array}{c}- \\
2,03 \\
42,47\end{array}$ & $\begin{array}{l}- \\
63,90 \\
65.02\end{array}$ \\
\hline 7-Butucatu-2 & $\begin{array}{l}: 1 \\
: 1 \\
c 1\end{array}$ & $\begin{array}{l}1 \\
2 \\
1 \\
2\end{array}$ & $\begin{array}{l}Y=35,47+1,342 x-0,0325 x^{2} \\
Y=30,21+0,774 x-0,0227 x^{2} \\
Y=42,64+0,2985 x-0,00662 \\
Y=42,07+2,581 x-0,0528 x^{2}\end{array}$ & $\begin{array}{l}9 \\
9 \\
9\end{array}$ & $\begin{array}{l}0,9306 \\
0,8855 \\
0.652 . \\
0.977 \%\end{array}$ & $\begin{array}{l}0,01 \\
0.09 \\
0.05 \\
0.01\end{array}$ & $\begin{array}{l}20,61 \\
17,05 \\
22,51 \\
24,43\end{array}$ & $\begin{array}{l}49,28 \\
36,80 \\
46,00 \\
74,28\end{array}$ \\
\hline B-matao & $\begin{array}{l}: 1 \\
\because 1 \\
c 1 \\
c 1\end{array}$ & $\begin{array}{l}1 \\
2 \\
1 \\
2\end{array}$ & $\begin{array}{l}Y=46,73+0,902 x-0,0204 X_{1} \\
Y=19,20 \div 3,540 x=0,0658 X^{2} \\
Y=41,65+1,083 x-0,0282 X^{2} \\
Y=13,99+1,406 x-0,0068 X^{2}\end{array}$ & $\begin{array}{l}9 \\
9 \\
9 \\
9\end{array}$ & $\begin{array}{l}0,8291 \\
0.9921 \\
0.9143 \\
0,9843\end{array}$ & $\begin{array}{l}0,01 \\
0,01 \\
0,01 \\
0,01\end{array}$ & $\begin{array}{l}22,10 \\
26,90 \\
19,20\end{array}$ & $\begin{array}{l}56,65 \\
66.82 \\
52.04\end{array}$ \\
\hline 9-Catalèo & $\begin{array}{l}\because 1 \\
: 1 \\
c^{\prime}\end{array}$ & $\begin{array}{l}1 \\
2 \\
1 \\
2\end{array}$ & $\begin{array}{l}y=40,90+0,411 x-0,0107 x^{\prime} \\
y=28,94+1,381 x \\
y=55,07=0,0162 x \\
y=66,73 \div 0,524 x-0,0052 x\end{array}$ & $\begin{array}{l}9 \\
9 \\
9\end{array}$ & $\begin{array}{l}0,8101 \\
0,9803 \\
0,0737 \\
0,8192\end{array}$ & $\begin{array}{l}0,01 \\
0,01 \\
n 8 \\
0.01\end{array}$ & $\begin{array}{l}19.11 \\
:-71\end{array}$ & $\begin{array}{l}44,53 \\
80,03\end{array}$ \\
\hline 10-S.S.Paraiso-1 & $\begin{array}{l}: 1 \\
: 1 \\
c 1\end{array}$ & $\begin{array}{l}1 \\
1 \\
1 \\
2\end{array}$ & 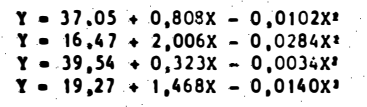 & $\begin{array}{l}9 \\
9 \\
9 \\
9\end{array}$ & $\begin{array}{l}0.9384 \\
0.9752 \\
0.8611 \\
0.99: 5\end{array}$ & $\begin{array}{l}0.01 \\
0,01 \\
0.01 \\
0.01\end{array}$ & $\begin{array}{l}39,61 \\
35,31 \\
46,81 \\
52,43\end{array}$ & $\begin{array}{l}53,05 \\
51,96 \\
47,12 \\
57,75\end{array}$ \\
\hline II-S.S.Paralso-2 & $\begin{array}{l}\because 1 \\
\because 1 \\
c 1\end{array}$ & $\begin{array}{l}1 \\
2 \\
1 \\
2\end{array}$ & 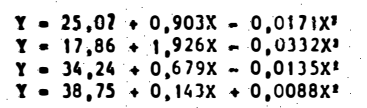 & $\begin{array}{l}9 \\
9 \\
9\end{array}$ & $\begin{array}{l}0.8299 \\
0.9288 \\
0.9427 \\
0.9540\end{array}$ & $\begin{array}{l}0,01 \\
0,01 \\
0.01 \\
0.01\end{array}$ & $\begin{array}{l}26,36 \\
28,98 \\
25,12 \\
7\end{array}$ & $\begin{array}{l}36,97 \\
45,76 \\
42,29 \\
2\end{array}$ \\
\hline 12-kio Paranalue & $\begin{array}{l}: 1 \\
\vdots 1 \\
c 1 \\
c 1\end{array}$ & $\begin{array}{l}1 \\
2 \\
1 \\
2\end{array}$ & 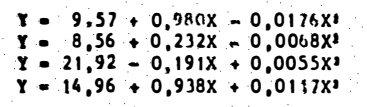 & $\begin{array}{l}9 \\
9 \\
9 \\
9\end{array}$ & $\begin{array}{l}0,951.0 \\
0,981,8 \\
0,4816 \\
0,9894\end{array}$ & $\begin{array}{l}0,01 \\
0,01 \\
\text { ne } \\
0,01\end{array}$ & $\begin{array}{l}21,26 \\
40,11\end{array}$ & $\begin{array}{c}23,10 \\
33,21\end{array}$ \\
\hline Soloe de 1.6 & $\begin{array}{l}\because 1 \\
c 1 \\
c 1\end{array}$ & $\begin{array}{l}1 \\
2 \\
1 \\
2\end{array}$ & $\begin{array}{l}y=26,20+0,649 x-0,0111 x^{2} \\
y=17,64+1,027 x=0.0098 x^{2} \\
y=36,92+0,0202 x=0.0046 x^{2} \\
y=20,56+1,229 x=0,0163 x^{2}\end{array}$ & $\begin{array}{l}54 \\
54 \\
54 \\
54\end{array}$ & $\begin{array}{l}0,1835 \\
0,4794 \\
0,0565 \\
0.4485\end{array}$ & $\begin{array}{l}0,05 \\
0,01 \\
\text { no } \\
0,01\end{array}$ & $\begin{array}{l}17,00 \\
52,40 \\
37,70\end{array}$ & $\begin{array}{l}34,02 \\
44,55 \\
43,72\end{array}$ \\
\hline Soloz de $7=12$ & $\begin{array}{l}\because 1 \\
81 \\
c 1\end{array}$ & $\begin{array}{l}1 \\
2 \\
1 \\
2\end{array}$ & $\begin{array}{l}x=33,43+1,082 x=0,0222 x^{2} \\
y=21,38+1,714 x=0.0237 x \\
y=42,55+0,334 x=0.069 x^{2} \\
y=31,60+1,569 x=0,0195 x\end{array}$ & $\begin{array}{l}54 \\
54 \\
54 \\
54\end{array}$ & $\begin{array}{l}0,3125 \\
0,5208 \\
0 ; 0730 \\
0,4548\end{array}$ & $\begin{array}{l}0,01 \\
0,01 \\
\text { ne } \\
0,01\end{array}$ & $\begin{array}{l}35.45 \\
36.16 \\
24.20 \\
40.23\end{array}$ & $\begin{array}{l}44.84 \\
52,37 \\
46,60 \\
63,16\end{array}$ \\
\hline
\end{tabular}

(1) Musencie (a/) a presenga (c/) de calagew, conforme recomendacöes.

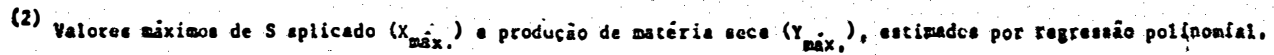


bela 4.8.), na ausência de calagem, os interceptos das equações de regressão conjunta foram de $26,2 \mathrm{~g} /$ vaso para o primeiro e segundo cultivos. Nos solos mais argilosos, com teores de carbono maiores que $1,2 \%(n \% s \quad 7$ a 12) os intercep tos acusaram valores de cerca de 30 a $50 \%$ superiores aos dos solos arenosos, referentes aos mesmos tratamentos. Os valores de enxofre mâximos ( $x_{\max }$, na tabela 4.8.) que estimam a produção mảxima de matéria seca no primeiro cujtívo, nos solos arenosos(nos 1 a 6 ) na ausência de calagem, fói igual a 17 ppm de $S$ aplicadas, elevando-se para 52,4 ppm no segundo cultivo; na presença de calagem, os valores de enxofre máximos foram de 32,9 nnm de $S$ no primeiro cultivo e 37,7 ppm no segundo cultivo. Nos solos com teores de car bono superiores a $1,2 \%$, os valores de enxofre máximos, na ausência de calagem, foram de 15,4 ppm de $S$ no primeiro e de 36,2 ppm no segundo cultivo; na presença de calagem obtiveram-se valores de 24,2 e 40,2 ppm de $S$, respectivamente. Entretanto,os valores de enxofre $\left(x_{\max .}\right)$, que estimam a produçao máxima de matéria seca da parte aérea do milho, na presença de calagem no primeiro cultivo, não são valores confiáveis, como mostram os coeficientes de determina ção respectivos. Podem-se apontar como causas da não signi ficância a variada resposta dos solos à calagem e a consequente disponibilização de enxofre(mineralização de $S$ orgâa nico e dessorção de $\mathrm{S}_{-} \mathrm{SO}_{4}^{-}$) e diferentes volumes de solo ex plorado, porque o experimento foi conduzido com base no peso dos solos. MC CLUNG et a 1 ii (1959) observaram aumento de 
produção de matéria seca de milheto com aumento do volume dos solos, porém com concentrações iguais de enxofre, de 1 para 2 vezes; todavia, quando se aumentaram os volumes dos solos de 2 para 4 vezes, a nrodução se manteve constante. O formato das curvas de resposta foi essencialmente igual pąra todos os volumes.

Nas condições desse experimento observou-se em ambos ne cultivos grande acûmulo de raízes nos fundos dos vasos, o que tambêm foi constatado por McCIUNG et alii (1959),utilizando vasos de tamanho médio e pequeno. Devido às limitações do sistema radicular em experimentos de vasos, o potencial de fornecimento de qualquer nutriente deve ser estimado através das quantidades retiradas do solo pelo elemento em estudo(GASSER,1963).

\subsubsection{DOSES DE GESSO VERSUS ABSORCÃO DE ENXO- FRE PELA PARTE AEREA DO MILHO}

$\mathrm{Na}$ tabela 4.9 encontram-se as equações de regressão da absorção de enxofre pela pạrte aérea do milho (mg/vaso) versus doses de gesso $(0,20,40 \mathrm{ppm}$ de $\mathrm{s})$. Ao conträrio da produção de matêria seca, na absorção de enxo fre pelo milho, os interceptos das equações de regressão (dose zero de gesso aplicado aos solos) mostram-se sistematicamente significativos na ausência e presença de calagem e dentro de cada cultivo. O efeito da calagem, como já foi discutido em secções anteriores, deve-se à disponi- 
Tabela 4.9 - Curvas de respostas de absorção de enxofre (ng/S/vaso)

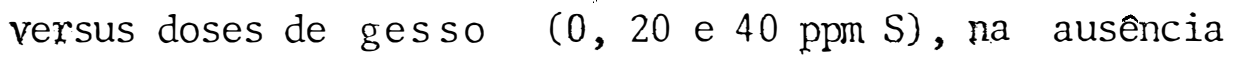
e presença de calagem e em dois cultivos dos solos, de for ma individual e conjunta.

\begin{tabular}{|c|c|c|c|c|c|c|c|c|}
\hline Solo: & Calegem & $\begin{array}{c}\text { Cultivo } \\
\text { (n8) }\end{array}$ & Equaçäo de Regressāo & $\begin{array}{l}\text { NP de } \\
\text { pares }\end{array}$ & $R^{2}$ & $p<a$ & $x_{\operatorname{mix}}{ }^{(2)}$ & $y_{\text {mix. }}{ }^{(2)}$ \\
\hline 1-Anhemb| & $\begin{array}{l}8(1) \\
81 \\
c 1 \\
c 1\end{array}$ & $\begin{array}{l}1 \\
2 \\
1 \\
2\end{array}$ & $\begin{array}{l}Y=35,70+2,270 x-0,0439 x^{2} \\
Y=11,6,+1,810 x=0,0209 x^{2} \\
Y=72,70+1,590 x=0,034 x^{2} \\
Y=18,30+1,050 x\end{array}$ & $\begin{array}{l}9 \\
9 \\
9\end{array}$ & $\begin{array}{l}0,9979 \\
0,9977 \\
0,8763 \\
0,9550\end{array}$ & $\begin{array}{l}0,01 \\
0,01 \\
0,01 \\
0,01\end{array}$ & $\begin{array}{l}25,85 \\
23,11 \\
43,18 \\
-\end{array}$ & $\begin{array}{l}65,11 \\
50,57 \\
90,54 \\
-\end{array}$ \\
\hline 2-Sio Pedro & $\begin{array}{l}: 1 \\
11 \\
c 1 \\
c 1\end{array}$ & $\begin{array}{l}1 \\
2 \\
1\end{array}$ & $\begin{array}{l}Y=30,63+0,900 x-0,0070 x^{2} \\
Y=12,60 \div 0,027 x+0,0115 x^{2} \\
Y=65,37+0,736 x=0,013 x^{2} \\
Y=14,23+0,637 x-0,0059 x^{2}\end{array}$ & $\begin{array}{l}9 \\
9 \\
9\end{array}$ & $\begin{array}{l}0,9848 \\
0,9687 \\
0,8012 \\
0,9602\end{array}$ & $\begin{array}{l}0,01 \\
0,01 \\
0,01 \\
0,01\end{array}$ & $\begin{array}{l}64,28 \\
28,64 \\
54,26\end{array}$ & $\begin{array}{l}59,56 \\
56,19 \\
31,51\end{array}$ \\
\hline 3-Assis & $\begin{array}{l}: 1 \\
: 1 \\
c 1 \\
c 1\end{array}$ & $\begin{array}{l}1 \\
2 \\
1 \\
2\end{array}$ & $\begin{array}{l}Y=28,67+1,610 X-0,0100 x 8 \\
Y=11,33+1,352 x=0,0189 x^{2} \\
Y=31,97+0,792 x+0,0141 x^{2} \\
Y=8,40+0,411 x\end{array}$ & $\begin{array}{l}9 \\
g \\
9 \\
9\end{array}$ & $\begin{array}{l}0,9885 \\
0.9790 \\
0.9919 \\
0.9394\end{array}$ & $\begin{array}{l}0.01 \\
0.01 \\
0,01 \\
0,01\end{array}$ & $\begin{array}{c}71,40 \\
35,47 \\
=\end{array}$ & $\begin{array}{r}86,86 \\
35,50 \\
\because \\
-\end{array}$ \\
\hline 4-Pira sununga-1 & $\begin{array}{l}81 \\
: 1 \\
c 1 \\
c 1\end{array}$ & $\begin{array}{l}1 \\
2 \\
1 \\
2\end{array}$ & $\begin{array}{l}x=19,40+1,630 x-0,0247 x^{2} \\
Y=6,83+1,060 x-0,0,0027 x^{2} \\
Y=31,09+0,500 x-0,000,36+0,701 x\end{array}$ & $\begin{array}{l}9 \\
g \\
g\end{array}$ & $\begin{array}{l}0,9881 \\
0,9912 \\
0,835 \\
0,9244\end{array}$ & $\begin{array}{l}0,01 \\
0,01 \\
0,01 \\
0,01\end{array}$ & $\begin{array}{l}32,99 \\
93,60 \\
-\end{array}$ & $\begin{array}{l}42,29 \\
43,70 \\
=\end{array}$ \\
\hline S-Piresununga-2 & $\begin{array}{l}: 1 \\
: 1 \\
c 1 \\
c 1\end{array}$ & $\begin{array}{l}1 \\
2 \\
1 \\
2\end{array}$ & $\begin{array}{l}y=17,60+2,370 x-0,0267 x \\
y=28,00+1,130 x-0,000+2,37 x-0,0350 x \\
y=28,80 \\
y=6,28+1,410 x-\end{array}$ & $\begin{array}{l}9 \\
9 \\
9\end{array}$ & $\begin{array}{l}0,9835 \\
0,9526 \\
0,9638 \\
0,9819\end{array}$ & $\begin{array}{l}0,01 \\
0,01 \\
0.01 \\
0.01\end{array}$ & $\begin{array}{l}44,38 \\
33,86 \\
-?\end{array}$ & $\begin{array}{l}70,40 \\
68,90 \\
-\end{array}$ \\
\hline 6-8otucatu-1 & $\begin{array}{l}: 1 \\
: 1 \\
c 1 \\
c 1\end{array}$ & $\begin{array}{l}1 \\
2 \\
1 \\
2\end{array}$ & $\begin{array}{l}X=62,30+1,152 x-0,0270 x \\
Y=37,17+0,615 x=0,0164 x^{2} \\
Y=78,07+0,112 x+0,0005 x \\
Y=35,10+2,880 x=0,0398 x\end{array}$ & $\begin{array}{l}9 \\
9 \\
9\end{array}$ & $\begin{array}{l}0,2657 \\
0,9646 \\
0,2487 \\
0.9951\end{array}$ & $\begin{array}{l}0,01 \\
0,01 \\
0.01\end{array}$ & $\begin{array}{l}21,33 \\
18,25 \\
-36,18\end{array}$ & $\begin{array}{l}99,16 \\
42,94 \\
87,20\end{array}$ \\
\hline 7-8otucetu-2 & $\begin{array}{l}81 \\
\vdots 1 \\
c 1 \\
c 1\end{array}$ & $\begin{array}{l}1 \\
2 \\
1 \\
2\end{array}$ & $\begin{array}{l}y=49,60+2,940 x-0,0696 x^{1} \\
y=41,27+1,157 x=0,0329 x^{2} \\
y=65,47+6,950 x+0,0155 x^{2} \\
y=45,63+5,517 x-0,1150 x^{2}\end{array}$ & $\begin{array}{l}9 \\
g \\
g\end{array}$ & $\begin{array}{l}0,9321 \\
0.8398 \\
0.9730 \\
0,9540\end{array}$ & $\begin{array}{l}0,01 \\
0,01 \\
0,01 \\
0,01\end{array}$ & $\begin{array}{l}21,12 \\
11,98 \\
20,22 \\
24,00\end{array}$ & $\begin{array}{r}80,65 \\
51,44 \\
73,04 \\
111,80\end{array}$ \\
\hline 8-Matio & $\begin{array}{l}: 1 \\
\therefore 1 \\
c 1 \\
c 1\end{array}$ & $\begin{array}{l}1 \\
2 \\
1 \\
2\end{array}$ & $\begin{array}{l}x=68,43+6,260 x-0,1340 x \\
=12,93+2,735 x=0,0417 x \\
Y=67,97+4,930 x=0,0997 x \\
Y=7,67+1,366 x\end{array}$ & $\begin{array}{l}9 \\
g \\
9\end{array}$ & $\begin{array}{l}0,9898 \\
0,9925 \\
0,9607 \\
0,9783\end{array}$ & $\begin{array}{l}0,01 \\
0,01 \\
0.01 \\
0,01\end{array}$ & $\begin{array}{l}27,12 \\
32,80 \\
24,12\end{array}$ & $\begin{array}{r}142,30 \\
57,27 \\
128,90 \\
\end{array}$ \\
\hline 9-Cataläo & $\begin{array}{l}: 1 \\
\because 1 \\
c 1 \\
c 1\end{array}$ & $\begin{array}{l}1 \\
2 \\
1 \\
2\end{array}$ & $\begin{array}{l}x=94,07+0,577 x-0,0120 x^{2} \\
y=23,94+1,940 x-9,0254 x^{2} \\
y=145,04+1,470 x-0,025 x^{2} \\
Y=63,07+1,634 x-0,0207 x^{2}\end{array}$ & $\begin{array}{l}9 \\
9 \\
9\end{array}$ & $\begin{array}{l}0,9674 \\
0,9862 \\
0,7434 \\
0,9650\end{array}$ & $\begin{array}{l}0,01 \\
0.01 \\
0,01 \\
0.01\end{array}$ & $\begin{array}{l}24,04 \\
28,94 \\
28,47\end{array}$ & $\begin{array}{l}101,00 \\
166,31 \\
95,31\end{array}$ \\
\hline 10-S.S.Paraiso-1 & $\begin{array}{l}: 1 \\
\vdots 1 \\
c 1 \\
c 1\end{array}$ & $\begin{array}{l}1 \\
2 \\
1\end{array}$ & $\begin{array}{l}y=64,17+4,570 x-0,0539 x^{\prime} \\
y=11,20+1,320 x-0,0726 x \\
y=84,33+4,360 x-0,0726 x^{2} \\
y=14,92+1,190 x\end{array}$ & $\begin{array}{l}9 \\
9 \\
9\end{array}$ & $\begin{array}{l}0,9651 \\
0.9659 \\
0.9743 \\
0,9771\end{array}$ & $\begin{array}{l}0,01 \\
0,01 \\
0.01 \\
0.01\end{array}$ & $\begin{array}{l}42,39 \\
30,03 \\
-\end{array}$ & $\begin{array}{l}161,63 \\
149,17\end{array}$ \\
\hline 11-s.s.Paraiso-2 & $\begin{array}{l}: 1 \\
\because 1 \\
81 \\
c 1\end{array}$ & $\begin{array}{l}1 \\
2 \\
1\end{array}$ & $\begin{array}{l}x=56,70+2,910 x-0,0627 x^{2} \\
x=13,52+1,250 x-060,059 x^{2} \\
y=69,90+2,520 x=0,0559+260 x- \\
x=34,99+1,260 x\end{array}$ & $\begin{array}{l}9 \\
9 \\
9\end{array}$ & $\begin{array}{l}0,9632 \\
0,9646 \\
0,8370 \\
0,9705\end{array}$ & $\begin{array}{l}0,01 \\
0,01 \\
0,01 \\
0,01\end{array}$ & $\begin{array}{l}23,20 \\
22,54\end{array}$ & $\begin{array}{l}90,46 \\
98,00\end{array}$ \\
\hline 12-Rio Paranaibz & $\begin{array}{l}: 1 \\
\vdots 1 \\
c 1 \\
c 1\end{array}$ & $\begin{array}{l}1 \\
2 \\
1 \\
2\end{array}$ & $\begin{array}{l}x=26,97+3,310 x-0,0339 x \\
y=9,20-0,106 x+0,0358 x \\
y=82,97-0,173 x+0,0152 x \\
y=22,77+1,935 x-0,0139 x\end{array}$ & $\begin{array}{l}9 \\
9 \\
9 \\
9\end{array}$ & $\begin{array}{l}0,9515 \\
0,9910 \\
0,62717 \\
0,9909\end{array}$ & $\begin{array}{l}0,01 \\
0,01 \\
0,05 \\
0,01\end{array}$ & $\begin{array}{c}49,70 \\
= \\
69,60\end{array}$ & $\begin{array}{l}107,76 \\
= \\
90,12\end{array}$ \\
\hline Solos de 1 e 6 & $\begin{array}{l}: 1 \\
: 1 \\
c 1 \\
c 1\end{array}$ & $\begin{array}{l}1 \\
\vdots \\
2\end{array}$ & $\begin{array}{l}y=32,30+1,663 x=0,0231 x^{2} \\
y=14,16+1,013 x=0,0025 x^{2} \\
y=42,89+0,977 x=0,011 \times 2 \\
y=15,48+1,121 x=0,0061 x^{2}\end{array}$ & $\begin{array}{l}54 \\
54 \\
54 \\
54\end{array}$ & $\begin{array}{l}0,5141 \\
0,5162 \\
0,2099 \\
0,3896\end{array}$ & $\begin{array}{l}0,01 \\
0,01 \\
0,01 \\
0,01\end{array}$ & $\begin{array}{l}36,08 \\
42,85\end{array}$ & $\begin{array}{l}62,32 \\
68,82\end{array}$ \\
\hline Soloe de 7 - 12 & $\begin{array}{l}: 1 \\
\vdots 1 \\
c 1 \\
c 1\end{array}$ & $\begin{array}{r}1 \\
2 \\
1 \\
2 \\
\end{array}$ & 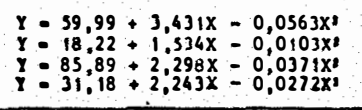 & $\begin{array}{l}54 \\
54 \\
54 \\
54 \\
\end{array}$ & $\begin{array}{l}0,3915 \\
0.3993 \\
0.2163 \\
0.4816\end{array}$ & $\begin{array}{l}0,01 \\
0,01 \\
0,01 \\
0,01\end{array}$ & $\begin{array}{l}30,62 \\
30 \\
41,27 \\
4,23 \\
\end{array}$ & $\begin{array}{l}112.42 \\
121.47 \\
109.83\end{array}$ \\
\hline
\end{tabular}

(1) Auséncie (al) e presence (c/) de calagex, conforime rẹconendacóes.

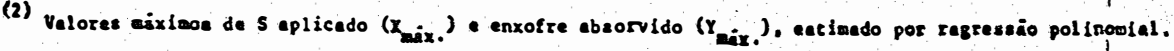


bilização(mineralização e dessorção de $\mathrm{S}_{-} \mathrm{SO}_{4}$ ), que se torna mais evidente no segundo cultivo na maioria dos solos, nos quais a equação da reta apresenta o melhor grau de ajustamento aos dados de observação. Nesses solos as doses máximas(40 ppm) de enxofre anlicados revelaram-se insuficientes para maximizar a absórção no segundo cultivo. No caso dos solos arenosos,embora em alguns casos a regressão poli nomial de segundo grau tenha dado melhor ajustamento (com exceção do solo de Botucatu-1), as absorções máximas obser vadas extrapolaram a dose mâxima aplicada. No solo de Botu catu-1, apesar de ser um solo arenoso, a regressão não se mostrou significativa na presença de calagem no primeiro cultivo; no segundo cultivo a regressão de segundo grau estimou o ponto de mâxima absorção de enxofre com $36,2 \mathrm{ppm}$ de enxofre aplicado. Presume-se,embora não se tenham infor mações a respeito, que o solo tenha sido adubado com alguma formulação de fertilizante com enxofre em cultivos anterio res a campo. No solo de Botucatu-2 a resposta à calagem de ve ser debitada ao baixo teor de magnésio no solo relativa mente ao cálcio, como se pode observar na tabela 4.2 ., mas não à deficiência de enxofre,pois a maximização da absorção ocorreu com 20 e 24 ppm de enxofre, respectivamente pa ra o primeiro e segundo cultivos. No solo de Matão a calagem mostrou efeito depressivo na absorção de enxofre. Conforme consta na tabela 3.1 , a quantidade de 0,43 t/ha de calcário aplicado não oferece nenhuma explicação a ceitável para essa diminuição do enxofre absorvido. Nos 
solos de Catalão, São Sebastião do Paraíso-1, São Sebastião do Paraíso-2 e Rio Paranaíba pode-se observar o efeito altamente signficativo da calagem através dos interceptos das regressões, tanto do primeiro quanto do segundo cultivo Em solos de cerrado, como o de Catalão, a calagem, além de neutralizar a acidez, o a Tumínio e manganês trocáveis e mi neralizar a matéria orgânica, tem a importante função de fornecer cálcio e magnésio como nutrientes. Segundo traba: tho de RITCHEY et alii(1980) as camadas superficial e subsuperficial dos latossolos vermelhos escuros orto, em que se pode enquadrar o solo de Catalão, são extremamente pobres em cálcio e magnêsio. Apesar de se terem aplicado, na ausência de calagem, 200 ppm de Ca antes do primeiro culti vo e 2/3 dessa mesma quantia antes do segundo cultivo, essas doses podem ter sido insuficientes para o desenvolvimen to simplesmente vegetativo do milho. Por outro lado, a 1 inearidade da equação de regressão do segundo cultivo, na ausência de calagem, sugere que a calagem provoca a dessor ção de apreciável quantidade de $\mathrm{S}_{-} \mathrm{SO}_{4}=$. Com a calagem a absorção máxima de enxofre ocorreu com cerca de $30 \mathrm{ppm}$ de $\mathrm{S}$ para o primeiro cultivo e $40 \mathrm{ppm}$ de $\mathrm{S}$ para o segundo culti vo. No solo de São Sebastião do Paraíso-1 e São Sebastião do Paraíso-2 nota-se, da mesma forma, alta resposta à calagem, que também $\vec{e}$ atribuívei ao fornecimento de cálcio e magnésio como nutrientes por causa do esgotamento nas amostras de terra analisadas após o primeiro e segundo cultivos(veja tabela 4.2.). Porêm, nesses solos a linearidade 
da equação no segundo cultivo, na ausência e presença de calagem, sugere um pequeno potencial de fornecimento de en xofre às culturas, principalmente no solo de São Sebastião do Paraíso-1, cujo teor de enxofre total(determinado gravimetricamente) chega a apenas 78 ppm. A deficiência de en xofre em solos de São Sebastião do Paraíso(MG) também foi detectada por GUIMARÃES et alii(1983) e PEDROSO et "alii (1986), em que o efeito do gesso foi atribuido ao fornecimento simultâneo de cálcio e enxofre no cafeeiro e à neutralização do alumínio sub-superficial. Além disso, PEDRoSo et alii(1986) observam ainda que o $S$ aplicado em cafeeiro fez efeito tanto em nîveis mêdios como altos de produ tividade.

No solo de Rio Paranaíba as equações de re gressão indicam ação simultânea da calagem e do gesso na absorção de enxofre. Pela tabela 4.2. verifica-se que o solo é pobre em câlcio e magnésio e pela tabela 4.5.confir ma-se que a calagem aumenta o notencial de mineralização a mais de $100 \%$. Embora o enxofre total desse solo jesteja por volta de $3200 \mathrm{ppm}$, as doses máximas aplicadas (40 ppm de S) não foram suficientes para maximizar a absorção de enxofre pelo milho. Apesar de não se conhecerem trabalhos especificos de adsorção de $\mathrm{S}-\mathrm{SO}_{4}=$ neste tipo de solo de cer rado, levanta-se a hipótese de que sua capacidade de adsor ção de ânions seja bastante elevada, com base na pequena recuperação do fósforo adicionado (veja tabela 4.2.) e à menor eficiência de extração de $\mathrm{S}_{-} \mathrm{SO}_{4}^{=}$pelo extrator de 
$\mathrm{Ca}\left(\mathrm{H}_{2} \mathrm{PO}_{4}\right)_{2} \cdot \mathrm{H}_{2} \mathrm{O}-500$ pprn Peln ácido acético 2, ON logo após a in cubação (veja tabela 4 do apêndice), se comparado com os demais solos estudados.

Analisando-se os solos de forma conjunta, as equações de regressão para os solos arenosos mostram que a calagem proporciona certo aumento na absorção de enxofre a penas no primeiro cultivo, ao passo que no segundo cultivo, na ausêncịa e presença de calagem as equações apresentam formato praticamente 1 inear, indicando esgotamento do enxofre liberado pela calagem e do adicionado. Nos solos mais argilosos (e com teores de carbono superiores a 1,2\%), a maximização da absorção, na ausência de calagem, não foi atingida com a dose mâxima de $40 \mathrm{ppm}$ de $\mathrm{S}$ aplicados; na presença de calagem, o máximo estimado foi de 41,23 ppm $\mathrm{S}$. Nota-se, assim, que os solos mais argilosos (concomitantemente os de maior teor de carbono) possuem maior reserva de enxofre, passîvel de ser posto à disposição das plantas. FONTES (1979), estudando solos de Minas Gerais, concluiu que o enxofre de reserva é mais elevado em solos com maiores teores de carbono. Entretanto, deve-se levar em conta que muitos solos tropicais, contendo óxidos de ferro e alu mínio, podem adsorver quantidades razoáveis de $\mathrm{S}_{-} \mathrm{SO}_{4}=$, mas que podem ser dessorvidas pelo aumento do $\mathrm{pH}$, como atestam os trabalhos de KAMPRATH et alii (1956), CATANI et alii (1971) e COUTO et alii (1979). As pesquisas de HINGSTON et alii (1972) e BROMFIELD (1972) conduzem à opinião de que o problema da retenção de $\mathrm{S}_{-} \mathrm{SO}_{4}=$ pelos solos tropicais está 
na relação de cargas positivas e negativas. Dentre os solos estudados nesse experimento, o LEd de Catalão e o LVd de Rio Paranaíba, pelas considerações acima, merecem estu dos detalhados sobre a retenção de sulfatos e a influência da calagem e da fosfatagem na sua dessorção.

Em trabalhos mais antigos de McCLUNG et alii (1961) com algodão, de MIKKELSEN et alii (1963) com milho, ambos em solos de campos cerrados e de WANG et alii (1976a, b) com arroz inundado, as produções máximas foram obtidas com quantidades de enxofre (como $S$ elementar), variando de 20 a $40 \mathrm{~kg} / \mathrm{ha}$. Deve-se, no entanto, estar atento para o nú mero "mágico" de $30 \mathrm{~kg}$ de $\mathrm{S} / \mathrm{ha}$ - acima do qual as culturas não respondem a $S$ - que pode não ser verdadeiro para espécies e cultivares de alto potencial produtivo, que respon dem a altas doses de $N$, como algumas variedades modernas de milho e arroz. Com base nos resultados desse experimento e assumindo que $1 \mathrm{ppm}$ de $S$ corresponde a $2 \mathrm{~kg}$ de $\mathrm{S} / \mathrm{ha}$, $\mathrm{O}$ milho tem condições de responder a doses de enxofre superiores às aplicadas, principalmente em condições de campo, em que o $\mathrm{S}_{-} \mathrm{SO}_{4}=$ pode ser 1 ixiviado para as camadas subsuperficiais, como atesta o trabalho de MARTINI \& MUTTERS ( 1984$)$. Por outro lado, altas doses de $N$ sem a suficiente contrapartida de enxofre podem induzix ao acúmulo de metabólitos tóxicos de nitrogênio (JANZEN \& BETTANY, 1983). Nes se experimento constatou-se, tambêm, que adubações pesadas de fósforo e nitrogênio induzem a relações N/S e P/S nutri 
cionalmente inadequadas, como serâ explanado na secção4.6.

\subsection{TEORES DE ENXOFRE TOTAL NA PARTE AÉREA E RAZÕES $\mathrm{N} / \mathrm{S}$ E P/S VERSUS PRODUÇÃO DE MATÉRIA SECA E AB- SORÇÃO DE ENXOFRE PELO MILHO}

\subsubsection{EVOLUCÃ̃ DOS TEORES DE NITROGENIO, FÓSFORO E ENXOFRE EM FUNÇ̃̃̃O DA CALAGEM; GESSO \\ E DOS CULTIVOS}

Na tabe1a 4.10. observam-se os teores de $N$, $P$ e $S$ totais na parte aérea do milho. O nitrogênio total tende a ser mais alto na ausência de calagem e de gesso se comparado com a sua presença. Com a adubação abundante de $\mathrm{N}$ e outros nutrientes (veja tabela 4.2.) e calagem, o enxofre nativo dos solos sofreu esgotamento progressivo do enxofre disponível dos solos, refletindo-se diretamente na diminuição dos teores de enxofre total e aumento de nitrogênio total na planta-teste do primeiro para o segundo cultivo. A deficiência de enxofre mostra-se particularmente severa no nível zero de enxofre. A partir do primeiro cultivo já se detectaram deficiências de enxofre em solos arenosos como o de Assis,, Piraçununga-1 e Piraçununga-2, de ficiências estas que se estenderam aos outros solos no segundo cultivo, no nível de $20 \mathrm{ppm}$ de $\mathrm{S}$. Nos solos de Botucatu-1 (latossolo arenoso) e Botucatu-2 (latossolo roxo ar- 


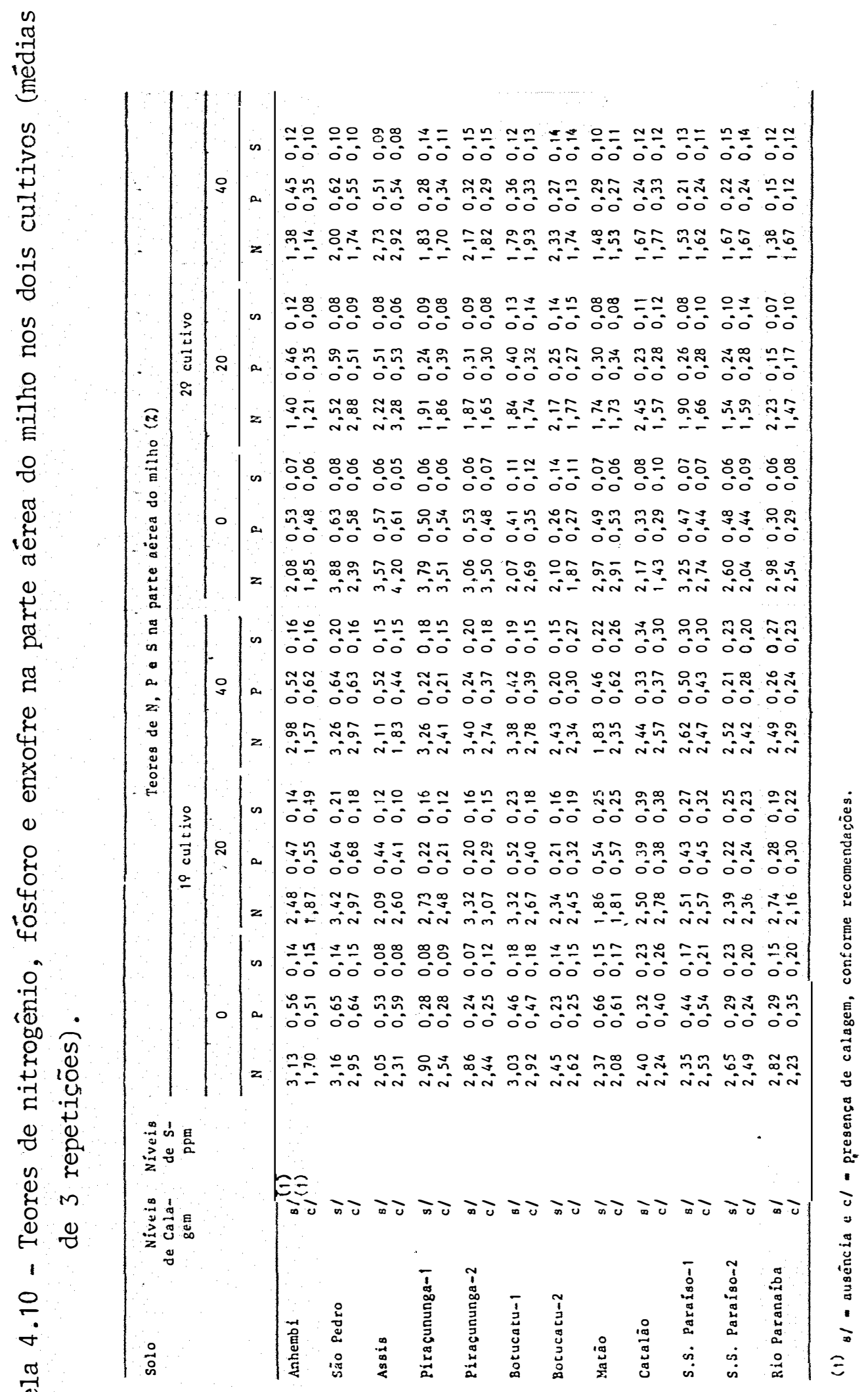


giloso) a deficiência de enxofre no milho mostrou-se menos severa, mesmo na dose zero de gesso do segundo cultivo.

Os teores de fôsforo total na parte aérea do milho refletem as quantidades de fósforo disponível, nos solos após os dois cultivos. Comparando-se os dados das ta belas 4.2. e 4.10, verifica-se, que os maiores teores de fósforo total nas plantas e fösforo disponível nos solos referem-se justamente aos solos de textura arenosa e dose zero de gesso. Esses altos níveis de $P$ (nos solos e plantas) contribuem para acentuar o desequilíbrio entre $\mathrm{P}$ e $\mathrm{S}$, como serâ demonstrado através da razão $\mathrm{P} / \mathrm{S}$ versus absorção de enxofre pelo milho. Nos solos mais argilosos a razão P/S tendem a ser mais equilibrada: o maior poder de fixação de fósforo (ALMEIDA NETO \& BRASIL SOBRo, 1977) e o maior potencial de fornecimento de enxofre (veja tabela 4.7.) podem ser responsabilizados pelo suprimento mais balanceado de enxofre e fósforo às plantas, mesmo com altas adubações fosfatadas.

\subsubsection{RELACÕES DO ENXOFRE TOTAL E RAZÕES N/S E $P / S$ NA PARTE AÉREA DO MILHO VERSUS PRODU- CÃ̃O DE MATÉRIA SECA E ABSORCẼ̃O DE ENXOFRE}

Na tabela 4.11 estão listados os coeficientes de determinação $\left(r^{2}\right.$ e $\left.R^{2}\right)$ da produção de matêria seca da parte aérea do mitho e absorção de enxofre versus per- 


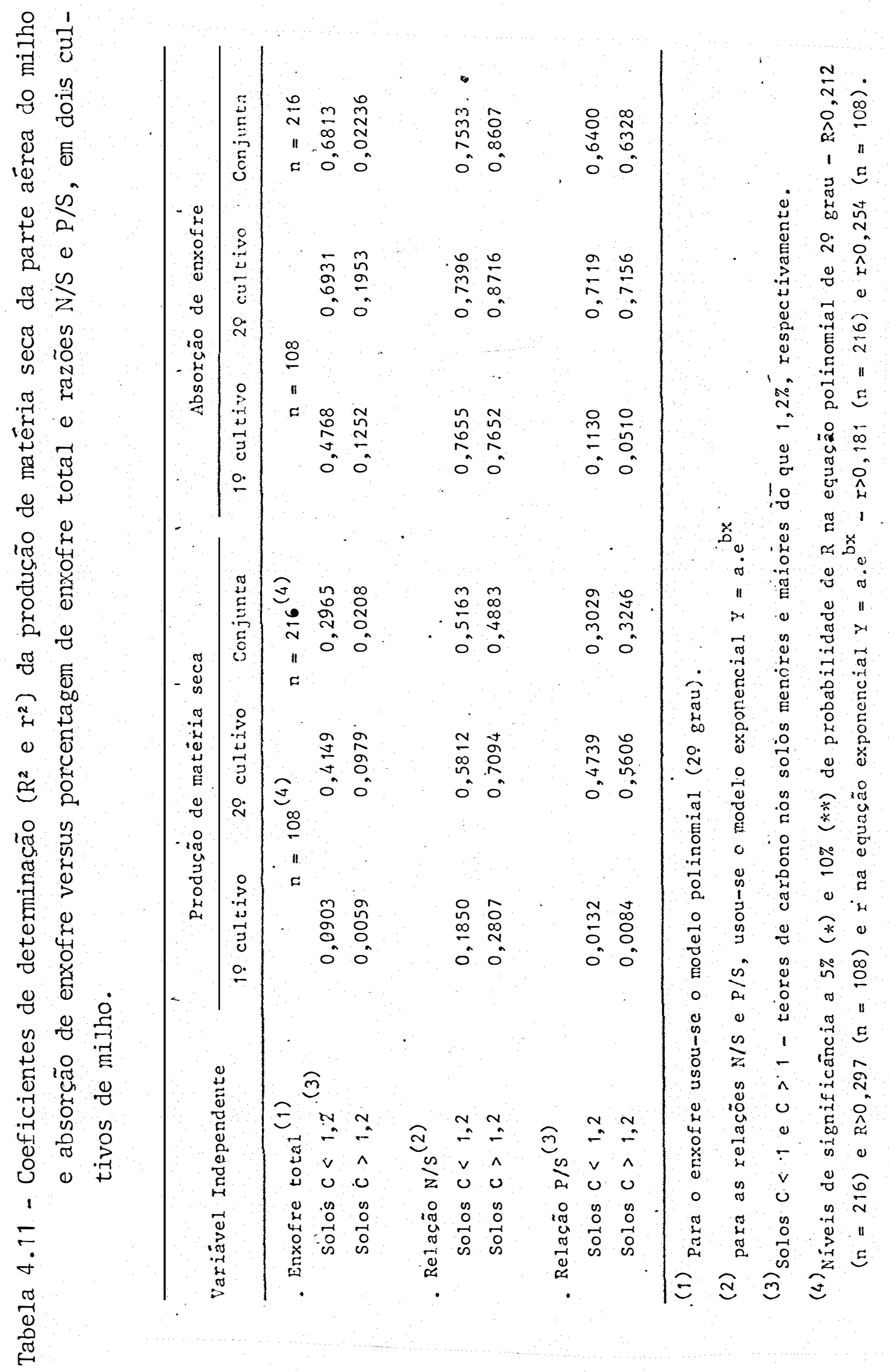


centagem de $S$ total e razões N/S e P/S. Nota-se que os coe ficientes de determinação da produção de matêria seca são mais baixos do que os da absorção de enxofre. Dados de MCCLUNG et alii (1959) demonstraram que o volume total de solo explorado restringe a expansão do sistema radicular, com produção de matéria seca consequentemente menor, porém sem maiores efeitos naa absorção de enxofre pelo milheto. Em trabalhos de correlação sobre disponibilidade de nitrogênio GASSER (1963) tambëm verificou estas mesmas restrições para os experimentos de casa-de-vegetação, se comparados com experimentos de campo.

Embora nos solos arenosos (com teores de car bono inferiores a $\left.1,2 \frac{\circ}{2}\right)$ os coeficientes de determinação $\left(r^{2}\right.$ e $R^{2}$ ) da produção de matéria seca e absorção de enxofre pe lo milho versus enxofre total se tenham mostrado superiores aos dos solos argilosos, os coeficientes das razões N/S e P/S tem mostrado relações mais estreitas, independen temente dos seus teores de carbono. Analisaremos, a seguir, cada caso, em particular.

4.6.2.1. Enxofre total na parte aérea do mi tho versus produção de matéria seca e absorção de enxofre

Para se estabelecer as relações de produção de matéria seca e absorção de enxofre pelo milho, versus en 


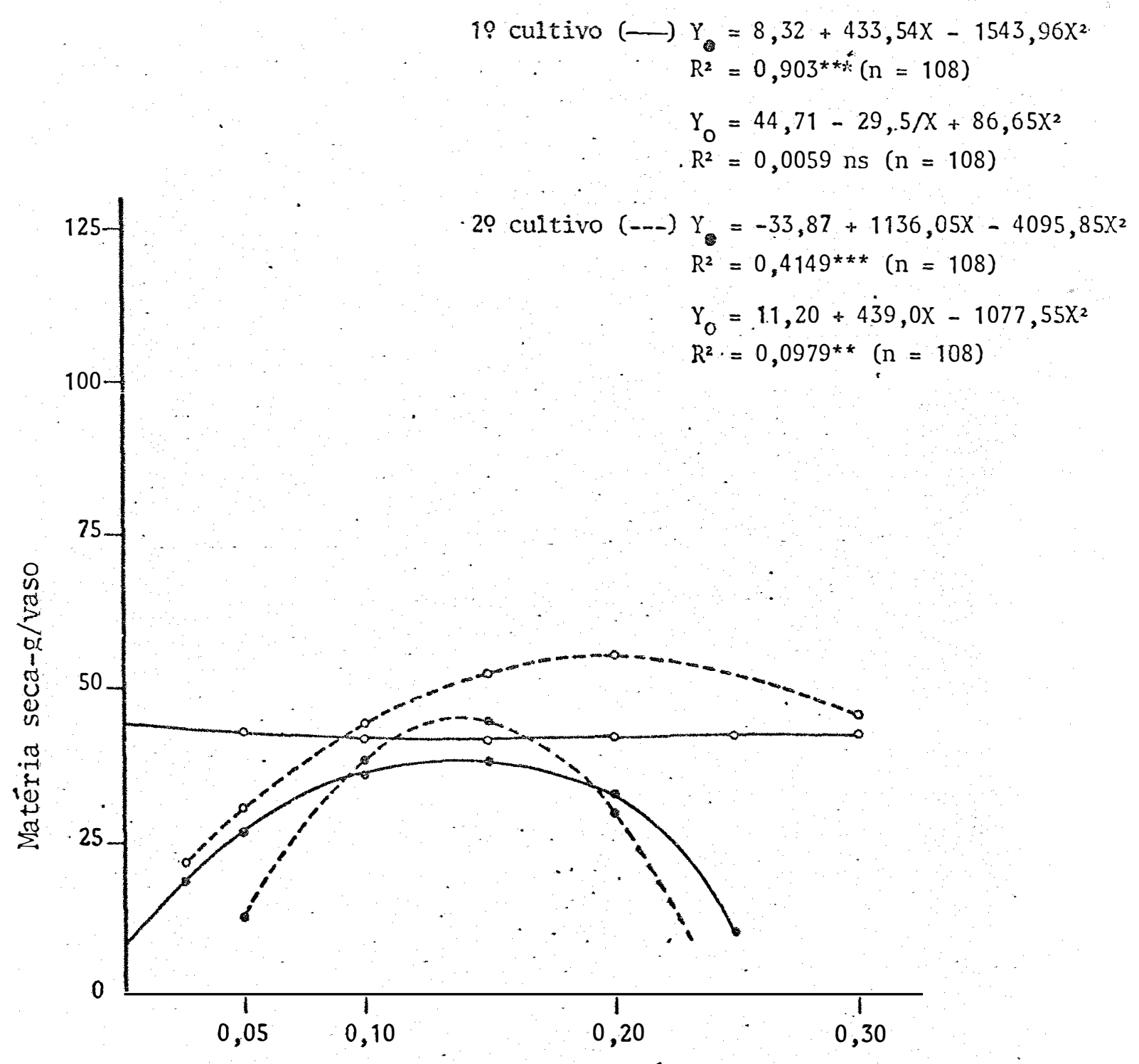

Percentagem de enxofre total (S) na planta

Figura 4.4 - Produção de matêria seca se milho versus teores de enxofre total nas plantas, com agrupamento dos solos pelos teores de carbono $(\mathrm{O}=\mathrm{C}<1,2 \%$ e $\mathrm{O}=\mathrm{C}>1,2 \%$ ) e pelos cultivos $(-=$ primeiro cultivo e -.- = segundo cultivo). 
xofre total nas plantas usou-se o modelo polinomial de segundo grau, discriminando-se os solos pelos teores de carbono. Observa-se nas figuras 4.4. e 4.5. que somente foi foi possivel determinar o nivel crítico de enxofre total $(0,14 \%)$ versus produção de matéria seca nos solos arenosos no primeirocultivo, o que concorda com o valor de $0,16 \%$ encontrado por FONTES(1979) para o sorgo granífero. Com relação à absorção de enxofre o nível crütico foi de 0.20 : para o enxofre total no milho. A regressão obtida para os solos mais argilosos (carbono superior a $1,2 \frac{0}{0}$ ) no primeiro cultivo não permitiu a estimativa dos níveis críticos de enxofre total nas plantas de milho: No segundo cultivo encon trou-se o mesmo nível crítico de $0,14 \%$ para a produção de matéria seca e absorção de enxofre nos solos arenosos;nos argilosos o esgotamento do enxofre nativo e as altas doses de adubação nitrogenada e fosfatada ensejaram niveis críticos mais elevados de enofre total, de $0,20:$ para a pro dução de matéria seca e de $0,30 \%$ para a adsorção de enxo fre. Essas diferenças podem ser atribuídas aos potenciais de mineralização de enxofre maiores dos solos argilosos e com teores de carbono mais altos. Pelo exposto não se pode tomar o nível crítico de enxofre total nas plantas com um valor estático, pois ele pode variar em função de teor de enxofre disponível nos solos, níveis de N, P e outros nutrientes disponíveis no solo ou adicionados pela adubação, reação do solo, e estágio de desenvolvimento das plantas. 


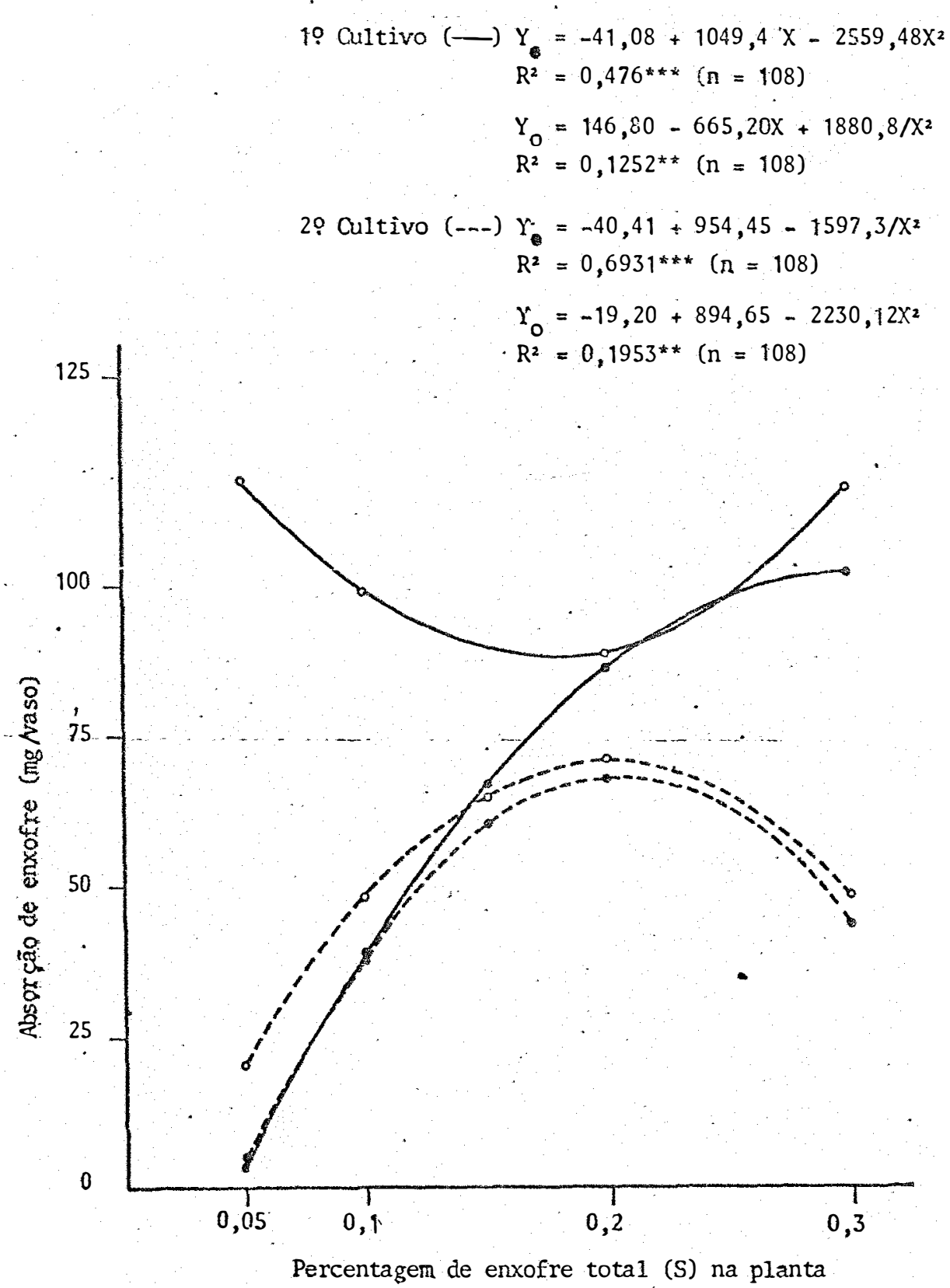

Figura 3.5 - Adsorção de enxofre pelo milho versus teores de enxofre total nas plantas, com agrupamento dos solos pelos teores de carbono ( $0=C<1,2 \%$ e $0=C>1,2 \%$ ) e pelos cultivos $(-=$ primeiro cultivo e --- = segundo cultivo) . 
Com relação a forrageiras tropicais o nîvel crítico de $S$ total ê de difícil interpretação, devido ao râpido declínio de seus níveis ao longo do período de desenvolvimento das plantas. Em geral, as forrageiras costumam apresentar crescimento rápido. Segundo SMITH \& DOLBY (1977), em capim colonião, o nível crítico diminui de $0,15^{\circ}$ aos 18 dias apôs a rebrota para $0,13 \%$ e $0,08 \%$, respectivamente 7 e 14 dias mais tarde. Nas condições desse experimento veri ficou-se ainda que em solos de diferente textura, com dife rentes teores de carbono, adubações pesadas de nitrogênio e fôsforo tem influência marcante nas razões $\mathrm{N} / \mathrm{S}$ e $\mathrm{P} / \mathrm{S}$.

$$
\begin{aligned}
& \text { 4.6.2.2. Razões N/S e P/S versus produção } \\
& \text { de matêria seca e absorção de en- } \\
& \text { xof̣re }
\end{aligned}
$$

De um modo geral, segundo COLEMAN (1966) a deficiência de enxofre, a nível mundial, manifesta-se com maior frequência em sọlos arenosos. Em condições brasileiras a deficiência de enxofre ê detectada em diversas situa ções. McCLUNG \& FREITAS (1959) afirmam que as constantes queimadas da vegetação dos cerrados conduzem à perda do en xofre por volatilização, que chega $75 \%$. McCLUNG \& QUINN (1959) e WANG et alii (1976a,b) constataram a râpida deple ção do enxofre nativo, quando são usadas doses elevadas de fertilizantes NP isentos de enxofre. Nas condicōes desse 
experimento verificaram se relações muito estreitas das ra zões N/S e P/S versus produção de massa seca e absorção de enxofre pelo milho, como consta na tabela 4.11. Ao contrário do teor de $S$ total na parte aêrea do milho, as razões N/S do primeiro e segundo cultivos e conjunta apresentam coeficientes de determinação mais elevados para os solos argilosos (com maiores teores de carbono) se comparados com os solos arenosos, apesar de altamente significativos a $1 \%$ de probabilidade, em ambos os casos. Na figura 4.6 . temos as respectivas equações de regressões (modelo exponecial $\left.Y=a e^{b x}\right)$. Constata-se que o esgotamento progress $\underline{i}$ vo do enxofre nativo e adicionado aos solos é agravado pela adubação nitrogenada, provocando o desbalanço do enxo fre em relação ao nitrogênio. As curvas referentes ao primeiro cultivo mostram que o valor crítico da razão N/S no primeiro cultivo está ao redor de $10 / 1$ para os solos mais argilosos, valor esse que se aproxima do encontrado por MCNAUGHT \& CHRISTOFFELS (1961), para gramineas (N/S = 11 a $12 / 1)$.

WOODHOUSE (1969) verificou que uma razão N/S maior do que $17 / 1$ limita o desenvolvimento do capim "Coastal" bermuda (Cynodon dactylon L.). O autor considera que esta situação ocorre com a aplicação de cerca de $450 \mathrm{~kg} / \mathrm{ha}$ de $\mathrm{N}$, juntamente com um teor de $S$ no tecido de $0,14 \%$. Nas condições desse experimento o nível crítico de $S$ no tecido foi de $0,14 \%$ para os solos arenosos, correspondendo a uma razão N/S por volta de 10 . Deve-se atentar por outro lado, pa 


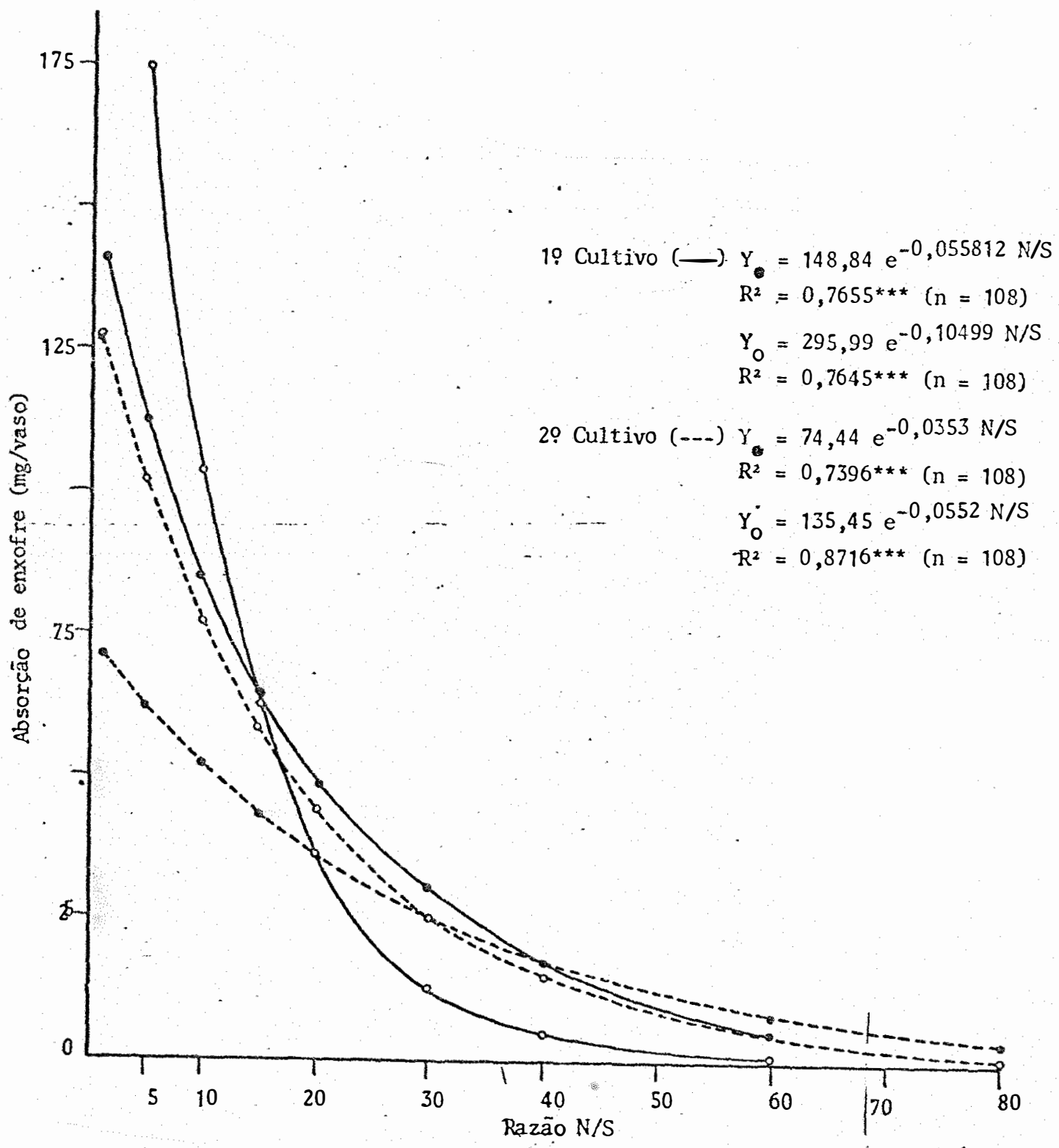

Figura 4.6 - Adsorção de enxofre pelo milho versus razões N/S das plantas, com agrupamento dos solos pelos teores de carbono $(\mathrm{O}=\mathrm{C}<1,2 \%$ e o $\mathrm{C}>1,2 \%$ ) e pelos cultivos (- $=$ primeiro cultivo e .... = segundo cultivo). 
ra o fato de no primeiro cultivo terem sido aplicados 240 $\mathrm{kg} / \mathrm{ha}$ de $\mathrm{N}$. A deficiência de enxofre tornou-se mais severa no segundo cultivo dos solos, nois as razões N/S obtidas mostram redução mais acentuađa na absorção de enxofre, estimado pelo modelo exponencial, como mostra a figura 4.6. 0 decréscimo na absorção de enxofre é agravado no segundo cultivo porque novamente foram aplicados $240 \mathrm{ppm}$ de $\mathrm{N}$, exacerbando o desbalanço entre $N$ e $S$ no solo e na parte aérea do milho. A razão N/S segundo PUMPHREY \& MOORE (1965) tem a vantagem de permanecer relativamente constante nos diversos estádios de desenvolvimento das plantas. Essa opi nião é confirmada pelos dados de MARTIN \& MATOCHA (1973) e MAYNARD et alii (1983), que obtiveram, respectivamente, pro duções relativas de grama "Coastal" bermuda (Cynodon dactylon L.) e de sementes de colza (Brassica napus e B. campestris) inversamente proporcionais à razão N/S. As relações encontradas para o $S$ total nas plantas (massa total e sementes), conforme os autores acima citados, são de nenhu ma ou pouca significância, devido à grande variação de seu teor em função do estádio de desenvolvimento das plantas (SMITH \& DOLBY, 1977) e variações climâticas (CLARK \& LEWIS, 1974).

Na tabela 4.11. ainda observamos os coeficientes de determinações $\left(r^{2}\right)$ da produção de matéria seca e absorção de enxofre versus razões P/S nas plantas de mi1ho. No primeiro cultivo, tanto para a matéria seca quanto 
para a absorção de enxofre os coeficientes de determinação não lograram significância estatística. A alta significância dos coeficientes no segundo cultivo explica-se pela disponibilidade de grandes quantidades de fósforo nos soIos, como se vê na tabela 4.2. (apôs o primeiro e segundo cultivos) e pelos maiores teores de $\mathrm{p}$ total em relação ao $S$ total nas plantas (veja tabela 4.10). Como consequência tiveram-se altas razões $\mathrm{P} / \mathrm{S}$ nas plantas, inversamente proporcionais à produção de matéria seca e absorção de enxofre pelo milho. Na figura 4.7 . as equações de regressão conjunta (primeiro mais segundo cultivos) e as referentes ao segundo cultivo isoladamente mostram relações ourvilineares muito estreitas entre as razões $\mathrm{P} / \mathrm{S}$ das plantas de milho e a absorção de enxofre. Todavia, não é possivel identificar precisamente o valor da razão P/S que caracterí za a deficiência de enxofre para o milho. Tentativamente, propõe-se o nível de $1 / 1$ para a razão $P / S$. É escassa a literatura sobre a razão $\mathrm{P} / \mathrm{S}$ como indicativo da deficiência de enxofre em plantas. MALAVOLTA et alii (1984a) consideram a relação P/S > 2 como indicadora de deficiência de enxofre em capim colonião. Em experimento com coḷa MALAVOLTA et alii (1984b) nos tratamentos sem enxofre estabeleceram a deficiência de enxofre com as relações $P / S=0,6$ na lâmina foliar e $\mathrm{P} / \mathrm{S}=0,5$ no pecîlo.

Os dados desse experimento chamam a atenção para o fato de que em solos arenosos o desequilíbrio fós 


$$
\begin{aligned}
& \text { 20. Cultivo (-.) } Y_{0}=108,33 \cdot \mathrm{e}^{-0,302 \mathrm{P} / \mathrm{S}} \\
& R^{2}=0,7156^{* * *}(n=108) \\
& \mathrm{Y}_{\mathrm{O}}=93,16 \cdot \mathrm{e}^{-0,230 \mathrm{P} / \mathrm{S}} \\
& R^{2}=0,7119^{\star \star *}(n=108) \\
& \text { Conjunta }\left(-\mathrm{Y}_{\mathrm{O}}=94,39 \cdot \mathrm{e}^{-0,221 \mathrm{P} / \mathrm{S}}\right. \\
& R^{2}=0,640 * \star *(n=108) \\
& Y_{0}=138,58 \cdot \mathrm{e}^{-0,331 \mathrm{P} / \mathrm{S}} \\
& R^{2}=0,6321^{\star \star *}(n=108)
\end{aligned}
$$

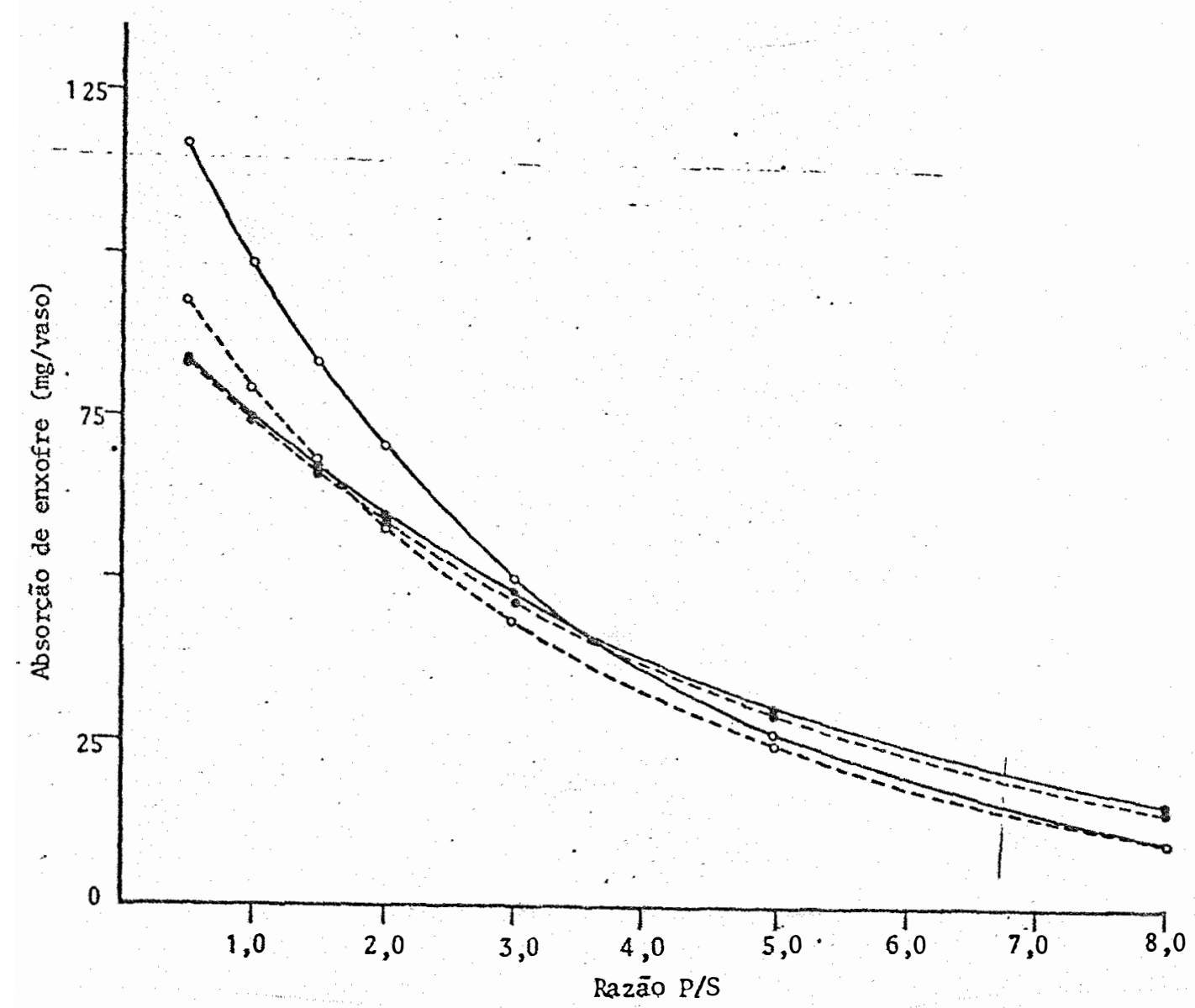

Figura 4.7 - Adsorção de enxofre pelo milho versus razões P/S nas plantas, com agrupamento dos solos pelos teores de carbono $\left(0=C<1,2^{\circ}\right.$ e $\left.O=C>1,2^{\circ}\right)$ e pelos cultivos (--- = segundo cultivo e - = conjunta, dos dois cultivos). 
foro/enxofre pode evidenciar-se com mais facilidade, o que ê corroborado pelos experimentos de MCCLUNG \& QUINN (1959) com grama batatais, mostrando interação significativa entre adubações fosfatada e sulfatada na prođução de matéria seca no terceiro corte. Em solos arenosos da Dinamarca JENSEN(1963) considera que adubações fosfatadas pesadas le vam à lixiviação do $\mathrm{S}_{-} \mathrm{SO}_{4} \overline{\mathrm{a}}$ para as camadas mais profundas. Tentativamente MALAVOLTA (1980) propõe que a relação $\mathrm{P}_{2} \mathrm{O}_{5} /$ $S$ na adubação seja igual a $7-10 / 1$, como meio de prevenir a deficiência de enxofre nos solos.

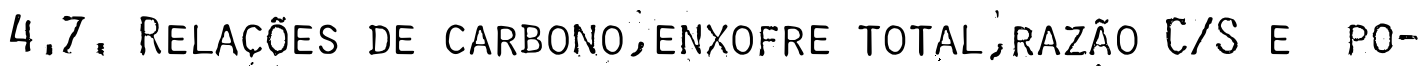 TENCIAIS DE MINERALIZACÃO DE ENXOFRE DOS SOLOS EN- TRE SI E COM A ABSORCÃO DE ENXOFRE PELO MILHO.}

Na tabela 4.12. tem-se os coeficientes de correlação linear simples entre carbono,enxofre total razão C/S e potenciais de mineralização de enxofre. Já se ob servou na secção 4.1.1. que a metodologia empregada na determinação do enxofre total apresenta sérios problemas de repetibilidade dos resultados. Isso explica, em parte, a baixa correlação obtida entre o $S$ total dos solos versus absorção de enxofre pelo mjilho,tanto na ausência quanto na presença de calagem $(r=0,234$ n.s. $r=0,137$ n.s., respectivamente). Como alternativa diversos pesquisadores tem as sociado o teor de enxofre total dos solos com o carbono 


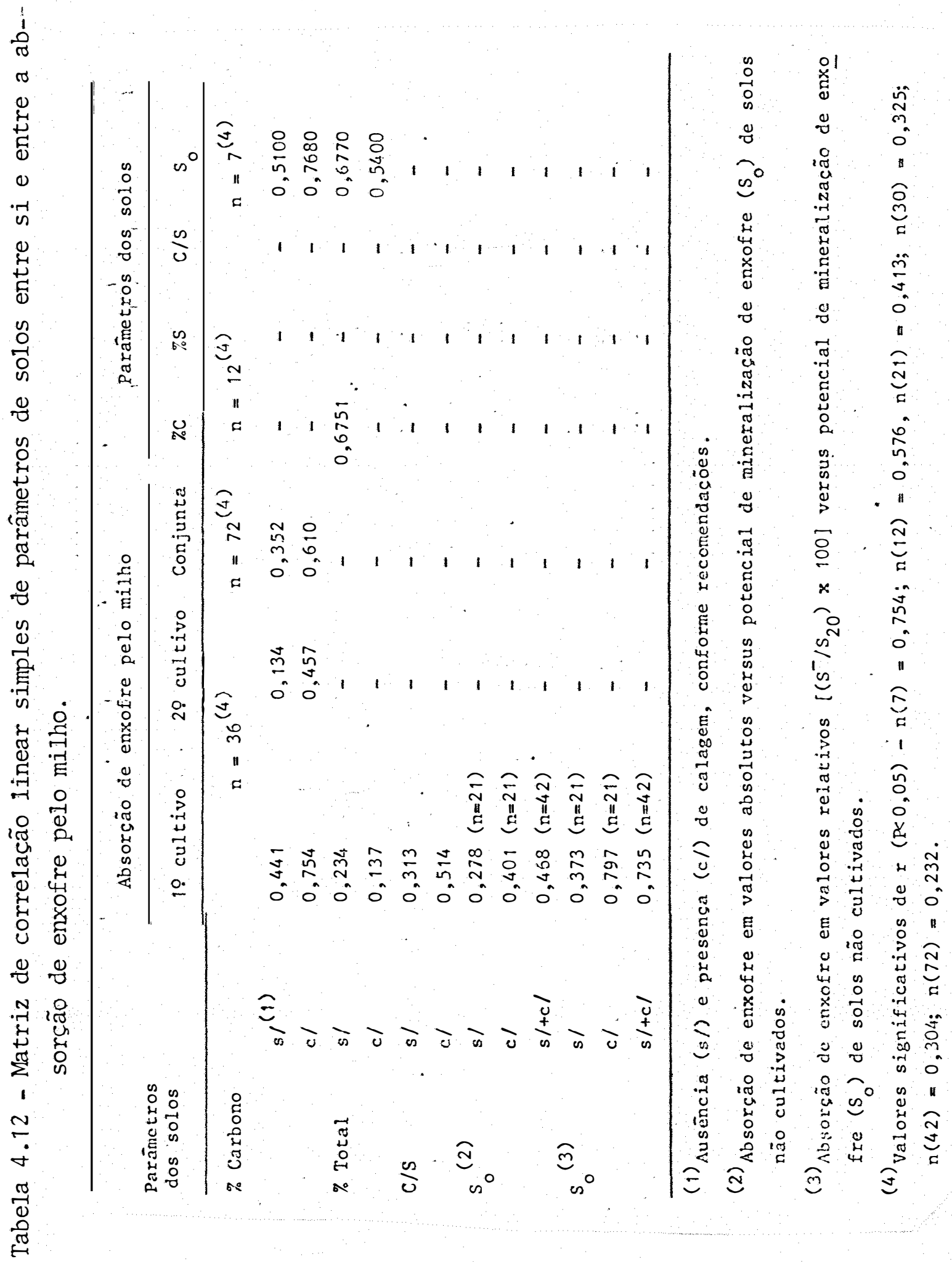


orgânico, em virtude da facilidade de sua determinação. Nos solos utilizados nesse exnerimento obteve-se a correlação Iinear $r=0,657$, com baixa significância. NASCIMENTO \& MORELLI (1980a), no entanto, obtiveram correlações altamen te significativas entre enxofre total versus carbono orgânico $\left(r=0,913^{*}\right)$ e enxofre total versus enxofre orgânico $(r=0,970 * *)$, trabalhando com solos do Rio Grande do Sul. FONTES (1979), em solos de Minas Gerais, obteve correlação altamente significativa entre o carbono orgânico e o enxofre de reserva, orgânico $(r=0,913 * *)$. Da mesma forma, as correlações entre o carbono orgânico e enxofre total e razão $\mathrm{C} / \mathrm{S}$ versus o enxofre potencialmente mineralizável ( $\mathrm{S}_{0}$ ) são muito baixas. Na tabela 4.12. vê-se que apenas a corre lação entre o carbono e o enxofre potencialmente mineralizävel, na presença de calagem, apresentam significância ao nível de $5 \%\left(r=0,768^{*}\right)$. A razão $C / S$, nas condições desse experimento, apresentou correlação positiva com a absorção de enxofre, embora significativa apenas na presença de calagem $\left(r=0,514^{* *}\right)$, o que contraria dados de literatura. NASCIMENTO \& MORELLI (1980b) obtiveram correlação negativa da produção relativa de alfafa com a relação $C / S(r=-0,849 * x)$. Essa discrepância pode ter explicação nas mais variadas rázões C/S dos solos - em alguns trabalhos de revisão de 1 iteratura a razão era tida como constante, por volta de 100/1. Todavia, segundo BETTANY \& STEWART (1983) a razão C/S varia de 60 a $150 / 1$, podendo, em casos extremos, alcan çar valores superiores a $300 / 1$, como em solos de florestas 
e turfas de regiões frias. Os solos utilizados nesse experimento possuem razões $C / S$ bem mais baixas, variando de 33 a $122 / 1$, aproximando-se dos valores encontrados por Mohr (1948), citado por MALAVOLTA (1950), emalguns solos do Rio Grande do Sul.

\subsubsection{RELACẼ̃O DA ABSORCÃ̃ DE ENXOFRE PELO MILHO VERSUS TEORES DE CARBONO NOS SOLOS SUBME- TIDOS A DOIS CULTIVOS NA AUSÊNCIA E PRE- SENCA DE CALAGEM}

Nas condições desse experimento o carbono orgânico dos solos revelou-se um bom indicador da capacida de de fornécimento de enxofre às plnatas. Na figura 4.8. constam as equações de regressão da absorção de enxofre ver sus o carbono dos solos. Com a exclusão do solo do Rio Paranaíba obtiveram coeficientes de correlação mais elevados do que os da tabela 4.12. com a inclusão de tódos os solos estudados. As relações mais estreitas foram obtidas na presença de calagem e no primeiro cultivo. Por outro lado, tanto na ausência como na presença de calagem, os menores coeficientes angulares das equações de regressão do segundo cultivo, comparados aos do primeiro denunciam o esgotamento das formas de enxofre mais facilmente disponiveis pa ra as plantas. Na ausência de calagem as equações de regressão demonstram que as menores quantidades absorvidas de enxofre são consequência da imobilização do enxofre (via 

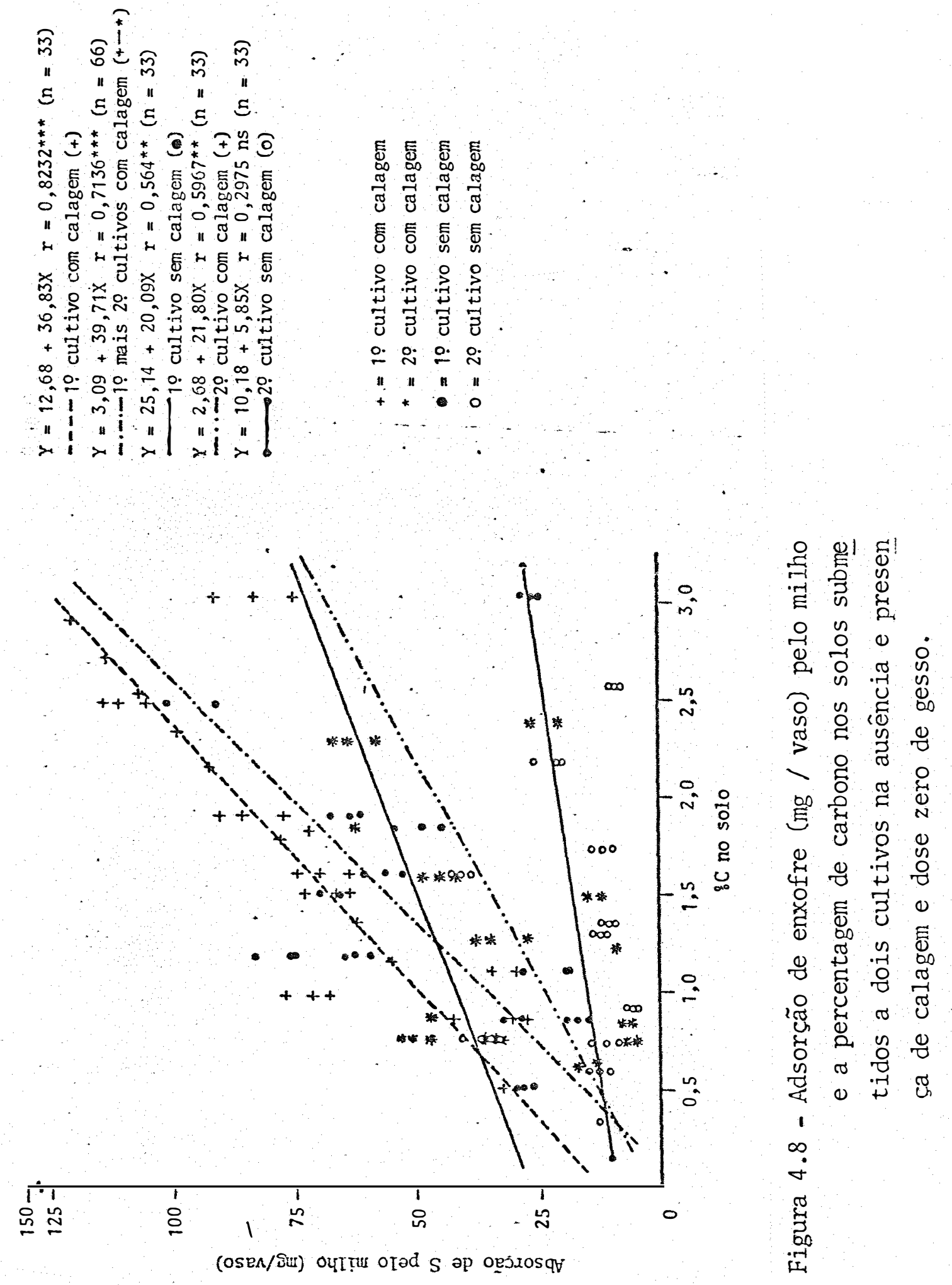
biológica) e da adsorção de $\mathrm{S}_{-} \mathrm{SO}_{4}=$ aos sitios de troca. Assim, os efeitos da calagem na disponibilização do enxofre traduzem-se na mineralização de matêria orgânica (WILLIAMS, 1967; SWIFT, 1985) e dessorção do $\mathrm{S}_{-} \mathrm{SO}_{4}^{=}$dos sítios de troca aniônica (PROBERT, 1976; COUTO et a1ii, 1979). Comparan do-se as interações entre calagem e cultivos (veja tabela 4.6. e 4.7.) com as equações da figura 4.8., compreende-se que o esgotamento do enxofre nativo dos solos é mais a centuado com a prätica da calagem.

\subsubsection{RELAÇ̃̃O ENTRE POTENCIAIS DE MINERALIZACÃO DE ENXOFRE DOS SOLOS E ABSORCÃO RELATIVA DE ENXOFRE PELO MILHO}

Na tabela 4.12. vê-se que a absorção de enxofre (em valores absolutos) versus potenciais de minerali zação de enxofre nativo dos solos apresenta coeficientes de correlação linear mais baixos do que quando esta relação foi calculados com os valores relativos de absorção $\mathrm{CS}^{-} /$ $\left.S_{20}\right) \times 100$, onde $S^{-}$significa ausência e $S_{20}$ a dose de 20 ppm de S. Utilizando-se os valores absolutos de absorção de enxofre verificou-se significância estatística a $5 \%$ na anâlise conjunta dos tratamentos com ausência e presença de calagem $\left(r=0,468^{*}\right)$. Pela figura 4.9. observa-se que os potenciais de minexalização de enxofre - estimado por e quações hiperbólicas (veja tabela 4.5. e figura 4.2.) a par tir do enxofre mineralizado por incubação aberta) são es- 
$\stackrel{2}{2}$

"I $\Xi "$

n * * *

m.

11. II

$4+4$

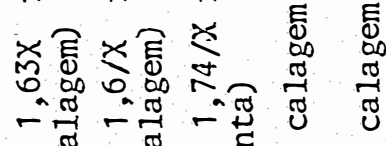

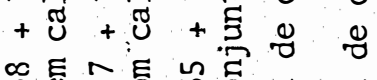

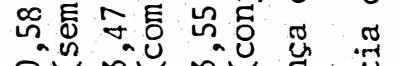

i m

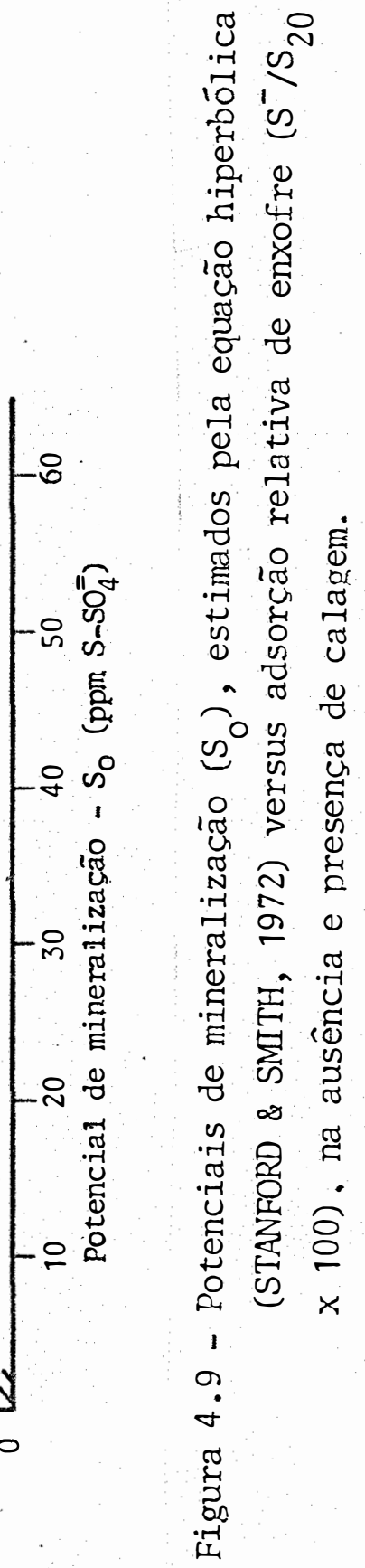

$>\quad>$ म

$1 i 100$ 
treitamente correlacionados com a absorção relativa do enxofre pelo milho na presença da calagem $\left(r=0,797^{* *}\right)$. Na ausência de calagem houve pequena absorção de enxofre, con comitantemente com a baixa mineralização de enxofre nos se te solos usados no experimento de incubação aberta. A baixa correlação obtida na ausência de calagem ( $r=0,373$ ns) deve-se à dispersão dos pontos no gráfico, principalmente àqueles circunscritos e indicados por uma flecha e se referem ao solo de Catalão. Esses "outliers" da equação de regressão sugerem que grande parte do enxofre disponibilizado pela calagem provêm da dessorção do $\mathrm{S}-\mathrm{SO}_{4} \overline{\bar{a}}$ dos sítios de troca aniônica, o que, entretanto, somente poderá ser confirmado através de experimentos de adsorção e dessorção de $\mathrm{S}_{-} \mathrm{SO}_{4}^{=}$na ausência e presença de calagem.

Os potenciais de mineralização de enxofre obtidos no experimento de incubação mostram que em experimentos futuros será necessârio trabalhar com um número maior de solos, com uma faixa mais ampla de matéria orgânica, pa ra que se possa agrupar solos com similares capacidades de suprimento de enxofre para as plantas. Por outro lado, devem-se experimentar outros modelos estimadores dos potenciais de mineralização do enxofre dos solos... E possível que os modelos matemáticos de duplos exponenciais discutidos por MOLINA et alii (1980) e utilizados por JUMA et alii (1984) possam discriminar as diferentes formas de enxofre do so10, passiveis de ser disponibilizadas atravês da incubação e da calagem. 
4.8. CORRELACÃO E CALIBRACÃ̃ DE ANÁLISES DE ENXOFRE-SUL FATO DISPONIVEL NOS SOLOS E DETERMINACÃO DOS NÍVEIS CRÍTICOS

Os métodos (têcnicas) de anậlises de solos pretendem simular a extração dos nutrientes pelas plantas. A sua utilização, para fins de recomendaçes de adubação ou correção dos solos, somente ê possîvel caso for estabelecida a correlação entre os resultados analíticos e a res posta das culturas. Entretanto, não existem teorias ou con ceitos que determinem "a priori" a escolha de modelos (fisicos e/ou formais) para avaliação dos níveis críticos de nutrientes nos solos que maximizem a produção física e oti mizem em termos econômicos. Desenvolveram-se diversos conceitos e "leis", tais como a "lei" do mínimo de Justus von Liebig (RUSSEL, 1973), a "lei" dos incrementos decrescentes de Mitscherlich (MENGEL \& KIRKBY, 1980), o conceito de percentagem de suficiência de Baule (TISDALE \& NELSON, 1975) e o conceito de mobilidade de nutrientes (BRAY, 1948). Segundo RAIJ (1981) o conceito de mobilidade de nutrientes tenta conciliar a "lei" do mínimo com o conceito de percen tagem de suficiência. Os nutrientes relativamente imóveis como o fósforo, o potássio, o cálcio e o magnésio teriam comportamento mais relaciona com o conceito de percentagem de suficiência. Os nutrientes môveis como o nitrogế nio-nítrico (e a âgua, segundo BRAY, 1948), comportar-se-iam mais de acordo com a lei do mínimo. 
Outros conceitos como a percentagem de resposta e a resposta atual foram empregados por HOEFT et alii (1973) e FONTES (1979) na avaliação do enxofre-sulfato disponível nos solos via diversos extratores. Os dois conceitos acima baseiam-se na premissa de que a resposta da produção (ou absorção) à adubação é inversamente proporcio nal à quantidade do elemento nativo (em forma disponivel) pre sente nos solos.

\subsubsection{CORRELACÃO DO S-SO VERSUS ABSORCÃO DE ENXOFRE}

Dentre os extratores testados rejeitou-se o $\mathrm{HCl} 0,05 \mathrm{M}$, idealizado por ISLAM \& PONNAMPERUMA (1982) para solos de várzeas. Esse extrator não apresentou comportamen to satisfatório em solos de sequeiro por não se enquadrar no pré-requisito bâsico da determinação turbidimétrica de $\mathrm{S}_{-} \mathrm{SO}_{4}^{=}$: a obtenção de extratos de solos absolutamente límpi dos. Na tabela 4.4. observa-se que os piores coeficientes de correlação ocorreram entre produção de matéria seca (e absorção de enxofre) versus o extrator $\mathrm{HCl}$ 0,0 M. Com o agrupamento dos solos pelos teores de carbono, aqueles com teores menores que 1,2\% (todos eles arenosos) apresentaram coeficientes de correlação baixos, embora signifi cativos. Nos solos mais argilosos, com teores de carbono superiores a $1,2 \%$ a correlação do extrator $\mathrm{HCl} 0,05 \mathrm{M}$ com a 
produção de matéria seca $(x=0,037 \mathrm{~ns})$ e abosrção de enxo fre $(r=0,033 \mathrm{~ns})$ simplesmente é inexistente. A observa çâo visual dos extratos acusou coloração vermelho-amarelada,cuja remoção não foì possível nem mesmo com a adição de carvão ativado e filtragens sucessivas. Essa coloração também foi observada nos extratos dos latossolos arenosos, como de Assis e de Botucatu- 1 .

Devido à grande variação entre o comportą mento dos solos, notou-se grande dispersão dos pontos gráfí $\cos$ de absorção de enxofxe versus $\mathrm{S}_{-} \mathrm{SO}_{4}=$ disponível, extraí do com $\mathrm{Ca}\left(\mathrm{H}_{2} \mathrm{PO}_{4}\right)_{2} \cdot \mathrm{H}_{2} \mathrm{O}-500 \mathrm{ppm}$ em ácido acético $2,0 \mathrm{~N}$ (figura 4.12), $\mathrm{NH}_{4} \mathrm{OAC} 0,5 \mathrm{~N}$ (figura 4.11.) e $\mathrm{CaCl}_{2} 0,15^{\circ}$ (figura 4.10 .3 . Vê-se que a capacidade de extração de $\mathrm{S}_{-} \mathrm{SO}_{4}=\bar{e}$ sensivelmente diminuída nos solos argilosos, para os três extratores estudados, à semelhança do que ocorre com o fós foro disponível nos solos. Por essa razão optou-se pelo agrupamento dos solos em duas classes, istoé, argilosos (com teor de carbono maior que $1,2 \%$ ) e arenosos. As equações de regressão foram calculadas e os diagramas de dispersão de pontos plotados a partir de médias de três repetições.

4.8.1.1. Correlação entre absorção de enxofre pelo milho e $\mathrm{S}_{-} \mathrm{SO}_{4}^{=}$extraído por $\mathrm{CaCl}_{2} 0^{\circ}, 15 \%$

Para o estudo da correlação entre a absor ção de enxofre pelo milho e $\mathrm{S}_{-} \mathrm{SO}_{4}=$ extraído por $\mathrm{CaCl}_{2} 0,15 \%$ 
obtiveram-se os diagramas de dispersão de pontos constantes na figura 4.10. , com as respectivas equações de regres são:

a) Solos com teores de carbono menores que $1,2 \%=$

$$
\begin{gathered}
X=18,37+1,86 X-68,88 \cdot 1 / X \\
R=0,769 * *(n=72):=
\end{gathered}
$$

b) Solos com teores de carbono maiores que $1,2 \%$

$$
\begin{gathered}
Y^{*}=48,86+2,90 X-158,88 \cdot 1 / X \\
R=0,662 * *(n=72)
\end{gathered}
$$

Os coeficientes de determinação das duas equações mostram que nos solos argilosos com maiores teores de carbono houve mais dispersão dos pontos. Na figura 4.10 , observa- se que a calagem influiu significativamente na extração de maiores quantidades de $\mathrm{S}_{-} \mathrm{SO}_{4}=$ por $\mathrm{CaCl}_{2}$ 0,15\%. Segundo HOEFT et alii (1973) as soluções diluídas de $\mathrm{LiCl}$ e $\mathrm{CaCl}_{2}$ extraem apenas o $\mathrm{S}-\mathrm{SO}_{4}=$ pron tamente solúvel em água, pois o ânion $\mathrm{Cl}^{-}$não ê capaz de deslocar o $\mathrm{S}_{-} \mathrm{SO}_{4}=$ adsorvido aos colöides dos solos. Assim é possível a tribuir à dessorção de $\mathrm{S}_{-} \mathrm{SO}_{4}=$ e à mineralização da matéria orgânica (WILLIAMS \& STEINBERGS, 1967; SINGH, 1984b; MARTINI \& MUTTERS, 1984) a maior absorção de enxofre pelo milho. No experimento de incuba ção aberta em laboratôrio tambëm se lixiviaram maiores quantidades de $\mathrm{S}-\mathrm{SO}_{4}=$ por efeito da calagem (veja figura 4.2 e tabela 4.5.).

As correlações obtidas entre absorção de en 
xofre e $\mathrm{S}_{-} \mathrm{SO}_{4}=$ extraido por $\mathrm{CaCl}_{2} 0,15^{\circ}$ nas condicões desse experimento (veja tabela 4.4. e figura 4.10.) aproximam-se bastante daquelas obtidas por outros pesquisadores (WILLIAMS \& STEINBERGS, 1959; KOWALENKO \& LOWE; 1975; CALVET, 1986). Apesar de $\mathrm{OCaCl}_{2} 0,15 \%$ apresentar extratos bem lím pidos após duas filtragens, esse extrator apresenta o inconveniente de facilitar o crescimento de fungos. Isso implica na imediata determinação analítica do $\mathrm{S}_{-} \mathrm{SO}_{4}^{=}$dos extratos, ou então no seu armazenamento em refrigerador.

Um outro asnecto que deve ser observado, ê que as quantidades de $\mathrm{S}_{-} \mathrm{SO}_{4}^{\bar{*}}$ extraído por $\mathrm{CaCl}_{2} 0,15^{\circ}$, nas condições desse experimento são, de um modo geral, mais elevadas que as encontradas por outros autores (WILLIAMS \& STEINBERGS, 1959 ; WILLIAMS \& STEINBERGS, 1967; BEATON \& FOX, 1971). Como na extração não se usou o carvão ativado para auxiliar no clareamento dos extratos, aventa-se a possibilidade de que a secagem tenha aumentado as quantidades de $\mathrm{S}_{-} \mathrm{SO}_{4}=$ extraível por $\mathrm{CaCl}_{2} 0,15^{\circ}$, segundo observações de FRENEY et alii (1962) e WILLIAMS \& STEINBERGS (1964). Como jâ se comentou na seç̧ão 3.1 .4 , o carvão ativado consegue reduzir a um nivel insignificante a variação dos teores de $\mathrm{S}_{-} \mathrm{SO}_{4}^{=}$nos solos, resultante da secagem e do armazenamento (PEVERILL et alii, 1974). 
.149 .

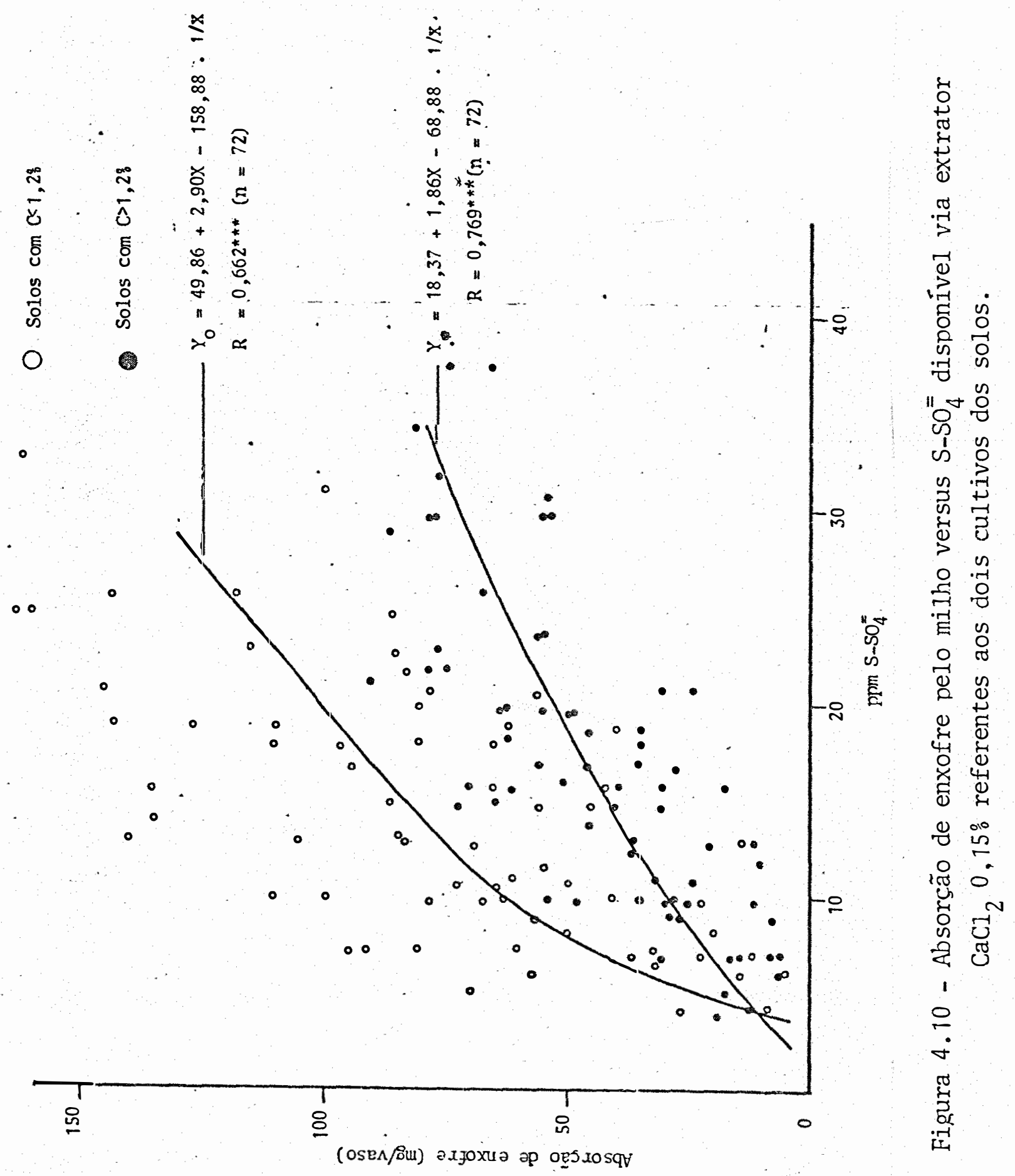


4.8.1.2. Correlação entre absorção de enxofre pelo milho e $\mathrm{S}_{-} \mathrm{SO}_{4}$ extraído por $\mathrm{NH}_{4} \mathrm{OAC} \quad 0,5 \mathrm{~N}$

Para o estudo da correlação da absorção de enxofre pelo milho versus $\mathrm{S}_{-} \mathrm{SO}_{4}=$ extraido por acetato de amônio $0,5 \mathrm{~N}$ obtiveram-se os diagramas de dispersão de pontos constantes na figura 4.T1. Para os solos argilosos (C) $1,2 \%$ ) obteve-se a seguinte equação de regressão:

$$
\begin{gathered}
Y^{*}=25,79+7,62 X-0,173 X^{2} \\
R=0,637 * * *(n=72)
\end{gathered}
$$

e para os solos arenosos $(C<1,2 \%$ a equação:

$$
\begin{gathered}
X=-6,68+6,12 X-0,125 X^{2} \\
R=0,814^{* * *}(n=72)
\end{gathered}
$$

Os gráficos mostram que a capacidade de extração de $\mathrm{S}_{-} \mathrm{SO}_{4}^{=}$pelo acetato de amônio $0,5 \mathrm{~N}$ é menor nos so los mais argilosos, à semelhança do que ocorre com os outros dois extratores estudados. REISENAUER et alii (1973) comentam que o extrator acetato de amônio r,oN desloca o $\mathrm{S}_{-} \mathrm{SO}_{4}=$ solúvel em água e parte do $\mathrm{S}_{-} \mathrm{SO}_{4}=$ adsorvido. McClung et alii (1959), por outro lado, consideram que mem solos previamente fertilizados com adubos contendo altos teores de enxofre, o $\mathrm{S}_{-} \mathrm{SO}_{4}=$ adsorvido (principalmente no subsolo) 


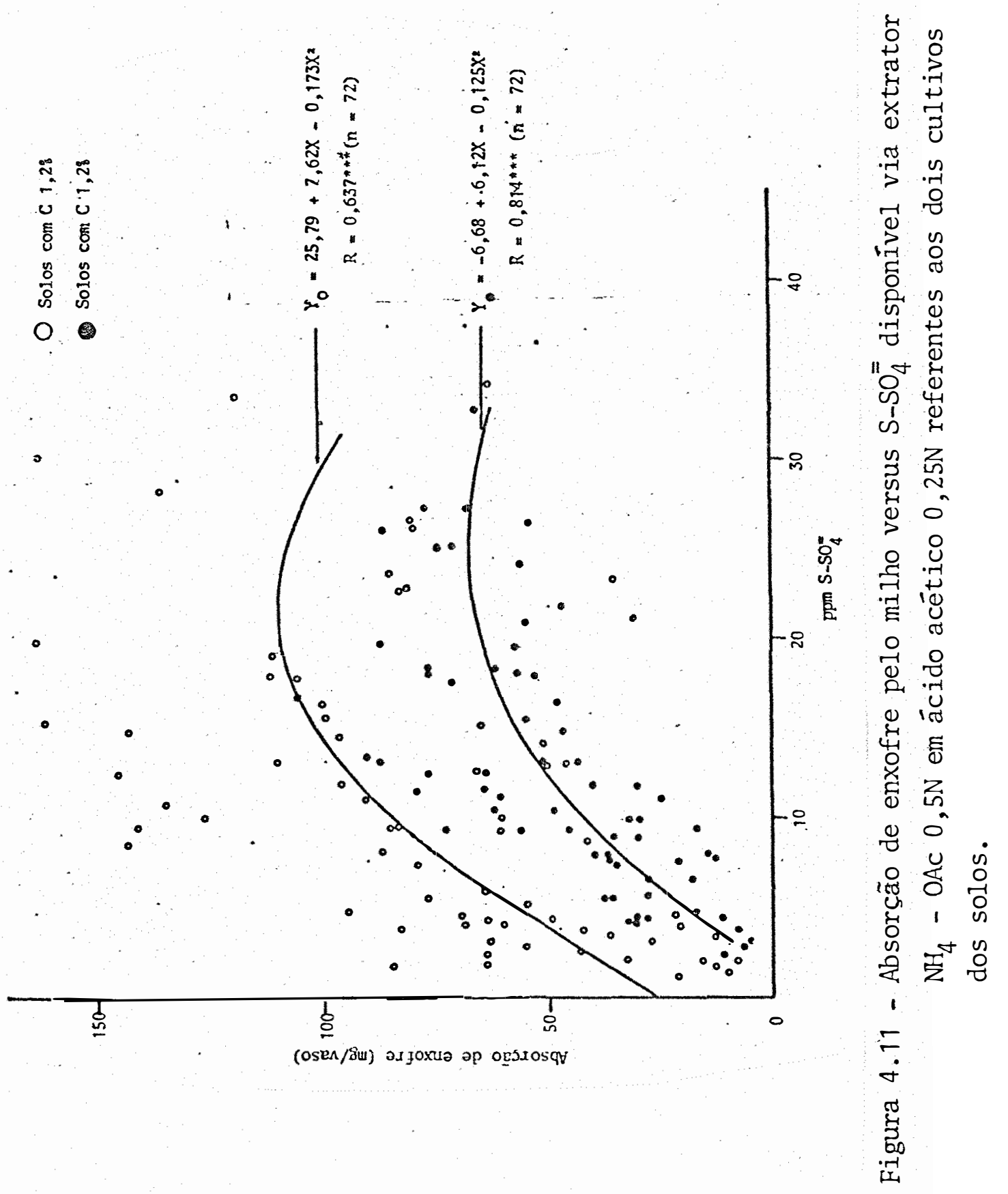


pode ser uma importante fonte de enxofre para as puantas. Na figura 4.1.1. verifica-se que a calagem tem influência menos marcante na extração de $\mathrm{S}_{-} \mathrm{SO}_{4}^{\bar{y}}$ por acetato de amônio $0,5 \mathrm{~N}$ do que a constatada para o extrator $\mathrm{CaCl}_{2} 0,15 \%$. Entretanto, em solos como o de Catalão, o $\mathrm{S}_{-} \mathrm{SO}_{4}^{=}$extraido pelo acetato de amônio $0,5 \mathrm{~N}$ em acêtico $0,25 \mathrm{~N}$ ê maior na presença de calagem, porque não houve maior adsorção aos colóides dos solos. No solo de Rio Paranaíba, a calagem so mente teve influência significativa na extração de $\mathrm{S}_{-} \mathrm{SO}_{4}^{=}$ na dose mais elevada de $\mathrm{S}_{-} \mathrm{SO}_{4}^{=}$adicionado $(40 \mathrm{ppm}$ de $\mathrm{S})$. Es sa situação confirma que esse extrator tem pequena capacidade de extração de $\mathrm{S}_{-} \mathrm{SO}_{4}^{\bar{z}}$ em solos argilosos como Catalão e Rio Paranaíba na ausência de calagem. A absorção de enxo fre mais elevada nos solos argilosos (com teores de carbono superiores a $1,2 \%$ ), anesar de menor a extração, é pronta mente explicada pela interação da calagem com a gessagem, conforme pode ser visto na tabela 4.6. de análise da variância conjunta e tabela 4.7. de comparações de médias. En tende-se, desse modo, a maior dispersão dos pontos na figu ra 4.11 . e o menor coeficiente de correlação da equação calculada para os solos argilosos $\left(R=0,637^{* *}\right)$, se comparada com o dos solos arenosos $(R=0,814 * * *)$. A maior absorção de enxofre no primeiro caso não teve correspondência na ex tração por acetato de amônio $0,5 \mathrm{~N}$. Todavia, os potenciais de mineralização dos sete solos estudados mostraram proporcio nalidade aproximada com a absorção de enxofre pelo milho, 
principalmente na presença de calagem (vieja figura 4.9.). Os coeficientes de correlação da absorção de enxofre obtidos por diversos autores mostram valores aproximadamente iguais, para diversas culturas, usando o $\mathrm{NH}_{4} \mathrm{HOAc} 0,5 \mathrm{~N}$ ou $1 \mathrm{~N}$. KANG et alii (1981) usando o milho como planta-teste em experimento de casa-de-vegetação com so los da Nigéria, obteve correlação linear simples muito sig nificativa, entre absorção de enxofre e enxofre extraído por $\mathrm{NH}_{4} \mathrm{OAC} i \mathrm{~N}$ pH 7,0 $\left(r=0,739^{* * *}\right)$. PALASKAR \& GHOSH (1981) por outro lado, trabalhando com solos da India e usando re polho como planta teste obteve correlação satisfatória entre produção relativa e $\mathrm{S}_{-} \mathrm{SO}_{4}^{=}$extraído por $\mathrm{NH}_{4} \mathrm{OAc} 0,5 \mathrm{~N}(\mathrm{r}=$ $0,64 *$ *). NASCIMENTO \& MORELLI (1980) obtiveram corrèlação não significativa entre produção relativa de alfafa com o mesmo método em solos do Ría Grande do Sul $(n=0,526 \mathrm{~ns})$.

Como já foi comentado para o extrator $\mathrm{CaCl}_{2}$ $0,15 \%$, os extratos de $\mathrm{NH}_{4} \mathrm{OAc} 0,5 \mathrm{~N}$ tambêm não podem ser con servados à temperatura ambiente por tempo prolongado. A presença de fungos foi observada nos extratos quandoos mes mos foram guardados à temperatura ambiente por periodos su periọres a 4 ou 5 dias. 
4.8.1.2. Correlação entre absorção de enxofre pelo milho e $\mathrm{S}-\mathrm{SO}_{4}^{=}$extraído por $\mathrm{Ca}\left(\mathrm{H}_{2} \mathrm{PO}_{4}\right)_{2} \cdot \mathrm{H}_{2} \mathrm{O}-500 \mathrm{ppm}$ de de $\mathrm{P}$ em ácido acético $2, \hat{\mathrm{o} N}$

Na figura 4.12 tem-se o diagrama de disper são de pontos de absorção de enxofre versus $\mathrm{S}_{-} \mathrm{SO}_{4}=$ extraído por $\mathrm{Ca}\left(\mathrm{H}_{2} \mathrm{PO}_{4}\right)_{2} \cdot \mathrm{H}_{2} \mathrm{C}-500$ ppm P em ácido acético 2,0N. Para os solos argilosos (C $>1,2 \%$ ) obteve-se a seguinte equação de regressão:

$$
\begin{gathered}
Y^{*}=87,56+2,56 \mathrm{X}-305,43 \cdot 1 / \mathrm{X} \\
\mathrm{R}=0,6698^{* * *}(\mathrm{n}=72)
\end{gathered}
$$

e para os solos arenosos $(C<1,2 \%$ ) a equação:

$$
\begin{gathered}
Y=62,38+0,54 X-280,40 \cdot 1 / X \\
R=0,840 * * * \quad(n=72)
\end{gathered}
$$

Os grấficos da figura 4.12 mostram grande dispersão de pontos pelas mesmas razões já apontadas na secção 4.8.1.2. REISENAUER et alii (1973) consideram que o sulfato solûvel mais o adsorvido e mais uma fração do en xofre orgânico são extraíveis com $\mathrm{NaHCO}_{3}$ e com as soluções de fosfatos em âcido acético. Nas condições desse experimento fizeram-se alguns pré-testes com bicarbonato de só- 


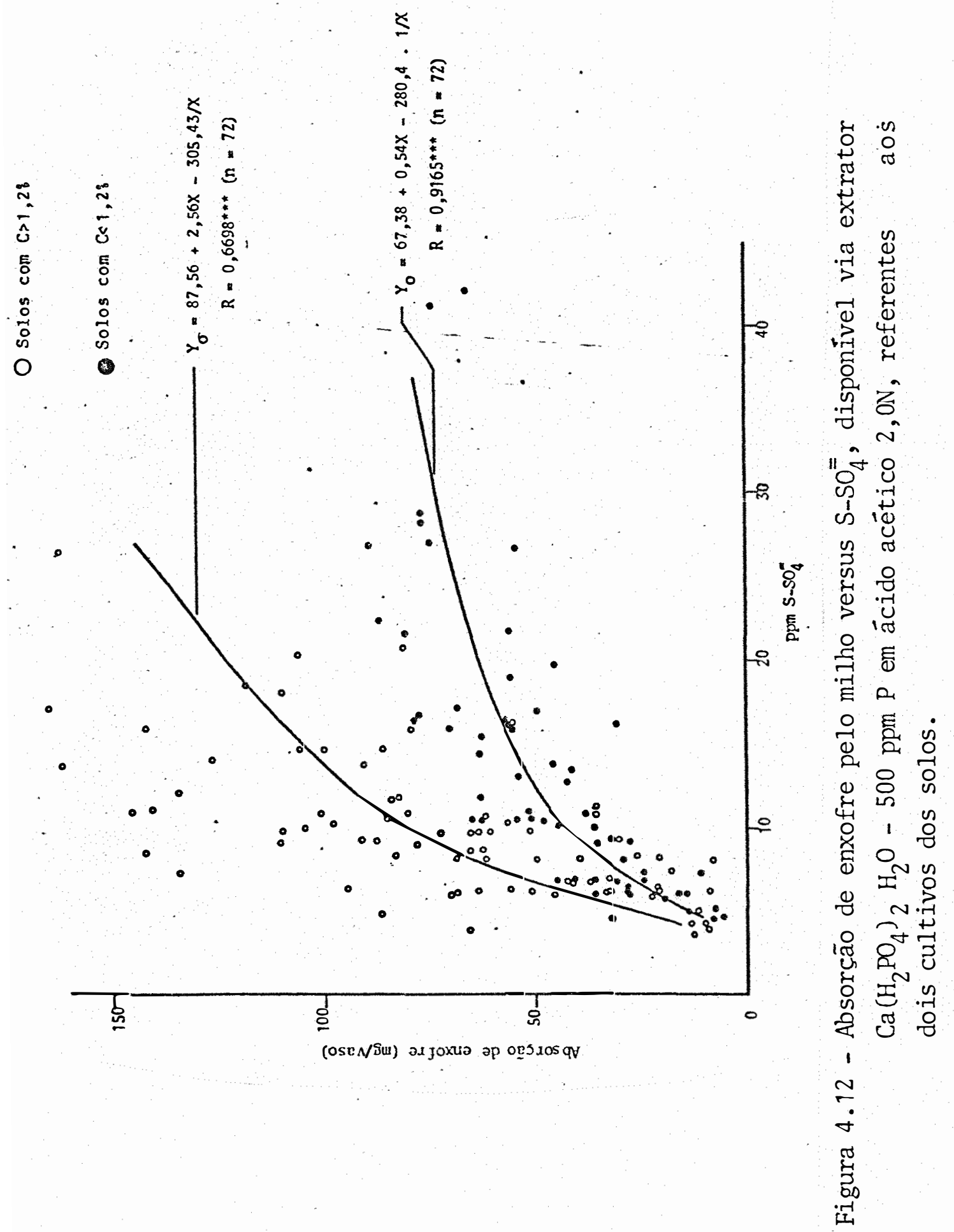


dio, porém o método foi prontamente abandonado após infrutíferas tentativas de clareamento dos extratos com carvão ativado.

Nos solos argilosos a capacidade de extração de $\mathrm{S}-\mathrm{SO}_{4}=$ pelo $\mathrm{Ca}\left(\mathrm{H}_{2} \mathrm{PO}_{4}\right)_{2} \cdot \mathrm{H}_{2} \mathrm{O}-500 \mathrm{ppm}$ de $\mathrm{P}$ em áci do acêtico $2,0 \mathrm{~N}$ é significativamente menor do que nos solos arenosos. SEARLE (1979) e METSON (1979) atribuem essa menor capacidade de extração à fixação do fosfato da solução extratora por óxidos de ferro e alumínio dos solos. Pa ra contornar o problema esses pesquisadores sugerem o aumento da relação solução extratora : solo. Apesar de essas restrições, o extrator foi o que apresentou o melhor desem penho, pois os extratos apresentaram-se completamente límpidos, não se notando aparecimento de fungos, mesmo depois de armazenados à temperatura ambiente pelo período de seis meses. As correlações entre absorção de enxofre e $\mathrm{S}_{-} \mathrm{SO}_{4} \overline{\text { ex }}$ traído por $\mathrm{Ca}\left(\mathrm{H}_{2} \mathrm{PO}_{4}\right)_{2} \cdot \mathrm{H}_{2} \mathrm{O}-500 \mathrm{ppm}$ de $\mathrm{P}$ em ácido acético $2,0 \mathrm{~N}$ cbtidas nesse experimento para os solos arenosos $\left(R=0,850^{* *}\right)$ e para os solos argilosos $\left(R=0,670^{* *}\right)$ tam bêm foram obtidas por HOEFT et alii (1973), FONTES (1979) e KANG et alii (1981). Para se obter correlações mais estreitas entre absorção de enxofre e $\mathrm{S}_{-} \mathrm{SO}_{4}^{=}$extraível por fos fatos em âcido acético em solos brasileiros sugere -se que sejam testadas diversas relações solução : solo e o agrupa mento dos solos em grupos mais homógêneos. Um dos critérios mais viáveis de agrupamento dos solos crê-se que seja 
discutido na secção 4.7.2. O critêrio de agrupamento pelo teor de carbono, usado nesse experimento, pode não ser o mais adequado, por que altos teores de carbono não correspondem necessariamente a altos teores de enxofre disponível e vice-versa. Entretanto, o critério de agrupamento dos solos pelos seus potenciais de mineralização de enxofre somente se torna viâvel quando se dispuser dessa informação a partir de um númerro elevados de solos.

\subsubsection{CALIBRACÃO DE MÉTODOS DE ANÁLISES DE ENXO- FRE-SULFATO DISPONÍVEL E NIVEIS CRITTICOS NOS SOLOS}

E crença corrente entre os cientistas de so los que todo programa de calibração de anâlises de disponi bilidade de um nutriente nos solos deve ser precedida de experimentos de correlação em estufa, visando a funcionalidade do método de anâlise. Os experimentos de calibração, propriamente ditos, deveriam ser executados a campo e realizados obrigatoriamente nara cada cultura em estudo. De vido ao alto custo operacional da experimentação a campo, as tentativas de se fazer a "calibração" de anälise de solos, em caráter exploratôrio, com dados de experimentos de casa-de-vegetação são vâlidas.

Como os solos estudados nesse experimento a presentam grande variação com relação à disponibilidade de 
enxofre transformaram-se os dados de produção de matéria seca para valores relativos, utilizando-se o conceito de percentagem de suficiência ou produção relativa (TISDALE \& NELSON, 1975; RAIJ, 1981). Nas condições desse experimento os valores de produção relativa de matéria seca da parte aérea do milho foram obtidas a partir de curvas de resposta à adubação sulfatada, estimađas por regressão polinomial. Quando as curvas acusavam máximos de produção (Y) den tro da faixa estudada de doses de gesso $(0,20$ e 40 ppm de $S$ ), esses valores foram usados como máximos da relação:

$$
\text { Produção relativa }=\frac{\text { Produção observada }}{\text { Produção máxima estimada }} \times 100 .
$$

Todavia, quando as equações de regressão estimadas acusaram máximos fora da faixa estudada, tomou-se como denominador da relação acima o valor máximo observado para cada solo e cada cultivo separadamente. As curvas de "calibração" foram calculadas com dados mêdios de três repetições:

4.8.2.1. Produção relativa de matéria seca de milho versus $\mathrm{S}_{-} \mathrm{SO}_{4}=$ extraído por $\mathrm{CaCl}_{2} 0,15 \%$

Na figura 4.13. observa-se grande dispersão dos pontos, na locação da produção relativa de matéria seca de milho contra o $\mathrm{S}_{-} \mathrm{SO}_{4}=$ extraido por $\mathrm{CaCl}_{2} 0,15 \%$, compu tando-se todos os solos, na ausência e presença de cala- 


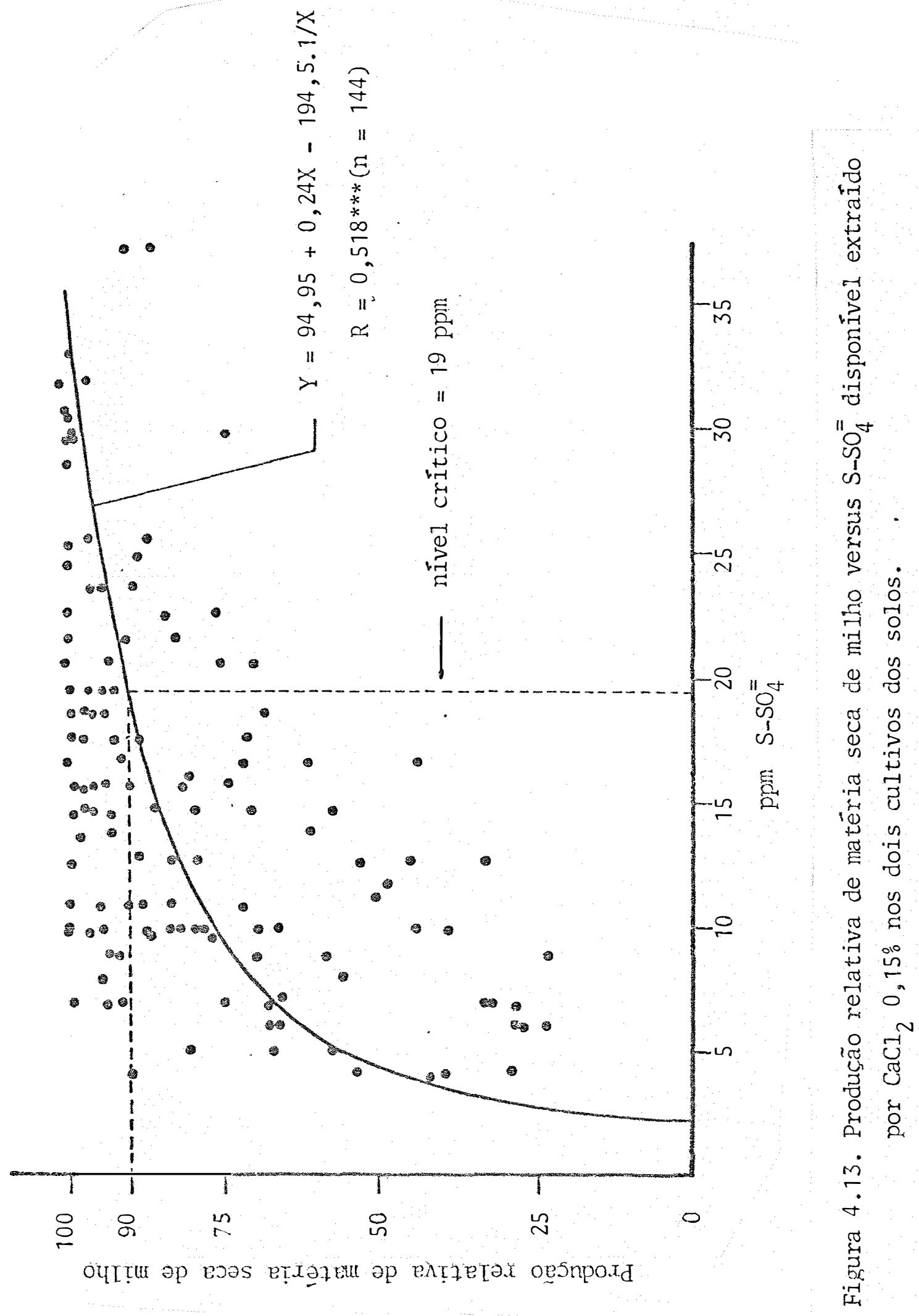


gem e nos dois cultivos. A equação de regressão:

$$
\begin{gathered}
Y=94,95+0,24 X-194,51 \cdot 1 / X \\
R=0,518^{* * *}(n=144)
\end{gathered}
$$

mostra um coeficiente de correlação altamente significati vo a $1 \%$ de probabilidade. Por interpolação verifica-se que para obter $90 \%$ da produção máxima, a análise de solo deve acusar 19 ppm de $\mathrm{S}_{-} \mathrm{SO}_{4}=$ extraível por solução de $\mathrm{CaCl}_{2}$ a 0,15\%. Este valor aproxima-se bastante da produção máxima, podendo assim ser considerado como o nível crítico de $\mathrm{S}_{-} \mathrm{SO}_{4}=$ no solo $(19 \mathrm{ppm})$, acima do qual, existe reduzida pos sibilidade de se obter resposta à adubação sulfatada. Na literatura mundial os níveis críticos de $\mathrm{S}_{-} \mathrm{SO}_{4}^{=}$, extraído por $\mathrm{CaCl}_{2} 0,15^{\circ}$ são significativamente menores do que o en contrado nas condições desse experimento. WALKER \& DOORNEN BAL (1972), em pastagem de leguminosas e gramíneas do Cana dá estabeleceram o nível crítico de 3 ppm de $\mathrm{S}_{-} \mathrm{SO}_{4}=$ extraído por $\mathrm{CaCl}_{2}$, $1 \mathrm{M}$ e BEATON \& FOX (1971) o nível crítico de $6 \mathrm{ppm}$ de $\mathrm{S}-\mathrm{SO}_{4}=$ extraído por $\mathrm{CaCl}_{2} 0,01 \mathrm{M}$.

4.8.2.2. Produção relativa de matéria seca de milho versus $\mathrm{S}_{-} \mathrm{SO}_{4}^{=}$extraído por acetato de amônio $0,5 \mathrm{~N}$ em áci do acético $0,25 \mathrm{~N}$ 
.161.

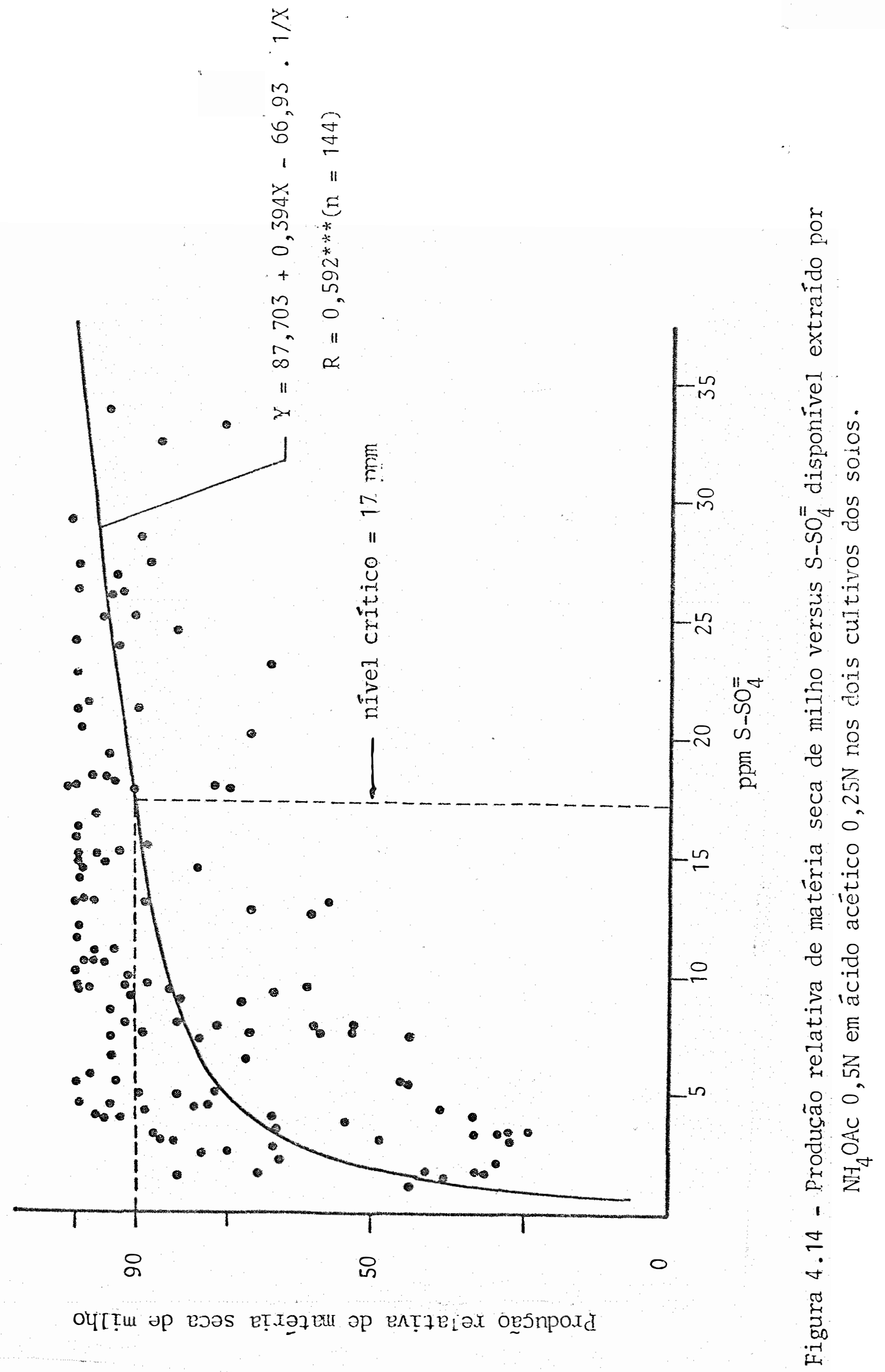


tuada dispersão đe pontos na locação da produção de ma tëria seca do milino contra o $\mathrm{S}-\mathrm{SO}_{4}^{=}$extraído por acetato de a mônio $0,5 \mathrm{~N}$ em âcido acêtico nas mesmas condições do extrator $\mathrm{CaCl}_{2} 0,15 \%$. A equação de regressão:

$$
\begin{gathered}
Y=87,70 * 0,39 \times * 66,93 \cdot 1 / X \\
R=0,592 * * *(n=144)
\end{gathered}
$$

mostra um coeficiente de correlação significativo a $1 \%$ de probabilidade, que permite a interpolação para $90 \%$ da produção relativa máxima, que corresponde a $17 \mathrm{ppm}$ de $\mathrm{S}-\mathrm{SO}_{4}=$ extraido por acetato de amônio $0,5 \mathrm{~N}$. Considerando-se esse valor como nível crîtico, ele também difere consideravel mente dos encontrados na 1 iteratura. Em solos de cerrados de São Paulo e Goiás (Brasil), usando o milheto como planta-teste. MCCLUNG et alii (1959) determinaram o nivel critico de 6-7 ppm. Para a a Ifafa HARIARJ et alii (1962) encontraram o nível crïtico de 12 ppm. Trabalhando com repo1ho, que é uma cultura de alta demanda de enxofre PALASKAR \& GHOSH (1981) obtiveram o nivel critico de 30 ppm de $\mathrm{S}_{-} \mathrm{SO}_{4}=$, para alcançar $85 \%$ da produção relativa máxima, em solos da India. 
.163.

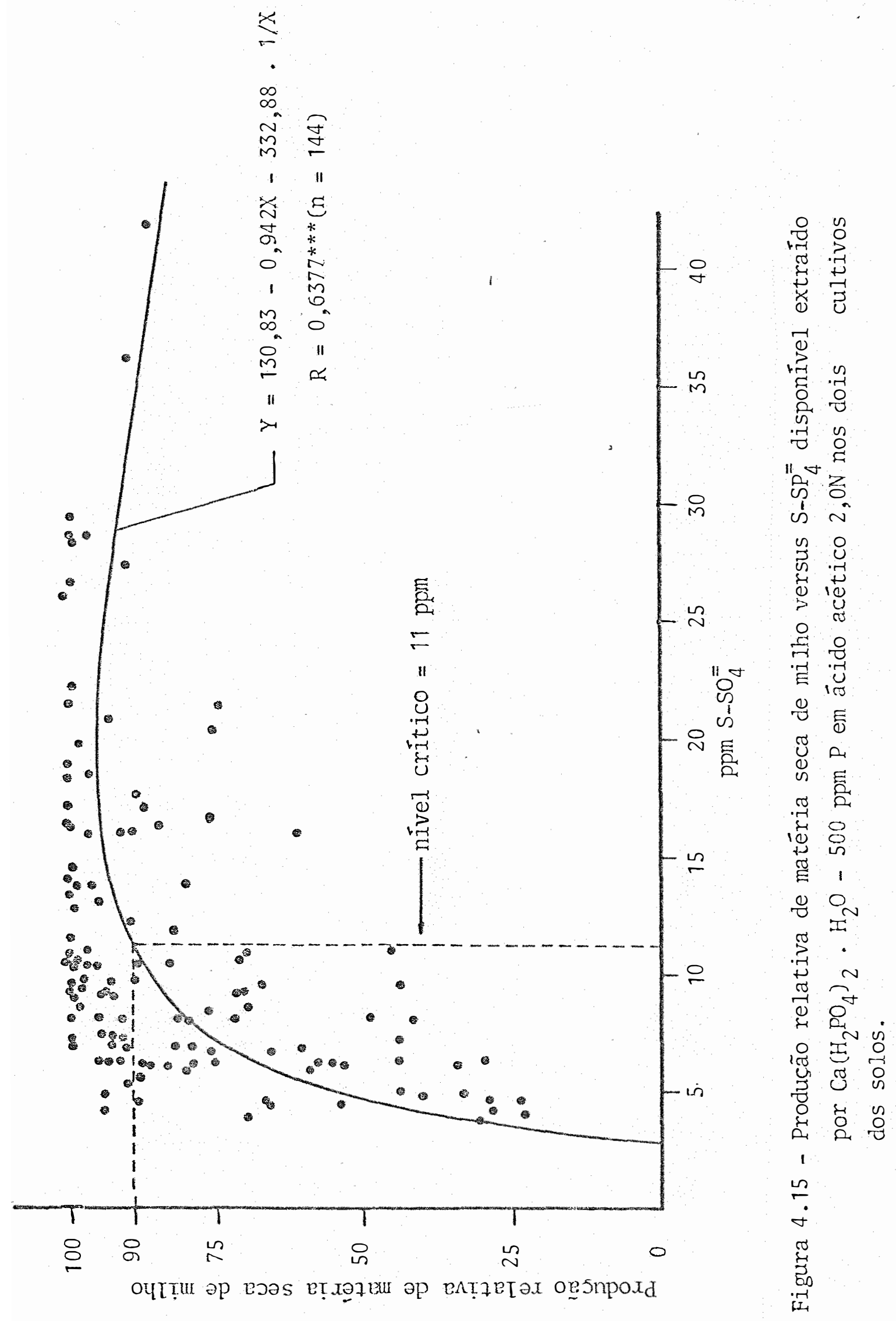


4.8.2.3. Produção relativa de matêria seca de milho versus $\mathrm{SmSO}_{4}^{=}$extraido por $\mathrm{Ca}\left(\mathrm{H}_{2} \mathrm{PO}_{4}\right)_{2} \cdot \mathrm{H}_{2} \mathrm{O}-500$ ppm pem $\underline{a}$ ciclo acêtico 2 , (îN

Na figura 4.15. tem-se a equação de regressão:

$$
\begin{gathered}
Y=130,83-0,94 X-332,88 \cdot 1 / X \\
R=0,6377 * * *(n=144)
\end{gathered}
$$

com um coeficiente de correlașão altamente significativo a 1\% de probabilidade. Por interpolação, $11 \mathrm{ppm}$ de $\mathrm{S}-\mathrm{SO}_{4}^{=} \mathrm{ex}-$ traidos por $\mathrm{Ca}\left(\mathrm{H}_{2} \mathrm{PO}_{4}\right)_{2} \cdot \mathrm{H}_{2} \mathrm{O}-500$ ppm de $\mathrm{P}$ em äcido ace् tico $2 \mathrm{~N}$ correspondem a $90 \%$ da produção relativa máxima. Es se valor aproxima-se dos encontrados por HOEFT et alii (1973) para a alfafa em solos de Wisconsin (USA). Em solos de Minas Gerais, FONTES (1979) encontrou o nivel crítico de 4 a $12 \mathrm{ppm}$ de $\mathrm{S}-\mathrm{SO}_{4}=$ para o extrator em questão, considerando ca da solo individualmente. Um outro extrator $-\mathrm{NaH}_{2} \mathrm{PO}_{4}-\mathrm{em}$ à cido acético $2 \mathrm{~N}$ - com comportamento provavelmente similar ao $\mathrm{Ca}\left(\mathrm{H}_{2} \mathrm{PO}_{4}\right)_{2}$. $\mathrm{H}_{2} \mathrm{O}-500 \mathrm{ppm}$ de $\mathrm{P}$ em âcido acético $2,0 \mathrm{~N}$ foi estudado por COOPER (1968) em pastagens de Nova Zelândia, obtendo o nível crítico de $10 \mathrm{ppm}$ de $\mathrm{S}-\mathrm{SO}_{4}=$ 


\subsubsection{ABSORGÃO RELATIVA DE ENXOFRE PELO MILHO VER SUS $\mathrm{S}^{-\mathrm{SO}_{4}}=$ ESTIMADO POR EXTRATORES QUIMICOS}

Os trabalhos de experimentação em vasos tem como inconveniente principal o crescimento restrito do sistema radicular, como mostram dados de McCLUNG et alii (1959). Essa restrição se traduz, segundo esses pesquisadores, em produção reduzida de matêria seca,porém sem maiores reflexos na absorção de um nutriente, no caso o enxofre pelo milheto. Por outro 3ado, SIMON-SYLVESTRE(1960)conside ra que no caso do enxofre não ocorre consumo de 1 uxo, como para a maioria das culturas. Trabalhos mais recentes parecem contrariar as afirmaçōes acima, principalmente em cul turas com altos indices de produtividade, o que em muitos casos é sinônimo de capacidadé de resposta a altas doses de nitrogênio. Já foì visto na secção 4.6.2. que relações N/S e P/S são inversamente proporcionais à produção de ma téria seca e absorção de enxofre pelo milho. Os trabalhos de JANZEN \& BETTANY(1984) e de MAYNARD et alii(1983 b) afirmam que altas adubações nitrogenadas induzem o consumo de maiores quantidade de enxofre induzindo a deficiência do elemento nos solos. Em condições brasileiras esse fato jâ foi observado por MCCLUNG \& OUINN(1959) em solos de cer rado, por WANG et alii(1976 a,b) em solos de vârzea da amazônia e por FREITAS \& JORGE(1982). Em todos os trabalhos acima a resposta ao enxofre aumentou com o tempo e a deficiência foi mais evidente com altas doses de nitrogênio. 
Nas condições desse experimento as elevadas adubações nitrogenadas "forçaram" a absorção de enxofre, levando os níveis críticos de enxofre total na parte aérea do milho, se considerada a absorção de enxofre(veja secção 4.6.T.). Da mesma maneira os níveis criticos de $\mathrm{S}_{-} \mathrm{SO}_{4}=\mathrm{ex}-$ traível pelos três extratores estudados são substancialmen te majoracios, se, em vez da nrodução relativa de matêria seca, for usada a absorsão relativa de enxofre versus extratores, como se observa na tabela 4.13. Apesar de os coe ficientes de correlação serem mais elevados do que os das equações referentes à produção relativa de matëria seca de milho, o nível critico de $\mathrm{S}-\mathrm{SO}_{4}=$ nos solos é super-estimado sistematjcamente para os três extratores. Pelo critério da matéria seca, o nível crítico de $\mathrm{S}_{-} \mathrm{SO}_{4}=$ nos solos pelo extrator acetato de amônia $0,5 \mathrm{~N}$ è de $17 \mathrm{ppm}$ enquanto que pe 10 critério da absorção de enxofre estimaram-se níveis crí ticos de $18 \mathrm{ppm}$ para os solos arenosos ( $\mathrm{C}$ menor que $1,2 \frac{\circ}{\circ}$ ) e de 30 ppm de $\mathrm{S}-\mathrm{SO}_{4}$ para os solos argilosos. Para o extra tor $\mathrm{CaCl}_{2} 0,15 \%$, pelo critério da matêria seca, o nível crí tico mẻdio(considerando-se todos os solos) é de $19 \mathrm{ppm}$ de $\mathrm{S}-\mathrm{SO}_{4}=$, enquanto que pelo critêrio da absorção de enxofre o nível crítico médio ê de $25 \mathrm{ppm}$. A menor discrepância entre os doịs critérios é observada com o extrator $\mathrm{Ca}\left(\mathrm{H}_{2} \mathrm{PO}_{4}\right)_{2}$ - $\mathrm{H}_{2} \mathrm{O}-500$ ppm de $\mathrm{P}$ em âcido acêtico 2,0 N: pela matéria seca o nível crítico ê de 11 ppm de S-SO= contra um valor médio(com todos os solos) de 15 ppm para a absorção de enxofre. 
Tabela 4.13 - Equações de regressão descritivas da relação entre a ab sọção relativa de enxofre pelo milho versus $\mathrm{S}_{-} \mathrm{SO}_{4}=\mathrm{ex}$ traivel por três extratores e respectivos niveis críti $\cos$ que estimam $90^{\circ}$ da absorção relativa máxima $(n=72)$.

\begin{tabular}{|c|c|c|c|c|}
\hline $\begin{array}{c}\text { Extra } \\
\text { tor }\end{array}$ & 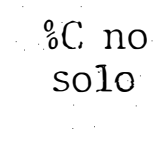 & Equações de Pegressão & $\mathrm{R}$ & $\begin{array}{l}\text { N.C. } \\
\mathrm{S}_{-} \mathrm{SO}_{4}=\end{array}$ \\
\hline \multirow[t]{2}{*}{$x_{1}^{2}$} & $<1,2 \%$ & $Y=68,06+1,13 X-196,17 \cdot 1 / X$ & $0,640 * *^{3}$ & 26 \\
\hline & $>1,2 \%$ & $Y=79,00+0,81 x-186,75 \cdot 1 / x$ & $0,535^{*^{3}}$ & 24 \\
\hline \multirow[t]{2}{*}{$x_{2}$} & $<1,2 \%$ & $Y=94,49+0,45 X-230,56 \cdot 1 / X$ & $0,798 * *$ & 18 \\
\hline & $>1,2 \%$ & $Y=89,44+0,10 X-85,58 \cdot 1 / X$ & $0,659 * *$ & 30 \\
\hline \multirow[t]{2}{*}{$x_{3}$} & $<1,2 \%$ & $Y=126,89+0,61 X-448,17 \cdot 1 / X$ & $0,783 * *$ & 17 \\
\hline & $>1,2 \%$ & $Y=150,27+1,67 X-506,70 \cdot 1 / X$ & $0,776 * *$ & 14 \\
\hline
\end{tabular}

${ }^{1}$ N.C. - nivel de $\mathrm{S}-\mathrm{SO}_{4}=$ nos solos, pelo extrator considerado para estimar $90^{\circ}$ da absorção relativa mâxima.

$2 . x$ - extrator $\mathrm{CaCl}_{2} 0,15^{\circ}$.

$\mathrm{x}_{2}$ - extrator $\mathrm{NH}_{4} \mathrm{OAC} 0,5 \mathrm{~N}$ em HOAc $0,25 \mathrm{~N}$

$\mathrm{x}_{3}$ - extrator $\mathrm{Ca}\left(\mathrm{H}_{2} \mathrm{PO}_{4}\right)_{2} \cdot \mathrm{H}_{2} \mathrm{O}$ - $500 \mathrm{ppm} \mathrm{P}$ em HOAC $2,0 \mathrm{~N}$

$3 * * \mathrm{e}^{*}$ - significativo ao nivel de $1 \%$ e $5 \%$ de probabilidade, respec tivamente, com 72 pares de observações.

Uma explicação adicional para a superestima cão do nivel crítico de $\mathrm{S}_{-} \mathrm{SO}_{4}^{=}$disponive1, independentemente do extrator usado, pode ser buscada no cultivo exaustivo dos solos, em condições de alta": temperatura e alta evapo- 
transpiração e nenhuma perda de $\mathrm{S}-\mathrm{SO}_{4}^{-}$por 1 ixiviação como ocorre em condições de campo.

4.9. RelaçóEs CONJUNTAS DE ANÁlises de SOLOS E DE PLANTAS COM A PRODUCÃO DE MATÉRIA SECA E ABSORCÃO DE ENXOFRE PELO MILHO

Para estabelecer as relações conjuntas de a nálises de solos e de plantas com a produção de matẻria se ca e absorção de enxofre pelo milho (em valores absolutos), usou-se a técnica de regressão "stepwise", em que foram consideradas as seguintes variâveis independentes:

a) anâlises de solos - $\mathrm{pH}, \mathrm{H}^{+}+\mathrm{Al}, \mathrm{Ca}, \mathrm{Mg}$ e carbono e $\mathrm{S}_{-} \mathrm{SO}_{4}^{=}$ disponivel extraivel por $\mathrm{Ca}\left(\mathrm{H}_{2} \mathrm{PO}_{4}\right)_{2} \cdot \mathrm{H}_{2} \mathrm{O}-500 \mathrm{ppm} \mathrm{P}$ em ácido acêtico 2 , on:

b) anâlises de plantas - enxofre total e razões N/S e P/S.

Excluîram-se do modelo de regressão linear mủltipla as variäveis independentes que não atingiram o ní vel de significância a $10 \%$ de probabilidade. Agruparam - se os solos pelos seus teores de carbono;, isto é, maiores e menores do que $1,2 \%$. 
4.9.1. RELACCóES dAS ANÁlises DE SOLOS E dE PLANTAS NOS SOLOS COM TEORES DE CARBONO MAIORES DO QUE $12 \%$ COM A PRODUCÃ̃ DE MATÉRIA SECA E ABSORCÃO DE ENXOFRE PELO MILHO

Para os solos arenosos, com teores de carbo no menores do que $1,2 \%$ calculou-se a seguinte equação de regressão linear múltipla para a relação da produção de ma tếria seca com as anâlises de solos e de plantas:

$$
\begin{gathered}
Y=59,5-148,5 \% \mathrm{~S}-0,66 \hat{\mathrm{N} / \mathrm{S}}+0,74 \mathrm{SO}_{4}= \\
\mathrm{R}^{2}=0,5598^{* * *}(\mathrm{n}=216)
\end{gathered}
$$

Na tabela 4.14 nota-se a contribuição altamente significativa dos teores de enxofre total e a razão $\mathrm{N} / \mathrm{S}$ nas plantas e do teor de $\mathrm{S}_{-} \mathrm{SO}_{4}^{=}$extraivel por $\mathrm{Ca}\left(\mathrm{H}_{2} \mathrm{PO}_{4}\right)_{2}$ - $\mathrm{H}_{2} \mathrm{O}-500 \mathrm{ppm} \mathrm{P}$ em ấcido acético 2,0 N. Esta contribuição confirma os resultados obtidos na análise individual das variâveis independentes consideradas. Pela tabela 4.11. percebe-se que a significância maior do coeficiente de determinação $\left(R^{2}\right)$ da produção de matêtia seca versus enxofre total nas plantas ocorre no segundo cultivo dos solos. 0 mesmo ocorre com a razão $\mathrm{N} / \mathrm{S}$. A contribuição do $\mathrm{S}-\mathrm{SO}_{4}^{=}$disponível nos solos ê confirmada pela regressão individual dessa variâvel com a produção de matêria seca (veja tabela 4.4. e figura 4.15.) 


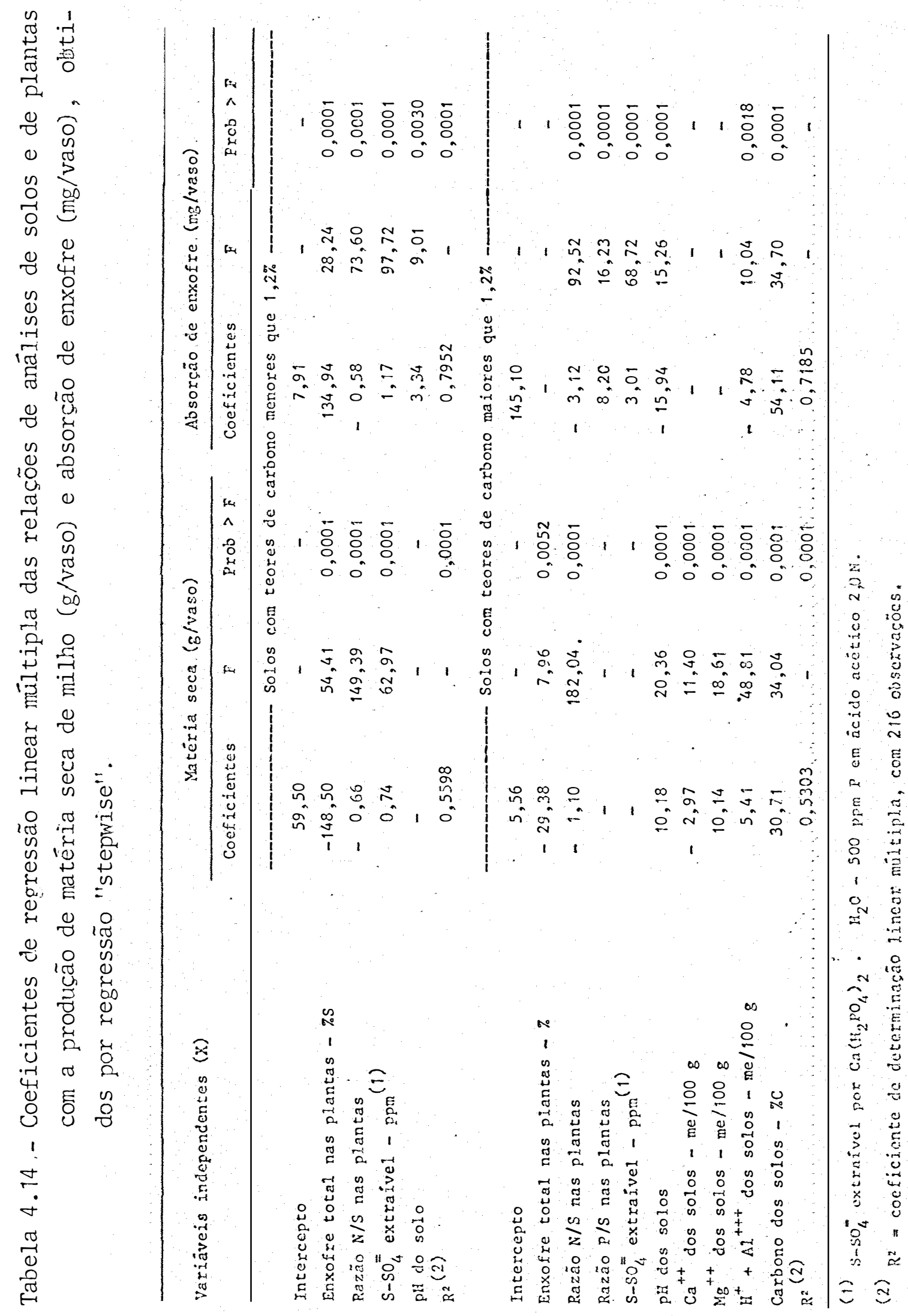


A equação de regressão linear müìipla calculada para a absorção de enxofre:

$$
\begin{gathered}
Y=7,91+134,94 \div S-0,58 \mathrm{~N} / \mathrm{S}+1,175 \mathrm{SO}_{4}^{=}+3,34 \mathrm{pH} \\
\mathrm{R}^{2}=0,7952 * * *(\mathrm{n}=216)
\end{gathered}
$$

mostra um coeficiente de determinação $\left(R^{2}\right)$ mais elevado do que para a produção de matêria seca. Além das variáveis jả consideradas, o pH dos solos, contribuiu, embora com signi ficância ligeiramente menor, para a absorção de enxofre. A ação da calagem e sua interação com a gessagem e cultivos (veja tabela 4.6. e 4.7.) mostram que em condições mais fa voráveis de pH houve maior absorção de enxofre pelo milho, mesmo nos solos arenosos, com bajxos teores de carbono orgânico e enxofre total.

\subsubsection{RELACÕES DAS ANÁLISES DE SOLOS E DE PLANTAS NOS SOLOS COM TEORES DE CARBONO MAIORES DO QUE $1,2 \%$ COM A PRODUCÃO DE MATERIA SECA E ABSORÇÃO DE ENXOFRE}

Para os solos argilosos (com teores de carbono maiores que $1,2 \%$ ) calculou-se a seguinte equação de regressão linear múltipla para a relação da produção de ma têria seca com as análises de solos e de plantas: 


$$
\begin{gathered}
Y=5,56-29,38 \% \mathrm{~S}-1,10 \mathrm{~N} / \mathrm{S}-2,97 \mathrm{Ca}+10,14 \mathrm{Mg}+ \\
5,41(\mathrm{H}+\mathrm{Al} 1)-30,71 \mathrm{C}+10,78 \mathrm{pH} \\
\mathrm{R}^{2}=0,5303^{* * *}(\mathrm{n}=216)
\end{gathered}
$$

Nessa equação nota-se que o coeficiente de regressão de menor significância estatîstica ẽ o cenxofre total nas plantas, se comparado com os outros coeficientes: razão N/S, pH, cẩcio, magnêsio, hidrogênio mais alumínio e carbono. A contribuição da reação do solo (pH, hidrogênio mais alumínio, câlcio e magnésio) se deve à fertilidade natural, muito baixa, onde o cälcio e o magnésio (via forma de carbonatos), funcionam além de neutralizantes da acidez, como nutrientes das plantas. Essa dupla função do calcário é de capital importância em solos de cerrado, como o de Catalão e de Rio Paranăba; onde os teores de cálcio e magnésio dos solos não conseguem suprir as necessida des das plantas. As interações de calagem, gessagem e cultivos (tabelas 4.6 e 4.7. ) dão suporte adicional à alta significância dos coeficientes de regressão mültipla, refe rentes ao pH, hidrogênio mais aluminio e cálcio e magnésio. E interessante citar o caso do latossolo roxo de Botu catu, que embora tendo um teor relativamente elevado de cálcio no solo (4,22 meq/100 g de solo), e relativamente baixo de magnésio $(0,94 \mathrm{meq} / 100 \mathrm{~g})$, respondeu significativamente à calagem, como pode ser verificado pelas equações de regressão constantes na tabela 4.8. e 4.9.). 
A equação de regressão múltipla referente à absorção de enxofre nos solos argillosos:

$$
\begin{aligned}
\mathrm{Y}= & 145,10-3,12 \mathrm{~N} / \mathrm{S}+8,19 \mathrm{P} / \mathrm{S}+3,01 \mathrm{SO}_{4}-15,94 \mathrm{pH}- \\
& 4,78(\mathrm{H}+\mathrm{Al})+54,11 \mathrm{C} \\
& \mathrm{R}^{2}=0,7185^{* * *}(\mathrm{n}=216)
\end{aligned}
$$

mostra que o enxofre total nas plantas não consta entre os coeficientes. As equações de regressão da percentagem de $S$ total nas plantas versus absorção de enxofre nos solos argilosos (veja figura 4.5.), mostram coeficientes de determinação extremamente baixos, o que pode ser atribuído às diferentes capacidades de suprimento de enxofre do grupo de solos com teores de carbono superiores a $1,2 \%$. A sig nificância dos coeficientes das razões N/S e P/S devem-se às abundantes adubações nitrogenada e fosfatada, como mos tram as equações de regressão da absorção de enxofre. Considerando a razão P/S individualmente, a absorção de enxofre foi influenciada significativamente a partir do segundo cultivo, o que confere a ela significância tambêm na a nálise conjunta dos dois cultivos. A razão N/S, como em to das as outras situações estựadas, contribuiu de forma altamente significativa na equação de regressão que prediz a absorção de enxofre.

O S.- $\mathrm{SO}_{4}^{=}$, extraível por $\mathrm{Ca}\left(\mathrm{H}_{2} \mathrm{PO}_{4}\right)_{2} \cdot \mathrm{H}_{2} \mathrm{O}-$ 500 ppm $\mathrm{P}$ em ácido acético $2,0 \mathrm{~N}$, igualmente contribuiu sig 
nificativamente na absorção de enxofre, ao contrário do que se verificou com a produção de matêria seca. Entretanto, essa estimação estatîstica deve ser analisada com cuidado, pois a não inclusão do $\mathrm{S}_{-} \mathrm{SO}_{4}^{=}$disponivel nos solos na equação de regressão referente aos solos argilosos pode ser de bitada ao crescimento "forçado" do milho em ambiente de umidade e temperatura elevadas e adubações nitrogenada e fos fata em abundância. Entretanto, as plantas de milho já a partir do primeiro cultivo mostraram deficiência severa de enxofre, na dose zero de gesso, como se constata na ta bela 4.10 .

o cầlcio e o magnésio foram excluídas da equação de regressão mûltipla, o que é consistente com as curvas de resposta (absorção de enxofre) referente aos so10 s com teores de carbono superiores a 1,2\% da tabela 4.9. Verifica-se que a absorção máxima estimada de enxofre ( $Y_{\operatorname{máx}}$.) não apresenta diferenças significativas, comparando-se o valor obtido na ausência ( $112,4 \mathrm{mg} /$ vaso) como na presença de calagem ( $121,5 \mathrm{mg} / \mathrm{vaso})$ no primeiro cultivo. Na produção de matéria seca a inclusão do cálcio e do magnésio na equação é debitável a seu papel nutricional nas plantas. Lê-se em MENGEL \& KIRKBY (1982), citando diversos autores, que o cálcio ê envolvido na elongação e divisão celular e na permeabilidade e integridade da membrana celular. O mag nêsio é componente da clorofila e participa de reações fotossintêticas. A deficiência de magnêsio, por outro lado, aumenta a proporção do nitrogênio não protéico. SUMNER (1981) 
na diagnose foliar (DRIS) das necessidades de enxofre para o milho e o trigo usa as razões $\mathrm{Ca} / \mathrm{S}$ e $\mathrm{Mg} / \mathrm{S}$. Existe uma alta probabilidade de que, caso os teores foliares de cálcio e magnêsio tivessem sido incluídos no modelo, se obteriam estimativas mais corretas das equações de regressão mú1 tipla referentes ao crescimento e à absorção de enxofre pe 10 milho. Nesse experimento não se determinaram os teores de câlcio e magnêsio na parte aêrea do milho.

os coeficientes de regressão do pH e do $\mathrm{H}+\mathrm{Al}$ dos solos mostraram-se altamente significativos, como é o esperado, devido à acidez dos solos, que se mostrou adversa à mineralização do enxofre no solo e sua absorção pelas plantas.

A inclusão do carbono em ambas as equaçôes do grupo de solos argilosos se justifica pela estreita corre lação obtida com a absorção de enxofre, como mostra a figu ra 4.8. Todavia, é preciso ressalvar que altos teores de carbono (matêria orgânica) não se traduzem necessariamente em altos potenciais de fornecimento de enxofre às plantas. Em solos ácidos, por exemplo, não existem condições ótimas de mineralização, como demonstram os potenciais de mineralização obtidos, via incubação aberta, listados na tabela 4.5. A correção da acidez aumentou os potenciais de minera lização de enxofre de forma mais intensa nos solos mais a $\underline{r}$ gilosos (com maiores teores de carbono), como è o caso dos solos de Catalão, São Sebastião do Paraíso-2 e Rio paranaí ba, se comparados com os solos arenosos de São Pedro e de 
Assis .

Existem poucos trabalhos que relacionam simultaneamente a produção ou a absorção de um nutriente com anâalises de solos e de plantas. HOEFT et alii (1973) deter minaram uma superficie de resposta mostrando o efeito do $\mathrm{pH}$ e do $\mathrm{S}-\mathrm{SO}_{4}^{=}$extraivel no aumento da produção de alfafa. Esse trabalho mostra claramente que com o aumento do pH, há diminuição dos teores $\mathrm{S}_{-} \mathrm{SO}_{4}=$ nos solos. Constatação simi lar foi feita por VITTI (1979), que obteve correlação inversa entre o $\mathrm{pH}$ do solo e o $\mathrm{S}_{-} \mathrm{SO}_{4}^{=}$extraível por acetato de amônio $1 \mathrm{~N}$ pH $Z, 0$, porẹm a absorção de enxofre pelo sorgo aumentou significativamente com o. pH. Os dados de HOEFT et alii (1973) e de VITTI (1979) são complementados pelos experimentos de MARTINI \& MUTTERS (1984), em que se eviden ciou a migração do $\mathrm{S}_{-} \mathrm{SO}_{4}=$ do horizonte $A$ para o B por efeito da calagem. Tal fato torna imprescindivel em experimen tos de campo, o estudo do $\mathrm{S}_{-} \mathrm{SO}_{4}^{=}$disponive1 em horizontes subsuperficiais. Nessa Iinha de raciocínio se enquadra o tra1ho de PROBERT \& JONES (197.7); que estudando os teores de $\mathrm{S}_{-} \mathrm{SO}_{4}=$ nas diversas camadas de solos da Austrālia, estabele ceram atravês da anâlise canônica variada, a importância re relativa do $\mathrm{S}-\mathrm{SO}_{4}^{=}$extrấvel em cada camada com o uso dos vetores das respectivas variâveis. Com esta têcnịca estatística os autores conseguiram discriminar locais não responsivos dos locais responsivos à aplicação de enxofre em pastagens de leguminosas da Austrâlia tropical.

Nas condições desse experimento a não dimi 
nuição dos teores de S. $\mathrm{SO}_{4}=$ disnonivel nas amostras de terra por efeito da calagem (veja figura 4.1.1. a 4.1.3.) não conflita com os dados de campo encontrado por autores acima citados, porque em ambiente de vasos não ocorre a lixiviação de ânions e câtions.

\subsection{CONSIDERACÕES FINAIS}

o experimento de casa-de-vegetação foi conduzido em condicoóes de temperatura e umidade elevadas e su primento abundante de nutrientes, com exceção do enxofre e remoção de todas as raizes para se proceder ao segundo cultivo. Nessas condições, o esgotamento do enxofre nativo e adicionado aos solos foi forçado. Na prâtica de campo, as situações de deficiências, provocadas no experimento de es tufa, provavelmente vão ocorrer apốs diversos cultivos dos solos, com adubação isenta de enxofre e remoção ou queima de restos culturais(p.ex. cana e algodoeiro). Há que se considerar ainda o potencial de suprimento de enxofre dos horizontes sub-superficiais, como foi demonstrado, em con dições de campo, por BLAKEMORE et alii(1969), PROBERT \& JO NES(1927) e MARTINI \& MUTTERS (1984).

A metorologia de incubação aberta dos solos e lixiviação periódica de $\mathrm{S}_{-} \mathrm{SO}_{4}=$ (STANFORD \& SMITH, 1972) oferece razoâveis possibilidades de sucesso na discriminação dos solos responsivos e não-responsivos à adubação sul- 
fatada, isto é, com baixos e altos potenciais de mineralização de enxofre nativo. Da figura 4.9. pode-se facilmente deduzir que correlações mais estreitas entre absorção de enxofre e potenciais de mineralização serão obtidas com um universo maior de solos, com faixa mais ampla de carbono e enxofre total nos solos.

$$
\text { O estudo do } \mathrm{S}_{-} \mathrm{SO}_{4}=\text { disponível via }
$$
extratores químicos, merece atenção em pesquisas futuras nos seguintes aspectos:

- estudo de diversas relações solo = solução;

- extração de $\mathrm{S}-\mathrm{SO}_{4}=$ via resinas, por causa de sua adsorção em diversos laboratörios de análises de solos brasilei ros;

- aprimoramento da técnica de determinação turbidimétrica de $\mathrm{S}-\mathrm{SO}_{4}^{=}$.

Embora a têcnica original de determinação turbidimêtrica de BARDSLEY \& LANCASTER (1965) tenha propor cionado boas curvas de calibração do espectrofotômetro para os quatro extratores testados (veja tabela 4.3.), a sua sensibilidade ê pequena em baixas concentrações nos extratos de $\mathrm{S}-\mathrm{SO}_{4}=$ dos solos.

Pelas ecuações de regressão mültipla da tabela 4.14 . e de regressão simples relativas à nutricão de enxofre, nitrogênio e fósforo das fíiguras 4.4. a 4.7. cons tata-se que a razão $\mathrm{N} / \mathrm{S}$ oferece nas condições desse experi 
mento, as melhores correlações com a producão de matêria seca e absorcão de cnxofne pelomilho, seguida da razão $P / S$. Com base nos resultados obtidos por MCCLUNG \& QUTNN (1959), WANG et a]ii (1976a,b), FREITAS \& JORGE (1959) e PEDRO SO et alii (1986) e nesse trabalho, os clássicos experi mentos NPK deverão ser acrescidos de $S$ ou até substituidos por NPS, estudando-se adicionalmente o efeito da...calagem na disponibilidade de enxofre nos solos e o potencial de fornecimento de $\mathrm{S}_{-} \mathrm{SO}_{4}=$ pelos horizontes sub-superficiais. 


\section{CONCLUSÕES}

Os solos arenosos e de baixos teores de car bono possuem pequenos potenciais de mineralização de nitro gênio e enxofre nativos, sendo afetados de forma não signi. ficativa pela calagem. Os solos argilosos e com mais altos teores de carbono tem potenciais de mineralização de nitro gênio e enxofre mais elevados, com efeitos significativos da calagem.

A meiamvida (tempo necessärio para minerali zar"a metade do nitrogênio e do enxofre potencialmente mineralizâveis), foi modificada pola calagem, não se verificando proporcionalidade na mineralização do nitrogênio e do enxofre.

A mineralização do nitrogênio e do enxofre e o decaimento da atividade especifica de ${ }^{35}$ S estabilizaram-.se por volta da oitava semana de incubação aberta, tanto na ausência quanto na presença de calagem.

Os teores de carbono e os potenciais de mineralização do enxofre dos solos são estreitamente correla cionados com a absorção de enxofre pelo milho, na presença de calagem. Não houve correlação significativa entre os potenciais de mineralizacão de enxofre no primeiro cultivo e os teores de carbono nos solos no segundo cultivo ver- 
sus absorção de enxofre na ausência de calagem, mostrando que a acidez reduz a mineralização e a dessorção do enxofre nativo dos solos. O enxofre total dos solos em nenhum caso apresentou correiação com a absorção de enxofre dos solos.

Dentre os extratores estudados, o Ca $\left(\mathrm{H}_{2} \mathrm{PO}_{4}\right)_{2}$ - $\mathrm{H}_{2} \mathrm{O}-500 \mathrm{ppm} \mathrm{p}$ em ăcico acético $2,0 \mathrm{~N}$ demonstrou o melhor desempenho tanto em termos oneracionais de laborató rio, quanco na correlação com a producão de matéria seca e absorção de enxofre pelo millho. O extrator HCI 0,05 M reve lou-se totalmente inadequado por não se terem obtido extra tos 1 impidos parą a determinação turbidimëtrica do $\mathrm{S}_{-} \mathrm{SO}_{4}=$ Os extratores $\mathrm{Ni}_{4} \mathrm{OAC} 0,5 \mathrm{~N}$ em ácido acético $0,25 \mathrm{~N}$ e o $\mathrm{CaCl}_{2} 0,15^{\circ}$ correlacionaram-se significativamente com a absorção de enxofre, mas apresentam o inconveniente da necessidade de determinação imediata do $\mathrm{S}_{-} \mathrm{SO}_{4}=$ dos extratos ou de seu armazenamento em refrigerador para evitar desenvolvimento de fungos.

Os niveis críticos de $\mathrm{S}_{-} \mathrm{SO}_{4}=$ nos solos para a obtenção de $90 \%$ da produção máxima relativa de matëria se a) $\mathrm{Ca}\left(\mathrm{H}_{2} \mathrm{PO}_{4}\right)_{2} \cdot \mathrm{H}_{2} \mathrm{O}-500$ ppm $\mathrm{P}$ em äcido acëtico $2,0 \mathrm{~N}: 11 \mathrm{ppm} ; \mathrm{N}$ : $\mathrm{NH}_{4} \mathrm{O} \Lambda \mathrm{c} 0,5 \mathrm{~N}$ em ácido acêtico 0,25N: $17 \mathrm{ppm}$; c) $\mathrm{CaCl}_{2}$ 0,15\%: $19 \mathrm{ppm}$.

os niveis criticos de enxofre total na parte aêrea do milho versus produção de matéria seca e absorção de enxofre foram de $0,14 \%$ e $0,20 \%$, respectivamente, no primeiro cultivo dos solos arenosos; no segundocultivo determinou-se o nível crítico de $0,14 \%$ para ambos os casos. 
No primejro cultivo dos solos argilosos (com teores de car bono superiores a $1,2 \%$ ); os coeficientes de regressão não significativos, näo se podendo, assim, estabelecer os níveis criticos; no segunço cutjoro; os nivejs de enxofre to taI nas plantas foram de $0,20 \%$ para a produção de matéria e de $0,30 \%$ para a absorcão de enxofre.

A razão N/S dia parte aẻrea do milho que caracteriza a deficiência de enxofre está por volta de 10 a 12/1, relacionada com a absorşão de enxofre. A correjação foi altamente significativa no primeiro e no segundo culti. vos.

A razäo P/S na parte aérea do milho não apresentou correlação significativa com a absorção de enxofre no primeiro cultivo. Na análise conjunta dos dois cultivos e no segundo isoladamente as correlações com a absorcão de enxofre foram significativas. Por causa da maior dispersão dos pontos não se node estabelecer precisamente a razão $P / S$ que caracteriza a deficiência de enxofre nas plantas. Tentativamente, propōe-se a räzão $\mathrm{P} / \mathrm{S} 1 / 1$ como va Ior critico.

Na avaliaça conjunta de anălises do solos e de plantas versus produção de matéria seca por regressão linear múltipla, contribuíram, significativanente os: seguintes parâmetros:

a) solos arenosos (teores de carbono menores que $1,2 \%$ ) - en xofre total e razão $\mathrm{N} / \mathrm{S}$ das plantas e $\mathrm{S}-\mathrm{SO}_{4}=\mathbf{e}$ extraível dos 
so10s;

b) solos argilosos (teores de carbono maiores que $1,2 \%$ ) enxofre total e razão $\mathrm{N} / \mathrm{S}$ das plantas, $\mathrm{pH}, \mathrm{Ca}, \mathrm{Mg}, \mathrm{H}+\mathrm{Al}$ e carbono dos solos;

e versus absorção de enxofre:

a) solos arenosos - enxofre total e razão N/S das plantas, $\mathrm{S}-\mathrm{SO}_{4}^{=}$extrâivel e pH dos solos;

b) solos argilosos - enxofre tótal e razôes N/S e P/S das plantas, $\mathrm{S}_{-\mathrm{SO}}=$ extraivel, $\mathrm{pH}, \mathrm{H}+\mathrm{Al}$ e carbono dos solos.

Dentre os parâmetros estudades, a razão N/S revelou-se como o mais preciso para diagnosticar a deficiência nutricional de enxofre para as plantas. 


\section{REFEREALCIAS BIBLIOGRÁFICAS}

ABRUNA, F.; VICENTE-CHANDLER, J; PEARSON, R.W. Effects of liming on yields and composition of heavily fertilized grasses and on soil properties under humid tropical conditions. Soil Science Society of America Proceedings, Madison, 28(5): 657-61, set./out. 1964 .

ADAMS, F. \& RAWIJFIH, $Z$. Basaluminite and alunite: a possible cause for sulnhate retention by acid soils. Soil Science Society of America Jotirnal, Madison, 41(4): 686-92, july/aug. 1977.

ALLISON, L.E. Organic carbon. In: BLACK, C.A. ed. Methods of soils analysis; chemical and microbiological properties. Madison, ASA, 1965. cap. 90, p. 1367-78 (Agronomy, 9).

AlMEIDA NETO, J.X. de \& BRASIl SOBRINHO, M.O.C. do. Fixa. ção de fósforo em três solos sob cerrado em Goiâs. Revista brasileira de Ciência do Solo, Campinas, 1(1): 12-5, jan./fev./mar. 1977. 
AlVAREZ V., V.H.; BRAGA, J.M.; ESTEVR̃O, M.M.; PINTO, O.C.B. Equilíbrio de formas disponiveis de fösforo e enxofre em dois latossolos de Minas Gerais. Experientiae, Viçosa, 22(1): 1-29, jan: 1976 .

ANDERSON, G.D. Potassium responses of various crops in East Africa. In: COLLONUIUM OF INTERNATIONAL POTASH INSTITUTE, 10 Abidjan, 1973. Proceedings... Bern, International Potash Institute, 1973 p. 413-37.

ANDERSON, A.J. \& SPENCER, K.D. MoIybdenm and nitrogen metabolism on legumes and nonlegumes. Australian of Journal of Agricultural Research, MeIbourne, 38(2): 414-30, febr. 1950 .

ANDREW C.S. Evaluation of plant and soil sulphur tests in Australia. In: MC LACHLAN, K.D., ed. Sulphur in Australian Agriculture, Sidney, Sidney University Press, 1982:p.93-127.

ARENS, K. O cerrado como vegetação oligotrófica. Boletim da Faculdade de Filosofia, Ciências e Letras da USP, São Paulo, 224 Bot. (15): 59-77, 1958. 
AYLMORE, L.A.G. \& KARTM, M. Leaching of fertilizers ions in soil columns. In: INTERNATIONAL CONGRESS IN SOIL SCIENCE, 9, Adelaide, 1968. Transactions... Amsterdam, Elsevier, 1969. v. T. p.143-53.

BARDSLEY, C.E. \& LANCASTER, J.D. SUIfUX. In: BLACK, C.A. Methods of soil anaysis; chemical and microbiological properties. Madison, ASA; 1965. cap. 79. p.1103-16. [Agronomy, 9].

BARDSLEY, C.E. \& KILMER, V.J. Sulphur supply of soils and crop yields in the Southeastern inited States. Soil Science Society of America Proceerings, Madison, 27(2): 197-9; mar/apr. 1963.

BARROW, N.J. Studies on extraction and availability to plants of adsorbed plus soluble sulphate. Soil Science, Baltimore, 104(4): 242-9, apr. 1967.

BARROW, N.J. Determination of elemental sulfur in soils. Journat of Sctence ôf Food and Àriculture, London, $19(7): 454-6$, aug. 1968 .

BARROW, N.J. Effects of adsorption of sulphate by soils on the amount of sulphate and its availability to plants. Soil Science, Baltimore, 108(3): 193-201, sept. 1969. 
BARROW, N.J. Comparison of the adsoxption of molybdate, suzphate and phosphate by soils. "Soil Science, Baltimore, $109(5): 282-8$, may; 1970 .

BEATON, J.D.; BIXBY, D.W.; TISDALE; S.I. ; PLATOU, J.S. Fertilizer SuIfur; status and potentia] in the U.S. Muscle Shoals, Alabama, The Sulfur Institute, 1974. [Boletim tếcnico, 9].

BEATON, J.D.; BURNS, G.R.; PLATOU, J. Determination of sulphur in soils and plant material. Washington, Sulphur Institute. 1968. 56p. [Boletim técnico, 14).

BEATON, J.D. \& FOX, R.L. Production', marketing and use of sulphux products. In: OLSON, R.A. et alii, eds. Fertilizer Technology and Use. 2ed. Madison, Soil Science Socjety of America. 1971. p.335.79.

BEATON, J.D.; HUBBARD, W.A.; SPEER, R.C.; GARDNER, R.T. Ammonium phosphate-sulphur and sulphur-gypsum: new granular sulphur-sources for alfalfa. The Sulphur Institute Journal, Washington, $4(1): 4-8$, jan. 1968-69. 
BETTANY, J.R.; STEWART, J.B.W.; HALSTEAD, E.H. Sulfur fractions and carbon, nitrogen and sulfur relationships in grassland, forest and associated transitional soils. Soil Science Society of America Proceedings, Madison, $37(6): 915-8$, nov./dec. 1973 .

BETTANY, J.R.; STEWART; J.W.B.; HALSTEAD; E.H. Assessment of available soil sulphur in an ${ }^{35} \mathrm{~S}$ growth chamber experiment, Canadian Journal of SolT Science, Otawa, 54(3): 309-15, aug. 1974.

BETTANY, J.R. \& STEWART, J.W.B. Sulphur cycling in soils. In: SEMINARIO SOBRE O USO DE TECNTCAS NUCLEARES EM ESTUDOS DE FERTILIDADE DO SOLO E FERTILIZANTES, piracicaba, 1983. Anais...P. Piracicaba, CENA/USP, 1983.

BIEDERBECK, V.O. Soil organic sulfur and fertility. In: SCHNITZER, M. \& KHAN, S.V., ed. SojI organic matter. Amsterdam, Elsevier, 1978. cap. 6. p.273-310.

BLAIR, G. Sulfur in the tropics. Muscle Shoals, Alabama, IFDC, 1979. 69p. [Boletim técnico; T-12]. 
BLAKEMORE, L.C.; LUDECKE; T.E.; LEAMY; M.L.; METSON, A.J. A study of the pattern of sulphur responses shown by dryland lucerne on some brown-gray earths. New Zealand Journal of Agricultural Research, Wellington, 12(2): $333-51,1969$.

BLOOMFIELD, C. Sulphate reduction in waterlogged soils. Journal of Soil Science, Oxford, 20(1): 207-21, 1969.

BOHNEN, H. Formas de nitrogênio e avaliação de métodos para a determinação de sua disponibilidade em 21 solos do Rio Grande do SuI. Porto Alegre, 1970. [Mestrado Solos - Fac. Agronomia/UFRGS].

BORATTO, F. Basic para engenherros deicntistas. Rio de Janeixo, LTC, 1984, 120p.

BORNEMIZSA, E. \& LLANOS, R. Sulphate movement, adsorption and desorption in three Costa Rica soils. Soil Science Society of America Proceedings, Madison, 31(3): 356-60, may/june. 1967.

BRAR, S.S.\& GIDDENS, J. Inhibition of nitrification in Bladen grassland soil. Soll Science Society of America proceedings, Madison, $32(6): 821-3$, nov./dec., 1968. 
BRAY, R.H. Correlation of soil tests with crop response to added fextilizers and with fertilizer requirements. In: KITCHEN, H.B., ed, Diagnostic techniques for soils and crops. Washington American Potash Institute, 1948. p. $53-86$.

BREMNER, J.M. TotaI nitrogen. In: BLACK, C.A., ed. Methods of soil analysis; chemical and microbiological properties. Madison, ASA, 1965. cap. 83, p.1149.78. [Agronomy, 9].

BROMFIEJD, A.R. Sulphur in northern Nigerian soils. 1. The effects of cultivation and fertilizers on total $S$ and sulphate patterns in soil profiles. Journal of Agricultural Science, Cambridge, 78(3): 465-70, june. 1972.

BUTTERS, B. e CHENERY, E.M. A rapid method for the determination of total sulphur in soils and plants. Analyst, Jondon; 84: 239-45, 1959 .

CALVET, J.L.R. Estudo do enxofre em diversos solos da região de Piracicaba-SP e avaliação de métodos de extração do enxofre disponivel usando ${ }^{35}$ S. Piracicaba, 1986. $102 \mathrm{p}$. [Mestrado-ESALQ/USP]. 
CAMPBELL, C.A.; MYERS, R.J.K.; WEIER, K.L. Nitrogen mineralization potentials, decomposition rates and their relationships to temperature for five Queensland soils. Australian Journal Sold Pesearch, Melbourne, 19 (2) : 323 -32. apr./june. T98\%.

CHAO, T.T.; HARWARD, M.E.; FANG, S.C. Adsorption and desorption phenomena of sulphate in soils. Soil Science Society of America Proceedings, Madison, 26 (3): 234-7. nay/june. 1962 .

CASAGRANDE, J.C. \& SOUZA, O.C. Efeitos de niveis de enxofre sobre quatro gramineas tropicais. pesquisa Agropecuâria Brasileira, Brasiıia, 17(1): 21-5, jan. 1982.

CASAGRANDE, J.C.; SOUZA, O.C.; SChunke, R.M. Avaliação da fertilidade de quatro solos do Mato Grosso do Sul: enxofre e nicronutrientes Descuísa Àgropecuária Brasileira, Brasizia, $17(3): 381-4$, maio, 1982 .

CATANI, R.A. \& JACINTHO, O. Avaliacão da fertilidade do solo; mêtodos de anâse. Piracicaba, Escola Superior de Agricultura "Luiz de Queiroz", 1974. 57p. [mimeografadol. 
CATANI, R.A.; GLÔRIA, N.A. da; VITTI, G.C. Adsorção de sulfato pelo solo. Anais da Escola Superior de Agricultura "Luiz de Queiroz", Piracicaba, 28: 235-45, 1971.

CHAPMAN, H. \& PRATT,F.P. Methods of analysis for soils. plants and waters. Davis, Univers. Californja, 1961. $309 \mathrm{p}$.

CLARK, A.I. \& LEWIS, D.C. Handbook on sulphur in Australian agriculture; South Australia. In: ; MCLACHLAN, K.D., ed. 1974. CSIRO, Melbourne, p.42-9.

COCHRAN, W.G. The combination of estimates from different experiments. Biometrics, Fort Collins, 10(1): 101-29, jan. Imay. 1954 .

COLEMAN, $R$. The importance of sulfur as a piant nutrient in world crop production. Soli Science, Baltimore, 101(4): $230-9$, apr. 1966 .

COLOZZA, M.T.; SAVASTANO; S.A.I. de; WERNER, J.C.; MONTEIRO, F.A. Efeitos da aplicação de gesso e calcärio dolomitico em dois solos ácidos cultivados com soja perene. Boletim de Indústria Animal, Nova Odessa, 40(1):75-96, jan.lfev. 1983 . 
COOPER, M. A comparison of five methods for determining the sulphur status of New Zealand soils. In: INTERNATIONAL CONGRESS OF SOIL SCILNCE, 9., Adelaide, 1968. Transactions... Amsterdam, E1sevier, 1969. v.2. p. 263-21.

COUTO, W.; LATHWELL, D.J.; BOULDIN, D.R. Sulfate sorption by two oxisols and alfisols of the tropics. Soil Science, Baltimore, 12z(1): 108-6, jan. 1979.

DAIGGER, L.A. \& FOX, R.L. Nitrogen and sulphur nutrition of sweet corn in relation to fertilization and water composition. Agromomy Journal, Madison, 63(5): 729-30, sept./oct. 1921 .

DE LONG, W.A. \& LOWE, L.E. Carbon-14 bonded sulfur in soils. Canadian Journal of Soil Science, Ottawa, $42(2)$ : 223-30, may, 1962 .

DIJKSHOORN, W. \& VIJK, A.L. van. The sulphur requirements of plants as evidenced by sulphur-nitrogen ratio in the organic matter: a nevjew of published data. Plant and Soi1, The Hague, 26(1): 129-57, jan. 1967 . 
EMBRAPA. Centro de pesquisa Agropecuária do Cerrado. Relatörio tecnico anual, $1929 / 80$. Brasilia, EMBRAPA, 1981. 190p.

EMBRAPA. Centro de Pesquisa Agropecuäria do Cerrado. Relatơrio técnico anual, 1980/1981. Brasília, EMBRAPA, 1982. $163 \mathrm{p}$.

EMBRAPA. Serviço Nacional de Levantamento e Conservacão de Solos. Manual de mêtodos de análises de solos Rio de Janeiro, EMBRAPA/SNLCS, 1979. [mimeografado].

EMBRAPA. Serviço Nacional de Levantamento e Conservação de Solos. Sistema brasileiro de classificacão de solos. 2ạ Aprox. Rio de Janeiro, 1981. 100 .

ENWEZOR, W.O. Sulphun deficjency in soils of Southeastern Nigeria. Geoderma, Amsterdam, 15(2): 401-11, feb. 1976.

ESMINGER, L.E. \& FRENEY, J.R. Diagnostic techniques for determining sulfur deficiencies in crops and soils. Soil Science, Baltimore, 102(2): 283-90, feb. 1966. 
ESMINGER, L.E. Some factors affecting the adsorption of sulfate by Alabama soils. Soli Scjerce Socjety of America proceedings, Madison, 18(2): $259.64,1954$.

FIELDES, M. \& SCHOFIELD, K.K. Mechanisms of ion adsorption by inorganic soil colloid. New Zealand Journal Soil Science, Wellington, 3(5): 563-79, may. 1960.

FONTES, M.P.F. Disponibilidade de enxofre em diferentes extratores químicos em alguns latossolos do Estado de Minas Gerais. Viçosa, 1979. 63p. [M.Sc. - Universidade Federal de Viçosa].

FREIRE, J.C.; LOPES, A.S.; AQUINO, L.H. de; CARVALHO, J.G. de. Influência do enxofre na produção de matêria seca do mitho. Agros, Lavras, 2(1):35-46. 1972.

FREIRE, J.C. MATTOS, R; SOUZA; J.J. de; BAHIA, F.G.F.F.C. Resposta a níveis de enxofre em solos de baixada, Vale do Sapucai, Minas Gerais. Agros, Lavras, 4(1): 30-44 . 1974.

FREITAS, L.M.M. de; MCCLUNG, A.C.; LOTT, W.L. Field studies on fertility problems of the brazilian campos cerrados. New York, IRI, 1960, 28p. [Boletim, 21]. 
FREJTAS, L.M.M. de; GOMES, F.P.; LOTT, W.L. Effects of fertilizer sulphur on coffee. The Sulphur Institute Journa 1, Washington; 8(1):9-12, jan., 1972 .

FREITAS, L.M.M. de \& JORGE, P.N. Resposta de capim swaneebermuda à aplicação de nitrogênio, fósforo e enxofre em região de cerrado. Revista Bxasileira de Ciêricia do So10, Campinas, 6(3): 195-202, sept./dec. 1982.

FRENEY, J.R.; BARROW, N.J.; SPENCER; K. A review of certain aspects of sulphur as a soil constituent and a plant nutrient. PIant and Soil, The Hague, 17(2): 295-308, feb. 1962 .

FRENEY, J.R.; MELVILLE; G.E.; WILLTAMS, C.H. Organic sulphur fractions labelied by addition of ${ }^{35}$ S-sulphate to soil. Soil Biology and Biochmistry, Oxford, 3(2): 133-41, mar.l apr. 1971 .

FRENEY, J.R.; SPENCER, K.; JONES, M.B. The diagnosis of sulfur deficjency in wheat. Australian Journa of Agricultural Research, Melbourne, 29(4): 729-38. jul. 1978. 
GASSER, J.R.K. Soil nitrogen. VI: Correlation between laboratory measurements of soil mineral $N$ and crop yields and responses in pot and fields experiments. Journal of Science of Food and Agriculture, London, 12(2): 562-73, aug. 1963.

GOH, K.M. \& KEE, K.K. Effects of nitrogen and sulfur fertilization on the digestibility and chemical composition of perennial ryegrass (Lolium penenne L.). Plant and Soil, The Hague, 50(1): 161-7, aug. 1978.

GOODLAND, R. \& PERRI, M.G. ECoTrogja do cerrado. São Paulo, EDUSP, 1979. 193p.

GREGG, P.E.H. \& GOH, K.M. Field studies with radioactive sulphur labelled gypsum fertilizer. New Zealand Journal of Agricuiturai Research, Wellington, 21(4): 593-601, nov. 1978.

GRIFFIN, G.F. \& LAINE, A.F. Nitrogen mineràization in soils previously amended with organic wastes. Agronomy Journal, Madison, Z5(1): 124-9, jan. 1983. 
GUIMARAES, P.T.G.; MEIIES, C.CA.: GREIRE, F.M. InfIuência do gesso e calcario como corretivos e fornecedores de cálcjo e enxofre para o cafceiro. In: CONGRESSO BRASILEIRO DE PESQUISAS CAFEEIRAS, 10, Posos de Caldas, 1983. Anais... Rio de Janeiro, Instituto Brasileiro do Café, 1983. p.164-5.

HARWARD, M.E. \& REISENAUER, H.M. Reactions and novement of inorganic soil sulphur. Soil Science, Baltimore, 101(4): $326-35$ apr. 1966.

HARWARD, M.E.; CHAO, T.T.; FANG, S.C. The sulphur status and sulphur supplying power of Oregon soils. Agronomy Jourial, Madison, 54(1): 101-6, jan. 1962.

HAGUE, I. \& WALMSLEY, D. Adsorption and desoxption of sulphate in soils of West Indies. Ceoderma, Amsteram, 9(2): 269-78, febr. 1973.

HESSE, P.R. SuIphur. In: - A textbook of soil chemical analysis. London, John Murray. 1972 cap. 13. p. $301-31$.

HINGSTON, F.J.; POSNER, A.M.; QUTRK, J.P. Anion adsorption by goethite and gibbsite. I. The role of the proton in determining adsorption envelopes. Journat of sojl. Science, Oxford, $23(1): 1977-92,1972$. 
HOEFT, R.G.; WALSH, L.M.; KEENEY, D.R. Evaquation of various extractants for available soil sulfur. Soil Science Society of America Proceedings, Madison, 37(2): 401-4, mar./apr. 1973.

HOMES, M.V. A new approach to the plant nutrition and fertilizer requirement. Solls and Fertilizers, Washington, $18(1): 101-3$, jan. 1955 .

HOMES, M.V. The method of systematic variations. Soil Science, Baltimore, 96(6): 380-6, dec 1963.

HOMES, M.V. Sulfur requirement in fertilizers as determined by the method of systematic variations. Soi] science, Baltimore, 101(4): 291-6, apr. 1966.

ISLAM, M.M. \& PONNAPERUMA, F.N. Soil and plant tests for available sulfur in wetland rice soils. Plant and soil, The Hague, 68(1): 97-113, jan. 1982 .

JANZEN, H.H.; BETTANY, J.R.; STEWART, J.W.B. Sulfur oxidation and fertilizer sources. Saskatchevan Institute of Pedology, Saskatchevan, 1982. 12p. [mimeografado]. 
JANZEN, H.H. \& BETTANY, J.R. Sulfur nutrition of rapeseed.

I. Influence of fextilizer nitrogen and sulfur rates.

Sol Science Socjety of America Journai, Madison, 48(1): $100-7$, jan./feb. 1984 .

JENSEN, J, Some investigations on plant uptake of sulphur. Sol1 Science, Baltimoxe, 95(1): 63-7, jan. 1963.

JOHNSON, C.M. \& NISHITA, H. Microestimation of sulphur in plant materials, soils and irrigation watexs. Analitical. Chemistry, Washington, 24(4): 736-42, apr. 1952 .

JUMA, N.G.; PAUL, E.A.; MARY, B. Kynetic analysis of net nitrogen mineralization. Sor Science Socjety of Anexica Proceedings, Madison, $48(4): 753-7$, juJ./aug. 1984.

JONES, M.B. \& QUAGLIATO, J.L. Respostas de quatro leguminosas tropicais e da alfafa a värios niveis de enxofre. Pesquisa Agropecuária Brasileira, Rio de Janeiro, 5 : $359-63,1970$.

KAMPRATH, E.J.; NELSON, W.L.; FITTS, F.W. The effect of pH, sulphate and phosphate concentrations on the adsorption of sulphate by soils. Soil Science Society of America Proceedings, Madison, 20(2): 463-6, mar./apr. 1956. 
KANG, B.T. \& OSINAME, O.A. Sulfur response of maize in Western Nigexia. Agronomy Tougnal, Madison, 68 (2): mar./apr; 1976.

KANG, B.T.; OKORO, E.; AQUAVE, D.; OSINAME, O.A. Sulfur status of some Nigerian soils from the savanna and forest zones. Solil Scjence, Baltimore, 132(3): 220-7, sept. $\quad 1981$

KINJO, T. \& PRATT, F.P. Nitrate adsorption. II. Jon competition with chloride, sulphate and phosphate. Soil Science Society of America Proceedings, Madison, 35(5): 725-8, sept.loct. 1971 .

KLIEMANN, H.J. Componentes nitrogenados de alguns solos do Rio Grande do Sul e sua relacão com a disponibilidade de nitrogênio para as plantas. Porto Alegre, 1973. 76p. [Mestrado - Solos - Fac. Agronomia/UFGRS].

KOWALENKO, C.G. \& LOWE, L.E. Evaluation of severaI extraction methods and of a closed incubation for sois sulfur mineralization. Canadian Journa 1 of Soil Science Ottawa, 55(1): 1-8, febr. 1975. 
KORENTAJER, K.; BYRNES, B.H.; HELLUMS, D.T. The effect of liming and leaching on the sulfur supplying capacity of soils. Soil Science Society of Anerica Joumal, Madison, 47(3): $525-30$, may ljune, 1983 .

LINDEMANN, W. \& CARDENAS, M. Nitrogen mineralization potential and nitrogen transformations of sludge-amended soil. Soil Science Society of America Journal, Madison, 48(5): 1072-77, sept.loct. 1984 .

LOWE, L.E. Distribution and properties of organic fraction in selected Alberta soils. Canadian Journal of Soil Science, Ottawa, 49(1): 129-41, febr. 1969.

LOWE, L.E. Sulfur fractions of selected Alberta soil profiles of the chernozenic and podzolic orders. Canadian Journai of Sòil Science, Ottawa, 45(2): 297303 , febr. 1965.

LOTT, W.L.; MCCLUNG, A.C.; MEDCALF, J.C. Sulphur deficiency in coffee. São Paulo, Inst. Pesq. IRI, 1960. [Boletim, 2]. $31 \mathrm{p}$.

MALAVOLTA, E. Estudos sobre o enxofre. Piracicaba, 1950. 93p: LLivre-Docência - Escola Superior de Agricultura "Luiz de Queiroz"/USP]. 
MALAVOLTA, E. Potássio, magnésio enxofre nos solos e culturas bxasileiras. Piracicaba, pOTAFOS, 1980. 43p. [Boletim, 4].

MALAVOLTA, E. Manua de quimica agricona; adubos e adubação. São Paulo, Ceres, 1981. cap.6. j.276-82.

MALAVOLTA, E. Nitrogênio e enxofre nos solos e culturas brasileiras. São Paulo, SN Centro de Pesquisa e Promoção do Sulfato de Amônio, 1982 . 59p. [Boletim técnico, 1].

MALAVOLTA, E. A prácica da càagem. 4ed. Sorocaba, Mineradora Pagizato, 1984.43p. [Boletin têcnico, 2].

MALAVOLTA, E.; VITTI, G.C.; FORNASIER FO, D.; GUIMARÃES, P.T.G.; GUILHERME, M.R.; E MORI; I. ; VASCONCELLOS, L.A. B.C.; MORAES, C.L.; KAMINSKT, T.; MUTTON, M.A.; CARVALHO, J.G.; RUY, V.M. Efeltos de doses e fontes de enxofre em culturas de interesse econômico: I. Capim colonião (Panicum, maximum Jacq.). São Paulo, SN Centro de Pesauisa e Promoção do Sulfato de Amônio, 1984.p. 9-22. [Boletim técnico, 3]. 
MALAVOLTA, E.; VITTI, G.C.; FORNASIERI Fo, D.; CARVALHO, J.G.; MAlavolta, M.L.; ZAMBblLo, F.C. Efeitos de doses. e fontes de enxofxe em culturas de interesse econômico; II. Colza (Brassica napus L, var. oleifera). São Paulo, SN Centro de Pesquisa e Promoşão do Sulfato de Amônio, 1984. p.26-42. [Boletim têcnico, 3].

MARTINI, J.A. \& MUTTERS, R.G. Effect of liming and fertilization on sulfur availability, mobility and uptake in cultivated soils of South Carolina. Soil Science, Baltimore, 138(6): 403-10, dec. 1984 .

MARY, B. e REMY, J.C. Essai d'appréciation de la capacité de minéralization de l'azote des sols ae grande culture. I. Signification des cinétiques de minéralization de la matière organjque humifiee. Annales Agronomiques, paris, 30: $513-27,1979$.

MAYNARD, D.G.; STEWART, J.W.B.; BETTANY, J.R. Use of plant analysis to predict deficiencies in rapeseed (Brassica napus and B. campestris). Canadian Journal of Soil Science, Ottawa, 63(2): 387..96, Eebr. 1983a

MAYNARD, D.G.; STEWART, J.W.B.; BETTANY, J.R. SuIphur and nitrogen mineralization in soils compared using two incubation techniques. Soj Biology ana Bochemistry, Oxford, 15(3): 251-6, may. 1983b. 
MCCLUNG, A.C. \& FREITAS, J.M.M. de, Sulfur deficiency in soil from brazilian campos. Ecology, Durham, $40(2)$ : $315-7$, apx. 1959 .

MCCLUNG, A.C.; FREITAS, L.M.M. de; LOTT, W.L. Analysis of several brazilian soils in relation to plant responses to sulfur. Soil Science Society of America proceedings, Madison, 23(2): $221 \cdots 4$, mars/apr. 1959.

MCCLUNG, A.C.; FREITAS, T.M.M. , , MIKKELSEN, D.S. ; LOTT, W.L. Adubação do algodoeiro em solos de campo cerrado no Estado de São Paulo. São Paulo, Inst. Pesq. IRI, 1961. 34p. [Boletim técnico, 27].

MCCLUNG, C.A. \& QUINN, L.R. Resposta grama batatais. (paspalum notatum L, às aplicacões de enxofre e fósforo. São Paulo, Iñst. Pesq. IRI, T959. [Boletim, 29].

McGILL, W.B. \& COLE, C.V. Comparative a spects of cycling organic C, N, S and $P$ through soil organic matter. Geoderma, Amsterdam, 26(4): 267-86, nov. 1981.

MCLAREN, A.; KEER, J.I.; SWIRT, R.S . SuJphur transformations in soils using sulphur 35 labelling. Soil Biology and Biochemistry, Oxford, 17(1):73-9, jan, 1985 . 
MCNAUGHT, K.N. \& CHRISTOFFELS, P.J.E. Effect of sulphur deficiency on sulphur and nitrogen levels in pastures and lucerne. New Zealand Journal of Agricultural Research, Wellington, 4 (2): 177-85, mar./apr. 1961.

MERARU, T. \& UEHARA, G. Anion afsorption in ferruginous tropical soils. Soil Science Society of America Proceedings, Madison, 36(2):296-300, mar./apr. 1972.

METSON, A.J. E L.C. BLAKEMORE. Sulphate retention of New Zealand soils in relation to the competitive effect of phosphate. New Zealand Journalo of Agricultural Research, Wellington, 2(2): 243-33, may. 1978 .

METSON, A.J. Sulphur in New Zealand soils. I. A review of sulphur in soils with particular reference to adsorbed sulphate-sulphur. New ZeaIand Journal of Agricultural Research, We11ington, 22(1): 95-114, febr. 1979.

MIKKELSEN, D.S.; FREITAS, L.M.M. de; MCCLUNG, A.C. Efeitos da calagem e adubação na produção de algodão, milho e soja em trếs solos dé campo cerrado. São paulo, Inst. Pes.. IRI, 1963. [Boletim, 29]. 
MIYASAKA, E.; FREIRE, E.; MASCARENHAS, A. A̧ubaS̃ão minera1 do feijoeiro. VIII. Efeitos de N, P, K, S e uma mistura de micronutrientes em Tatuî e Tietê. Bragaritia, Campinas, $25(26): 393-405$, out: 1966 .

MOLINA, J.A.E.; CLAPP, C.E.; LARSON, W.E. Potential Iy mineralizable nitrogen in soil: the simple exponential model does not apply for the first 12 weeks of incubation. Soil Science Society of America Journa1, Madison, 44(2): $\operatorname{mar} . / \mathrm{apr} .1980$.

MONTEIRO, F.A.; CARRIEL, J.M.; MARTINS, L.; CASTRO, J.V. de; LIEM, T.H. Aplicacão dos núveis de enxofre, na forma de gesso, para cultivo de leguminosas forrageiras. Boletim de Industria Arimal, Nova Odessa; 40(2): 229-40, 1983.

MOSER, V.S. \& OLSON, R.T. Sulfur oxidation in four soils as influenced by soil moisture tension and sulfur bacteria. Soil Science, Baltimore, 76(3): 251-7, sept. 1953.

NASCJMENTO FO, V.F. \& LOBAO, A.O. Deteçáo de P-32 em amos-. tras de origem animal e vegetal por efeito Cerenkov, cirtijaço Iíquida e detector G.M. Piracicaba, CENA-USP, [Boletim cientifico, $\mathrm{BC}-48$ ]. 
NASCIMENTO, J.A.L. do \& MORELLI, M. Enxofre em solos do Rio Grande do SuI. I. Formas no solo. Revista Brasileira Ciência do Solo, Campinas, 4(3): 131-5, set./dez. $1980 \mathrm{a}$.

NASCIMENTO, J.A.L. do \& MORELH, M. Enxofre em solos do Rio Grande do Sul. II. Disponibilidade. Revista BrasiIeira Ciência do Solo, Campinas, 4(3): 135-8, set./dez. $1980 \mathrm{~b}$.

NELSON, L.E. Status and transformation of sulfur in Mississipi soils, Soll Science, Baltimore, 97(5): $300-$ -6 , may 1964.

NEPTUNE, A.M.L.; TABATABAI, M.A.; HANWAY, J.J. Sulfur fractions and carbon-nitrogen-phosphorus - sulfur relationships in some Brazilian and Iowa soils. Soil Science Society of America Proceedings, Madison, 39(1): $51-5, j a n . / f e b x .1975$.

OSINAME, O.A. \& KANG, B.T. Response of rice to sulphur application under upland conditions. Comminications in Soil Science and plant Aralysìs, New York, 6(5): $585-98$, 1975 . 
PALASKAR, M.S. \& GHOSH, B.A. EvaIuation of some soil test methods for available sulphur using cabbage as a test crop. Joumal of Nuclear Agriculture and Blology, N. Delhi, 10(1): 88-91, jan. 1981.

PATTERSON, M.S. \& GREEN, R.C. Measurment of low betaemitters in aquoeus solutiors by liquid scintilation counting of emulsious. Analitical Chemistry, Washington, 37 ( 7$): 854-7$, june. 1965 .

PAVAN, M.A.; BINGHAM, F.T.; PRATT, P.F. Redistribution of exchageable calcium, magnesium and aluminium following lime and gypsum application on a brazilian oxisol. Soil Science Society of America Toumal, Madison, $48(1): 33-8$, jan. 1984 .

PEARSON, R.W.; ABRUNA, F. ; VICENTE-CHANDLER, J. Effects of lime and nitrogen applications on the downard movement of $\mathrm{Ca}$ and $\mathrm{Mg}$ in two humid tropical soils of Puerto Rico. Soil Science, Baltimore, 93(1): 77-82, jan. 1962.

PEDROSO, P.A.C.; VITTI, G.C.; DE NADAI; O.E.; GUIMARAES, P.T.G.; MELLES, C.C.A.; MALAVOLTA, M.L.; MALAVOLTA, E. Efeito de fontes doses de enxofre èm culturas de interesse economico IV Cáfé. São Paulo, SN Centro de Pesquisa e Promoção do Sulfato de Amônio, 1986. 41p. [Boletim tềnico, 4]. 
PEVERILI, K.I.; BRINER, G.P.; WALBRAN, W.T. Problems associated with soil testing for sulphur. In: INTERNATIONAL CONGRESS OF SOIL SCTENCE, 10, MOSC•W, 1974. Transactions... Amsterdam, Elsevier, 1975 . v.2. p. $174-80$.

PREVOT, P. \& OLAGNIER, M. La carence en soufre de l'arachide en Afrique. Agrochimica, Paris, 81(3): 210-21, mar. 1964 .

PROBERT, M.E. Studies of available and isotopically exchangeable sulphur in some North Queensland soils. Plint and Soil, The Hague, 45(2): 461-75, febr., 1976.

PROBERT, M.E. \& JONES, R.K. The use of soil analysis for predicting the response to sulphur of pasture, in the Australian tropics. Austratian Journal of Agricultural Research, Melbourne, 28(1): 137-46, jan. 1977 .

PUMPHREY, F.V. \& MOORE, D.P. Diagnosing sulfur deficiency of alfalfa from plant analysis. Agronomy Journal, Madison, $5 i(4): 364-6$, julylaug. 1965 . 
QUAGGIO, J.A.; DECHEN, A.R.; RAIJ, B. van. Efeitos da aplicașão de calcânio e gesso sobre a produção de amendoim e lixiviação de bases no solo. Revista Brasileira de Ciência do Soio, Campinas, 6 (3), $189-94$, set./dez. 1982 .

QUAGgio, J.A. Métodos de laboratório para determinação da necessidade de calagem em solos. In: RAIJ, B. van et alii, coord. Acidez e calagem no Brasil. Campinas, Sociedade Brasileira Ciência do Solo, 1983, p.33-48.

QUINN, L.R.; MOTT, G.O.; BISCHOFF, W.V.A. Fertilização de pastos de capion colonia e produção de carne com novilhos zebu. São pau1o, Inst. Pesq. IRI, 1961. 30p. [Boletim têcnico, 24].

QUINN, B.F. \& WOODS, P.H. Rapid manual determination of sulphur and phosphorus in piant material. Comminications in Soil Science and Plant Analysis, New York, $\underline{7}(4): 415-$ $26,1976$.

RAIJ, B. van. Avaliação da fextilidade do solo. Piracicaba, Instituto da Potassa (EUA-Suíca), $1981.142 \mathrm{p}$. 
RAIJ, B. van. Propriedades eletroquímicas de solos. In: SIMPÓSIO AVANCADO DE QUIMICA E FERTILIDADE DO SOLO, Piracicaba, 1986. Anais... Campinas, Fundação Cargil1, 1986. p.9-39.

RASSMUSSEN, P.E.; RAMIG, R.E.; EKIN, L.G.; ROHDE, C.R. Tissue analysis guidelines for diagnosing sulphur deficiency in white wheat. Plant and Soil, The Hague, 46(1): 153-63, jan. 1927 .

REEVE, N.G. \& SUMNER, M.E. Amelioration of sub-soil acidity in Natal oxisols by leaching of surface-applied amendements. Agrochemophysica, Pretoria, 4: 1-6, 1972.

REISENAUER, H.M.; WALSH, L.M.; HOEFT, R.G. Testing soils for sulphur, boron, inolybdenum and chlorine. In: WALSH, L.M. \& BEATON, J.D., eds. SOII testing and plant analysis, Madison, ASA, 1973, cap. 12. p.173-99.

REISENAUER, H.M. Soil assays for reconition of sulphur deficiency. In: MCLACHLAN, K.D., ed., Sulphur in Australian Agriculture, Sidney, Sidney University Press, 1975. p. $182-7$. 
RICHARD, L. Adaptação ao meio natural do método das "variantes systematiques" do Prof. HOMES - Fertilité, Paris, $7: 21-31$. juin. 1959.

RICKE, W. Contribution to geochemistry of sulphur. Geochinica et Cosmochimica Acta, London, 21(1):35-80. jan. 1960 .

RITCHEY, K.D.; SOUZA, D.M.G.; LOBĀO, E.; CORRETA, O.' Calcium leaching to increase rooting depth in a brazilian savannah oxisol. Agroromy Journal, Madison, 72(1): 40-4, jan./febr. 1980 .

RITCHEY, K.D.; SILVA, J.E. da; ESPINOZA, W.; LOBATO, E. Downward movement of calcium and the improvement of sub-soil rooting in oxisols in Brazil. In: RUSSEL, R.S. et alii, eds., 1981. The soil root system in relation to Brazilian agriculture. Londrina, IAPAR, 1982. p. $137-51$.

RUSSEL, E.W. Soil conditions and plant growth. 10 ed. Longman, London, 1973. $849 \mathrm{p}$. 
SAGGAR, S.; BETTANY, J.R.; STEWART, J.W.B. Sulfur transformations in relation to carbon and nitrogen in incubated soits. Soitiology and Biochemistry, oxford, $13(2): 499-511$, mar./apr. 1981.

SANSUM, L.L. \& ROBINSON, J.W.D. Wet digestion, manual and automated analysis of total sulphur in plant material. Communications in SoII Science and Plant Analysis, New York, $5(5): 365-83,1974$.

SARRUGE, J.R. \& HAAG, H.P. Manual de analise foliar. Piracicaba, Escola Suparior de Agricultura "Luiz de Queiroz", 56p. [mimeografado].

SAS INSTITUTE INC. SAS USeris guide; statistics. North Carolina, NC SU, 1.982 .

SAUNIERS, W.M.H. \& COOPER, D.M. Evaluation of soil and plant analysis to determine sulphur status of New Zealand soils. In: MCLACHLAN, K.D., ed. Sulphur in Australasian Agriculture. Sidney University Press, 1975. p.188-95.

SCHARPENSEEI, H.W. \& KRAUSE, R. Radiochromatographic investigations on the cycie of the sulfate and of the $S$ amino-acids cystine and methionine. Zeitschrift für PfIanzenernährung, Düngung und Bodenkunde, Leipzig, $101(1): 11-23,1963$. 
SEARLE, P.L. Measurement of adsorbed sulphate in soils effects of varying soil: extractant ratios and methods of measurement. New Zealand Journal of Agricultural Research, Wellington, 22ì(2): 287-90, may, 1979 .

SHEARD, R.W. Initial and residual utilization by alfalfa and bromegrass of sulphur from ${ }^{35} S$ - labelled gypsum. Communications in Soil Science and plant Analysis, New York, 11(6): 605-619, 1980 .

SILVA, J.E. da \& RITCHEX, K.D. Adubação potâssica em solos de cerrado. In: Potâssio na Agricultura Brasileira, Londrina, IAPAR, 1982. p.323-38.

SIMON-SYLVESTRE, G. Les composês du soufre du sol et leur rêvolution - rapports avec la microflore, utilization par les plantes. Annates Aoronomiques, Paris, 3 : 311 $-32,1960$.

SINGH, B.R. Sulfate sorption by acid forest soils:

1. Sulfate adsorption isotherms and comparison of different adsorption equations in describing adsorption. Soil Science, Ba1timore, 135(6): 489-97, dec. 1984a. 
SINGH, B.R. Sulfate sorption by acid forest soils:

3. Desorption of sulfate from adsorbed surfaces as a function of time, desorbing ion, $\mathrm{pH}$ and amount of adsorption. Soil Science, Baltimore, 138(5): 346-53, nov. $1984 b$.

SMITH, F.W. \& DOIBY, G.R. Derivation of dianostic indices for assessing the sulphur status of Panicum maximum var. trichoglume. Commurrications in Soil Science and Plant Analysis, New York, $\underline{8}(3): 221-40,1977$.

SMITH, J.I. ; SCHNABEL, R.R.; MCNEAI, B.L.; CAMPBELL, G.S . Potential errors in the first-order model for estimating soil nitrogen mineralization potentials. Soil Science Society of America Procédings, Madison, 44(5): 996-1000, sept./oct. 1980 .

SPENCER, K. \& FRENEY, J.R. A comparison of several procedures for estimating the sulphur status of soils. Australian Journal of Agricultural Research, Melbourne, 11(6): 948-59, nov./dec.'1960.

SPENCER, K. \& FRENEY, J,R. Assessing the sulphur status of field-grown wheat by plant analysis. Agronomy Journa 1 , Madison, $72(2): 469-72$, mar./apr. 1980 . 
STANFORD, G. \& SMITH, S.J. Nitrogen mineralization potentials of soils. SoiI Science Society of America Proceedings, Madison, 36(3): 465-72, may/jun: 1972.

STANFORD, G.; CARTER, J.N.; WESTERMAN, D.T.; MEISINGER, J.J. Residual nitrate and mineralizable soil nitrogen in relation to nitrogen uptake by irrigated sugarbeets. Agronomy Journa, Madison, 69(2): 303-8, mar./apr. 1977 .

SUMNER, M.E. Diagnosing the sulfur requirements of corn and wheat using foliar analysis. Soil Sciences Society of America Journa1, Madison, 45(1): 87-90, jan. 1981.

SWIFT, R.S. Mineralization and immobilization of sulphur in soil. Sulphur in Agriculture, Washington, 9(2): 20-4, febr. 1985 .

TABATABAI, M.A. \& BREMENR, J.M. An alkaline oxidation method for determination of total sulphur in soils. Soit Science Society of America Proceedings, Madison, $34(1): 62-5$, jan./febr. 1970 ,

TABATABAI, M.A. \& BREMNER, J.M. Arylsulfatase activity in soils. Soil Science society of America Proceedings, Madison, 34(2): 225-9, mar./apr. . 1970 . 
TABATABAI, M.A. \& BREMNER, J.M. Factors affecting soil arylsulfatase activity. SoII Science Society of America Proceedings, Madison, 34(3): 427.9 , may/jun. 1970 .

TABATABAI, M.A. \& BREMNER, J.M. Distribution of total and available sulfur in selected soils and soil profiles. Agronomy Journa 1, Madison, 64(1):40-4, jan./febr. 1972 .

TABATABAI, M.A. \& AL-KHAFAJI, A.A. Comparison of nitrogen and sulfur mineralization in soils. Soil Science Society of America Journa 1, Madison, 44(5): 1000-6, sept./oct. 1980 .

TSUJI, T. \& GOH, K.M. Evaluation of soil sulphur fractions as sources of plant availabje sulphur using radioactive sulphux. New Zealand Journal ò Agricultural Research, Wellington; 22(4):595-602, nov. 1979 .

TISDALE, S. \& NELSON, W. Soil fertility and fertilizers. 3ed. London, McMillan, 1975. 694p.

VILLAMIZAR, F. \& LOTERO; J Respuesta del pasto Pangola a differentes fuentes $y$ dósis de nitrógeno. Revista del. Instituto Colombiano Agropecuârio, Bogotá, 2(3): 57-70, sept. 1967 . 
VITOLINS, M.I. \& SWABY, R.J, Activity of sulphur-oxidizing microorganisms in some Australian soils. Australian Journal of Soil Research, Melbourne, $7(1): 171-3$, jan./ febr. 1969.

VITTI, G.C. \& RODELLA, A.A. A determinaça do enxofre em matêria vegetal pelo metodo turbidimêtrico. Fac.Ci. Vet. - UNESP, Jaboticaba1. 1982. 13p. [mimeografado].

VITTI, G.C. \& MALAVOLTA, E. Fosfogesso; uso agrícola. In: MALAVOLTA, E., cOOXd., SEMINARIO SOBRE CORRETIVOS AGRICO LAS, Piracicaba, T984. Añàs... Campinas, Fundação Cargi11, 1985, p.16\%-201.

VITTI, C.G. Efeito do valor do pH na disponibilidade de enxofre em latossolos do Município de Jaboticabal. Jaboticaba], 1979. [Mestrado em Produção Vegetal - UNESP, Jaboticabal].

VITTI, G.C. \& SUZUKI, J. A determinacão do enxofre - sulfato pejo mêtodo turbidimetrico. Jaboticabal, Fac. Ci. Agr. Vet. . UNESP, 1978. 13p. [mimeografado]. 
WANG, C.H.; LIEM, T.H.; MIKKEISEN, D.S. Sulfur deficiency - a liniting factor in rice production in the low Amazon basin. I. Development of sulfur deficiency as a 1 imiting factor in rice production. New York, IRI Res. Inst., 1976a. 54p. [Bo1etim, 47].

WANG, C.H.; LIEM, T.H.; MTKKEISEN, D.S. Sulfur deficiency a limiting factor in rice production in the low Amazon basin. TI. Sulfur requirement for rire production. New York, IRI Res. Inst., 1976b. 46p. [Boletim, 48].

WATSON, E.R. The influence of subterraneum clover pastures on soil fertility. III. The effect of applied phosphorus and sulphur. Austratian Journal of Agricultural Research, Melbourne, 20(3): 447-56, febr. 1969 .

WHITE, J.G. Mineralization of nitrogen and sulphur in sulphur deficient soils. New Zealand Journal of Agricultural Research; Wellington, $2(2): 255-8$, apr./ june. 1959 .

WILLIAMS, C.H. \& STEINBERGS, A. Soil sulphur fractions as chemical indices of available sulphur in some Australian soils. Australian Journal of Agricultural Science, Melbourne, 10(2): 340-52, febr. 1959 . 
WILLIAMS, C.H. \& STEINBIRGS, A. The evaluation of plant sulphur in soils. TI. The availability of adsorbed and insolubles sulphates. Plant and Soil, The Hague, 21(1): $50-62$, jan. 1964.

WILLIAMS, C.H. Some factors affecting the mineralization of organic sulphur in soils. Plant and Soil, The Hague, 26 (2): 205-22, febr. 1967 .

WOODHOUSE JUNIOR, W.W. Longterm fertility requirements of Coastal Bermuda grass. III. Sulphur Agronomy Journal, Madison, 61(5): $705-8$, sept./oct. 1969 . 
.222.

7. APENDICE 
Tabela 1 - Resultados das anälises de rotina de terra amostradas, após a incubação (A), após primeiro cultivo (B) e após o segundo cultivo (C) (mêdias de 3 repetições).

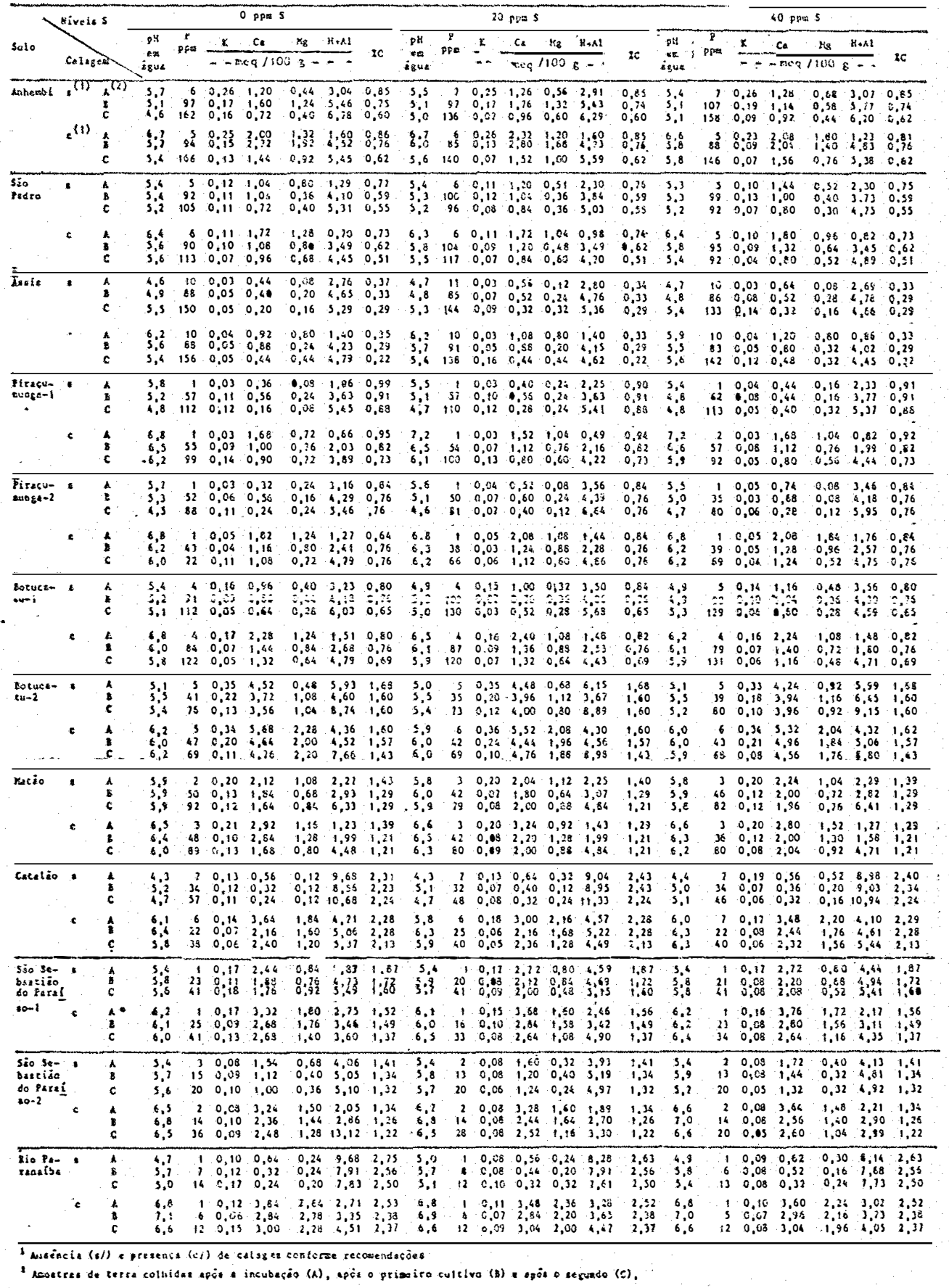


Tabela 2 - Produção de matéria seca da parte aérea do milho (g/vaso), em função da calagem e gessagem, com dois cultivos sucessivos.

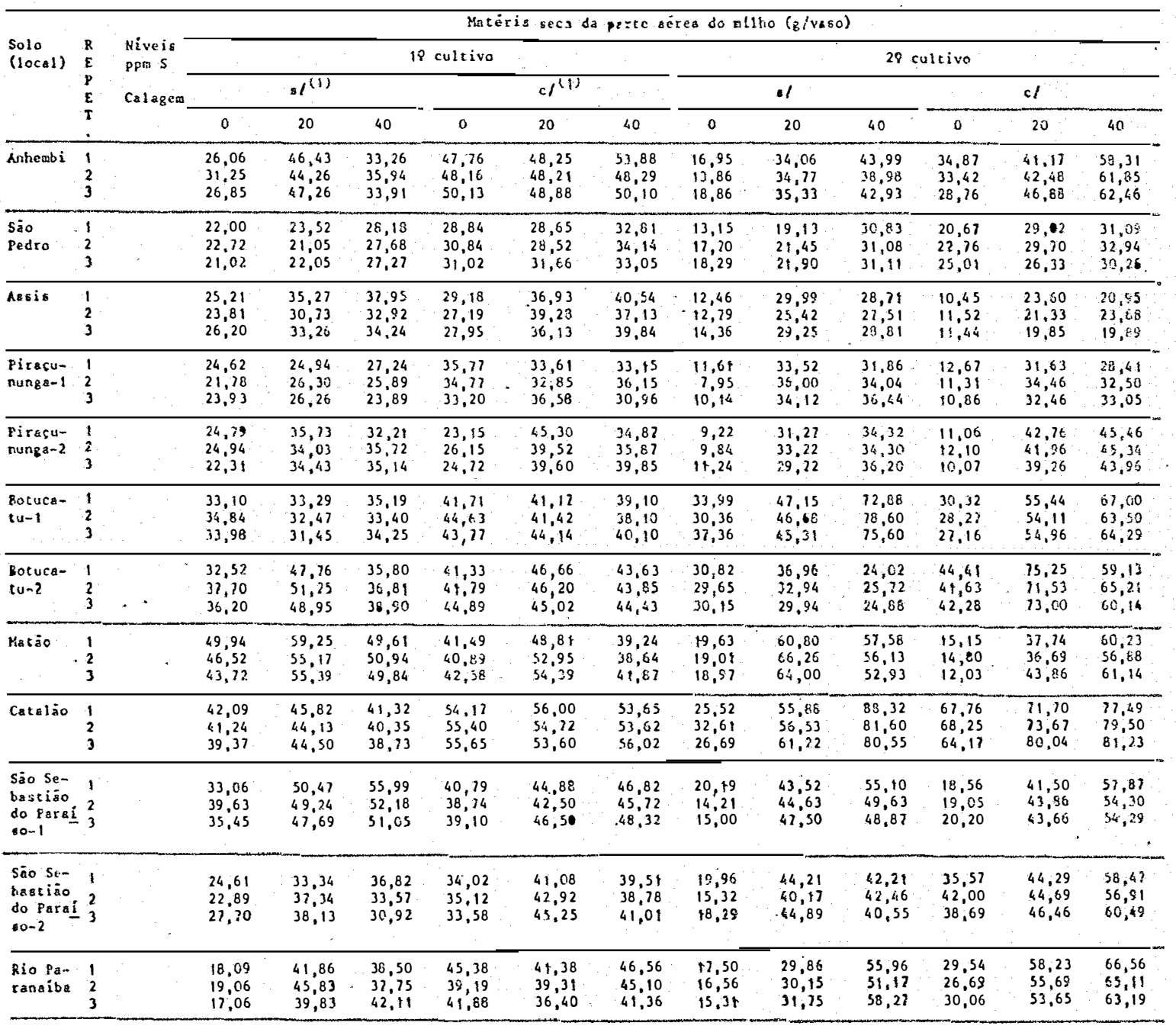

(1) Auséncia (s/) e presenga (c/) de calagea conforse recobiendacöes. 
Tabela 3 - Teores totais de nitrogênio, fósforo e enxofre na parte aêrea do milho, em função da calagem e da gessagem em dois cultivos sucessivos.

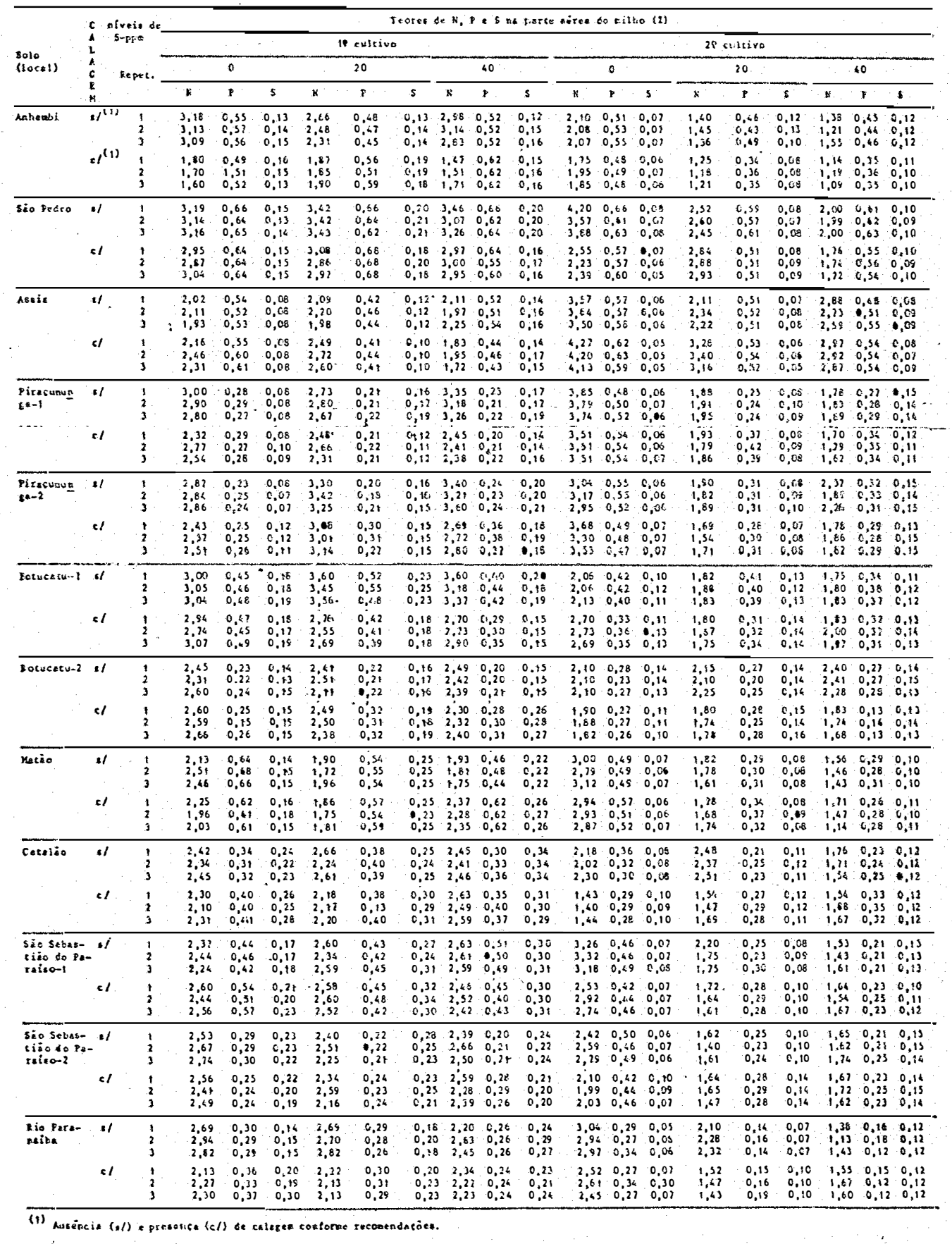


Tabela 4.1 - Resultados das deteminações de $\mathrm{S}_{-} \mathrm{SO}_{4}=$ disponivel nas amostras de terra após a incubação, após o primeiro culti vo e apôs o segundo cultivo

\begin{tabular}{|c|c|c|c|c|c|c|c|c|c|c|c|c|c|c|c|c|c|c|c|}
\hline \multirow{3}{*}{\multicolumn{2}{|c|}{ 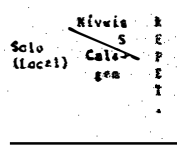 }} & \multicolumn{18}{|c|}{ 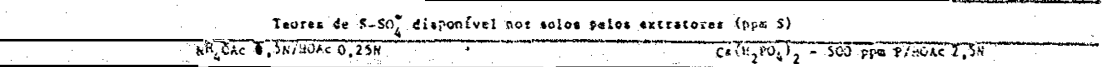 } \\
\hline & & \multicolumn{3}{|c|}{0} & & \multicolumn{3}{|c|}{80.} & \multicolumn{3}{|c|}{0} & \multicolumn{3}{|c|}{20} & \multicolumn{3}{|c|}{40} \\
\hline & & $a^{(2)}$ & $8^{(2)}$ & $c^{(2)}$ & 1 & 8 & $c$ & $A$ & 8 & $\varepsilon$ & $\therefore$ & 1 & $c$ & 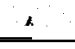 & $\cdot$ & c & 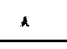 & 1 & c \\
\hline \multirow[t]{2}{*}{ maneasi } & (1) & 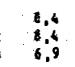 & 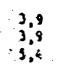 & $\begin{array}{ll}3.4 \\
s, 4 \\
s, 4\end{array}$ & & $\begin{array}{ll}8.4 \\
8,4 \\
6,9\end{array}$ & 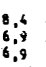 & $\begin{array}{l}-16 \\
19,1 \\
19,8 \\
19,8\end{array}$ & $\begin{array}{ll}111,4 \\
11,4 \\
11,4\end{array}$ & 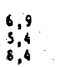 & $\begin{array}{l}8.2 \\
i, 2 \\
6,2\end{array}$ & 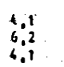 & 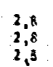 & & 然: & & 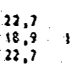 & 染, & $\begin{array}{ll}6.2 \\
i_{2}^{2} \\
i_{2}^{2}\end{array}$ \\
\hline & $c^{11}$ & 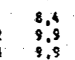 & $\begin{array}{ll}6.3 \\
8.4 \\
6.9\end{array}$ & 要, & $\begin{array}{l}31,0 \\
13,0 \\
14.6\end{array}$ & $\begin{array}{l}8.4 \\
8.4 \\
8.4\end{array}$ & sis & 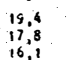 & $\begin{array}{ll}13.0 \\
13,4\end{array}$ & s: & & $\begin{array}{ll}6.2 \\
6.2 \\
6,2\end{array}$ & 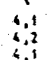 & $\begin{array}{l}31,7 \\
\text { is.? } \\
13,2\end{array}$ & 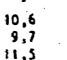 & $\because$ & $\begin{array}{l}20,8 \\
22,2,8 \\
20,8\end{array}$ & $\begin{array}{l}1,2,2 \\
1,3,2 \\
1,2,1\end{array}$ & $\because 1$ \\
\hline \multirow[t]{2}{*}{ 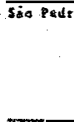 } & & $\frac{6.9}{8.9}$ & $\begin{array}{ll}0.4 \\
8,4\end{array}$ & $\begin{array}{l}8.49 \\
8: 9 \\
8: 9\end{array}$ & $\begin{array}{ll}131,0.0 \\
146,0\end{array}$ & $\begin{array}{l}71,4 \\
8,4 \\
8,4\end{array}$ & $\begin{array}{l}6,9,9 \\
8,9 \\
8,6\end{array}$ & $\begin{array}{l}25,4 \\
20,4 \\
20 ; 4\end{array}$ & $\begin{array}{l}211,40 \\
13,0 \\
11,4\end{array}$ & $\begin{array}{l}6.9 \\
6.99 \\
699\end{array}$ & 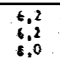 & 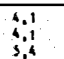 & $\begin{array}{l}8.12 \\
8.2 \\
6.2\end{array}$ & $\begin{array}{l}33.1 \\
13: 1 \\
13,2\end{array}$ & $\begin{array}{l}8.2 \\
8.22 \\
8,2\end{array}$ & $\begin{array}{l}8 \% 1 \\
8 \% 2 \\
8,2\end{array}$ & $\begin{array}{l}710.0 \\
210.8 \\
18,8\end{array}$ & $\begin{array}{l}8,0 \\
8: 0 \\
8,0\end{array}$ & 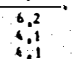 \\
\hline & I & $\int_{4}^{11.4}$ & 4 & $\begin{array}{l}8.9 \\
8 \% 4\end{array}$ & $\begin{array}{l}29,4,4 \\
19,4,4 \\
19 ; 4\end{array}$ & $\because \because 6^{9}$ & 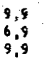 & $\begin{array}{l}212,8 \\
32,8 \\
3,1,3\end{array}$ & $\begin{array}{l}22,1 \\
22,0 \\
19,0 \\
19,4\end{array}$ & 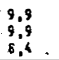 & $\begin{array}{l}6.2 \\
8.0 \\
6.2\end{array}$ & $\begin{array}{l}8.2 \\
6.2 \\
6.22\end{array}$ & \begin{tabular}{l}
8.0 \\
\hdashline$: 1$ \\
0.2
\end{tabular} & $\begin{array}{c}31,2,2 \\
15,0, \\
15,2\end{array}$ & $\begin{array}{l}8.0 \\
8.2 \\
6.22\end{array}$ & $3: \frac{1}{30}$ & $\begin{array}{l}26,6 \\
26,6 \\
26,2,2\end{array}$ & 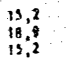 & : \\
\hline \multirow[t]{2}{*}{ wat } & 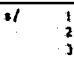 & $\begin{array}{l}5,4 \\
6,9 \\
6,9\end{array}$ & $\begin{array}{l}2,4, \\
2,4 \\
2,4\end{array}$ & $\begin{array}{l}3,9 \\
3,99 \\
3,99\end{array}$ & 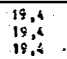 & $\begin{array}{l}3.94 \\
3,5 \\
0,4\end{array}$ & $\begin{array}{l}5,4 \\
5,4,4 \\
3,4\end{array}$ & $\begin{array}{l}27,8, \\
276,8 \\
27,8\end{array}$ & $\begin{array}{l}6,99 \\
69.9\end{array}$ & $\begin{array}{l}0.9 \\
5.40 \\
3.49\end{array}$ & $\begin{array}{l}8,0 \\
9,7 \\
9,7\end{array}$ & $\begin{array}{l}8.0 \\
6,2 \\
6,2\end{array}$ & $\begin{array}{l}8,0 \\
8,0 \\
8,0 \\
8,0\end{array}$ & $\begin{array}{l}15,2,2 \\
1 ;, 0 \\
i, 0,0\end{array}$ & $\begin{array}{l}9,20 \\
8,0 \\
8,7\end{array}$ & $\begin{array}{l}6 \% 8 \\
8 \% \\
8 \%\end{array}$ & $\begin{array}{l}26,6,6 \\
30,2 \\
28,6\end{array}$ & $\begin{array}{l}9.7 \\
9.7 \\
8: 0\end{array}$ & $\begin{array}{lll}8: 1 \\
8: 0 \\
8: 0\end{array}$ \\
\hline & & $\begin{array}{l}6.9 \\
8.9 \\
89\end{array}$ & $\begin{array}{l}3: 2 \\
2: 4 \\
2,4\end{array}$ & $\begin{array}{l}3,9 \\
3 ; 9 \\
3,9\end{array}$ & $\begin{array}{l}17,8, \\
18,6, \\
18,4\end{array}$ & $\begin{array}{l}899 \\
899 \\
54.9\end{array}$ & $\begin{array}{l}2,3 \\
2,5 \\
2,5 \\
3.9\end{array}$ & $\begin{array}{l}22,8 \\
22,8 \\
26,6\end{array}$ & 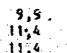 & $\begin{array}{l}2,5 \\
3,4 \\
3,4\end{array}$ & $\begin{array}{l}9.2 \\
: 2.7 \\
0.7\end{array}$ & $\begin{array}{l}8: 0 \\
8: 0 \\
8: 0\end{array}$ & 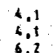 & $\begin{array}{l}11,5 \\
1:, 3 \\
10,2\end{array}$ & $\begin{array}{l}8,0 \\
8,2 \\
6,2\end{array}$ & $\begin{array}{l}8.2 \\
8.2 \\
6,2\end{array}$ & $\begin{array}{r}29,6 \\
299,7 \\
26,6\end{array}$ & $\begin{array}{l}6.2 \\
8.0 \\
i, 1\end{array}$ & 800 \\
\hline \multirow[t]{2}{*}{ 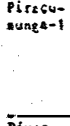 } & & $\begin{array}{l}3,9 \\
3,4,8 \\
3,4\end{array}$ & $\begin{array}{l}2,2,2 \\
3,9\end{array}$ & $\begin{array}{l}2.2 \\
3.9\end{array}$ & 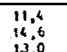 & $\begin{array}{l}8,4 \\
8,4 \\
9,4\end{array}$ & 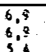 & $\begin{array}{l}212,0 \\
22,2 \\
2,20\end{array}$ & $\begin{array}{l}9.5 \\
s, 9 \\
\text { sis }\end{array}$ & $\begin{array}{l}6,9,9 \\
5,4,4 \\
6,4\end{array}$ & $\begin{array}{l}0,3 \\
6,2\end{array}$ & 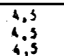 & $\begin{array}{l}4.55 \\
4.5 \\
0,5\end{array}$ & $\begin{array}{l}13.3 \\
10.4 \\
15,3\end{array}$ & $\begin{array}{l}8.2 \\
8.0 \\
9,2\end{array}$ & $\begin{array}{l}8,3 \\
6.25 \\
0.25\end{array}$ & $\begin{array}{l}17,0 \\
177,0 \\
12,0\end{array}$ & 98,7 & $\frac{6.2}{6.2}$ \\
\hline & 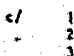 & $9 ;$ & $\begin{array}{l}3,9 \\
3,9 \\
3,9\end{array}$ & $\begin{array}{l}2,5 \\
3,5 \\
3,9\end{array}$ & $\left\{\begin{array}{l}13,0 \\
13,0\end{array}\right.$ & $\begin{array}{l}5.4 \\
5,4 \\
; 04\end{array}$ & $\begin{array}{l}3,9 \\
3,5 \\
2,5 \\
2,5\end{array}$ & $\begin{array}{l}17,6 \\
10,1 \\
16,1\end{array}$ & $\begin{array}{l}6.9 \\
8.9 \\
8.4\end{array}$ & $\begin{array}{l}3.4 \\
5.4\end{array}$ & $\begin{array}{l}82 \\
\therefore: 2\end{array}$ & 43 & $\begin{array}{l}4.5 \\
4.5\end{array}$ & $\begin{aligned} 13,3 \\
111.4\end{aligned}$ & $\begin{array}{l}8.2 \\
6: 2\end{array}$ & 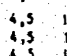 & $\begin{array}{l}18,9 \\
15,2\end{array}$ & $\begin{array}{l}6.2 \\
6.22\end{array}$ & 9.5 \\
\hline \multirow[t]{3}{*}{ 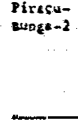 } & II & 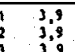 & $\begin{array}{l}2,5,5 \\
2,5,\end{array}$ & 1,09 & $\begin{array}{l}14,6 \\
14,6,6 \\
14,6\end{array}$ & 3.99 & $\begin{array}{l}3.9 \\
5.9\end{array}$ & $\begin{array}{l}22,4 \\
22,5 \\
22,0\end{array}$ & 18,1 & 6,9 & 4.55 & 4.5 & 6.2 & $\because 4,4$ & $\begin{array}{l}8.2 \\
6.2\end{array}$ & $\begin{array}{l}6.2 \\
6.2\end{array}$ & $\begin{array}{l}13,22 \\
17,0\end{array}$ & $\begin{array}{l}8,7 \\
13,3\end{array}$ & 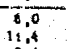 \\
\hline & et & & 3.9 & 5,4 & 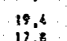 & 3.9 & 2,5 & 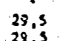 & $s, 9$ & 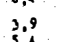 & 6.2 & $\because$ & $\because 3$ & 9 & 争, & 2.8 & 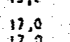 & $\because$ & \\
\hline & & 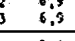 & $\begin{array}{l}3,3 \\
2,3\end{array}$ & $\begin{array}{l}2.3 \\
2,5 \\
2.5\end{array}$ & 17,.8 & $3 ; 9$ & 年, & $\begin{array}{l}28,3 \\
24,4\end{array}$ & 年, 9 & $3 ; 9$ & $\begin{array}{l}6.22 \\
6,2 \\
\end{array}$ & 8,5 & 箈, & 然, 9.4 & 4.3 & 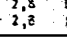 & 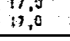 & 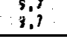 & 8 \\
\hline \multirow[t]{2}{*}{$\begin{array}{l}\text { Solvech- } \\
\text { evy-1 }\end{array}$} & " & $\begin{array}{l}\frac{1}{3} \\
3 \\
3\end{array}$ & s.9.9 & $\begin{array}{l}2,3 \\
3,0 \\
5,4\end{array}$ & $\begin{array}{c}17,8,8 \\
1,8,8 \\
1,8,8\end{array}$ & 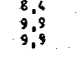 & 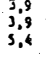 & 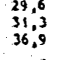 & 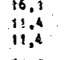 & $\begin{array}{l}3,9 \\
3,5 \\
3,8\end{array}$ & $\begin{array}{l}3,3,3 \\
1,0,0 \\
15,2\end{array}$ & & $\begin{array}{l}6.22 \\
6.22 \\
6.2\end{array}$ & $\begin{array}{l}28,66 \\
28,6 \\
26,6,6\end{array}$ & 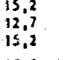 & $\begin{array}{l}8.0 \\
8.00 \\
8.0 \\
8.0\end{array}$ & 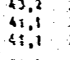 & $\begin{array}{l}28,6 \\
32,0 \\
36,6\end{array}$ & $\begin{array}{ll}8,0 \\
: ? 7 \\
80\end{array}$ \\
\hline & c & $\begin{array}{l}3: 9 \\
10,4 \\
10,4\end{array}$ & 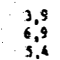 & $\begin{array}{l}2,3 \\
2,9 \\
3,4 \\
3,4\end{array}$ & 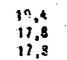 & 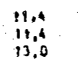 & 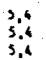 & 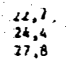 & $\begin{array}{l}21,0.0 \\
21,0.0 \\
21,0\end{array}$ & $\begin{array}{l}5.4 \\
5,4 \\
5,4\end{array}$ & 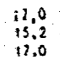 & $\begin{array}{l}9.7 \\
9,7,7 \\
9,7\end{array}$ & $\begin{array}{l}5,2 \\
6,2.2 \\
6,2\end{array}$ & $\begin{array}{l}2: 0, \frac{6}{30,6} \\
20,6,6\end{array}$ & 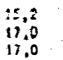 & $\begin{array}{l}8.2 \\
6 \% 2 \\
6,2\end{array}$ & 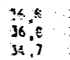 & 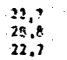 & 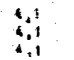 \\
\hline \multirow[t]{2}{*}{ 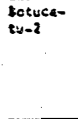 } & .1 & $\begin{array}{lll}1310 \\
2 \\
3 \\
3\end{array}$ & $\begin{array}{l}8,4,4 \\
8,9 \\
8,4\end{array}$ & $\begin{array}{l}69,9 \\
9: 99 \\
699\end{array}$ & 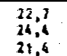 & $\begin{array}{l}13,0 \\
0,0.0 \\
18,1\end{array}$ & 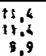 & $\begin{array}{l}33,9 \\
33,0 \\
3+, 1\end{array}$ & $\begin{array}{l}19,4,4 \\
26,2,2 \\
24,4\end{array}$ & 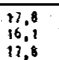 & $\begin{array}{l}8,8 \\
8,0 \\
8,0\end{array}$ & $\begin{array}{l}8.2 \\
8.2 \\
6,2\end{array}$ & 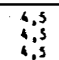 & $11 ; 4 ;$ & $\begin{array}{l}9.7 \\
9,2,7 \\
\varepsilon, 7\end{array}$ & $\begin{array}{l}8.2 \\
6.2 \\
6,2 \\
6,2\end{array}$ & 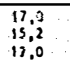 & $\begin{array}{l}3,3,3 \\
\text { s:? } \\
8: 4\end{array}$ & $\begin{array}{l}8,0 \\
800 \\
80\end{array}$ \\
\hline & \& & $\begin{array}{l}14,6 \\
14,6 \\
10,6\end{array}$ & $\begin{array}{l}13,0 \\
13,0 \\
13,0\end{array}$ & 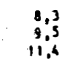 & $\begin{array}{l}24,4 \\
24,4 \\
22,7\end{array}$ & 19:48, & 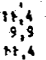 & $\begin{array}{l}34,3 \\
34,5, \\
34,9\end{array}$ & $\begin{array}{l}22,7 \\
22,0 \\
24,0\end{array}$ & 消, & $\begin{array}{l}8,8 \\
8,0 \\
110,4\end{array}$ & $\begin{array}{l}6.2 .2 \\
6.2 .2 \\
6.2\end{array}$ & 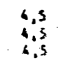 & $\begin{array}{l}15.2,2 \\
\text { is.2, } \\
\text { is.3 }\end{array}$ & 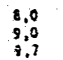 & $\left\{\begin{array}{l}i, 0 \\
i: 0 \\
i, 0\end{array}\right.$ & 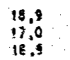 & $\operatorname{lin}_{i 1,4}$ & 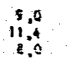 \\
\hline & "í & $\begin{array}{l}3,9 \\
3 ; 9 \\
3,9\end{array}$ & $\begin{array}{l}3,9 \\
3,9,9 \\
2,4\end{array}$ & $\begin{array}{l}2 ; 4 \\
2 ; 9 \\
3,9\end{array}$ & s; & 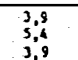 & $\begin{array}{l}3.9 \\
3,4.9 \\
3.9\end{array}$ & 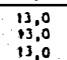 & $\begin{array}{l}3,4,4 \\
3,9,9 \\
5,4\end{array}$ & $\begin{array}{l}2,4, \\
3,9 \\
3,4\end{array}$ & $\begin{array}{l}3,3 \\
3,2 \\
2,2\end{array}$ & 8 & $\begin{array}{l}6.2 \\
6,2,2 \\
6.2\end{array}$ & 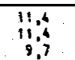 & $\begin{array}{l}6.2 \\
6,2 \\
6,2,2\end{array}$ & 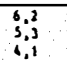 & $\begin{array}{l}17,0 \\
178,9 \\
17,0\end{array}$ & , & 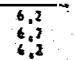 \\
\hline & & $\begin{array}{l}3,9 \\
3,9 \\
3,9\end{array}$ & $\begin{array}{l}3,9 \\
3,9 \\
3,9\end{array}$ & $\begin{array}{l}3.9 \\
2.4 \\
3,4\end{array}$ & מ: & $\begin{array}{l}3,9 \\
3,9 \\
2,4\end{array}$ & $\begin{array}{l}2,4 \\
2,4 \\
2,4\end{array}$ & 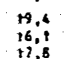 & $\begin{array}{l}3,9 \\
3,9 \\
5,4\end{array}$ & $\begin{array}{l}2.4 \\
2,4 \\
2,4\end{array}$ & $\begin{array}{l}6,0 \\
8,0 \\
8,0 \\
8.0\end{array}$ & 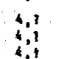 & 4 & $\begin{array}{l}13,3.3 \\
13,3 \\
5,3\end{array}$ & $\begin{array}{l}8.0 \\
8.2 \\
8.2 .2\end{array}$ & 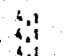 & $\begin{array}{l}28,9 \\
38,9 \\
18,9\end{array}$ & $\begin{array}{l}8,1 \\
, 0,1 \\
, 2\end{array}$ & $\because$ \\
\hline \multirow[t]{3}{*}{ Catentio } & & $\begin{array}{l}9.9 \\
8: 9\end{array}$ & $\begin{array}{l}3.9 \\
2,6 \\
2,4\end{array}$ & 勇, & 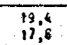 & 16,6 & 999 & $\begin{array}{l}27,3 \\
28,3 \\
28,5\end{array}$ & $\begin{array}{l}16.1 \\
16.6\end{array}$ & 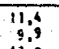 & $\frac{6.2}{8.2}$ & $\begin{array}{l}6,2 \\
6.2\end{array}$ & $\therefore 1$ & $\begin{array}{l}9,7 \\
9,7\end{array}$ & 8,7 & $\begin{array}{l}6.2 \\
6.2 \\
6.2\end{array}$ & 111,4 & $\begin{array}{l}6,2 \\
6.2\end{array}$ & 6.22 \\
\hline & & & 2.4 & & 12,8 & & & & & & & & & & & & & & \\
\hline & & & 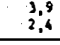 & $\begin{array}{l}7,2 \\
2,4\end{array}$ & $\begin{array}{l}2,1,0 \\
21,0 \\
\end{array}$ & $\begin{array}{l}9.9 \\
8.4\end{array}$ & $\begin{array}{l}2,4 \\
i, 2 \\
i, 2\end{array}$ & $\begin{array}{l}29,3 \\
32,0 \\
32\end{array}$ & $\begin{array}{l}11,6.6 \\
13,0\end{array}$ & 3.4. & 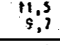 & 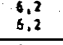 & $\begin{array}{l}6.2 \\
3.3 \\
\end{array}$ & $\begin{array}{ll}117: 0 \\
17.0\end{array}$ & $\begin{array}{l}8,7 \\
8,0 \\
\end{array}$ & $\begin{array}{l}6.2 \\
8.2 \\
\end{array}$ & $\begin{array}{l}28,6.6 \\
28,6\end{array}$ & $\begin{array}{l}31,1.2 \\
15,2\end{array}$ & 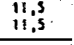 \\
\hline \multirow{2}{*}{ 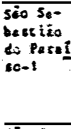 } & & 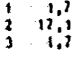 & 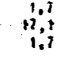 & 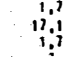 & 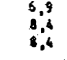 & $\begin{array}{l}2,4 \\
3,0 \\
3,9 \\
3,9\end{array}$ & $\begin{array}{l}i_{i}^{7} \\
i, 2 \\
i, 2\end{array}$ & $\begin{array}{l}17,8 \\
13,0 \\
13,6\end{array}$ & $\begin{array}{l}8,9 \\
5,4 \\
5.4\end{array}$ & $\begin{array}{l}2,4 \\
3,4 \\
3,4\end{array}$ & 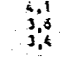 & $\begin{array}{l}2,8 \\
4,1 \\
4,1\end{array}$ & 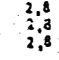 & $\begin{array}{l}8,2.2 \\
8.0 \\
6,2\end{array}$ & $\begin{array}{l}6,2,2 \\
3,3 \\
, 1\end{array}$ & $\begin{array}{l}4,0 \\
i, 0 \\
i, 8\end{array}$ & $\begin{array}{l}13,3 \\
\text { and, } \\
13,3\end{array}$ & $\begin{array}{l}\{: 0 \\
: 0 \\
:, 0\end{array}$ & $\begin{array}{l}8,7 \\
7: 0 \\
8,0\end{array}$ \\
\hline & & 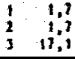 & 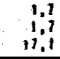 & 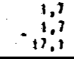 & $\begin{array}{l}9,9 \\
6.98 \\
8.9\end{array}$ & $\begin{array}{l}2,4 \\
2,4 \\
2,4 \\
2.4\end{array}$ & $\begin{array}{l}0,2 \\
0,2 \\
0,2\end{array}$ & $\begin{array}{l}14,8 \\
146,6 \\
14,6\end{array}$ & $\begin{array}{l}3,9 \\
3,9 \\
3,9\end{array}$ & 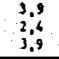 & 4 & $\begin{array}{l}3,3 \\
3,1 \\
3,3\end{array}$ & $\begin{array}{l}6,2 \\
4: 4 \\
4: 1\end{array}$ & $\begin{array}{l}8.0 \\
8.0 \\
8.0\end{array}$ & $\begin{array}{l}8,0 \\
6.2 \\
6.2 \\
6.2\end{array}$ & $\begin{array}{l}6,2 \\
6,2 \\
6,2,2\end{array}$ & $\begin{array}{l}88,9 \\
18,0 \\
18,9\end{array}$ & 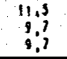 & $\begin{array}{l}3.3 \\
: 1 \\
.2\end{array}$ \\
\hline \multirow{2}{*}{ 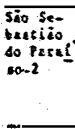 } & & $\begin{array}{l}3: 9 \\
3: 9 \\
2,4\end{array}$ & $\begin{array}{l}1: 0 \\
i: 0 \\
2,4\end{array}$ & $: 00$ & 98 & $\begin{array}{l}3,9 \\
3 ; 99\end{array}$ & $\begin{array}{l}2,4 \\
2,4 \\
3,4\end{array}$ & 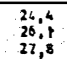 & $\begin{array}{l}8.4 \\
8,4,4\end{array}$ & $\begin{array}{l}6.9 \\
6.96 \\
6.9\end{array}$ & 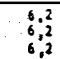 & 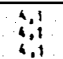 & $\begin{array}{l}2,8 \\
2,8,8 \\
i, 0\end{array}$ & $\begin{array}{l}9.7 \\
8,8 \\
8,8\end{array}$ & $\begin{array}{l}6,2,2 \\
\delta, 2,2 \\
6,2\end{array}$ & $\begin{array}{l}6.2,2 \\
6.2 \\
6,2\end{array}$ & 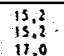 & 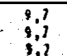 & $\begin{array}{l}8: 0 \\
80 \\
80\end{array}$ \\
\hline & & & 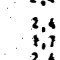 & $\because \because 0$ & 10,0 & s.4. & : & $\begin{array}{l}26,4 \\
24,4 ; \\
24,5\end{array}$ & 98 & $\begin{array}{l}2,4 \\
3,99\end{array}$ & & $\begin{array}{l}6,2 \\
6,2 \\
6,2\end{array}$ & $\begin{array}{l}6,2 \\
6.2 .2 \\
6,2\end{array}$ & , 9.7 & $\begin{array}{l}8,0 \\
8,0\end{array}$ & $\begin{array}{l}6,2 \\
8,2 \\
6.2\end{array}$ & $\begin{array}{l}20,5 \\
10,8 \\
10,8\end{array}$ & in.s. & 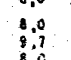 \\
\hline \multirow[t]{3}{*}{ 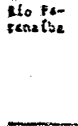 } & . & 9.7 & 2.4 & $\begin{array}{l}2.4 \\
2 \therefore 4\end{array}$ & $\begin{array}{l}8.9 \\
8.94\end{array}$ & 3,9 & 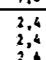 & $\begin{array}{ll}16.1 \\
16.0 .1\end{array}$ & 8 & $\begin{array}{l}3.4 \\
6.3\end{array}$ & & $\begin{array}{l}6.2 \\
6.2\end{array}$ & $\begin{array}{l}6.2 \\
6.2 \\
6.2\end{array}$ & $\begin{array}{l}8,0 \\
8: 0 \\
: 0\end{array}$ & $\begin{array}{l}8,0 \\
8,0\end{array}$ & 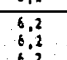 & qu & 800 & 8.80 \\
\hline & " & , & $1: 0$ & 1.00 & $\because 4$ & 1,4 & 2.4 & : & 3.4 & 2,4 & 8,0 & $\frac{12}{12}$ & 6.2 & $\sqrt{11.3}$ & 8,0 & : & i, & 1,0 & 4 \\
\hline & & & & & & & & & & & & & &., 1 & 8,0 & & 3.1 & & \\
\hline
\end{tabular}

(cont.) 
Tabela 4.2 - Resultados das determinações de $\mathrm{S}_{-} \mathrm{SO}_{4}=$ disponível nas amostras de terra após a incubação, após o primeiro culti vo e apôs o segundo cultivo.

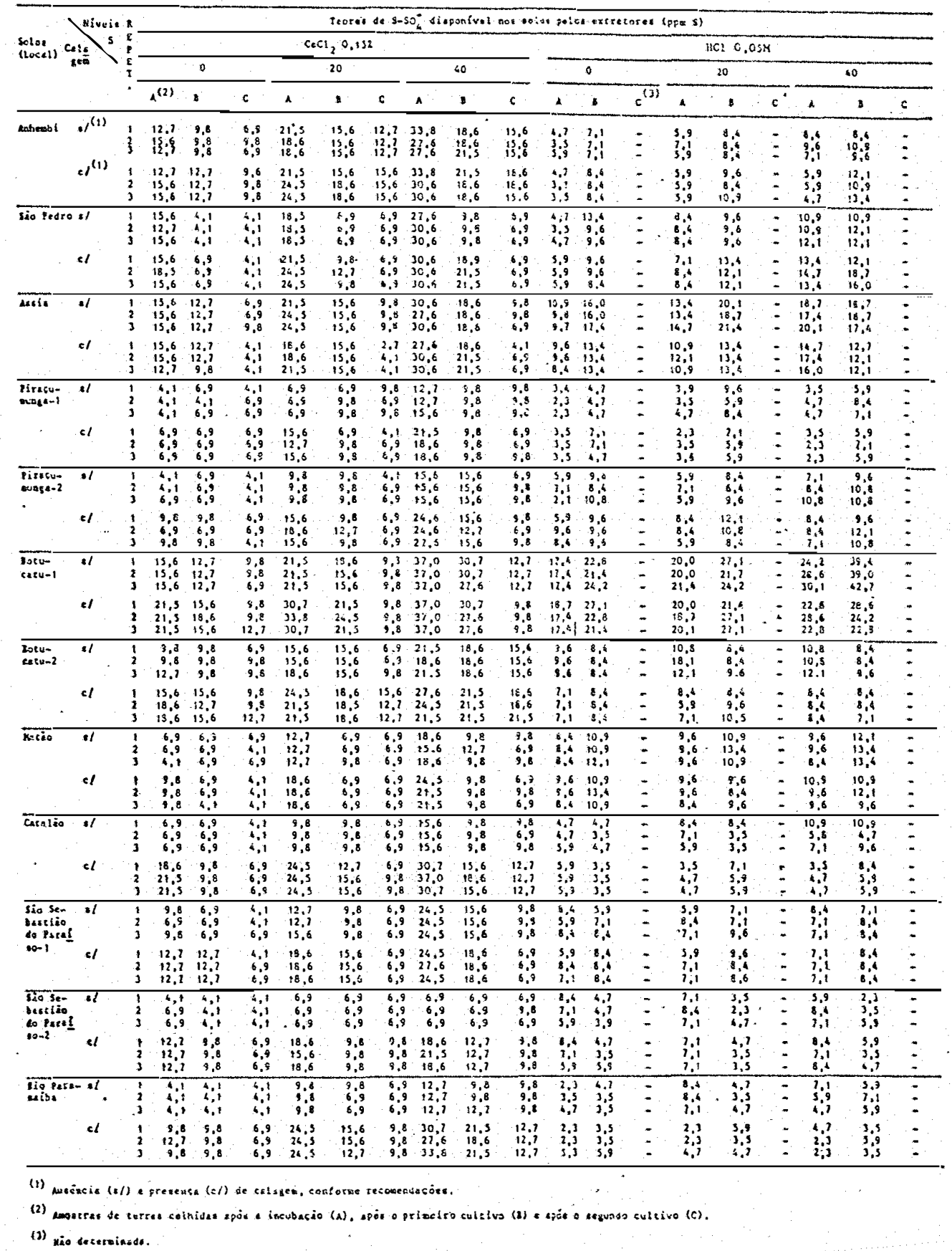


Tabela 5.1 - Efeitos da incubação aberta e da calagem na mineraliza ção do enxofre dos solos ( $\mathrm{S}-\mathrm{SO}_{4}^{\bar{\Xi}}$ ) em condições de microcolunas, submetidas à lixiviação periōdica.

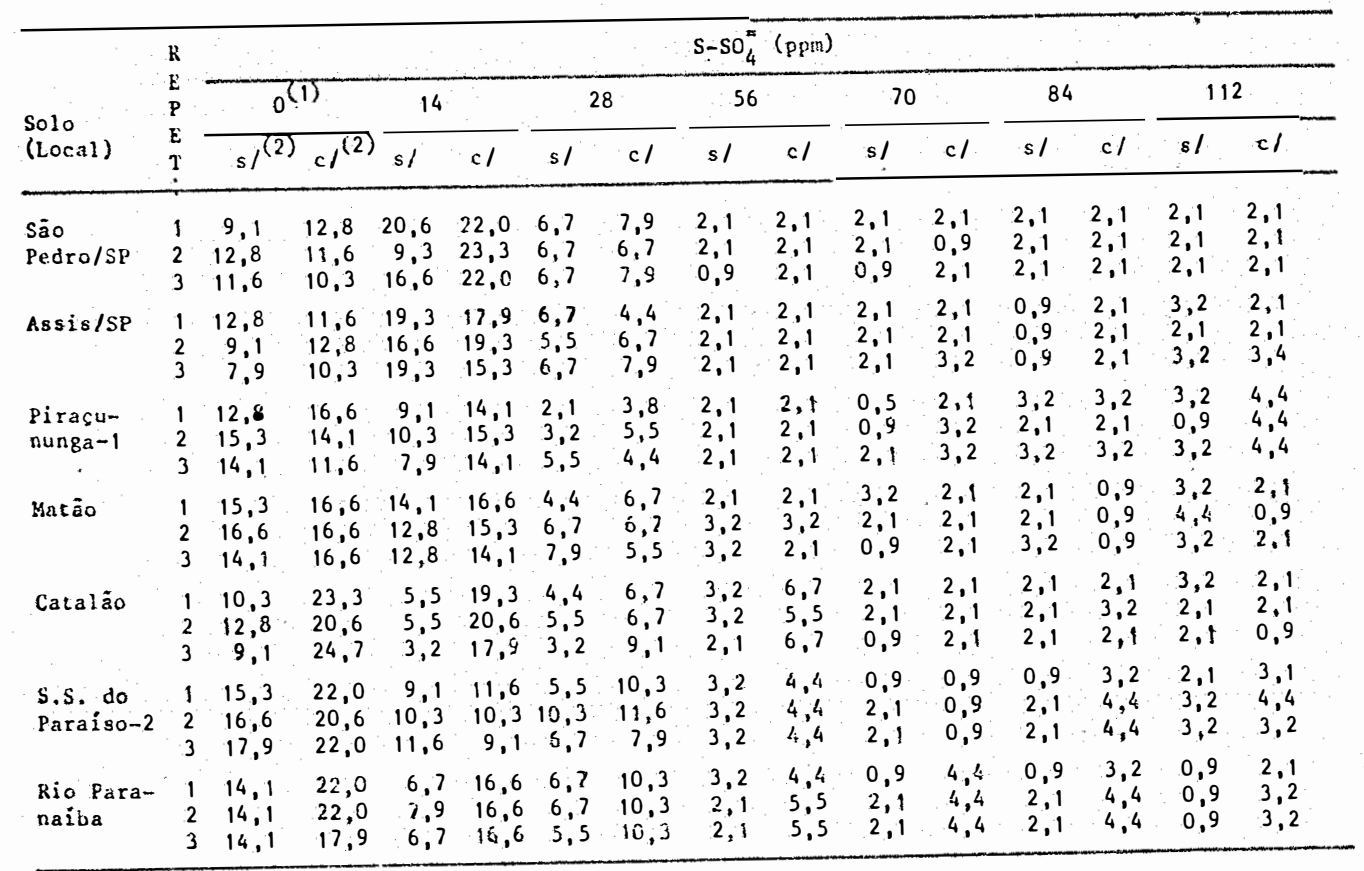

(1) Tempo de lixiviacáo (incervalo de 14 dias).

(2) s/ - sem calagem e cl - com calagem, conforme reconendagóes. 
Tabela 5.2 - Efeitos da incubação aberta e da calagem na mineraliza ção do nitrogênio dos solos $\left(\mathrm{N}_{4}^{+}+\mathrm{NO}_{3}^{-}\right)$em condições de microcolunas, submetidas à lixiviação periódica.

\begin{tabular}{|c|c|c|c|c|c|c|c|c|c|c|c|c|c|c|c|}
\hline \multirow{3}{*}{$\begin{array}{l}\text { Solo } \\
\text { (L.oca1) }\end{array}$} & \multirow{3}{*}{$\begin{array}{l}\mathrm{R} \\
\mathrm{E} \\
\mathrm{P} \\
\mathrm{E} \\
\mathrm{T}\end{array}$} & \multicolumn{14}{|c|}{$\mathrm{N}\left(\mathrm{Nu}_{4}^{+}+\mathrm{NO}_{3}^{-}\right)-\mathrm{Ppm}$} \\
\hline & & \multicolumn{2}{|c|}{$a^{(1)}$} & \multicolumn{2}{|l|}{14} & \multicolumn{2}{|l|}{28} & \multicolumn{2}{|l|}{56} & \multicolumn{2}{|l|}{20} & \multicolumn{2}{|l|}{84} & \multicolumn{2}{|l|}{$1+2$} \\
\hline & & $\left.s\right|^{(2)}$ & $c l^{(2)}$ & )$_{81}$ & $\mathrm{cl}$ & 81 & $\mathrm{cl}$ & $\& 1$ & $\mathrm{cl}$ & sl & $\mathrm{cl}$ & sl & cl & sl & cl \\
\hline $\begin{array}{l}\text { São } \\
\text { Pedro/SP }\end{array}$ & $\begin{array}{l}1 \\
2 \\
3\end{array}$ & $\begin{array}{l}55,2 \\
49,8 \\
58,7\end{array}$ & $\begin{array}{l}60,8 \\
47,8 \\
50,1\end{array}$ & $\begin{array}{l}13,4 \\
11,0 \\
12,3\end{array}$ & $\begin{array}{l}11,3 \\
12,6 \\
12,6\end{array}$ & $\begin{array}{r}7,3 \\
10,0 \\
8,3\end{array}$ & $\begin{array}{l}8,4 \\
9,3 \\
7,4\end{array}$ & $\begin{array}{l}5,2 \\
5,2 \\
5,7\end{array}$ & $\begin{array}{l}4,8 \\
6,5 \\
5,2\end{array}$ & $\begin{array}{l}2,4 \\
2,6 \\
2,7\end{array}$ & $\begin{array}{l}2,2 \\
3,8 \\
2,4\end{array}$ & $\begin{array}{l}3,1 \\
2,3 \\
3,2\end{array}$ & $\begin{array}{l}2,4 \\
3,2 \\
2,7\end{array}$ & $\begin{array}{l}3,5 \\
3,2 \\
3,0\end{array}$ & $\begin{array}{l}3,3 \\
3,3 \\
3,7\end{array}$ \\
\hline Assis & $\begin{array}{l}1 \\
2 \\
3 .\end{array}$ & $\begin{array}{l}29,9 \\
26,0 \\
25,9\end{array}$ & $\begin{array}{l}24,7 \\
24,7 \\
27,7\end{array}$ & $\begin{array}{l}7,0 \\
6,3 \\
6,3\end{array}$ & $\begin{array}{l}11,3 \\
14,8 \\
17,8\end{array}$ & $\begin{array}{l}4,1 \\
3,1 \\
4,7\end{array}$ & $\begin{array}{r}6,6 \\
7,0 \\
11,0\end{array}$ & $\begin{array}{l}4,1 \\
2,7 \\
4,2\end{array}$ & $\begin{array}{l}3,3 \\
4,9 \\
4,9\end{array}$ & $\begin{array}{l}3,5 \\
3,1 \\
3,2\end{array}$ & $\begin{array}{l}2,8 \\
2,7 \\
2,9\end{array}$ & $\begin{array}{l}2,8 \\
2,9 \\
2,9\end{array}$ & $\begin{array}{l}2,8 \\
2,5 \\
2,7\end{array}$ & $\begin{array}{l}3,2 \\
2,9 \\
3,1\end{array}$ & $\begin{array}{l}2,8 \\
2,7 \\
2,5\end{array}$ \\
\hline $\begin{array}{l}\text { Piracu- } \\
\text { nunga-1 }\end{array}$ & $\begin{array}{l}1 \\
2 \\
3\end{array}$ & $\begin{array}{l}12,9 \\
10,9 \\
12,2\end{array}$ & $\begin{array}{r}6,9 \\
10,7 \\
12,7\end{array}$ & $\begin{array}{l}22,1 \\
21,7 \\
22,6\end{array}$ & $\begin{array}{l}22,4 \\
22,5 \\
22,3\end{array}$ & $\begin{array}{l}6,9 \\
5,8 \\
8,2\end{array}$ & $\begin{array}{l}4,9 \\
5,0 \\
5,5\end{array}$ & $\begin{array}{l}6,9 \\
4,9 \\
6,4\end{array}$ & $\begin{array}{l}3,8 \\
3,4 \\
3,7\end{array}$ & $\begin{array}{l}4,5 \\
2,7 \\
4,0\end{array}$ & $\begin{array}{l}2,9 \\
2,8 \\
3,6\end{array}$ & $\begin{array}{l}4,5 \\
2,7 \\
3,2\end{array}$ & $\begin{array}{l}2,9 \\
2,3 \\
2,2\end{array}$ & $\begin{array}{l}4,0 \\
2,1 \\
2,9\end{array}$ & $\begin{array}{l}2,9 \\
2,3 \\
4,9\end{array}$ \\
\hline Matão & $\begin{array}{l}1 \\
2 \\
3\end{array}$ & $\begin{array}{l}10,1 \\
10,7 \\
10,3\end{array}$ & $\begin{array}{l}10,0 \\
12,4 \\
12,7\end{array}$ & $\begin{array}{l}6,8 \\
7,7 \\
5,5\end{array}$ & $\begin{array}{r}12,0 \\
10,6 \\
8,3\end{array}$ & $\begin{array}{l}3,4 \\
3,5 \\
4,7\end{array}$ & $\begin{array}{l}3,5 \\
3,0 \\
3,5\end{array}$ & $\begin{array}{l}3,4 \\
3,5 \\
3,2\end{array}$ & $\begin{array}{l}3,0 \\
2,9 \\
2,6\end{array}$ & $\begin{array}{l}2,4 \\
2,6 \\
2,2\end{array}$ & $\begin{array}{r}2,9 \\
2,9 \\
2,1\end{array}$ & $\begin{array}{l}2,2 \\
2,1 \\
2,5\end{array}$ & $\begin{array}{l}2,2 \\
2,0 \\
2,8\end{array}$ & $\begin{array}{l}2,2 \\
2,0 \\
2,0\end{array}$ & $\begin{array}{l}2,0 \\
1,7 \\
2,8\end{array}$ \\
\hline Catalão & $\begin{array}{l}1 \\
2 \\
3\end{array}$ & $\begin{array}{l}58,1 \\
75,1 \\
83,7\end{array}$ & $\begin{array}{r}87,4 \\
78,2 \\
105,5\end{array}$ & $\begin{array}{l}39,7 \\
42,0 \\
34,8\end{array}$ & $\begin{array}{l}40,8 \\
41,6 \\
44,2\end{array}$ & $\begin{array}{l}15,9 \\
19,5 \\
16,1\end{array}$ & $\begin{array}{l}18,0 \\
16,3 \\
16,2\end{array}$ & $\begin{array}{r}13,4 \\
11,0 \\
8,9\end{array}$ & $\begin{array}{r}11,3 \\
9,7 \\
10,3\end{array}$ & $\begin{array}{l}7,9 \\
8,4 \\
6,6\end{array}$ & $\begin{array}{l}7,2 \\
8,2 \\
7,6\end{array}$ & $\begin{array}{l}5,7 \\
5,8 \\
4,9\end{array}$ & $\begin{array}{l}2,1 \\
2,0 \\
7,0\end{array}$ & $\begin{array}{l}4,6 \\
4,8 \\
3,7\end{array}$ & $\begin{array}{l}5,3 \\
9,5 \\
6,3\end{array}$ \\
\hline $\begin{array}{l}\text { S.S. do } \\
\text { Paraiso-2 }\end{array}$ & $\begin{array}{l}1 \\
2 \\
3\end{array}$ & $\begin{array}{l}14,7 \\
14,2 \\
15,2\end{array}$ & $\begin{array}{l}15,5 \\
12,2 \\
16,7\end{array}$ & $\begin{array}{l}15,5 \\
16,7 \\
18,8\end{array}$ & $\begin{array}{l}27,1 \\
34,5 \\
31,3\end{array}$ & $\begin{array}{l}12,2 \\
12,5 \\
12,4\end{array}$ & $\begin{array}{l}13,7 \\
16,3 \\
13,0\end{array}$ & $\begin{array}{l}6,4 \\
6,6 \\
5,7\end{array}$ & $\begin{array}{l}6,2 \\
9,3 \\
6,4\end{array}$ & $\begin{array}{l}2,9 \\
4,6 \\
3,9\end{array}$ & $\begin{array}{l}3,5 \\
2,3 \\
4,1\end{array}$ & $\begin{array}{l}4,0 \\
4,9 \\
3,2\end{array}$ & $\begin{array}{l}3 ; 8 \\
5 ; 9 \\
3,2\end{array}$ & $\begin{array}{l}2,2 \\
2,8 \\
2,9\end{array}$ & $\begin{array}{l}6,1 \\
5,8 \\
3,6\end{array}$ \\
\hline $\begin{array}{l}\text { Rio Para- } \\
\text { naiba }\end{array}$ & $\begin{array}{l}1 \\
2 \\
3\end{array}$ & $\begin{array}{l}14,8 \\
18,1 \\
18,8\end{array}$ & $\begin{array}{l}16,2 \\
12,4 \\
16,5\end{array}$ & $\begin{array}{l}30,0 \\
31,4 \\
36,1\end{array}$ & $\begin{array}{l}36,1 \\
36,5 \\
43,3\end{array}$ & $\begin{array}{l}19,9 \\
24,9 \\
24,0\end{array}$ & $\begin{array}{l}23,0 \\
22,9 \\
22,9\end{array}$ & $\begin{array}{l}12,9 \\
14,0 \\
14,2\end{array}$ & $\begin{array}{l}23,3 \\
22,8 \\
21,8\end{array}$ & $\begin{array}{l}6,5 \\
7,2 \\
7,9\end{array}$ & $\begin{array}{r}8,8 \\
15,3 \\
14,6\end{array}$ & $\begin{array}{l}5,8 \\
4,5 \\
4,4\end{array}$ & $\begin{array}{r}2,1 \\
10,2 \\
7,4\end{array}$ & $\begin{array}{l}6,4 \\
4,3 \\
4,8\end{array}$ & $\begin{array}{l}6,8 \\
8,3 \\
9,1\end{array}$ \\
\hline
\end{tabular}


Tabela 6.1 - Valores de cpm $(0,1 \mathrm{ml}$ (corrigidos para o tempo "zero" nos lixiviados em $\mathrm{KCl} 0,01 \mathrm{M}$ sob condições de incubação aberta, na ausência e presença de calagem.

\begin{tabular}{|c|c|c|c|c|c|c|c|c|c|c|c|c|c|}
\hline \multirow{3}{*}{ Solo } & \multirow{3}{*}{$\begin{array}{l}\mathrm{E} \\
\mathrm{P} \\
\mathrm{E} \\
\mathrm{T}\end{array}$} & \multicolumn{10}{|c|}{ cpux $1000 / 1$ ml de lixiviado } & \multirow{2}{*}{\multicolumn{2}{|c|}{84}} \\
\hline & & \multicolumn{2}{|c|}{$0^{(1)}$} & \multicolumn{2}{|c|}{14} & \multicolumn{2}{|c|}{28} & \multicolumn{2}{|c|}{56} & \multicolumn{2}{|c|}{70} & & \\
\hline & & $3 l^{(2)}$ & $c l^{(2)}$ & $8 /$ & cl & $\varepsilon /$ & $c /$ & s/ & $\mathrm{cl}$ & $6 /$ & cl & $6 !$ & cl \\
\hline Sāo Pedro & $\begin{array}{l}1 \\
2 \\
3\end{array}$ & $\begin{array}{l}170,7 \\
150,1 \\
167,3\end{array}$ & $\begin{array}{l}118,8 \\
154,5 \\
133,3\end{array}$ & $\begin{array}{l}50,3 \\
36,5 \\
16,9\end{array}$ & $\begin{array}{l}20,0 \\
21,4 \\
18,9\end{array}$ & $\begin{array}{l}4,4 \\
4,2 \\
6,9\end{array}$ & $\begin{array}{l}3,8 \\
6,9 \\
6,2\end{array}$ & $\begin{array}{l}1,4 \\
0,8 \\
1,3\end{array}$ & $\begin{array}{l}1,0 \\
1,1 \\
0,9\end{array}$ & $\begin{array}{l}0,6 \\
0,5 \\
0,6\end{array}$ & $\begin{array}{l}1,2 \\
0,9 \\
0,6\end{array}$ & $\begin{array}{l}0,9 \\
0,7 \\
1,3\end{array}$ & $\begin{array}{l}0,9 \\
0,6 \\
0,4\end{array}$ \\
\hline Assis & $\begin{array}{l}1 \\
2 \\
3\end{array}$ & $\begin{array}{l}105,3 \\
184,7 \\
135,3\end{array}$ & $\begin{array}{r}65,9 \\
103,1 \\
180,3\end{array}$ & $\begin{array}{l}40,3 \\
58,4 \\
67,5\end{array}$ & $\begin{array}{l}76,4 \\
61,4 \\
54,6\end{array}$ & $\begin{array}{l}5,7 \\
5,0 \\
5,8\end{array}$ & $\begin{array}{l}11,9 \\
12,1 \\
22,5\end{array}$ & $\begin{array}{l}1,4 \\
1,7 \\
1,4\end{array}$ & $\begin{array}{l}4,8 \\
4,1 \\
2,6\end{array}$ & $\begin{array}{l}0,5 \\
1,1 \\
7,1\end{array}$ & $\begin{array}{l}3,5 \\
4,7 \\
1,8\end{array}$ & $\begin{array}{l}0,6 \\
1,0 \\
1,3\end{array}$ & $\begin{array}{l}3,6 \\
4,0 \\
1,4\end{array}$ \\
\hline Pirasumunga & $\begin{array}{l}1 \\
2 \\
3\end{array}$ & $\begin{array}{l}23,0 \\
32,8 \\
44,7\end{array}$ & $\begin{array}{l}157,3 \\
138,5 \\
180,3\end{array}$ & $\begin{array}{l}12,4 \\
11,1 \\
27,7\end{array}$ & $\begin{array}{r}7,9 \\
15,2 \\
17,1\end{array}$ & $\begin{array}{l}4,8 \\
6,2 \\
7,4\end{array}$ & $\begin{array}{l}2,4 \\
2,9 \\
1,5\end{array}$ & $\begin{array}{l}3,3 \\
2,4 \\
6,1\end{array}$ & $\begin{array}{l}1,2 \\
1,4 \\
1,4\end{array}$ & $\begin{array}{l}4,4 \\
3,3 \\
2,5\end{array}$ & $\begin{array}{l}0,9 \\
0,9 \\
0,9\end{array}$ & $\begin{array}{l}9,2 \\
4,2 \\
8,6\end{array}$ & $\begin{array}{l}1,2 \\
0,5 \\
0,5\end{array}$ \\
\hline Matão & 1 & $\begin{array}{l}105,0 \\
120,7 \\
1.16,8\end{array}$ & $\begin{array}{l}168,4 \\
171,2 \\
166,7\end{array}$ & $\begin{array}{r}8,1 \\
6,8 \\
14,8\end{array}$ & $\begin{array}{r}9,4 \\
9,0 \\
18,8\end{array}$ & $\begin{array}{l}7,5 \\
5,2 \\
3,4\end{array}$ & $\begin{array}{l}1,1 \\
4,4 \\
1,4\end{array}$ & $\begin{array}{l}1,2 \\
1,0 \\
1,4\end{array}$ & $\begin{array}{l}1,1 \\
1,0 \\
1,0\end{array}$ & $\begin{array}{l}0,8 \\
0,4 \\
0,7\end{array}$ & $\begin{array}{l}0,3 \\
0,7 \\
0,3\end{array}$ & $\begin{array}{l}0,8 \\
0,3 \\
0,5\end{array}$ & $\begin{array}{l}0,3 \\
0,4 \\
0,3\end{array}$ \\
\hline Catalào & $\begin{array}{l}1 \\
2 \\
3\end{array}$ & $\begin{array}{l}10,9 \\
15,6 \\
16,5\end{array}$ & $\begin{array}{r}58,6 \\
145,0 \\
157,4\end{array}$ & $\begin{array}{l}14,9 \\
17,7 \\
21,5\end{array}$ & $\begin{array}{l}14,4 \\
17,8 \\
21,0\end{array}$ & $\begin{array}{l}3,5 \\
6,4 \\
9,1\end{array}$ & $\begin{array}{l}3,9 \\
5,6 \\
8,5\end{array}$ & $\begin{array}{l}7,2 \\
6,4 \\
2,2\end{array}$ & $\begin{array}{l}4,9 \\
4,6 \\
2,6\end{array}$ & $\begin{array}{l}2,4 \\
5,5 \\
6,2\end{array}$ & $\begin{array}{l}4,9 \\
4,2 \\
9,2\end{array}$ & $\begin{array}{l}2,8 \\
4,4 \\
3,2\end{array}$ & $\begin{array}{l}4,9 \\
4,7 \\
2,7\end{array}$ \\
\hline $\begin{array}{l}\text { S.s. Parai- } \\
\text { so-2 }\end{array}$ & $\begin{array}{l}1 \\
2 \\
3\end{array}$ & $\begin{array}{l}56,3 \\
72,7 \\
78,0\end{array}$ & $\begin{array}{l}164,5 \\
135,0 \\
100,1\end{array}$ & $\begin{array}{l}19,8 \\
19,6 \\
17,7\end{array}$ & $\begin{array}{l}24,3 \\
21,6 \\
24,6\end{array}$ & $\begin{array}{l}6,0 \\
2,3 \\
3,6\end{array}$ & $\begin{array}{r}8,4 \\
7,9 \\
10,5\end{array}$ & $\begin{array}{l}2,9 \\
2,2 \\
2,4\end{array}$ & $\begin{array}{l}1,0 \\
2,3 \\
2,1\end{array}$ & $\begin{array}{l}2,3 \\
4,1 \\
2,3\end{array}$ & $\begin{array}{l}1,0 \\
0,5 \\
3,6\end{array}$ & $\begin{array}{l}1.2 \\
1,8 \\
2: 1\end{array}$ & $\begin{array}{l}0,2 \\
0,4 \\
0,4\end{array}$ \\
\hline $\begin{array}{l}\text { Rio Para- } \\
\text { naiba }\end{array}$ & $\begin{array}{l}1 \\
2 \\
3\end{array}$ & $\begin{array}{l}26,7 \\
33,0 \\
28,7\end{array}$ & $\begin{array}{r}84,0 \\
80,4 \\
106,7\end{array}$ & $\begin{array}{l}11,4 \\
18,3 \\
11,1\end{array}$ & $\begin{array}{l}49,8 \\
38,1 \\
40,5\end{array}$ & $\begin{array}{l}3,5 \\
2,9 \\
2,9\end{array}$ & $\begin{array}{l}18,5 \\
18,5 \\
13,1\end{array}$ & $\begin{array}{l}5,5 \\
3,8 \\
3,7\end{array}$ & $\begin{array}{l}5,8 \\
2,1 \\
5,1\end{array}$ & $\begin{array}{l}3,5 \\
3,5 \\
3,0\end{array}$ & $\begin{array}{l}6,4 \\
5,8 \\
5,8\end{array}$ & $\begin{array}{l}3,5 \\
4,9 \\
5,5\end{array}$ & $\begin{array}{l}3,5 \\
4,9 \\
3,2\end{array}$ \\
\hline
\end{tabular}

(1) Tempo de lixiviasão (intervalo de 14 dias).

(2) s/ - sem calagen e cl - com calagen, conforme recornendacōes. 
Tabela 6.2 - Valores de atividade específica de ${ }^{35} \mathrm{~S}$ nos 1 ixiviados em KCI $0,01 \mathrm{M}$ sob condições de incubação aberta, na au sência e presença de calagem.

\begin{tabular}{|c|c|c|c|c|c|c|c|c|c|c|c|c|c|}
\hline \multirow{3}{*}{$\begin{array}{l}\text { Solo } \\
\text { (local) }\end{array}$} & \multirow{3}{*}{$\begin{array}{l}R \\
E \\
P \\
E \\
T\end{array}$} & \multicolumn{10}{|c|}{ Atividade especifica de ${ }^{33} \mathrm{~S}-\mathrm{cpq} \times 1000 / \mathrm{Hg}-\mathrm{SO}_{4}^{m}$} & \multirow{2}{*}{\multicolumn{2}{|c|}{84}} \\
\hline & & \multicolumn{2}{|c|}{$0^{(1)}$} & \multicolumn{2}{|l|}{14} & \multicolumn{2}{|c|}{28} & \multicolumn{2}{|c|}{56} & \multicolumn{2}{|c|}{70} & & \\
\hline & & $B /^{(2)}$ & $\mathrm{cl}^{(2)}$ & sl & cl & s/ & cl & Bl & cl & B! & $c l$ & 81 & $c l$ \\
\hline Sāo Pedro & $\begin{array}{l}1 \\
2 \\
3\end{array}$ & $\begin{array}{l}187,6 \\
122,7 \\
144,5\end{array}$ & $\begin{array}{r}92,8 \\
133,2 \\
129,4\end{array}$ & $\begin{array}{l}24,4 \\
18,9 \\
10,2\end{array}$ & $\begin{array}{l}9,1 \\
9,2 \\
8,5\end{array}$ & $\begin{array}{r}6,6 \\
6,3 \\
10,3\end{array}$ & $\begin{array}{r}4,8 \\
10,2 \\
7,8\end{array}$ & $\begin{array}{l}6, ? \\
9,0 \\
6,7\end{array}$ & $\begin{array}{l}4,6 \\
5,8 \\
4,3\end{array}$ & $\begin{array}{l}2,8 \\
2,3 \\
6,2\end{array}$ & $\begin{array}{r}5,5 \\
10,3 \\
2,9\end{array}$ & $\begin{array}{l}4,6 \\
3,1 \\
6,2\end{array}$ & $\begin{array}{l}4,5 \\
2,7 \\
1,8\end{array}$ \\
\hline Assis & $\begin{array}{l}1 \\
2 \\
3\end{array}$ & $\begin{array}{r}82,3 \\
203,0 \\
171,3\end{array}$ & $\begin{array}{l}56,9 \\
80,5 \\
91,1\end{array}$ & $\begin{array}{l}20,9 \\
30,3 \\
40,7\end{array}$ & $\begin{array}{l}39,6 \\
37,0 \\
35,7\end{array}$ & $\begin{array}{l}8,5 \\
9,0 \\
8,6\end{array}$ & $\begin{array}{l}27,1 \\
25,5 \\
28,5\end{array}$ & $\begin{array}{l}6,5 \\
8,2 \\
6,2\end{array}$ & $\begin{array}{l}22,9 \\
19,9 \\
12,6\end{array}$ & $\begin{array}{l}2,3 \\
5,5 \\
5,4\end{array}$ & $\begin{array}{r}16,6 \\
22,6 \\
5,5\end{array}$ & $\begin{array}{l}6,2 \\
15,0 \\
14,9\end{array}$ & $\begin{array}{r}17,4 \\
19,1 \\
6,8\end{array}$ \\
\hline Piraçununga & $\begin{array}{l}1 \\
2 \\
3\end{array}$ & $\begin{array}{l}18,0 \\
23,3 \\
29,2\end{array}$ & $\begin{array}{l}117,7 \\
119,4 \\
108,6\end{array}$ & $\begin{array}{l}13,6 \\
10,7 \\
26,9\end{array}$ & $\begin{array}{l}5,6 \\
10,8 \\
11,2\end{array}$ & $\begin{array}{l}23,1 \\
19,4 \\
13,5\end{array}$ & $\begin{array}{l}5,4 \\
5,3 \\
3,9\end{array}$ & $\begin{array}{l}15,8 \\
13,0 \\
29,1\end{array}$ & $\begin{array}{l}5,9 \\
6,7 \\
6,8\end{array}$ & $\begin{array}{l}25,1 \\
15,7 \\
12,1\end{array}$ & $\begin{array}{l}4,2 \\
2,8 \\
2,2\end{array}$ & $\begin{array}{l}28,8 \\
20,8 \\
26,9\end{array}$ & $\begin{array}{l}3,9 \\
2,2 \\
1,6\end{array}$ \\
\hline Matão & $\begin{array}{l}1 \\
2 \\
3\end{array}$ & $\begin{array}{l}68,7 \\
72,7 \\
82,8\end{array}$ & $\begin{array}{r}101,4 \\
94,6 \\
100,4\end{array}$ & $\begin{array}{r}6,3 \\
5,3 \\
10,5\end{array}$ & $\begin{array}{l}6,1 \\
6,3 \\
6,2\end{array}$ & $\begin{array}{l}9,5 \\
7,7 \\
7,8\end{array}$ & $\begin{array}{l}2,0 \\
6,6 \\
2,6\end{array}$ & $\begin{array}{l}5,8 \\
3,1 \\
4,4\end{array}$ & $\begin{array}{l}5,4 \\
3,2 \\
4,9\end{array}$ & $\begin{array}{l}2,5 \\
1,8 \\
3,5\end{array}$ & $\begin{array}{l}1,4 \\
3,2 \\
1,5\end{array}$ & $\begin{array}{l}3,6 \\
1,2 \\
1,5\end{array}$ & $\begin{array}{l}3,2 \\
4,0 \\
3,4\end{array}$ \\
\hline Catalāo & $\begin{array}{l}1 \\
2 \\
3\end{array}$ & $\begin{array}{l}10,6 \\
17,1 \\
12,9\end{array}$ & $\begin{array}{l}68,1 \\
70,4 \\
63,7\end{array}$ & $\begin{array}{l}46,6 \\
32,2 \\
38,5\end{array}$ & $\begin{array}{l}14,3 \\
17,8 \\
21,0\end{array}$ & $\begin{array}{l}10,9 \\
20,1 \\
16,6\end{array}$ & $\begin{array}{l}5,2 \\
8,4 \\
9,4\end{array}$ & $\begin{array}{l}24,0 \\
20,2 \\
34,4\end{array}$ & $\begin{array}{l}7,3 \\
8,4 \\
3 ; 9\end{array}$ & $\begin{array}{l}11,6 \\
26,8 \\
29,7\end{array}$ & $\begin{array}{l}23,5 \\
20,2 \\
43,9\end{array}$ & $\begin{array}{l}13,5 \\
21,0 \\
15,5\end{array}$ & $\begin{array}{l}23,3 \\
14,7 \\
36,7\end{array}$ \\
\hline $\begin{array}{l}\text { S.S, Parai- } \\
\text { so-2 }\end{array}$ & $\begin{array}{l}1 \\
2 \\
3\end{array}$ & $\begin{array}{l}36,8 \\
43,8 \\
43,6\end{array}$ & $\begin{array}{l}74,8 \\
61,3 \\
48,6\end{array}$ & $\begin{array}{l}21,7 \\
19,1 \\
15,3\end{array}$ & $\begin{array}{l}22,3 \\
21,0 \\
21,2\end{array}$ & $\begin{array}{l}9,0 \\
?, 1 \\
6,5\end{array}$ & $\begin{array}{l}8,2 \\
9,9 \\
9,0\end{array}$ & $\begin{array}{l}9,2 \\
8,5 \\
7,4\end{array}$ & $\begin{array}{l}2,4 \\
5,2 \\
4,8\end{array}$ & $\begin{array}{r}11,1 \\
9,8 \\
11,0\end{array}$ & $\begin{array}{l}2,3 \\
1,1 \\
8,2\end{array}$ & $\begin{array}{r}13,0 \\
8,5 \\
10,2\end{array}$ & $\begin{array}{l}2,9 \\
4,2 \\
4,1\end{array}$ \\
\hline $\begin{array}{l}\text { Rio Paranai- } \\
\text { ba }\end{array}$ & $\begin{array}{l}1 \\
2 \\
3\end{array}$ & $\begin{array}{l}19,0 \\
23,4 \\
20,3\end{array}$ & $\begin{array}{l}38,2 \\
36,5 \\
59,6\end{array}$ & $\begin{array}{l}17,0 \\
23,0 \\
16,6\end{array}$ & $\begin{array}{l}30,0 \\
23,0 \\
24,4\end{array}$ & $\begin{array}{r}5,3 \\
11,9 \\
5,2\end{array}$ & $\begin{array}{l}18,0 \\
17,9 \\
12,7\end{array}$ & $\begin{array}{l}17,2 \\
18,3 \\
18,6\end{array}$ & $\begin{array}{r}13,3 \\
93,0 \\
9,3\end{array}$ & $\begin{array}{l}16,6 \\
16,9 \\
4,2\end{array}$ & $\begin{array}{l}14,5 \\
13,4 \\
+3,2\end{array}$ & $\begin{array}{l}37,9 \\
23,4 \\
16,4\end{array}$ & $\begin{array}{r}10,9 \\
+1,2 \\
7,2\end{array}$ \\
\hline
\end{tabular}

(1) Tempo de lixiviaşa (intervalo de 14 dias).

(2) s/ - sem calagem e c/ - con calagen, conforme reconendacöes, 